\title{
Regulatory and Financial Influence of Federal Government Activities on Local Economies: A Three Essay Approach
}

\author{
Brianne Renee Firth \\ West Virginia University, brzimmerman@mix.wvu.edu
}

Follow this and additional works at: https://researchrepository.wvu.edu/etd

Part of the Agricultural and Resource Economics Commons

\section{Recommended Citation \\ Firth, Brianne Renee, "Regulatory and Financial Influence of Federal Government Activities on Local Economies: A Three Essay Approach" (2018). Graduate Theses, Dissertations, and Problem Reports. 3705. \\ https://researchrepository.wvu.edu/etd/3705 \\ This Dissertation is protected by copyright and/or related rights. It has been brought to you by the The Research Repository @ WVU with permission from the rights-holder(s). You are free to use this Dissertation in any way that is permitted by the copyright and related rights legislation that applies to your use. For other uses you must obtain permission from the rights-holder(s) directly, unless additional rights are indicated by a Creative Commons license in the record and/ or on the work itself. This Dissertation has been accepted for inclusion in WVU Graduate Theses, Dissertations, and Problem Reports collection by an authorized administrator of The Research Repository @ WVU. For more information, please contact researchrepository@mail.wvu.edu.}




\title{
REGULATORY AND FINANCIAL INFLUENCE OF FEDERAL GOVERNMENT ACTIVITIES ON LOCAL ECONOMIES: \\ A THREE ESSAY APPROACH
}

Brianne R. Firth

\begin{abstract}
Dissertation submitted to the
at West Virginia University

in partial fulfillment of the requirements

for the degree of

Doctor of Philosophy in

Natural Resource Economics

Alan Collins, Ph.D., Chair

Heather Stephens, Ph.D.

Michael Strager, Ph.D.

Donald Lacombe, Ph.D.

Stephan Goetz, Ph.D.
\end{abstract}

Davis College of Agriculture, Natural Resources, and Design

Division of Resource Economics and Management

Morgantown, West Virginia

2018

Keywords: Regional economics, environmental economics, spatial econometrics, rural development, environmental regulations, government funding, conservation programs

Copyright 2018 Brianne R. Firth 


\begin{abstract}
Regulatory and Financial Influence of Federal Government Activities on Local Economies: A Three-Essay Approach
\end{abstract}

\author{
Brianne R. Firth
}

This dissertation examines the effects of federal government activities on local economies. Specifically, I examine the effects of regulatory and financial programs mandated by the federal government on regional development. Three research questions are addressed: (1) How do federal environmental regulations influence local economic growth?, (2) What regional factors influence the spatial distribution of federal conservation programs?, and (3) How does location-based federal funding effect economic resilience within the targeted region? Regional economic analysis and spatial econometric techniques are implemented to answer these questions.

The first essay examines the effects of the air pollution standards promulgated under the US Clean Air Act on county level economic growth. Within the past two decades air pollution standards have become more stringent to protect clean air, minimize health impacts and preserve environmental amenities; however, these standards have placed new restrictions on polluting industries. We explore the relationship between increased pollution standards and the effects on long-term labor markets at the county level. This essay contributes to the literature as we explore the changes in pollution abatement standards and local economic growth in the eastern US. The results illustrate, in the long run, the impacted regions have adapted to the changes in the pollution standards. To meet these abatement standards, regions are becoming less dependent upon the manufacturing industry and other polluting industries, and diversifying their industry portfolio.

The second essay identifies regional determinants of participation in federal conservation programs in West Virginia (WV). The Natural Resource Conservation Service (NRCS) has developed assistance programs to provide aid in land management and conservation applications. This essay expands upon the literature by measuring program participation at a regional level, instead of an individual or farm-based measure. We attempt to capture the effects of social networking on program participation by examining factors such as the number of farms, average farm size, farm operation size, and internet accessibility by farmers. Additionally, we evaluate the spatial distribution of participation at the census-tract level. Through this analysis we can observe if federal assistance is being directed towards areas to promote conservation throughout the state. The results of this analysis identify underserved regions for future outreach by the WV NRCS state office. These results indicate that the NRCS is strategically targeting areas to promote efficient farm management techniques and to protect stream water quality as the amount of agricultural land and stream miles impact the number of applied practices within a census tract. Participation is also influenced by spatial spillover effects related to public land ownership and share of surface-mined land and developed land. Except for federal land ownership, each of these spillover effects is 
negatively related to program participation. Distance to an NRCS field office is also a significant impact on conservation practice adoption, as access to information and nearby resources has a significant effect on conservation practice adoption. We also find some evidence of factors influencing social networks among farmers via more farms and higher internet access both leading to increased conservation practice adoption at a regional scale.

The third essay evaluates the significance of Appalachian Regional Commission (ARC) project investments on local economic resilience within the greater Appalachian region. This essay contributes to the literature by observing the influence of location-based project investments on regional economic resilience. Understanding the link between investments and resilience could help local policymakers who are allocating scarce resources and help communities weather the inevitable economic downturns in the future. This essay investigates several county-level measures such as employment, demographic, mobility, and additional wealth to understand what explains levels of resilience within the region. County-level characteristics that promote or restrict economic resilience are identified in this analysis. Based on the results of our analysis we are also able to identify local and regional policy strategies that promote resilience within Appalachia. Local policy strategies directly benefit the host county, while not helping or hurting resilience in surrounding counties. Policies with spillover effects could influence cooperative strategies, having the same impact on the focus county and surrounding counties, or they could introduce competitive strategies, creating an inverse effect between the focus county and surrounding counties. Based on the empirical results, local and regional policy strategies to strengthen resilience in the greater ARC region are identified. We find policies related to educational attainment and employment within the coal industry should be addressed as a local policy strategy. These approaches do not help nor hurt resilience levels of the neighboring counties. Policies that are related to mobility, workforce participation, and entrepreneurship should be addressed as cooperative regional strategies. These policies strengthen resilience throughout the entire region. Policies that influence innovation potential, residence-born population, and employment in the oil and gas industry are competitive regional strategies. These policies benefit the county implementing the policy but hurt resiliency of the surrounding counties. ARC project investments are most beneficial as a regional policy strategy approach. 


\section{DEDICATION}

I would like to dedicate my dissertation research to the late Dr. Jerald J. Fletcher. Dr. Fletcher was my major advisor during the Ph.D. program until his passing on Monday, June 19, 2017 after battling health issues. Dr. Fletcher became a significant part of my life; I miss him dearly.

When I first started the program at West Virginia University, I was not offered financial assistance. In my head, I believed the faculty did not have confidence in my success in the program. I believed that I had to prove myself. I remember the joy I felt the day, someone finally believed in me. Dr. Fletcher found me in the hall and mentioned that he had funding for me. He offered me meaningful work and unique opportunities through his role in the US China Energy Center. Since that day, I felt Dr. Fletcher was truly on my side and could support me throughout this journey. He helped me with any issues in the department that he could, protected me from unnecessary hurdles. He blessed me with many opportunities. Over time I gained a great amount of respect for the professor; mostly for how he believed in me, how he treated me as an equal, and how he always invited me into his home.

Before passing, Dr. Fletcher wrote a recommendation letter to a summer training program. He forwarded the letter to me, and the contents of recommendation letter were very sincere. I am fortunate to have that letter to hold onto for remembrance. I will look at the letter when am I feeling overwhelmed with my research and remember that Dr. Fletcher was always on my side.

I am forever grateful for the support from Dr. Fletcher, and the rest of the faculty at WVU.

I would also like to dedicate my research to my loving husband. I still remember studying for the GRE in his apartment while at FSU. I knew I had a long way to go to be prepared for this program; however, I knew he would be by my side every step of the way. To this day, he has been nothing but supportive of my goals. I am so proud of what we have both accomplished together. Without the support of my very patient family, I would not have been able to start this journey. Though they may not be particularly interested in my research, they have stood by me through the challenges and frustrations. I know they are proud with everything I have done, I only hope to continue to make them proud with all that I will accomplish in the future. 


\section{ACKNOWLEDGMENTS}

As I arrive at the end of this educational journey, I am grateful for the knowledge and experience garnered from the support of my committee and of my classmates.

My advisor, Dr. Collins, provided the necessary guidance and constant support throughout the preparation of this dissertation. He provided research opportunities which provided the foundation for my research ideas and interest. He was patient and reassuring when I or any other student entered his office for help.

The rest of my committee has been just as supportive throughout this endeavor.

Dr. Stephens has been the most resourceful in regards to research and the job market. Her knowledge and advice enhanced my research and prepared me for presentations at conferences. I will carry her guidance and recommendations with me as I prepare to enter the job market. She is a great role model for women in the field of applied economics.

Dr. Strager is easily the friendliest face in the department. He has always been very approachable and willing to listen. I am so glad I had an opportunity to take a few of his GIS courses. It quickly became a passion of mine. Spatial analysis added another dimension and view to my research. His guidance led me to acquire a graduate certificate in GIS and Spatial Analysis.

Dr. Lacombe is a great instructor and very supportive. His classes made spatial econometrics easy to understand. I also was privileged to work with him outside of class to develop spatial models for the cooperative agreement project between WV NRCS and WVU.

Dr. Goetz provided great insight in economic theory. He is creative in addressing issues related to the subject field. I was privileged to be led by and to learn from Dr. Goetz and Dr. Collins in the collaborative ARC funded research project on economic resilience.

I am grateful for the opportunity to work with these brilliant, talented and dedicated individuals. Their assistance and encouragement allowed me to learn and grow through research and teaching opportunities. Sincerely, I thank you and promise to take the skills and knowledge that I have obtained to be a productive member of the work force and to help others use applied economics as a means to better understand the world around us and to make better data-driven decisions. 


\section{TABLE OF CONTENTS}

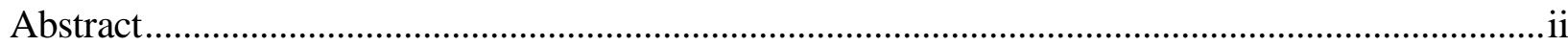

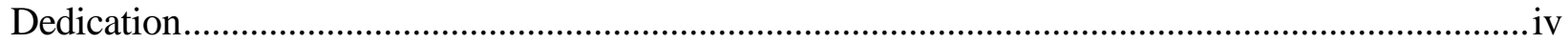

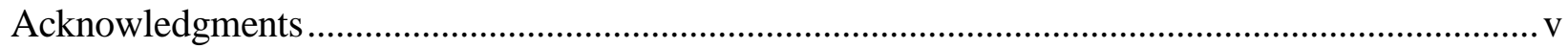

Table of Contents ........................................................................................................................

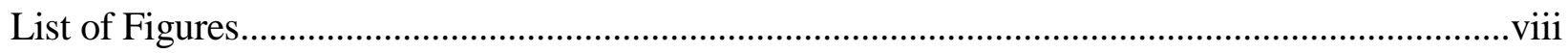

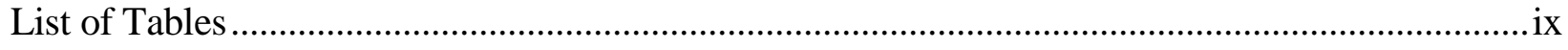

CHAPTER 1: INTRODUCTION.........................................................................................

CHAPTER 2: ESSAY 1 - THE IMPACT OF FEDERAL ENVIRONMENTAL REGULATIONS

ON LOCAL ECONOMIC GROWTH .......................................................................

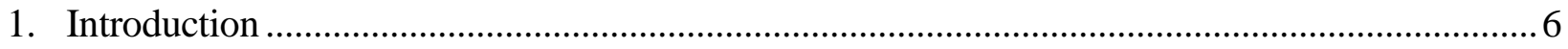

1.1 US Clean Air Act and the Criteria Pollutants …………….....................................................

1.2 Federal Environmental Regulations and their Health Impacts ..................................................... 8

1.3 Federal Environmental Regulations and the Impacts on Regional Economies ........................... 9

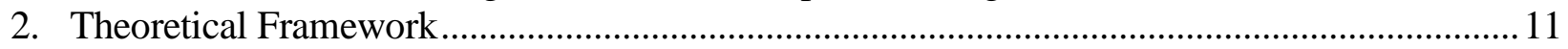

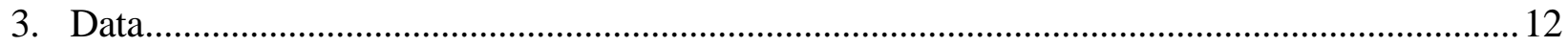

3.1 Changes in Manufacturing Cluster Regions …………….................................................... 13

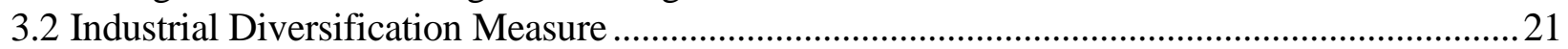

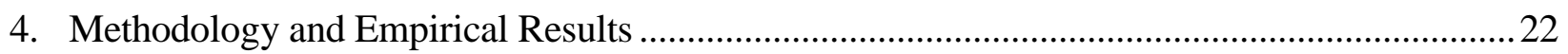

4.1 Effects of Pollution Standards on Total Employment ..............................................................22

4.2 Effects of Pollution Standards on Manufacturing Employment.................................................2

4.3 Effects of Pollution Standards on Population...........................................................................2

4.4 Effects of Pollution Standards on Industrial Diversification ...................................................2





CHAPTER 3: ESSAY 2 - ASSESSMENT OF THE SPATIAL DISTRIBUTION OF NRCS

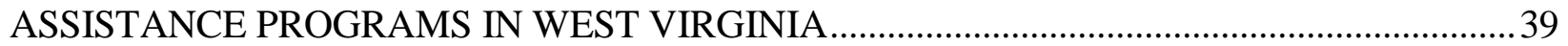

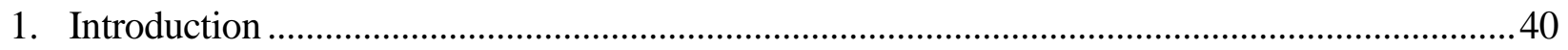

1.1 West Virginia Natural Resource Conservation Service Assistance Programs .............................42

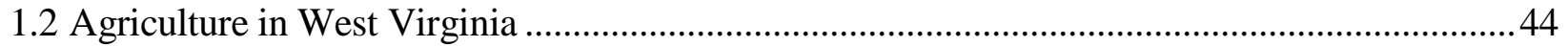

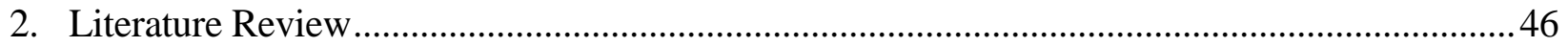

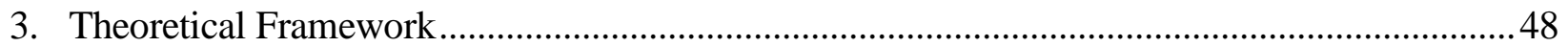

4. Spatial Distribution of NRCS Conservation Practices..................................................................49

5. Empirical Methodology and Data …………………............................................................5

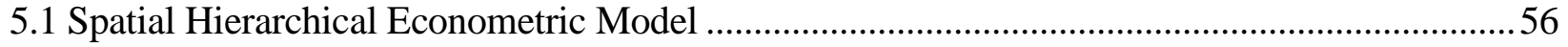

6. Spatial Hierarchical Model Results ..................................................................................58

6.1 Spatial Hierarchical Econometric Model Level 1 Effects ..............................................................58

6.2 Spatial Hierarchical Econometric Model Level 2 Effects ..........................................................60

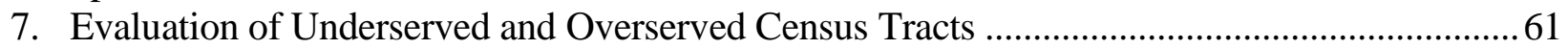

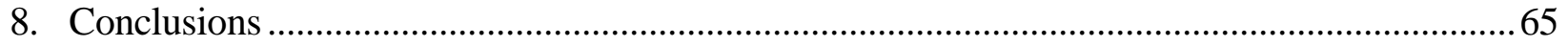

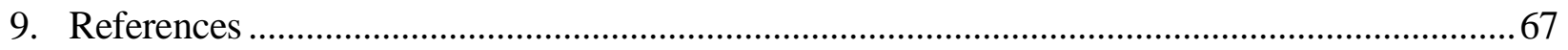


CHAPTER 4: ESSAY 3 - THE INFLUENCE OF ARC FUNDING ON REGIONAL

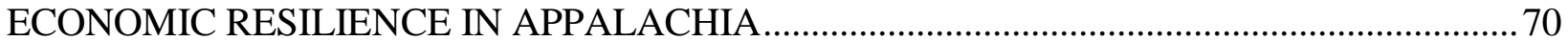



1.1 Appalachian Regional Commission (ARC) and Economic Status in Appalachia........................73

1.2 Overview of ARC Grant Project Investments..........................................................................75

2. Federal Funding and Regional Strategies to Address Rural Development .................................78

2.1 ARC Project Investments and Rural Development ………......................................................

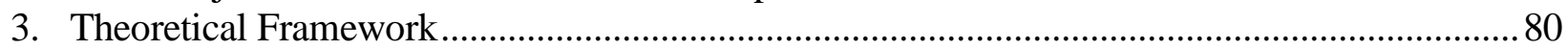

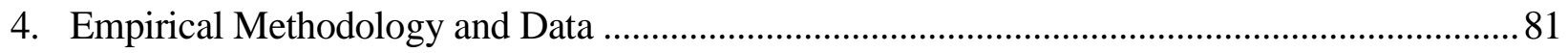

4.1 Measuring Regional Economic Resilience ………………………………………………........ 81

4.2 Regional Factors Underlying Economic Resilience ………..................................................... 84

4.3 Spatial Hierarchical Econometric Model …………................................................................ 87

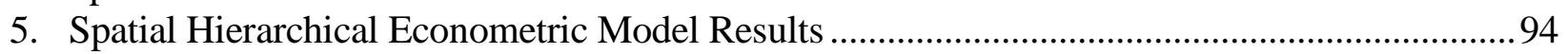

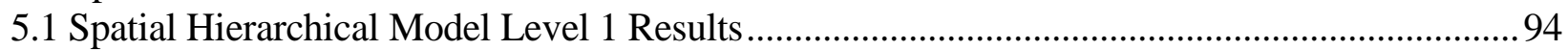

5.2 Spatial Hierarchical Model Level 2 Results ...........................................................................95

6. Local and Regional Policy Strategies for Economic Resilience ..................................................108

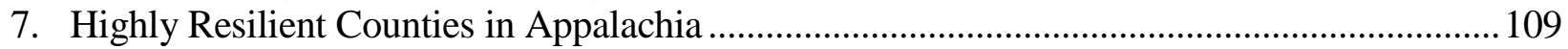



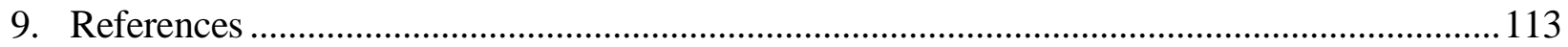

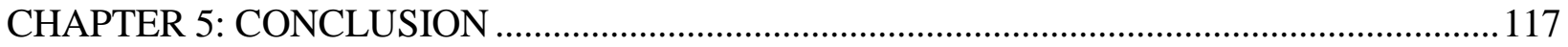




\section{LIST OF FIGURES}

\section{CHAPTER 2 - ESSAY 1}

Figure 1-1: 1-Hour Ozone, 8-Hour Ozone, and Particulate Matter Attainment Designations

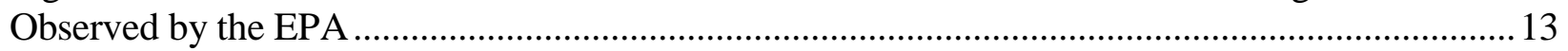

Figure 1-2: Manufacturing Employment in the US ..................................................................... 14

Figure 1-3: Manufacturing Employment Analysis from 2006 to 2016 …………………................. 16

Figure 1-4: Location Quotient Analysis from 2006 to 2016.......................................................... 17

Figure 1-5: Hot Spot Analysis from 2006 to 2016 ……….......................................................... 18

Figure 1-6: Potential Cluster Region Analysis from 2006 to 2016 .................................................... 19

\section{CHAPTER 3 - ESSAY 2}

Figure 2-1: WV NRCS Applied Conservation Practices .43



Figure 2-3: Percent of Farm Operators Listing Farming as their Primary Occupation .....................45

Figure 2-4: Applied NRCS Conservation Practices in WV ..............................................................51

Figure 2-5: Census Tract Level Distribution of Applied Practices ..................................................5. 52

Figure 2-6: Getis-Ord Gi* Hot Spot Analysis on Practice-Level Data ..............................................53

Figure 2-7: Spatial Distribution of WV NRCS Financial and Technical Assistance Practices.........62

Figure 2-8: Selected Areas for Future Outreach Efforts .....................................................................66

\section{CHAPTER 4 - ESSAY 3}

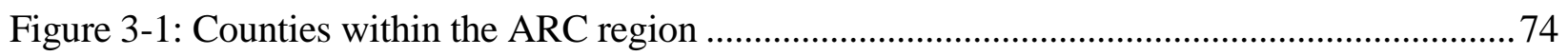

Figure 3-2: ARC County Economic Status Designations .................................................................. 74

Figure 3-3: County Economic Status Designations in 2002 and 2008 .............................................

Figure 3-4: ARC Total Project Investments from 1966 to 2006 ...................................................76

Figure 3-5: Employment Changes in Response to Economic Shocks ............................................... 82

Figure 3-6: ARC and Non-ARC Regions in Each State .................................................................. 85

Figure 3-7: Counties with the Highest and Lowest Resilience Levels ............................................ 111 


\section{LIST OF TABLES}

\section{CHAPTER 2 - ESSAY 1}

Table 1-1: Pollution Standards for the Criteria Pollutants Observed by EPA ....................................

Table 1-2: Descriptive Statistics for Labor Market Variables and Nonattainment Measures ............15

Table 1-3: Percent change in Total Employment model estimates ..................................................28

Table 1-4: Percent change in Total Employment model with Spatially-lagged Variables .................30

Table 1-5: Percent change in Manufacturing Employment model estimates.....................................32

Table 1-6: Percent change in Population model estimates ....................................................................33

Table 1-7: Percent change in Industrial Diversification model estimates ............................................34

\section{CHAPTER 3 - ESSAY 2}

Table 2-1: WV NRCS Assistance Programs Applied from 2004-2015 ……………….....................44

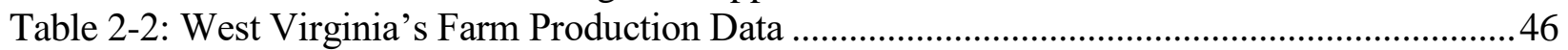

Table 2-3: Summary Statistics of Census Tract Level Variables .....................................................5

Table 2-4: Distribution of Applied Practices by Land Cover Type.................................................56

Table 2-5: Descriptive Statistics of County Level Variables..............................................................58

Table 2-6: Level 1 Coefficient Estimates for Spatial Hierarchical Models ......................................63

Table 2-7: Level 2 Estimates for Spatial Hierarchical Models .............................................................64

\section{CHAPTER 4 - ESSAY 3}

Table 3-1: Explanatory Variable Definitions and Data Sources............................................................. 86

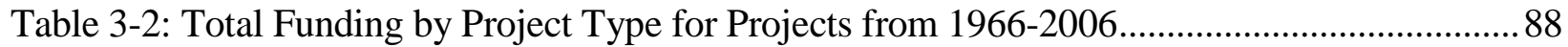

Table 3-3: Total Funding by Project Type for Projects from 1987-1996 ........................................... 89

Table 3-4: Total Funding by Project Type for Projects from 1997-2006 ………............................90

Table 3-5: Funding Per Capita by Project Type for Projects from 1987-1996 .................................91

Table 3-6: Funding Per Capita by Project Type for Projects from 1997 - 2006 ................................ 91

Table 3-7: Descriptive Statistics of Level 2 Explanatory Variables .................................................92

Table 3-8: Change in Business Development Per Capita Model .........................................................96

Table 3-9: Change in Child Development Per Capita Model ..............................................................97

Table 3-10: Change in Community Development Per Capita Model ...............................................98

Table 3-11: Change in Education and Job Training Per Capita Model............................................99

Table 3-12: Change in Environment and Natural Resources Per Capita Model ..............................100

Table 3-13: Change in Highways and Access Roads Per Capita Model............................................ 101

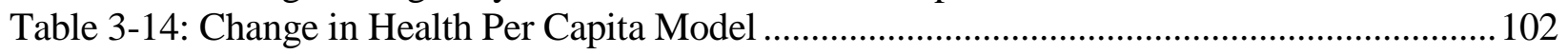

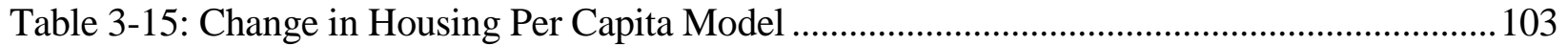

Table 3-16: Change in Leadership and Civic Capacity Per Capita Model....................................... 104

Table 3-17: Change in Local Development District Planning \& Administration Model ................. 105

Table 3-18: Change in Research and Technical Assistance Per Capita Model.................................106

Table 3-19: Change in Total Project Investments Per Capita Model .................................................. 107

Table 3-20: Policy Strategies to Influence Economic Resilience ......................................................109

Table 3-21: Highly Resilient Counties Based on Residual Values ....................................................110 


\section{CHAPTER 1: INTRODUCTION}

The underlying theme of this dissertation is the identification of effects of federal government policies and programs, both intended and unintended, on local economies. I explore the role of the federal government including financial and regulatory actions, and the impacts on local economic development within the United States. The purpose of this dissertation is to identify the effects of federal involvement on regional economies, and whether these federal activities provide a net gain to the local market.

The government has two microeconomic roles: to improve general microeconomic capacity through improving the quality and efficiency of firms and to establish microeconomic rules and incentives governing competition that will encourage productivity growth (Porter, 2000). ${ }^{1}$ Government does have the role to exist within the market; however, government involvement should not solely determine the success or failure of industries within a region. Government involvement in the market can provide economic stability with additional support and to address externalities; however, unintentionally it could also create obstacles such as trade barriers, infrastructure constraints, and unnecessary inefficiencies such as government regulations.

Stiglitz (1996) identified that government activities such as regulated policies and support practices can improve the well-being of the economy when imperfections in information or competition, or incomplete markets exist. ${ }^{2}$ However, to improve "living" standards government actions must be held to certain criteria. First, the government must address serious imperfections in the marketplace. Secondly, the government policies must be regulated efficiently such that the benefits outweigh the cost. It is very important to evaluate the impacts of government activities.

Along with providing a national infrastructure, the federal government can also address inefficiencies occurring at the local or regional level. The federal government can provide additional support to underdeveloped regions such as the Appalachian region, this region has persistent poverty and lags in economic development when compared to the rest of the nation. In the mid-1960s, Congress formed the Appalachian Regional Commission, formally known as the Conference of Appalachian Governors, to address issues related to high poverty levels and scarce employment opportunities ${ }^{3}$. By providing additional financial support, the government can increase the stability within the regional economy.

The federal government can also create regulations to address local resource concerns and externalities. In 1970, the US Clean Air Act (CAA) was enacted to introduce air pollution standards for sulfur dioxide $\left(\mathrm{SO}_{2}\right)$. The purpose of this law was to address air quality issues from burning sulfur within the coal plants for electricity generation. Electricity generation was directly

\footnotetext{
1 Porter, M.E., 2000. Location, competition, and economic development: Local clusters in a global economy. Economic Development Quarterly 14 (1): 15-34.

${ }^{2}$ Stiglitz, J.E., 1996. The role of government in economic development. In Annual World Bank Conference on Development Economics:11-23.

${ }^{3}$ Appalachian Regional Commission. “ARC History”. Accessed on April 18, 2017. https://www.arc.gov/about/ARCHistory.asp
} 
related to sulfur dioxide emissions which is an important source of environmental pollution (Harvey 1986). ${ }^{4}$ Without this environmental regulation, firms would continue to degrade the air quality and impose severe health risks, a negative externality. However, these regulations also impose a negative externality on the labor market. The federal government can also address issues such as the preservation of endangered species such as the spotted owl in the northwest region of the country. It is important to preserve this animal species as they have an important role in the environment. For example, Andre and Velasquez (1991) state that the benefits of preserving the spotted owl and its habitat far outweigh the costs. They state " $[\mathrm{t}]$ he spotted owl is considered an indicator species - a gauge of the health of the ecosystem of its habitat." They can identify a change in the quality of the ecosystem, in which other animals, plants, and humans are dependent upon. Montgomery et al. (1994) also identify the marginal costs and benefits associated with the federal action for the preservation of the species. ${ }^{6}$ Increasing the population of the spotted owl will lead to an increase in the designated amount for critical habitat capacity. This will also lead to a decrease in the amount of timber available for harvest.

The federal government has many roles; the most important role is to protect the wellbeing of the economy. The government can direct additional resources, such as financial support, to areas that are persistently undeveloped when compared to the nation. They can also mandate the preservation of natural resources through policies that can promote or constrain activities within specific regions. In this dissertation, microeconomic theory will be utilized to evaluate the financial and regulatory roles of the federal government, and its influence on the economic development of a local region.

The first essay investigates changes to air pollution standards within the CAA and their influence on local economic growth. Environmental regulations provide numerous benefits such as addressing health risks and environmental concerns; however, these pollution standards may also impose unintended consequences on the labor market. Strengthening air pollution standards by increasing environmental regulation raises operating costs of manufacturing firms and other polluting industries. These unintended effects may perhaps lead to the shutdown of firms, decrease the demand for labor in the manufacturing sector and potentially reduce total employment for the region. However, the loss of dependency on the manufacturing sector could also be a driving force behind industrial diversification in a region, which is beneficial for economic sustainability.

This essay investigates the changes in the air pollution standards of the 1990 Amendment of the CAA on changes in employment and population levels, and industrial composition at the county level in the eastern US. The results suggest that, in the long run, areas designated as nonattainment are adapting to the stricter pollution standards. Nonattainment regions are becoming less dependent upon polluting industries, as the manufacturing sector is shrinking nationally, and are diversifying their industry portfolio. Due to changes in the county's industry

\footnotetext{
${ }^{4}$ Harvey, C. E. 1986. Coal in Appalachia: An Economic Analysis. Lexington, Kentucky: The University Press of Kentucky.

${ }^{5}$ Andre, C., and M. Velasquez. 1991. "Ethics and the Spotted Owl Controversy." Issues in Ethics 4.

${ }^{6}$ Montgomery, C. A., and D. M. Adams. 1994. "The marginal cost of species preservation: the northern spotted owl." Journal of Environmental Economics and Management 26 (2): 111-128.
} 
diversity, the region is still seeing small, but positive employment growth and population growth. At the same time, the effects of nonattainment on manufacturing employment were negative, but not significant.

The second essay identifies regional determinants of census tract level participation in Natural Resource Conservation Service (NRCS) conservation programs in West Virginia. The Resource Conservation and Development (RC \& D) Program, developed by NRCS, promotes conservation through financial and technical assistance programs in RC \& D areas. ${ }^{7}$ The entire state of West Virginia was designated as a focus area for resource conservation. Financial and technical assistance programs were implemented to provide aid in farm management and conservation applications. By providing additional support to the farmers and landowners, assistance programs are cost-effective and they enhance efficiency. This increase in efficiency could provide additional stability within the agricultural sector.

This essay expands from the previous literature by measuring program participation at a regional (census tract) level, instead of an individual measure. We investigate the significance of land cover attributes and socioeconomic characteristics on program participation. This study also assesses influence of social networking on the spatial distribution of program participation. In this study, I conclude by identifying target regions for future outreach. By increasing participation in farm management applications and conservation practices, the region should benefit from increased cost-effectiveness and efficiency in the agricultural sector.

These results indicate NRCS is strategically targeting areas to promote efficient farm management techniques and to protect stream water quality. Surface mining discourages practice implementation within surface-mined affected areas in the census tract and the neighboring areas. The amount of developed land within a census tract also restricts the amount of land available for conservation practice adoption. Distance to an NRCS field office is also significant, as access to information and nearby resources has a significant effect on conservation practice adoption. This is supported by the positive total effect of farms with internet access on practice adoption levels throughout the state. We also find strengthening the social network of farmers, such as increasing the number of farms and the size of the operations, has a positive total effect on conservation practice adoption for the state.

The third essay evaluates the significance of project investments provided by the Appalachian Regional Commission (ARC) on economic resilience within the greater Appalachian region. ARC was established to address the persistent poverty issues. This agency supports projects to improve the economic conditions of the region including: education and job training, community development, network improvement and infrastructure support. The benefits from these projects help build a foundation for industrial growth and employment opportunities. Since the establishment of the ARC, the region has grown rapidly in population, per capita income, earnings, and employment.

\footnotetext{
${ }^{7}$ Natural Resource Conservation Service. "Resource Conservation and Development Areas" Accessed on April 11, 2018. https://www.nrcs.usda.gov/wps/portal/nrcs/detail/national/technical/nra/nri/?cid=nrcs143_013723
} 
This essay contributes to the literature by investigating the influence of location-based federal funding on regional economic resilience. Regional investments sustain the unique attributes of a region, improve its economic foundation, and in turn, generate more localized spending. Increased localized spending leads to an increase in economic growth and economic resilience for the region. It is important to address economic concerns in a region that is historically lagging in growth when compared to the nation. The results indicate ARC project investments do not have statistically significant impacts on economic resilience; however, estimated effects for ARC project investments generally were positive. The additional support provided by ARC project investments to a region might be attractive to new firms and could also leverage funding from other public and private sources. These funding opportunities provide a foundation for industrial growth and employment opportunities.

This essay also investigates policy-related issues such as employment, demographic, mobility, and additional wealth to pursue higher levels of resilience within the region. The results of investigating these topics provide policy suggestions to further ensure economic resilience. Policy strategies could be most effective as local or regional policy strategies based on the significance of the spillover effects. Regional policy approaches are identified as multi-county cooperative strategies or competitive strategies. 


\title{
CHAPTER 2: ESSAY 1 - THE IMPACT OF FEDERAL ENVIRONMENTAL REGULATIONS ON LOCAL ECONOMIC GROWTH
}

With Heather Stephens

\begin{abstract}
In recent years, changes have been made to U.S. environmental regulations with a goal of improving society's health and well-being. Specific changes include new, stricter air pollution standards under the 1990 Amendment to the U.S. Clean Air Act. As a result, regions with air emissions that exceed these standards face restrictions on stationary sources, such as manufacturing plants. Thus, the new standards may negatively impact businesses and employment in the manufacturing sector, and potentially total employment, in the impacted regions. However, the loss of dependency on the manufacturing sector could also be a driving force behind industrial diversification, which previous research has found to be beneficial for long-term economic sustainability (e.g. Louis 1980). This essay investigates how changes in the air pollution standards affect manufacturing employment and total employment as well as industrial diversity in the eastern US. A cross-sectional analysis is performed at the county level looking at changes from 2006 to 2016. While controlling for various economic and other factors that contribute to a county's nonattainment status and growth, we observe the effects of the pollution standards for ozone and particulate matter on long-term economic growth. The conclusions of this study provide some evidence that, in the long run, regions designated in nonattainment are becoming more industry diverse, less dependent upon the manufacturing sector, and are experiencing employment and population growth. This suggests regions have adapted to the new regulations and are still seeing economic growth in the long run.
\end{abstract}

Keywords: Local economic growth, industry diversity, environmental regulations, policy changes 


\section{Introduction}

Since the passage of the Clean Air Act of 1990, the Environmental Protection Agency (EPA) has continuously updated the pollution standards for several critical air pollutants as new information has become available about the health impacts of these pollutants. For example, the ozone pollution standards have increased twice, while the standards for particulate matter (PM) have increased three times over. Pollution standards for sulfur dioxide and lead have also recently increased. As standards increase, this leads to a greater number of counties designated as "nonattainment," meaning their air quality is not up to the new standards. Industry composition and climate are the main drivers of air pollution. For areas in nonattainment, which are also likely to have more polluting industries, this designation might have a significant impact the region's labor market and its overall economy.

For current nonattainment regions to gain the EPA's attainment status, existing industries in these regions could be required to install new pollution control equipment that has significant impacts on their production costs. New facilities wanting to locate in a nonattainment area may also be required to install tighter pollution controls or take on operational limits that are not required in other regions. Due to compliance costs reducing demand for the regulated businesses' products, there will also be a reduction in these businesses' demand for labor (Bartik 2015). Thus, an increase in environmental standards leads to the shutdown of older (more polluting) industries and could freeze the development of new plants and other economic activity in a region. These regulations also increase firms' operating costs and may also lead to the closing of older facilities (Guttman, Sierck, and Friedland 1992). Fraas, Graham, and Holmstead (2017) have observed the limitations placed on the manufacturing sector by the New Source Review (NSR) under the CAA. The NSR establishes guidelines for a facility that wants to enter an attainment or nonattainment region. According to their analysis, the requirements of these regulations make it nearly impossible to establish a new plant or modify an older plant in a nonattainment region.

To understand the impact of the changes in air quality standards on regional economies, we explore the effects of a "nonattainment" designation on the counties in the eastern US, which includes the states east of the Mississippi River. We observe the change in the ozone standard in 2005, and the effect on local economic growth. By observing the entire eastern US, we can include a diverse observation of county nonattainment levels. Harvey stated "[h]istorically, the majority of coal tonnage mined in the United States has been extracted east of the Mississippi River" (1986). Coal mining in this region is the direct source of air quality issues related to burning sulfur within plants for electricity generation. Much of the region also has hot summer weather that can contribute to air pollution, especially ozone. Some areas within this region have a long history of high levels of employment in polluting industries, as well as economic distress. Thus, if polluting industries are affected by this policy it possibly will enhance this distress. However, if counties experience industrial diversification because of declines in polluting industries, such as manufacturing, they may experience higher levels of long-term growth (e.g. Louis 1980). Thus, we assess the impacts of environmental regulations on changes in county level total employment, changes in manufacturing employment, population change, and changes in industrial diversity.

This essay contributes to the literature by not only measuring the impact of the attainment status for the pollution standards on local development, but also the impact of amending pollution standards, such as introducing stricter Ozone pollution standards, on local economic growth. 


\subsection{US Clean Air Act and the Criteria Pollutants}

Under the authority of the Clean Air Act, the EPA enforces federal air quality standards known as the National Ambient Air Quality Standards (NAAQS) in the United States. Ambient air is the air within the atmosphere to which the public has access. NAAQS includes both primary and secondary air quality standards. Primary NAAQS are set to protect the public health with "an adequate margin of safety." Secondary NAAQS were created to protect the environment and the public welfare. The purpose of the CAA is to regulate air pollution at the national level from stationary and mobile sources and to protect the public from hazardous airborne pollutants that could be dangerous to human health. ${ }^{8}$

Congress updated the Clean Air Act in 1977 and then again in 1990, to provide the EPA with an even broader authority to enforce reductions of air pollutant emissions. When updated in 1990, the amendments required an issuance of technology-based standards for stationary "major sources." This provided a new emphasis on finding more cost-effective approaches to reduce air pollution. Firms in nonattainment were required to improve their production technology. In addition to increasing the national standards, the amendments provide for state-level enforcement and plans for meeting attainment standards.

The air quality standards include regulations for six categories of pollutants, known as the criteria pollutants. The criteria pollutants include: carbon monoxide, lead, ozone, nitrogen oxides, particulate matter, and sulfur dioxide. Bernard et al. (2001) have identified multiple sources for pollutants such as natural, agricultural, commercial, industrial, transportation, and residential. These pollutants are released from stationary sources such as chemical plants, gas stations, and power plants; and from mobile sources such as automobiles, trucks, and planes. Concentration of one or more criteria pollutants within a region that exceeds the regulated level classifies the region as a nonattainment region. If the criteria pollutants are evaluated below the established attainment level, then area is considered an attainment region and is not subject to regulatory restrictions. The current standards for the criteria pollutants are in Table 1-1 below.

Table 1-1: Pollution Standards for the Criteria Pollutants Observed by Environmental Protection Agency (EPA)

\begin{tabular}{|c|c|}
\hline Ozone (Oz) & Particulate Matter (PM) \\
\hline 8-Hr Ozone (2008 Standard) & PM-2.5 (2012 Standard) \\
\hline 8-Hr Ozone (1997 Standard)* & PM-2.5 (2006 Standard) \\
\hline \multirow[t]{2}{*}{ 1-Hr Ozone (1979 Standard)* } & $P M-2.5$ (1997 Standard) \\
\hline & PM-10 (1987 Standard) \\
\hline Sulfur Dioxide $\left(\mathrm{SO}_{2}\right)$ & Lead \\
\hline Sulfur Dioxide (2010 Standard) & Lead (2008 Standard) \\
\hline Sulfur Dioxide (1971 Standard) & Lead (1978 Standard) \\
\hline Carbon Monoxide (CO) & Nitrogen Dioxide $\left(\mathrm{NO}_{2}\right)$ \\
\hline Carbon Monoxide (1971 Standard) & Nitrogen Dioxide (1971 Standard) \\
\hline
\end{tabular}

*From the EPA's Green Book Nonattainment Areas website: “The 8-hour Ozone (1997 standard) was revoked on April 6, 2015, and the 1-hour Ozone (1979 standard) was revoked on June 15, 2005".

\footnotetext{
8 EPA. "Overview of the Clean Air Act and Air Pollution" Accessed on March 28, 2017. https://www.epa.gov/clean-air-actoverview
} 


\subsection{Federal Environmental Regulations and their Health Impacts}

Air pollutant standards are set to minimize negative health, environmental, and economic impacts from pollutants. For example, Kampa and Castanas (2008) have identified various health effects related to air pollutants. These effects range from minor illnesses to significant respiratory effects. Asthma sufferers are more sensitive to air pollution and nearly 25 million adults and children in the United States have been diagnosed with asthma. ${ }^{9}$ Air pollution can also aggravate health problems for the elderly and others with heart or respiratory diseases. For example, Brunekreef and Holgate (2002) find exposure is associated with increased mortality and hospital visits and they identify effects related to very low levels of exposure. Air pollutants are also contributors to other illnesses, which decrease the workforce and its productivity. ${ }^{10}$ The following provides more detail on the health impacts of each criteria pollutant.

Carbon monoxide (CO) is a colorless, odorless, and poisonous gas. Vehicle exhaust contributes roughly $60 \%$ of all $\mathrm{CO}$ emissions nationwide and up to $95 \%$ in cities. $\mathrm{CO}$ is harmful because interferes with the ability of the blood to transport oxygen to organs and tissue throughout the body. This can cause slower reflexes, confusion, and drowsiness. It can also reduce visual perception and coordination and decrease the ability to learn and the efficiency in the workplace.

Lead is a metal found naturally in the environment as well as in manufactured products. Excessive lead exposure can cause seizures, brain and kidney damage, intellectual and development disabilities, and/or behavioral disorders. Exposure to lead can occur through multiple pathways, including inhalation of air and ingestion of lead in food, water, soil, or dust; however, the major source of lead emissions today is metals processing. The highest levels of lead in air are generally found near lead smelters, waste incinerators, utilities, and lead-acid battery manufacturers.

Ozone $\left(\mathrm{O}_{3}\right)$ pollutants are created by a chemical combination of nitrogen oxide and volatile organic compound emissions and are especially a problem in the summer when higher temperatures increase the levels. Major sources of these emissions include: industrial facilities, electric utilities, motor vehicle exhausts, gasoline vapors and chemical solvents. Ozone is associated with lung diseases such as asthma and other respiratory problems.

Nitrogen dioxide $\left(\mathrm{NO}_{2}\right)$ is a highly reactive gas whose two major emission sources are motorized vehicles and stationary fuel combustion sources such as electric utilities and industrial boilers. This pollutant can irritate the lungs, causing bronchitis and pneumonia, and lowering resistance to respiratory infections. Nitrogen oxides also contribute to formation of both ozone and acid rain ${ }^{11}$ and may affect both terrestrial and aquatic ecosystems.

Particulate matter (PM) is a combination of extremely small particles and liquid droplets from various sources including vehicles, burning of materials, and soil and dust particles. These air pollutants can lead to more severe respiratory infections and diseases. The EPA measures

\footnotetext{
${ }^{9}$ Centers for Disease Control and Prevention. "Asthma in the US". Accessed on October 29, 2017. https://www.cdc.gov/vitalsigns/asthma/index.html

${ }^{10}$ EPA. "Criteria Air Pollutants". Accessed on March 28, 2017. https://www.epa.gov/criteria-air-pollutants

${ }^{11}$ Acid rain is any form of precipitation with acidic components, such as sulfuric or nitric acid that fall to the ground (US EPA). EPA." What is Acid Rain?" Accessed on October 11, 2017. https:/www.epa.gov/acidrain/what-acid-rain
} 
particulate matter in two different sizes, 10 micrometers and 2.5 micrometers. PM-10 consists of particulate matter larger than 2.5 micrometers but smaller than 10 micrometers, which are commonly referred to as inhalable coarse particles. PM-2.5 is particulate matter smaller than 2.5 micrometers, also known as fine particles. Prominent sources of these fine particles include smoke and haze from forest fires and gases emitted from power plants. Both evaluated PM measurements are related to industrial processes.

Sulfur dioxide $\left(\mathrm{SO}_{2}\right)$ is a gas that is largely produced during the combustion of fossil fuels at power plants and other industrial facilities. This pollutant is linked to respiratory infections and acid rain. The EPA revised the primary standard in 2010 for sulfur dioxide to a 1-Hour Standard at 75 parts per billion or at the annual rate of 0.053 parts per million.

\subsection{Federal Environmental Regulations and the Impacts on Regional Economies}

Pollution standards from the US Clean Air Act of 1990 address the negative air pollution externality by regulating its production. In the absence of regulation, given the numerous pollutants and sources of pollutants, it is unlikely that businesses and individuals would voluntarily reduce pollution to safe levels. Prior to the initial passage of the Clean Air Act, dangerously high pollution levels existed in some regions of the country.

While the regulations address negative pollution externalities, they also increase the production costs for firms (Jorgenson and Wilcoxen 1990; Greenstone 2002). Industries in nonattainment areas may be required to install additional pollution control equipment that could have significant impacts on their production costs. New facilities wanting to locate in nonattainment areas might also be required to install tighter pollution controls or have more stringent operational limits than if they were to locate in an attainment region. Firms unable to withstand the cost effects of the control equipment may relocate elsewhere, negatively impacting employment.

The use of alternative fuels and new technological advances may mitigate these impacts, but they are also not without their costs. For example, if a manufacturing plant switched from getting its power from a coal-fired power plant to a natural gas power plant there would be lower emissions. However, while getting power from other alternative fuels, like wind or solar, plants could also reduce air emissions, they may not produce enough energy or provide enough reliability since the sun does not always shine and the wind does not always blow. New technologies also help industries adapt to the new pollution standards and industries and individual companies that can afford to and are able to adopt newer technologies will be less affected by environmental regulations. However, it may be difficult for older plants to adopt new technology as "[m]achines and equipment are generally designed and built to accommodate a given technology if energy consumption and cannot be altered easily" (Harvey 1986). Thus, an increase in environmental regulations might lead to the shutdown of plants and it may freeze the development of new plants within a region. In the long run, this could affect (positively or negatively) the industrial mix, employment growth, and the economic vitality in the region.

This article builds upon a wealth of previous research that has considered questions related to federal environmental regulations, pollution abatement, the location of manufacturing firms, changes in industrial activity and industrial diversification, and local employment growth and employment stability. This literature is discussed within the following paragraphs. 
Not only will environmental regulations restrict the production of a firm, but they also increase production costs due to the need to use emissions control technology. Jorgenson and Wilcoxen (1990) forecast simulations on the growth of the U.S. economy with and without pollution controls to quantify the costs of regulations on long-term growth. Their analysis included the interaction between industries to capture the full repercussions of environmental regulations; however, they did not attempt to assess the benefits resulting from a cleaner environment. They found that environment regulations impose a significant cost from emissions control.

Several papers have found negative impacts on the number of firms and employment in polluting industries in regions affected by new air quality regulations. Greenstone (2002) showed, not surprisingly, that, by the tightening of regulation standards, more counties fall into nonattainment. He also found that newly labeled nonattainment counties decline in employment in polluting industries and investments and shipments from manufacturing plants. Becker and Henderson (2000) examined plant level data from 1963 to 1992 and the impact of attainment with air quality standards. They found being in nonattainment areas reduced the number of firm births in polluting industries by 26 to 45 percent and that bigger plants were affected the most, shifting the industrial structure toward less regulated, single-plant firms.

Recent literature has also explored the effects of environmental regulations on employment changes at the county level. Yan and Carr (2013) analyzed the effects of Clean Air Act regulations on employment growth and employment stability by characterizing the responses in key indicators of local economic development. They find that enhanced employment stability is associated with nonattainment areas for total suspended particulates (TSP) and 1-hour ozone. They also find that positive employment growth is associated with counties in 1-hour ozone and sulfur dioxide nonattainment areas, and negative employment growth is found in TSP and carbon monoxide nonattainment areas. Walker (2011) also measures the impact of changes in county-level environmental regulations on plant and sector employment levels. Estimates from a variety of specifications suggest a strong connection between changes in environmental regulatory stringency and changes in the employment growth in the affected sectors. The author-preferred estimates suggest that changes in county level regulatory status due to the Clean Air Act Amendments of 1990 reduced the size of the regulated sector by as much as 15 percent in the 10 years following the changes. These results hint that regulated industries may be diminishing; however, labor force is moving into other sectors for continued work.

If the labor force within a region is moving from manufacturing into other sectors, the region is becoming more industry diverse. Regions that are more industry diverse may be resistant to economic shocks. Specialized regions are more susceptible to market booms-and-busts, leading to higher unemployment rates and unstable income (Louis 1980; and Sayago-Gomez and Stair 2015). Carr and Yan (2012) highlight the impact of air-quality regulations on local industrial diversification in regions observed with nonattainment and gained-attainment status. The authors defined gained-attainment status as counties that were previously in a nonattainment region but have improved to being in attainment over time. They determined that the nonattainment status based on ozone, carbon monoxide, or sulfur dioxide pollutants in a region significantly decreases local industrial specialization. These affects persist after a gained-attainment status has been achieved in a region for these pollutants. Sanchez and McKinley (1998) discovered that older plants and customized-production plants are more responsive to product innovation in relation to 
environmental regulations. Older plants must take more drastic measures such as using cleaner inputs and manufacturing completely new products to meet the standards. Customized-production plants are flexible to modifications for customers and environmental regulations and may make a region more diverse.

Previous research has found that job displacement in manufacturing industries does not substantially fade (Schoeni and Dardia, 2003; and Davis and von Wachter, 2011). Thus, the research question(s) addressed in this essay include:

How do stricter standards affect the total employment growth in the region, employment in manufacturing, and industrial specialization over time?

Can regions recover from this employment change by diversifying their economy into other, non-polluting industries?

\section{Theoretical Framework}

Changes in employment levels in a region are based on movement of households and firms (e.g. Stephens and Partridge, 2011; Roback, 1982). As Stephens and Partridge (2015) state "[h]ousehold movements affect labor supply and firm movements affect labor demand; and they jointly determine a region's employment level." While the previous literature found population change is a good proxy for household migration, or changes in labor supply (Rappaport, 2007; Faggian, Olfert, and Partridge, 2012), no similar measure is available to measure labor demand separately. This study replicates and expands upon the Stephens and Partridge (2015) theoretical framework to explain changes in employment levels in a region because of changes in air quality standards. Thus, changes in employment will depend on the net effects of labor demand and labor supply.

For nonattainment regions, pollution standards can lead to higher costs for some polluting firms, thus reducing the output from those industries. This decrease in output will ultimately lead to a decrease in the number of polluting industries in the region. The decrease in the number of regulated firms will have a negative impact on labor demand and reduce the number of employed workers in that region.

At the same time, tighter environmental regulations may increase the environmental quality of the region, making it more attractive to households and increasing the number of people who migrate into that region, thus increasing labor supply. There is also evidence (for example, Stephens and Partridge, 2015) that those who migrate for higher environmental quality are likely to be more highly educated, thus this in-migration may result in a more highly skilled workforce. Because of the exit of polluting industries leaving more slack in the workforce, and the entrance of more highly-skilled labor, the same region may be more attractive to firms that are unaffected by the environmental regulations. Thus, this may lead to an increase in non-polluting firms, which will have an offsetting increase in labor demand for the region, as well as increasing industry diversity. The change in overall employment will depend on the net changes in labor supply and demand. Bartik (2015) states "[e]nvironmental regulations are unlikely to have major net job effects because aggregate demand is unaffected. Environmental regulation reallocates labor demand." 
In this analysis, we examine net effects of nonattainment designations and changes in the pollution standards on the labor market. We examine the long-run effects on changes in total employment, manufacturing employment, population, and industry diversity. We expect do not expect any net effects on wages as they are transfers between workers and employers (Bartik, 2015). ${ }^{12}$ Employment levels within a region may decrease if not enough new firms enter, may remain constant, or may even grow.

\section{Data}

The Environmental Protection Agency (EPA) conducts an annual evaluation on each of the six criteria pollutants at the county level, which is reported in the Code of Federal Regulations. Either a part of a county or a whole county can be found in nonattainment for a criteria pollutant.

However, the partial status of a county does not follow county boundaries and could be due to nearby county status. Thus, we focus on the designation of nonattainment for a whole county. Counties designated as in nonattainment have a high concentration of one or more pollutants. The air pollutants identified by the EPA as the six criteria pollutants include: ground-level ozone, particulate matter, sulfur dioxide, nitrogen dioxide, sulfur dioxide, and lead.

Brunekreef and Holgate (2002) state "[n]ow that the concentration of sulfur dioxide has decreased strikingly, attention has shifted to ozone, nitrogen dioxide, and particulates." Since ozone and particulate matter are the pollutants widely observed within this region, the pollution standards for these criteria pollutions are the focus of this analysis. The pollutants that were evaluated within the region include ozone and particulate matter as these are the primary pollutants that affect a county's attainment status in the eastern US. The focus of this study is the regulatory designations of nonattainment and the effects on local employment change. Information on the county-level attainment status for the air pollution standards and the changes in these standards is collected from Green Book of Nonattainment from the U.S. EPA website. Figure 1-1 illustrates the regional distribution of nonattainment designations for the criteria pollutants observed in this study region. As shown, there is a high concentration of nonattainment counties in the states on the east coast between Maryland and Maine.

\footnotetext{
${ }^{12}$ We tested this hypothesis by conducting an empirical analysis on the percent change in wages and salaries from 2006 to 2016 . We found evidence to support this hypothesis as nonattainment designations did not have a statistically significant impact on wages.
} 




Figure 1-1: 1-Hour Ozone, 8-Hour Ozone, and Particulate Matter Attainment Designations Observed by the EPA

To measure labor market change, county-level employment data for total employment, manufacturing employment, population and employment by industry were collected from the Bureau of Economic Analysis. Data for the economic control variables were collected from the US Census Bureau Decennial Census and the Bureau of Labor Statistics. The economic control variables will be used to predict the impact of nonattainment on employment change and changes in industrial diversity of a region. Data on factors that contribute to a region's pollution level and attainment status were collected from the USDA Economic Research Service and US Energy Information Association. Descriptive statistics of the explanatory variables included within this analysis are provided below (Table 1-2).

\subsection{Changes in Manufacturing Cluster Regions}

Amendments to the pollution standards can have a significant impact on polluting industries, such as firms in the manufacturing employment sector. By analyzing manufacturing employment data in ArcGIS, we identify regional changes to employment levels within the sector from 2006 to 2016. Figure 1-2 illustrates manufacturing employment levels for the entire US. 


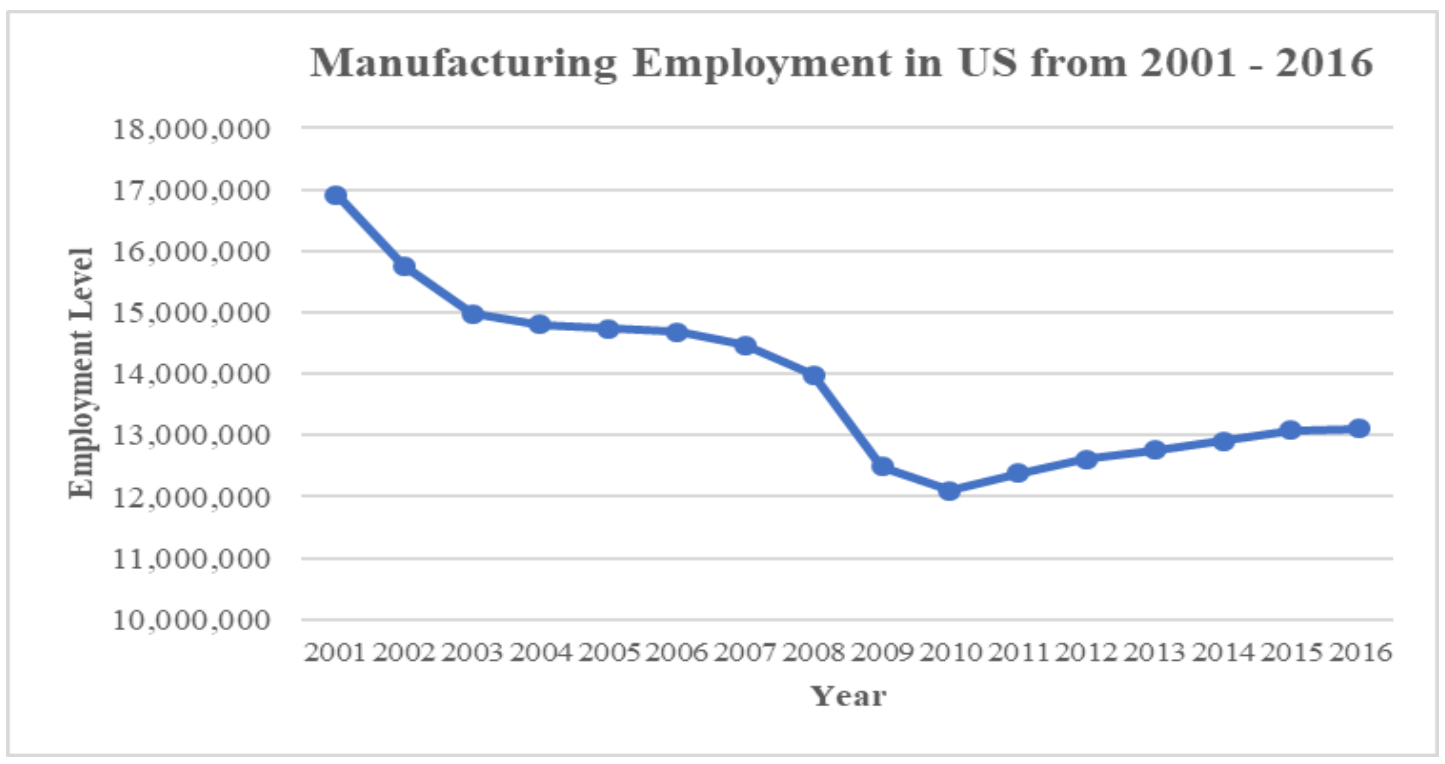

Figure 1-2: Manufacturing Employment in the US

As shown in Figure 1-2, there is an overall decrease in manufacturing employment throughout the nation. However, the national average does not illustrate how this impacts the regional distribution of manufacturing. Figure 1-3 displays the changes in the regional distribution from 2006 to 2016. We identify manufacturing specialized regions by using a regional economic analysis technique known as the employment location quotient analysis. The employment location quotient (LQ) helps identify regions that are specialized in the manufacturing industry:

$$
L Q_{j, R}^{t}=\frac{\frac{E_{j, R}^{t}}{E_{R}^{t}}}{\frac{E_{j, N}^{t}}{E_{N}^{t}}}
$$

The location quotient is calculated by dividing the portion of county R's employment in a sector $\mathrm{j}$ by the nation N's portion of employment in the same sector $\mathrm{j}$. A location quotient that is greater than 1 means that the county has a larger portion of its employment in that sector than the nation. Therefore, if the location quotient is greater than 1, the region is assumed to be an exporter in that employment sector or is specialized in that employment sector. As shown in Figure 1-4, from 2006 to 2016, there was not a large shift in the counties designated as manufacturing specialized, or counties that have a higher proportion of manufacturing employment when compared to the nation; however, overall employment levels have decreased during this time period. 
Table 1-2: Descriptive Statistics for Labor Market Variables and Nonattainment Measures

Variables

Dependent variables

Percent change in total employment from 2006 to 2016

Percent change in manufacturing employment from 2006 to 2016

Percent change in industrial diversification from 2006 to 2016

Percent change in total population from 2006 to 2016

Explanatory Variables

Percent change in total population from 1969 to 1979

Historical industrial diversification measure (coefficient of specialization), 1969

Population density, 2000

Unemployment rate, 2005

Median age, 2005

Percent of population 25 years and older with a high school degree, 2000

Percent of population 25 years and older with a bachelor's degree or higher, 2000

Percent of white, non-Hispanic population in 2000

Natural amenity score, 1999

Mean temperature in July, 1941-1970

Average annual capacity in megawatts for existing generating units, 2003

Distance to nearest metro $(\mathrm{km})$

Incremental distance to a metro $>250,000$ population

Incremental distance to a metro $>500,000$ population

Incremental distance to a metro $>1,500,000$ population

Share of non-farm proprietors employment, 2005

Share of manufacturing employment, 2005

Nonattainment measures

County is in nonattainment for 1-hour ozone (1979) standard, 2004

County is in nonattainment for 8-hour ozone (1997) standard, 2004

County is in nonattainment for 8-hour ozone (1997) standard, 2005

County is in nonattainment for PM-2.5 (1997) standard, 2005

County remains in nonattainment through ozone standard change, 2004

County changes from attainment to nonattainment through ozone standard change, 2004

County changes from nonattainment to attainment through ozone standard change, 2004

County is in nonattainment for either PM-2.5 or 8-hour ozone standard, 2005
Source Mean

SD Minimum Maximum

\begin{tabular}{|c|c|c|c|c|}
\hline BEA & 1.10 & 10.37 & -36.75 & 57.43 \\
\hline BEA & -10.83 & 29.22 & -93.64 & 326.48 \\
\hline BEA, Author & 7.53 & 66.27 & -91.10 & 1821.50 \\
\hline BEA & 1.70 & 8.00 & -25.80 & 51.72 \\
\hline BEA & 14.84 & 15.83 & -19.66 & 145.34 \\
\hline BEA, Author & 23.90 & 9.45 & 3.70 & 88.17 \\
\hline Census Bureau & 0.37 & 2.17 & 0.00 & 55.10 \\
\hline BLS & 5.65 & 1.52 & 1.75 & 13.50 \\
\hline Census Bureau & 37.22 & 3.09 & 23.20 & 50.10 \\
\hline Census Bureau & 36.31 & 6.58 & 11.70 & 53.20 \\
\hline Census Bureau & 16.13 & 8.33 & 4.90 & 60.20 \\
\hline Census Bureau & 84.53 & 16.44 & 11.53 & 99.28 \\
\hline ERS & -0.58 & 1.43 & -5.40 & 3.33 \\
\hline ERS & 75.12 & 3.88 & 61.80 & 82.30 \\
\hline EIA & 349.61 & 784.75 & 0 & 8027.53 \\
\hline Author & 25.90 & 22.60 & 0 & 201.60 \\
\hline Author & 24.84 & 34.56 & 0 & 195.85 \\
\hline Author & 36.26 & 51.69 & 0 & 240.65 \\
\hline Author & 66.89 & 87.69 & 0 & 390.09 \\
\hline BEA & 19.81 & 5.75 & 0 & 42.81 \\
\hline BEA & 12.85 & 8.14 & 0 & 52.45 \\
\hline EPA & 0.12 & 0.33 & 0 & 1 \\
\hline EPA & 0.24 & 0.43 & 0 & 1 \\
\hline EPA & 0.23 & 0.42 & 0 & 1 \\
\hline EPA & 0.12 & 0.32 & 0 & 1 \\
\hline $\mathrm{EPA}$ & 0.11 & 0.31 & 0 & 1 \\
\hline $\mathrm{EPA}$ & 0.13 & 0.34 & 0 & 1 \\
\hline $\mathrm{EPA}$ & 0.02 & 0.12 & 0 & 1 \\
\hline EPA & 0.24 & 0.43 & 0 & 1 \\
\hline
\end{tabular}



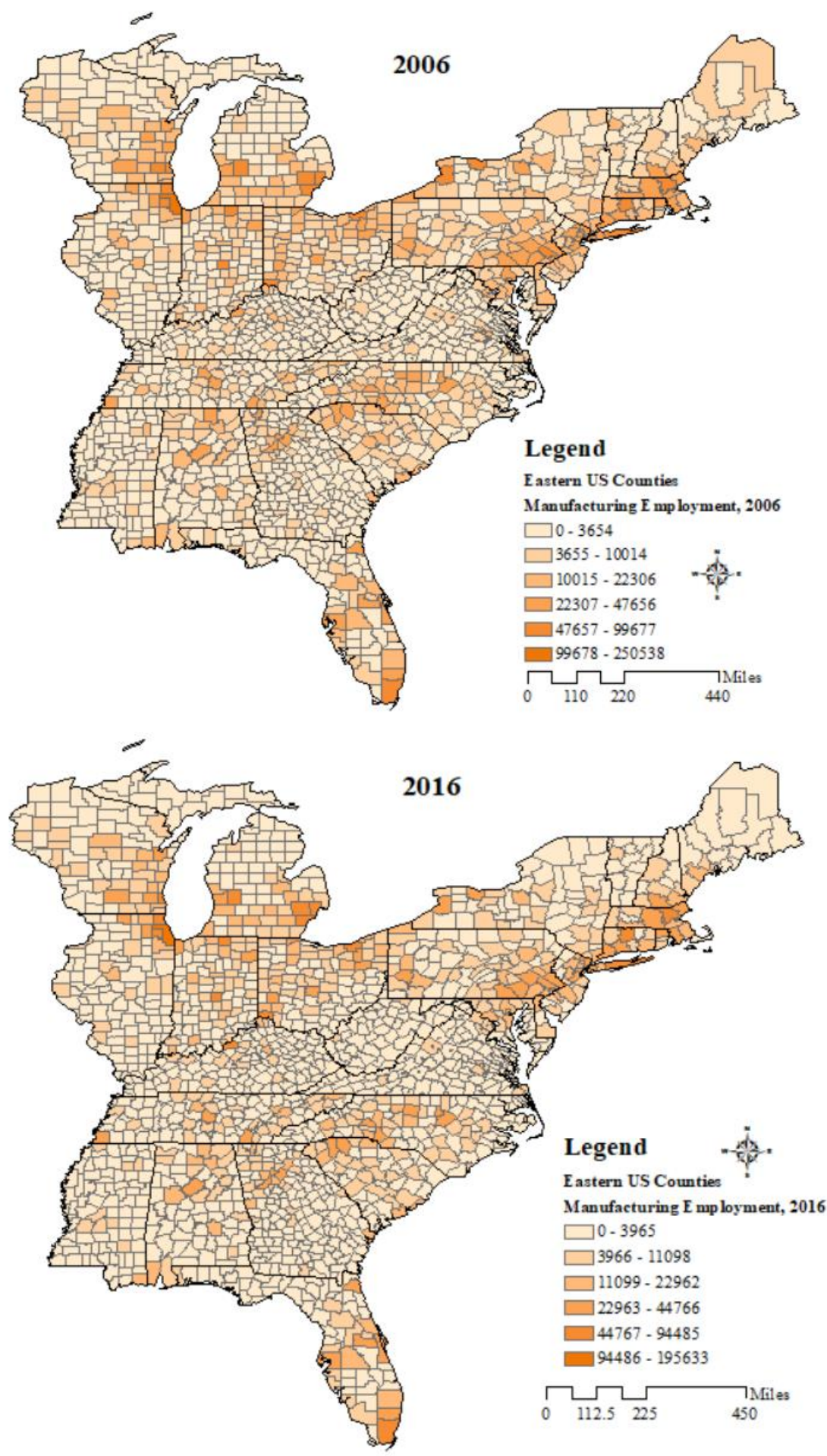

Figure 1-3: Manufacturing Employment Analysis, 2006 - 2016 

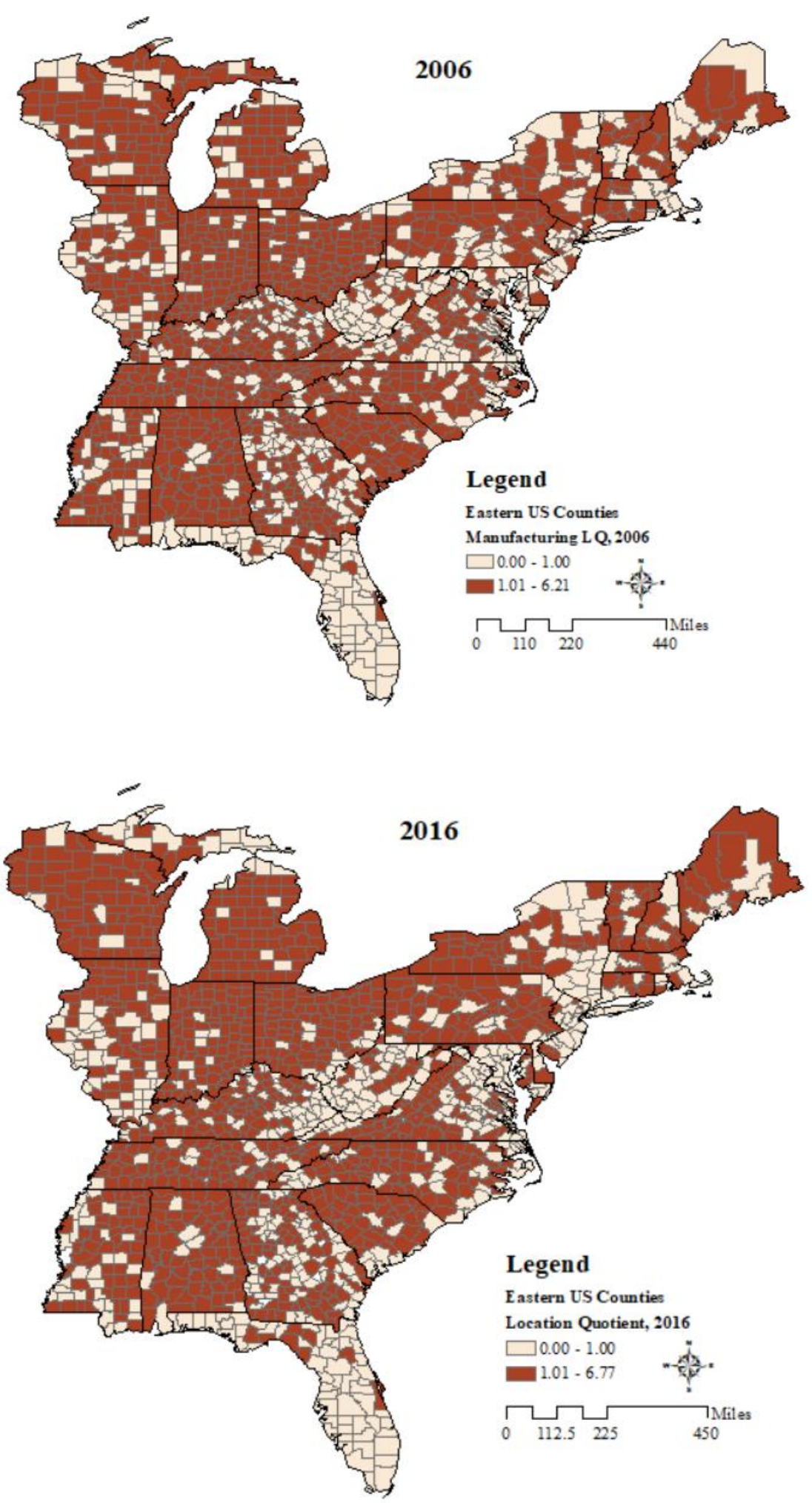

Figure 1-4: Location Quotient Analysis, 2006 - 2016 

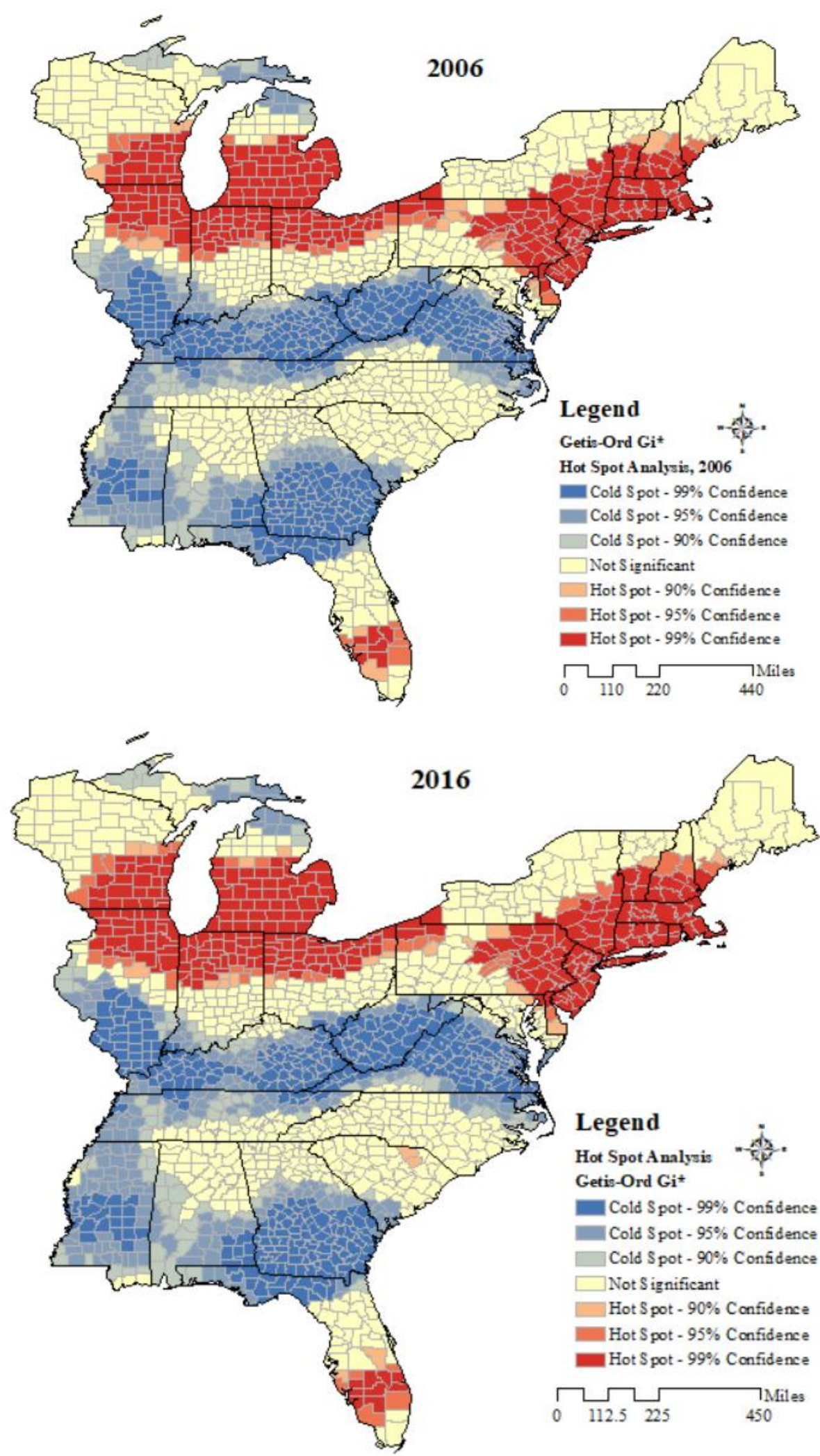

Figure 1-5: Hot Spot Analysis, 2006 - 2016 

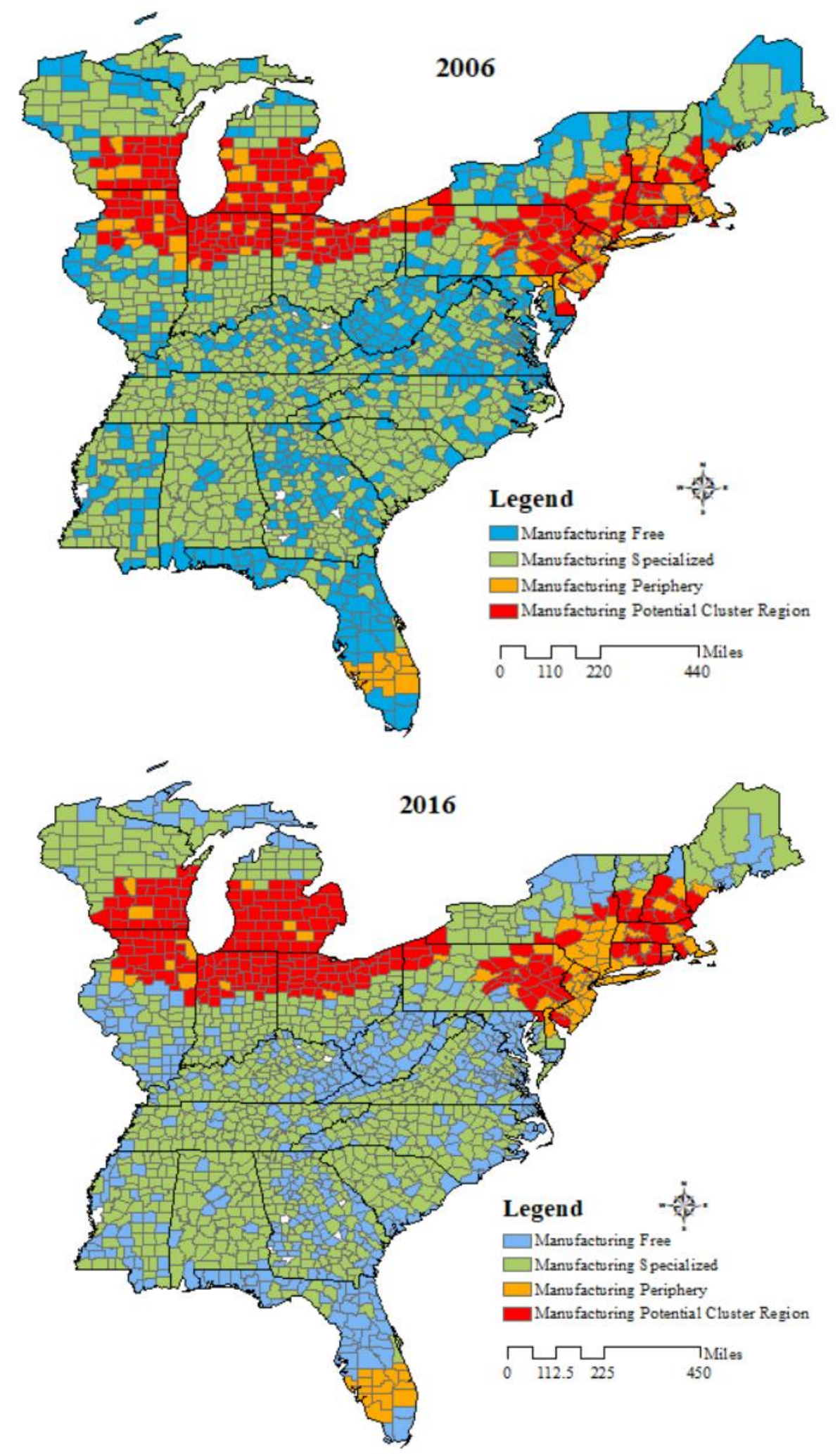

Figure 1-6: Potential Cluster Region Analysis, 2006 - 2016 
This change in manufacturing employment levels is more efficiently observed through the hot spot analysis. The location quotient only considers the industrial structure within a county, while the hot spot analysis considers the characteristics of the surrounding areas (Carroll, Reid, and Smith 2007). The Getis-Ord Gi* hot spot analysis is used to identify spatial patterns of the manufacturing industry within the study region. This analysis was conducted in ArcGIS under the Spatial Statistics Toolbox. This analysis identifies statistically significant hot spots and cold spots for manufacturing employment, based on the z-score value. The equation for the Getis-Ord local statistic is given as:

$$
G_{i}^{*}=\frac{\sum_{j=1}^{n} w_{i, j} x_{j}-\bar{X} \sum_{j=1}^{n} w_{i, j}}{S \sqrt{\frac{\left[n \sum_{j=1}^{n} w_{i, j}^{2}-\left(\sum_{j=1}^{n} w_{i, j}\right)^{2}\right]}{n-1}}}
$$

where:

$$
\begin{gathered}
\bar{X}=\frac{\sum_{j=1}^{n} x_{j}}{n} \\
S=\sqrt{\frac{\sum_{j=1}^{n} x_{j}^{2}}{n}-(\bar{X})^{2}}
\end{gathered}
$$

In this equation $\mathrm{x}_{j}$ is manufacturing employment in county $j, \mathrm{w}_{i, j}$ is the spatial weight between counties $i$ and $j$, and $\mathrm{n}$ is the total number of counties. The Gi* statistic is calculated as a $\mathrm{Z}$-score, meaning it represents the deviation from the mean.

Figure 1-5 contains the results of this analysis. ${ }^{13}$ Counties identified as statistically significant cold spots at the 99 percent level are indicated in deep blue. These groups of counties are regions with low employment levels in the manufacturing sector. From 2006 to 2016, the cold spots throughout the study region have slightly grown. Counties identified as statistically significant hot spots at the 99 percent level are indicated in red. These groups of counties are regions with high employment levels in the manufacturing sector. From 2006 to 2016, the high spots throughout the study region have noticeably decreased in area, specifically in Pennsylvania (PA) and New York (NY).

\footnotetext{
${ }^{13}$ Results of this analysis could be biased as counties are not uniform in shape and size. Additionally, the statistical significance of the border counties may be inflated as there is a restriction on the spatial influence due to the lack of neighbors for these counties. For more information see the previous literature referring to the modifiable areal unit problem (MAUP) (Wong, 2009; Fotheringham and Wong, 1991; and Yang, 2005).
} 
Finally, we combine the location quotient analysis and hot spot analysis approach to identify those counties that are considered a manufacturing specialized regions (location quotient greater than 1), and geographical manufacturing hot spots (z-score greater than 1.96). These regions are also known as potential cluster regions. In Figure 1-6, they are denoted in red (Carroll, Reid, and Smith, 2007). Potential cluster regions illustrate concentrations of interconnected industries. These counties have the highest potential for successful cluster-based economic development in the manufacturing sector. They provide insight into places with high industry competition and location-based competitive advantage which is beneficial to policymakers. (Porter, 2000).

In Figure 1-6, the cluster analysis is also used to define counties that are located near potential cluster regions but do not have the industrial base to contribute to a manufacturing cluster region. These are the counties denoted in orange and are considered periphery counties with a high Gi* z-score and a low location quotient value. Notice from 2006 to 2016, there was a large shift in the number of manufacturing periphery counties. Manufacturing specialized regions, denoted in green, have low $\mathrm{Gi}^{*} \mathrm{z}$-scores but high location quotient values. These counties are geographically isolated as their neighbors are not considered manufacturing exporters. The last category, Manufacturing Free, is denoted in blue. These counties have low Gi* z-scores and low location quotient values for manufacturing, meaning that manufacturing is not that important to their economies. Overall, the cluster region analysis helps identify the regions that may remain manfacturing exporters as the pollution standards continue to increase.

\subsection{Industrial Diversification Measure}

Along with observing the change in employment levels, the study includes looking at the change in each county's industry portfolio. The regional industry specialization index, known as the coefficient of specialization (COS), is used as the measure for industrial diversification. If a county is specialized in the manufacturing industry this measure will indicate economic dependency with the polluting industries for the observed region. The equation for COS is provided below: ${ }^{14}$

$$
\boldsymbol{C}_{\boldsymbol{O}} \boldsymbol{O}_{R}^{t}=\sum_{j}^{R} \frac{\left|\left(\frac{E_{j, R}^{t}}{E_{R}^{t}}-\frac{E_{j, N}^{t}}{E_{N}^{t}}\right)\right|}{2} ; \text { Coefficient of Specialization }
$$

COS measures the level of industry specialization that is occurring in county level employment. A large value indicates a region with a highly specialized industrial employment portfolio. A value of zero indicates the region operates at the same level of industry diversification as the nation. The COS for each county $R$, at time $t$, is the sum of the relative difference for each industry $j$, between the share of county-level employment $E$, in that industry and the national $N$, share of employment in that industry.

The COS measure is based on finance portfolio theory. It measures the level of sector employment specialization or diversity that is occurring within the region when compared to the nation. If a

\footnotetext{
${ }^{14}$ Computation of COS values and a discussion of its application is provided by technical document written by Sayago-Gomez and
} Stair (2015). 
region is highly specialized in an employment sector it may be at a higher risk of recessionary impacts. In other words, a diverse employment portfolio leads to less risk of negative employment impacts. A higher COS value means a region is more industry specialized. Lowering a region's COS value means the region's economy is dependent on a wider array of employment sectors. Carr and Yan (2012) analyze the impact of federal environmental policy on local industrial diversification. They discuss how industrial diversity has a positive impact on economic stability. A diverse portfolio is risk-averse and when impacted by industrial shocks provides economic stability to a county. Thus, in this paper, the impacts of the changes in the pollution standards on industrial diversification are also investigated.

\section{Methodology and Empirical Results}

This essay expands upon the previous literature by estimating the significance of policy changes in the CAA Amendments of 1990 for existing criteria pollutants on local employment change and industrial diversification. The percent change in county-level total employment, manufacturing employment, population, and industrial diversification from 2006 to 2016 are evaluated in this analysis. Industrial diversification is measured by the COS as described Equation 5 above. General empirical specifications are shown in Equation 1.6.

The study focuses on a county-level analysis for the states in the eastern US region. Coal production is a major industry in this historically economically-distressed and predominantly rural region and was listed as main cause for the development/passage of the US Clean Air Act of 1970 (Harvey, 1986). Electricity generation has also been a major contributor to the sulfur dioxide pollution concentration in this region. The region also has a long history of manufacturing. As previously mentioned, the concentration of sulfur dioxide pollution has decreased tremendously in this region. The current focus has been directed towards ozone, nitrogen dioxide, and particulate matter (Brunekreef and Holgate, 2002). Currently, ozone and particulate matter are the pollutants widely observed within this region, thus the pollution standards for these criteria pollutions are the focus of this analysis.

This analysis focuses on the policy changes in the CAA after 1990. The 1990 regulations required technological improvements for stationary sources, leading to more cost-effective approaches to reduce air pollution. By starting with the 1990 regulations, this analysis can focus particularly on policy changes directed at improving air quality standards. States that contain zero observations for whole county nonattainment are removed from this study. ${ }^{15}$

$$
\begin{gathered}
\text { EconomicGrowth }_{i}=\alpha+\beta_{i} \boldsymbol{X}_{\boldsymbol{i}}+\delta_{\rho}\left(\text { Nonattainment }_{\rho i}\right)+\theta_{j}+\varepsilon_{i} \\
\text { EconomicGrowt }_{i}=\left\{\begin{array}{c}
\text { Total Employment Change from } 2006 \text { to } 2016 \\
\text { Manufacturing Employment Change from } 2006 \text { to } 2016 \\
\text { Population Change from } 2006 \text { to } 2016 \\
\text { Change in Industrial Diversification from } 2006 \text { to } 2016
\end{array}\right.
\end{gathered}
$$

\footnotetext{
${ }^{15}$ States removed from this analysis due to a lack of attainment measures include Vermont, Mississippi, South Carolina, and Florida.
} 
Cross-sectional empirical analyses are conducted to measure the economic impacts related to attainment designations by the EPA at the county level $(i)$. A vector of control variables $(X)$ is used to explain these impacts and to control for other factors that are known to impact the dependent variables. Included are lagged population growth measure from 1969 to 1979, historical industrial diversification measure, and other control variables following the guidance of previous literature (Deller et al., 2001; Glaeser, Scheinkman, and Schleifer, 1995; and Stephens and Partridge, 2011). We also estimated a lagged employment growth measure from 1969 to 1979; however, it did not have a significant effect on current total employment growth, and therefore we did not include this measure within our analysis.

Control variables that are included within this analysis are: demographic measures, educational attainment, distance to metropolitan cities, the natural amenity score, and other industry employment measures. Ethnicity, median age, and population size are used to capture a region's market characteristics. Educational attainment, unemployment rate, and shares of industry employment are used to estimate a region's labor characteristics. Higher levels of educational attainment can increase the attractiveness of a region. Employment shares represent economic opportunities and the region's industrial mix (Stephens and Partridge, 2011). Historical industrial diversification measure also represents the region's industrial legacy. Natural amenities are also predicted to have a positive association with employment growth in rural areas (Deller et al., 2001), thus we include the natural amenity score and the mean July temperature from the USDA/ERS. We include distance to the nearest metropolitan city, as well as incremental distances, since access to urban amenities influences a region's attractiveness which would influence population change.

We also included variables that represent factors that contribute to a county's pollution levels and attainment status. These variables include population density, as a county-level proxy for traffic congestion and vehicle emission concentration, and electricity generation capacity. High levels of pollution make a region unattractive to households and workers, therefore negatively influencing labor supply.

Nonattainment is observed as an indicator variable in which a county gets a value of 1 if it is in nonattainment for the pollution standard, zero if otherwise. This analysis evaluates four different measures of nonattainment for the pollution standards $(\rho)$ of ozone and particulate matter. The first model contains nonattainment indicators for each of the observed pollutants: 1-hour ozone in 2004, 8 -hour ozone in 2004, and particulate matter in 2005 . $^{16}$

The second model includes the nonattainment status for each of the pollutants in 2005 . The third model includes an aggregated measure in 2005, where the county has a value of one if it is designated nonattainment for either measures, or both measures. The 1-hour ozone pollution standard was revoked in 2005 and updated to the 8-hour ozone standard. A fourth model estimates

\footnotetext{
${ }^{16}$ The 1 Hour Ozone (1979) standard is revoked in June 15, 2005 and updated to the 8 Hour Ozone (1997) standard. The first
} observation of nonattainment for the PM (1997) standard was from 2005. 
the effects of the ozone standard policy change in 2004. Finally, we observe whether a county remains in nonattainment, changes to nonattainment, and if it gains attainment from the transition in the pollution standard.

Robust standard errors are used to adjust for heteroscedasticity. All models include state-fixed effects $\left(\theta_{j}\right)$ to control for other policy effects and state-level enforcement.

\subsection{Effects of Pollution Standards on Total Employment}

Tables 1-3 displays the empirical results from the model predicting the percent change in total employment growth from 2006 to 2016. The adjusted R-squared indicates on average 37 percent of the change in total employment is explained by the predictor variables. Model (1) displays the results of the model estimated with the attainment measure for the 1-hour ozone (1979) standard in 2004, 8-hour ozone (1997) standard in 2004, and the particulate matter (1997) standard in 2005. Model (2) displays the results of the estimation with the 8-hour ozone (1997) and the particulate matter (1995) attainment standards in 2005. Model (3) is estimated with the aggregated nonattainment measure in 2005. Model (4) explores the effects of the change in the ozone pollution standard, from the 1-hour standard to the 8-hour standard, on total employment change. Models (5) - (7) are similar to models (1) - (3), however they include an interaction term between nonattainment and the share of manufacturing employment in 2005.

Through the different variations of the models, the sign and significance of the economic control variables remain consistent. It is important to address the influence of population change and industry composition on employment change. Lagged population growth is positive and statistically significant at the 99 percent level. Regions that have experienced population growth, historically, are continuing to increase their employment (which is also affected by increases in population). Being, historically, more industry specialized is associated with a decrease in employment growth. As expected, high unemployment rates are negatively associated with employment growth. Although, having a younger, more educated workforce is associated with higher employment growth. Share of employment in the self-employment and manufacturing industries are also statistically significant. Counties with a larger share of self-employment experience increases in total employment. However, counties with a larger share of manufacturing employment are associated with a decrease in employment growth.

Turning to our key measures, we find that nonattainment for 8-hour ozone and particulate matter are associated with positive employment growth. A designation of nonattainment for 8-hour ozone pollution standard is associated with a 1.2 percent increase in total employment growth. A designation of nonattainment for either standard in 2005 is associated with a 1.6 percent increase in total employment growth. While places with higher manufacturing shares appear to have lower total employment growth, when we tested interaction variables between nonattainment and share of manufacturing employment, we did not find any statistically significant evidence of an additional effect of nonattainment in these areas.

For the percent change in total employment model, we also tested spatially-lagged explanatory variables and nonattainment measures. Empirical results for this model are displayed in Table 1-4. Adding the spatially-lagged variables did not improve the explanatory power of the total 
employment model. However, higher population densities in one county are associated with higher employment growth (about 4 percent) in neighboring counties. We also find that, if a county retains its nonattainment status through the change in the ozone pollution standard, it is associated with negative employment growth in the surrounding counties.

\subsection{Effects of Pollution Standards on Manufacturing Employment}

Table 1-5 displays the empirical results from the model predicting manufacturing employment growth. On average, only 8 percent of the change in manufacturing employment from 2006 to 2016 is explained by the predictor variables (adjusted R-squared). Model (1) displays the effects of the attainment measures for the1-hour ozone (1979) standard in 2004, 8-hour ozone (1997) standard in 2004, and the particulate matter (1997) standard in 2005. Model (2) displays the results of the estimation with the 8-hour ozone (1997) and the particulate matter (1995) attainment standards in 2005. Model (3) is estimated with the aggregated nonattainment measure where a value of 1 is given if a county is in nonattainment for either standards observed in 2005. Model (4) explores the effects of the change in the ozone pollution standard on total employment change.

Through the different variations of the models, the sign and significance of the economic control variables remain consistent. Counties that are becoming more urbanized, with higher levels of population density and younger populations, are experiencing a decrease in manufacturing employment growth. Higher unemployment rates are also associated with a decrease in manufacturing employment. As before, the effect of the share of manufacturing employment was negative and statistically significant, indicating that a larger share of manufacturing employment in 2005 is associated with a decrease in the percent change in manufacturing employment growth.

Surprisingly, designation of nonattainment for the criteria pollutants does not appear to have a statistically significant impact on manufacturing employment from 2006 to 2016. This is consistent with results from the total employment model. As shown in Figure 1-2, this may be due to the decrease in the overall employment levels of the manufacturing sector during this period, regardless of the attainment status. The lack of statistical significance in the nonattainment measures may also be a result of the weak explanatory power of the model.

\subsection{Effects of Pollution Standards on Population}

Table 1-6 displays the empirical results from the model predicting population growth from 2006 to 2016. On average, 58 percent of the change in population growth is explained by the variation in the predictor variables (adjusted R-squared). Model (1) displays the results of the model estimated with the attainment measures for the 1-hour ozone (1979) standard in 2004, 8-hour ozone (1997) standard in 2004, and the particulate matter (1997) standard in 2005. Model (2) displays the results of the estimation with the 8-hour ozone (1997) and the particulate matter (1995) attainment standards in 2005. Model (3) is estimated with the aggregated nonattainment measure where a value of 1 is given if a county is in nonattainment for either standards observed in 2005. Model (4) explores the effects of the change in the ozone pollution standard on total employment change.

Through the different variations of the models, the sign and significance of the economic control variables remain consistent. Counties that experienced population growth in the past are still seeing 
population growth. Areas that were historically industry specialized are associated with negative population growth. Consistently, higher unemployment rates in 2005 are associated with lower population growth from 2006 to 2016. Counties with an educated, younger workforce are experiencing increased population growth. A higher share of self-employment is positively associated with higher levels of population growth.

Consistent with the employment results, nonattainment for 8-hour ozone and particulate matter are associated with a positive, statistically significant, effect on population growth from 2006 to 2016. A designation of nonattainment for particulate matter is associated with, on average, a 1.4 percent increase in population growth. While a designation of nonattainment for the 8-hour ozone pollution standard is associated with, on average, a 0.9 percent increase in population growth.

\subsection{Effects of Pollution Standards on Industrial Diversification}

Table 1-7 displays the empirical results from the model predicting the change in industrial diversification from 2006 to 2016. COS value is used as the measure for industrial diversification. As mentioned previously, a negative effect on the COS value suggests an increase in industrial diversification, which previous research suggests leads to increased economic stability. Model (1) displays the results of the model estimated with the attainment measures for the 1-hour ozone (1979) standard in 2004, 8-hour ozone (1997) standard in 2004, and the particulate matter (1997) standard in 2005. Model (2) displays the effects of the 8-hour ozone (1997) and the particulate matter (1995) attainment standards in 2005. Model (3) is estimated with the aggregated nonattainment measure where a value of 1 is given if a county is in nonattainment for either standards observed in 2005. Model (4) explores the effects of the change in the ozone pollution standard on total employment change.

As before, through the different variations of the models, the sign and significance of the economic control variables remain consistent. For example, having a younger workforce is associated with an increase industrial diversity. Additionally, it appears that counties in nonattainment for any of the pollution standards in 2004 or 2005 are becoming more industry-diverse, perhaps to reverse their nonattainment status. The negative and statistically significant coefficient for areas which remain in nonattainment through the policy change in the ozone standard also supports this evidence.

\section{Conclusion}

Air quality regulations have been the center of many political debates within the past decade. While air pollutants have significant impacts on the health and well-being of society, the pollution standards that came out of the Clean Air Act have the potential to impact economic growth if they result in closures of major employers. This analysis identifies long-term labor market effects related to the nonattainment designation in the eastern US region. In the long run, it appears that impacted regions have adapted to the policy changes resulting from changing pollution standards under the Clean Air Act. Contrary to previous literature, we find little evidence of a long-term negative effect on employment. Greenstone (2002) illustrated the tightening of regulation standards lead to more counties in nonattainment. However, Greenstone (2002) and Becker and Henderson (2000) identified negative impacts on employment levels and number of firms in polluting and manufacturing industries, due to the increase in counties in nonattainment. The nonattainment 
status may be negatively impacting the size of the labor market and the number of firms in polluting industries; however, in the long run counties are adapting to the changes in the regulated pollution standards of the Clean Air Act.

We find nonattainment has a small, but positive, effect on total employment growth as well as population growth at the county level. However, we do not find any significant impacts of nonattainment on manufacturing employment change. This may be due to an overall national trend downward in manufacturing employment, regardless of attainment status.

We also find areas designated as in nonattainment are becoming more industry diverse. Carr and Yan (2010) also found evidence of these effects. This may be motivated by the need for regions to improve their conditions in order to gain attainment. Our research shows that areas who remain in nonattainment or who gain attainment through the ozone policy change are also becoming more industry diverse. For those gaining attainment status during the ozone policy change, this is perhaps an additional signal that becoming more industry-diverse is a positive outcome of the air quality standards. Kotkin (2014) notes that larger metro areas within the historical Rust-Belt region are reviving the auto-manufacturing industry with new technological improvements and lower energy costs. Results of this analysis suggest that regions and firms that are affected by nonattainment designation may be able to adapt to the new policy standards.

With aggregate data, we are unable to prove whether increased pollution standards lead to regional labor market changes such as shifts in demand from low-skill to high-skill industry jobs or deviations in demand for labor-intensive positions. These are research questions that should be explored by future researchers.

If polluting industries are major resources of employment, state governments should prepare for significant economic impacts in their regions if there is another increase in standards in the future. However, they may be able to improve the long-term health of their regions by attracting higher educated workers and the non-polluting firms that are interested in hiring them. They can also consider other types of policies to abate pollution including auctioned permits, emissions taxes and subsidies, issued marketable permits, and performance standards (Jung, Krutilla, and Boyd, 1994). Since air quality standards are unlikely to be reduced significantly, regions would benefit from finding ways to adapt and position themselves economically for the future. Holmes (2017) observes that major manufacturing cities, such as Pittsburgh, PA and Cleveland, OH, have turned to cleaner industries to re-brand their economies. She mentions how Pittsburgh is now focused on cleaner industries such as technology, education, and medicine, and Cleveland is now attracting entrepreneurs, artists, and families back into the city with the cleaner atmosphere. Based on our analysis, in the long run, counties are adapting to the changes in the pollution standards by diversifying their industry portfolio. By having a more diverse industry portfolio, counties are in a better, more stable position to weather future economic shocks. 
Table 1-3: Percent change in Total Employment from 2006 to 2016

\begin{tabular}{|c|c|c|c|c|c|c|c|}
\hline TOTAL EMPLOYMENT MODEL - EXPLANATORY VARIABLES & (1) & (2) & (3) & (4) & (5) & (6) & (7) \\
\hline Percent change in total population from 1969 to 1979 & $\begin{array}{c}0.081 * * * \\
(0.020)\end{array}$ & $\begin{array}{c}0.082^{* * *} \\
(0.019)\end{array}$ & $\begin{array}{c}0.082 * * * \\
(0.019)\end{array}$ & $\begin{array}{c}0.081 * * * \\
(0.020)\end{array}$ & $\begin{array}{c}0.082^{* * * *} \\
(0.020)\end{array}$ & $\begin{array}{c}0.082 * * * \\
(0.020)\end{array}$ & $\begin{array}{c}0.082 * * * \\
(0.020)\end{array}$ \\
\hline Historical industrial diversification measure (coefficient of specialization), 1969 & $\begin{array}{c}-0.053^{*} \\
(0.031)\end{array}$ & $\begin{array}{c}-0.053^{*} \\
(0.031)\end{array}$ & $\begin{array}{l}-0.056^{*} \\
(0.031)\end{array}$ & $\begin{array}{c}-0.053^{*} \\
(0.031)\end{array}$ & $\begin{array}{l}-0.052^{*} \\
(0.031)\end{array}$ & $\begin{array}{c}-0.053^{*} \\
(0.031)\end{array}$ & $\begin{array}{l}-0.056^{*} \\
(0.031)\end{array}$ \\
\hline Population density, 2000 & $\begin{array}{c}0.481 \\
(0.303)\end{array}$ & $\begin{array}{c}0.485 \\
(0.302)\end{array}$ & $\begin{array}{l}0.513^{*} \\
(0.306)\end{array}$ & $\begin{array}{c}0.482 \\
(0.304)\end{array}$ & $\begin{array}{c}0.483 \\
(0.309)\end{array}$ & $\begin{array}{c}0.479 \\
(0.307)\end{array}$ & $\begin{array}{l}0.511^{*} \\
(0.309)\end{array}$ \\
\hline Unemployment rate, 2005 & $\begin{array}{c}-1.107 * * * \\
(0.258)\end{array}$ & $\begin{array}{c}-1.108^{* * * *} \\
(0.258)\end{array}$ & $\begin{array}{c}-1.121^{* * * *} \\
(0.257)\end{array}$ & $\begin{array}{c}-1.106^{* * *} \\
(0.258)\end{array}$ & $\begin{array}{c}-1.104 * * * \\
(0.259)\end{array}$ & $\begin{array}{c}-1.107 \text { *** } \\
(0.258)\end{array}$ & $\begin{array}{c}-1.122 * * * \\
(0.258)\end{array}$ \\
\hline Median age, 2005 & $\begin{array}{c}-0.603 * * * \\
(0.099)\end{array}$ & $\begin{array}{c}-0.603 * * * \\
(0.099)\end{array}$ & $\begin{array}{c}-0.595^{* * *} \\
(0.099)\end{array}$ & $\begin{array}{c}-0.603 * * * \\
(0.099)\end{array}$ & $\begin{array}{c}-0.604 * * * \\
(0.099)\end{array}$ & $\begin{array}{c}-0.604 * * * * \\
(0.099)\end{array}$ & $\begin{array}{c}-0.595^{* * *} \\
(0.099)\end{array}$ \\
\hline Percent of population 25 years and older with a high school degree, 2000 & $\begin{array}{c}0.011 \\
(0.093)\end{array}$ & $\begin{array}{c}0.011 \\
(0.093)\end{array}$ & $\begin{array}{c}0.002 \\
(0.092)\end{array}$ & $\begin{array}{c}0.011 \\
(0.093)\end{array}$ & $\begin{array}{c}0.015 \\
(0.094)\end{array}$ & $\begin{array}{c}0.013 \\
(0.094)\end{array}$ & $\begin{array}{c}0.001 \\
(0.093)\end{array}$ \\
\hline Percent of population 25 years and older with a bachelor's degree or higher, 2000 & $\begin{array}{c}0.296^{* * *} \\
(0.073)\end{array}$ & $\begin{array}{c}0.297 * * * \\
(0.073)\end{array}$ & $\begin{array}{c}0.302^{* * *} \\
(0.073)\end{array}$ & $\begin{array}{c}0.297 * * * \\
(0.073)\end{array}$ & $\begin{array}{c}0.299^{* * *} \\
(0.075)\end{array}$ & $\begin{array}{c}0.298^{* * * *} \\
(0.075)\end{array}$ & $\begin{array}{c}0.301 \text { *** } \\
(0.074)\end{array}$ \\
\hline Percent of white, non-Hispanic population, 2000 & $\begin{array}{c}-0.064 * * \\
(0.027)\end{array}$ & $\begin{array}{c}-0.065 * * \\
(0.027)\end{array}$ & $\begin{array}{c}-0.067 * * \\
(0.027)\end{array}$ & $\begin{array}{c}-0.064 * * \\
(0.027)\end{array}$ & $\begin{array}{c}-0.064 * * \\
(0.028)\end{array}$ & $\begin{array}{c}-0.064 * * \\
(0.027)\end{array}$ & $\begin{array}{c}-0.067 * * \\
(0.027)\end{array}$ \\
\hline Natural amenity score, 1999 & $\begin{array}{c}-0.264 \\
(0.234)\end{array}$ & $\begin{array}{c}-0.264 \\
(0.233)\end{array}$ & $\begin{array}{l}-0.269 \\
(0.233)\end{array}$ & $\begin{array}{l}-0.265 \\
(0.234)\end{array}$ & $\begin{array}{l}-0.258 \\
(0.234)\end{array}$ & $\begin{array}{l}-0.258 \\
(0.233)\end{array}$ & $\begin{array}{l}-0.268 \\
(0.233)\end{array}$ \\
\hline Mean temperature in July, 1941-1970 & $\begin{array}{c}0.088 \\
(0.110)\end{array}$ & $\begin{array}{c}0.088 \\
(0.110)\end{array}$ & $\begin{array}{c}0.083 \\
(0.110)\end{array}$ & $\begin{array}{c}0.088 \\
(0.110)\end{array}$ & $\begin{array}{c}0.091 \\
(0.111)\end{array}$ & $\begin{array}{c}0.092 \\
(0.111)\end{array}$ & $\begin{array}{c}0.083 \\
(0.111)\end{array}$ \\
\hline Average annual capacity in megawatts for existing generating units, 2003 & $\begin{array}{c}0.001 * * * * \\
(0.000)\end{array}$ & $\begin{array}{c}0.001 \text { **** } \\
(0.000)\end{array}$ & $\begin{array}{c}0.001 * * * \\
(0.000)\end{array}$ & $\begin{array}{c}0.001 * * * \\
(0.000)\end{array}$ & $\begin{array}{c}0.001^{* * * *} \\
(0.000)\end{array}$ & $\begin{array}{c}0.001 * * * \\
(0.000)\end{array}$ & $\begin{array}{c}0.001 * * * \\
(0.000)\end{array}$ \\
\hline Distance to nearest metro $(\mathrm{km})$ & $\begin{array}{l}-0.010 \\
(0.011)\end{array}$ & $\begin{array}{l}-0.010 \\
(0.011)\end{array}$ & $\begin{array}{l}-0.008 \\
(0.011)\end{array}$ & $\begin{array}{l}-0.010 \\
(0.011)\end{array}$ & $\begin{array}{l}-0.009 \\
(0.011)\end{array}$ & $\begin{array}{l}-0.010 \\
(0.011)\end{array}$ & $\begin{array}{l}-0.008 \\
(0.011)\end{array}$ \\
\hline Incremental distance to a metro $>250,000$ population & $\begin{array}{c}0.003 \\
(0.007)\end{array}$ & $\begin{array}{c}0.003 \\
(0.007)\end{array}$ & $\begin{array}{c}0.002 \\
(0.007)\end{array}$ & $\begin{array}{c}0.004 \\
(0.007)\end{array}$ & $\begin{array}{c}0.003 \\
(0.007)\end{array}$ & $\begin{array}{c}0.003 \\
(0.007)\end{array}$ & $\begin{array}{c}0.002 \\
(0.007)\end{array}$ \\
\hline Incremental distance to a metro $>500,000$ population & $\begin{array}{c}-0.014 * * * \\
(0.005)\end{array}$ & $\begin{array}{c}-0.014 * * * * \\
(0.005)\end{array}$ & $\begin{array}{c}-0.015^{* * * *} \\
(0.005)\end{array}$ & $\begin{array}{c}-0.013 * * * \\
(0.005)\end{array}$ & $\begin{array}{c}-0.014 * * * \\
(0.005)\end{array}$ & $\begin{array}{c}-0.014 * * * * \\
(0.005)\end{array}$ & $\begin{array}{c}-0.015^{* * * *} \\
(0.005)\end{array}$ \\
\hline Incremental distance to a metro $>1,500,000$ population & $\begin{array}{c}0.011 * * * \\
(0.004)\end{array}$ & $\begin{array}{c}0.011 \text { **** } \\
(0.004)\end{array}$ & $\begin{array}{c}0.011 * * * \\
(0.004)\end{array}$ & $\begin{array}{c}0.011 \text { *** } \\
(0.004)\end{array}$ & $\begin{array}{c}0.011^{* * * *} \\
(0.004)\end{array}$ & $\begin{array}{c}0.011^{* * * *} \\
(0.004)\end{array}$ & $\begin{array}{c}0.011^{* * * *} \\
(0.004)\end{array}$ \\
\hline Share of non-farm proprietors employment, 2005 & $\begin{array}{c}0.421^{* * *} \\
(0.065)\end{array}$ & $\begin{array}{c}0.422^{* * *} \\
(0.065)\end{array}$ & $\begin{array}{c}0.420^{* * *} \\
(0.065)\end{array}$ & $\begin{array}{c}0.421 * * * \\
(0.065)\end{array}$ & $\begin{array}{c}0.420^{* * * *} \\
(0.066)\end{array}$ & $\begin{array}{c}0.420^{* * * *} \\
(0.066)\end{array}$ & $\begin{array}{c}0.420 * * * \\
(0.066)\end{array}$ \\
\hline Share of manufacturing employment, 2005 & $\begin{array}{c}-0.079 * * \\
(0.039)\end{array}$ & $\begin{array}{c}-0.079 * * \\
(0.039)\end{array}$ & $\begin{array}{c}-0.081^{* *} \\
(0.039)\end{array}$ & $\begin{array}{c}-0.079 * * \\
(0.039)\end{array}$ & $\begin{array}{l}-0.082^{*} \\
(0.042)\end{array}$ & $\begin{array}{l}-0.081^{*} \\
(0.042)\end{array}$ & $\begin{array}{l}-0.080^{*} \\
(0.042)\end{array}$ \\
\hline
\end{tabular}




\section{TOTAL EMPLOYMENT MODEL - ATTAINMENT MEASURES}

County is in nonattainment for 1-hour ozone (1979) standard, 2004

County is in nonattainment for 8-hour ozone (1997) standard, 2004

County is in nonattainment for PM-2.5 (1997) standard, 2005

County is in nonattainment for 8-hour ozone (1997) standard, 2005

County is in nonattainment for either PM-2.5 or 8-hour ozone standard, 2005

County remains in nonattainment through ozone standard change, 2004

County changes from attainment to nonattainment through ozone standard change, 2004

County changes from nonattainment to attainment through ozone standard change, 2004

Interaction between 1 Hour Ozone nonattainment (2004) and manufacturing share (2005)

Interaction between 8 Hour Ozone nonattainment (2004) and manufacturing share (2005)

Interaction between PM-2.5 nonattainment (2005) and manufacturing share (2005)

Interaction between 8 Hour Ozone nonattainment (2005) and manufacturing share (2005)

Interaction between nonattainment for either standard (2005) and manufacturing share (2005)

Constant

Spatial Fixed Effects

Observations

R-squared

Adjusted R-squared

Robust standard errors in parentheses
(1)

(2)

(3)

(4)

(5)

(6)

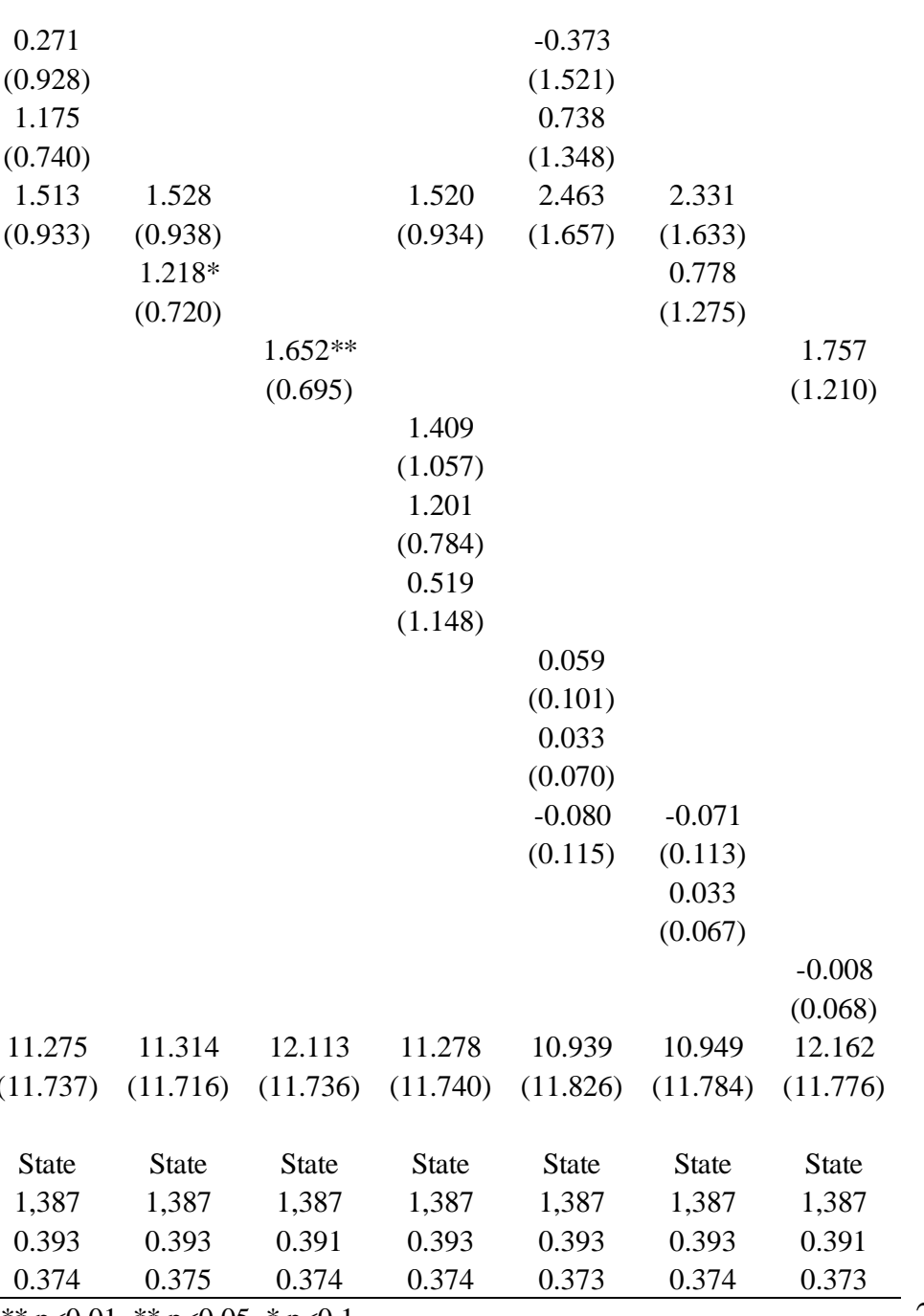


Table 1-4: Spatially-lagged Explanatory variables for Total Employment model

TOTAL EMPLOYMENT MODEL
SPATIALLY LAGGED EXPLANATORY VARIABLES

Percent change in total population from 1969 to 1979

Historical industrial diversification measure (coefficient of specialization), 1969

Population density, 2000

Unemployment rate, 2005

Median age, 2005

Percent of population 25 years and older with a high school degree, 2000

Percent of population 25 years and older with a bachelor's degree or higher, 2000

Percent of white, non-Hispanic population, 2000

Natural amenity score, 1999

Mean temperature in July, 1941-1970

Average annual capacity in megawatts for existing generating units, 2003

Distance to nearest metro $(\mathrm{km})$

Incremental distance to a metro $>250,000$ population

Incremental distance to a metro $>500,000$ population

Incremental distance to a metro $>1,500,000$ population

Share of non-farm proprietors employment, 2005

Share of manufacturing employment, 2005

Spatially-lagged historical industrial diversification measure, 1969

Spatially-lagged population density, 2005

Spatially-lagged unemployment rate, 2005

Spatially-lagged annual capacity for existing generating units, 2003

Spatially-lagged manufacturing share, 2005

$\begin{array}{cccc}0.089 * * * & 0.087 * * * & 0.088 * * * & 0.089 * * * \\ (0.021) & (0.020) & (0.020) & (0.021) \\ -0.068 * * & -0.069 * * & -0.070 * * & -0.068 * * \\ (0.032) & (0.032) & (0.032) & (0.032) \\ 0.125 & 0.148 & 0.152 & 0.128 \\ (0.319) & (0.320) & (0.322) & (0.319) \\ -0.894 * * * & -0.909 * * * & -0.912 * * * & -0.892 * * * \\ (0.291) & (0.292) & (0.290) & (0.292) \\ -0.595 * * * & -0.606 * * * & -0.604 * * * & -0.595 * * * \\ (0.107) & (0.107) & (0.106) & (0.107) \\ -0.030 & -0.015 & -0.027 & -0.029 \\ (0.100) & (0.098) & (0.097) & (0.100) \\ 0.306 * * * & 0.309 * * * & 0.313 * * * & 0.308 * * * \\ (0.082) & (0.082) & (0.081) & (0.082) \\ -0.050 & -0.051 * & -0.048 & -0.051 * \\ (0.031) & (0.030) & (0.030) & (0.031) \\ -0.246 & -0.245 & -0.253 & -0.260 \\ (0.245) & (0.245) & (0.245) & (0.245) \\ 0.111 & 0.105 & 0.093 & 0.113 \\ (0.121) & (0.121) & (0.121) & (0.121) \\ 0.001 * * & 0.001 * * & 0.001 * * & 0.001 * * \\ (0.000) & (0.000) & (0.000) & (0.000) \\ -0.005 & -0.006 & -0.005 & -0.004 \\ (0.011) & (0.011) & (0.011) & (0.012) \\ 0.001 & 0.001 & -0.001 & 0.002 \\ (0.008) & (0.008) & (0.008) & (0.008) \\ -0.013 * * & -0.013 * * & -0.015 * * * & -0.012 * * \\ (0.006) & (0.006) & (0.006) & (0.006) \\ 0.010 * * & 0.009 * * & 0.008 * & 0.010 * * \\ (0.005) & (0.005) & (0.005) & (0.005) \\ 0.377 * * * & 0.380 * * * & 0.378 * * * & 0.377 * * * \\ (0.066) & (0.066) & (0.066) & (0.067) \\ -0.110 * * * & -0.110 * * * & -0.110 * * * & -0.110 * * * \\ (0.042) & (0.042) & (0.042) & (0.042) \\ -0.422 & -0.198 & -0.135 & -0.262 \\ (0.874) & (0.827) & (0.821) & (0.909) \\ 5.368 * * & 4.653 * * & 5.076 * * * & 5.592 * * * \\ (2.122) & (1.993) & (1.930) & (2.147) \\ -4.416 & -3.357 & -3.344 & -4.450 \\ (2.971) & (2.795) & (2.798) & (2.976) \\ 0.019 & 0.016 & 0.021 & 0.020 \\ (0.015) & (0.014) & (0.014) & (0.015) \\ 1.181 * & 1.381 * * & 1.383 * * & 1.228 * \\ (0.691) & (0.644) & (0.642) & (0.699)\end{array}$




\begin{tabular}{|c|c|c|c|c|}
\hline $\begin{array}{l}\text { TOTAL EMPLOYMENT MODEL } \\
\text { SPATIALLY LAGGED ATTAINMENT MEASURES }\end{array}$ & (1) & (2) & (3) & (4) \\
\hline County is in nonattainment for 1-hour ozone (1979) standard, 2004 & $\begin{array}{c}0.089 \\
(1.021)\end{array}$ & & & \\
\hline County is in nonattainment for 8-hour ozone (1997) standard, 2004 & $\begin{array}{c}0.932 \\
(0.833)\end{array}$ & & & \\
\hline County is in nonattainment for PM-2.5 (1997) standard, 2005 & $\begin{array}{c}0.880 \\
(1.080)\end{array}$ & $\begin{array}{c}0.879 \\
(1.091)\end{array}$ & & $\begin{array}{c}0.899 \\
(1.085)\end{array}$ \\
\hline County is in nonattainment for 8-hour ozone (1997) standard, 2005 & & $\begin{array}{c}1.071 \\
(0.801)\end{array}$ & & \\
\hline County is in nonattainment for either PM-2.5 or 8-hour ozone standard, 2005 & & & $\begin{array}{c}1.277 \\
(0.787)\end{array}$ & \\
\hline County remains in nonattainment through ozone standard change, 2004 & & & & $\begin{array}{c}1.070 \\
(1.157)\end{array}$ \\
\hline County changes from attainment to nonattainment through ozone standard change, 2004 & & & & $\begin{array}{c}0.916 \\
(0.898)\end{array}$ \\
\hline County changes from nonattainment to attainment through ozone standard change, 2004 & & & & $\begin{array}{c}0.408 \\
(1.198)\end{array}$ \\
\hline Spatially-lagged measure county is in nonattainment for 1 Hour Ozone (1979) standard, 2004 & $\begin{array}{l}-22.440 \\
(18.636)\end{array}$ & & & \\
\hline Spatially-lagged measure county is in nonattainment for 8 Hour Ozone (1979) standard, 2004 & $\begin{array}{l}-15.384 \\
(18.456)\end{array}$ & & & \\
\hline Spatially-lagged measure county is in nonattainment for PM-2.5 (1997) standard, 2005 & $\begin{array}{c}15.290 \\
(25.510)\end{array}$ & $\begin{array}{c}10.663 \\
(25.802)\end{array}$ & & $\begin{array}{c}18.588 \\
(25.783)\end{array}$ \\
\hline Spatially-lagged measure county is in nonattainment for 8 Hour Ozone (1979) standard, 2005 & & $\begin{array}{l}-22.178 \\
(17.799)\end{array}$ & & \\
\hline Spatially-lagged measure county is in nonattainment for either PM-2.5 or 8 Hour Ozone standard, 2005 & & & $\begin{array}{l}-22.109 \\
(16.169)\end{array}$ & \\
\hline Spatially-lagged measure county remains in nonattainment through Ozone standard change, 2004 & & & & $\begin{array}{c}-44.352^{* *} \\
(22.564)\end{array}$ \\
\hline Spatially-lagged measure county changes from attainment to nonattainment through Ozone standard change, 2004 & & & & $\begin{array}{c}-13.898 \\
(18.928)\end{array}$ \\
\hline Spatially-lagged measure county changes from nonattainment to attainment through Ozone standard change, 2004 & & & & $\begin{array}{c}33.800 \\
(50.140)\end{array}$ \\
\hline Constant & $\begin{array}{c}25.134 \\
(33.834)\end{array}$ & $\begin{array}{c}12.353 \\
(29.878)\end{array}$ & $\begin{array}{c}11.575 \\
(29.902)\end{array}$ & $\begin{array}{c}19.734 \\
(34.747)\end{array}$ \\
\hline Spatial Fixed Effects & State & State & State & State \\
\hline Observations & 1,338 & 1,338 & 1,338 & 1,338 \\
\hline R-squared & 0.395 & 0.395 & 0.394 & 0.396 \\
\hline Adjusted R-squared & 0.372 & 0.373 & 0.373 & 0.372 \\
\hline
\end{tabular}


Table 1-5: Percent change in Manufacturing Employment from 2006 to 2016

\begin{tabular}{|c|c|c|c|c|}
\hline VARIABLES & (1) & (2) & (3) & (4) \\
\hline Percent change in total population from 1969 to 1979 & $\begin{array}{c}0.097 \\
(0.066)\end{array}$ & $\begin{array}{c}0.096 \\
(0.064)\end{array}$ & $\begin{array}{c}0.096 \\
(0.064)\end{array}$ & $\begin{array}{c}0.099 \\
(0.066)\end{array}$ \\
\hline Historical industrial diversification measure (coefficient of specialization), 1969 & $\begin{array}{c}0.359 * * * \\
(0.096)\end{array}$ & $\begin{array}{c}0.358^{* * *} \\
(0.096)\end{array}$ & $\begin{array}{c}0.363^{\text {*** }} \\
(0.096)\end{array}$ & $\begin{array}{c}0.360 * * * \\
(0.096)\end{array}$ \\
\hline Population density, 2000 & $\begin{array}{c}-0.558 * * * \\
(0.206)\end{array}$ & $\begin{array}{c}-0.567 \text { *** } \\
(0.209)\end{array}$ & $\begin{array}{c}-0.603 \text { *** } \\
(0.218)\end{array}$ & $\begin{array}{c}-0.549 * * * \\
(0.205)\end{array}$ \\
\hline Unemployment rate, 2005 & $\begin{array}{c}-2.627 * * * \\
(0.805)\end{array}$ & $\begin{array}{c}-2.637 * * * \\
(0.804)\end{array}$ & $\begin{array}{c}-2.632 \text { **** } \\
(0.803)\end{array}$ & $\begin{array}{c}-2.612 * * * \\
(0.807)\end{array}$ \\
\hline Median age, 2005 & $\begin{array}{l}-0.420 \\
(0.295)\end{array}$ & $\begin{array}{c}-0.423 \\
(0.295)\end{array}$ & $\begin{array}{c}-0.434 \\
(0.293)\end{array}$ & $\begin{array}{c}-0.420 \\
(0.295)\end{array}$ \\
\hline Percent of population 25 years and older with a high school degree, 2000 & $\begin{array}{c}0.221 \\
(0.348)\end{array}$ & $\begin{array}{c}0.218 \\
(0.348)\end{array}$ & $\begin{array}{c}0.228 \\
(0.345)\end{array}$ & $\begin{array}{c}0.220 \\
(0.349)\end{array}$ \\
\hline Percent of population 25 years and older with a bachelor's degree or higher, 2000 & $\begin{array}{c}0.119 \\
(0.223)\end{array}$ & $\begin{array}{c}0.120 \\
(0.223)\end{array}$ & $\begin{array}{c}0.116 \\
(0.224)\end{array}$ & $\begin{array}{c}0.122 \\
(0.223)\end{array}$ \\
\hline Percent of white, non-Hispanic population, 2000 & $\begin{array}{c}-0.179 * * \\
(0.086)\end{array}$ & $\begin{array}{c}-0.179 * * \\
(0.085)\end{array}$ & $\begin{array}{c}-0.180^{* *} \\
(0.085)\end{array}$ & $\begin{array}{c}-0.180 * * \\
(0.086)\end{array}$ \\
\hline Natural amenity score, 1999 & $\begin{array}{c}-0.314 \\
(0.762)\end{array}$ & $\begin{array}{c}-0.301 \\
(0.761)\end{array}$ & $\begin{array}{c}-0.295 \\
(0.760)\end{array}$ & $\begin{array}{c}-0.323 \\
(0.763)\end{array}$ \\
\hline Mean temperature in July, 1941-1970 & $\begin{array}{c}-0.258 \\
(0.413)\end{array}$ & $\begin{array}{l}-0.252 \\
(0.413)\end{array}$ & $\begin{array}{c}-0.253 \\
(0.413)\end{array}$ & $\begin{array}{c}-0.261 \\
(0.413)\end{array}$ \\
\hline Average annual capacity in megawatts for existing generating units, 2003 & $\begin{array}{c}0.001 \\
(0.001)\end{array}$ & $\begin{array}{c}0.001 \\
(0.001)\end{array}$ & $\begin{array}{c}0.001 \\
(0.001)\end{array}$ & $\begin{array}{c}0.001 \\
(0.001)\end{array}$ \\
\hline Distance to nearest metro $(\mathrm{km})$ & $\begin{array}{c}-0.016 \\
(0.039)\end{array}$ & $\begin{array}{c}-0.016 \\
(0.039)\end{array}$ & $\begin{array}{c}-0.017 \\
(0.039)\end{array}$ & $\begin{array}{c}-0.014 \\
(0.039)\end{array}$ \\
\hline Incremental distance to a metro $>250,000$ population & $\begin{array}{c}-0.031 \\
(0.026)\end{array}$ & $\begin{array}{c}-0.031 \\
(0.025)\end{array}$ & $\begin{array}{c}-0.030 \\
(0.025)\end{array}$ & $\begin{array}{c}-0.029 \\
(0.026)\end{array}$ \\
\hline Incremental distance to a metro $>500,000$ population & $\begin{array}{c}-0.005 \\
(0.018)\end{array}$ & $\begin{array}{c}-0.005 \\
(0.018)\end{array}$ & $\begin{array}{c}-0.005 \\
(0.018)\end{array}$ & $\begin{array}{c}-0.004 \\
(0.018)\end{array}$ \\
\hline Incremental distance to a metro $>1,500,000$ population & $\begin{array}{c}0.013 \\
(0.013)\end{array}$ & $\begin{array}{c}0.014 \\
(0.013)\end{array}$ & $\begin{array}{c}0.014 \\
(0.013)\end{array}$ & $\begin{array}{c}0.013 \\
(0.013)\end{array}$ \\
\hline Share of non-farm proprietors employment, 2005 & $\begin{array}{c}0.621^{* *} \\
(0.287)\end{array}$ & $\begin{array}{c}0.620 * * \\
(0.287)\end{array}$ & $\begin{array}{c}0.621 * * \\
(0.288)\end{array}$ & $\begin{array}{c}0.619 * * \\
(0.288)\end{array}$ \\
\hline Share of manufacturing employment, 2005 & $\begin{array}{c}-0.543 \text { **** } \\
(0.112)\end{array}$ & $\begin{array}{c}-0.543^{* * * *} \\
(0.112)\end{array}$ & $\begin{array}{c}-0.542 \text { *** } \\
(0.112)\end{array}$ & $\begin{array}{c}-0.542 * * * \\
(0.112)\end{array}$ \\
\hline County is in nonattainment for 1-hour ozone (1979) standard, 2004 & $\begin{array}{c}-0.584 \\
(2.397)\end{array}$ & & & \\
\hline County is in nonattainment for 8-hour ozone (1997) standard, 2004 & $\begin{array}{c}2.466 \\
(1.987)\end{array}$ & & & \\
\hline County is in nonattainment for PM-2.5 (1997) standard, 2005 & $\begin{array}{l}-2.150 \\
(2.155)\end{array}$ & $\begin{array}{c}-1.983 \\
(2.186)\end{array}$ & & $\begin{array}{l}-2.073 \\
(2.157)\end{array}$ \\
\hline County is in nonattainment for 8-hour ozone (1997) standard, 2005 & & $\begin{array}{c}1.901 \\
(1.897)\end{array}$ & & \\
\hline County is in nonattainment for either PM-2.5 or 8-hour ozone standard, 2005 & & & $\begin{array}{c}0.937 \\
(1.768)\end{array}$ & \\
\hline County remains in nonattainment through ozone standard change, 2004 & & & & $\begin{array}{c}1.477 \\
(2.827)\end{array}$ \\
\hline County changes from attainment to nonattainment through ozone standard change, 2004 & & & & $\begin{array}{c}2.751 \\
(2.080)\end{array}$ \\
\hline County changes from nonattainment to attainment through ozone standard change, 2004 & & & & $\begin{array}{c}2.109 \\
(3.745)\end{array}$ \\
\hline Constant & $\begin{array}{c}27.653 \\
(43.057)\end{array}$ & $\begin{array}{c}27.478 \\
(43.034)\end{array}$ & $\begin{array}{c}27.541 \\
(42.915)\end{array}$ & $\begin{array}{c}27.677 \\
(43.063)\end{array}$ \\
\hline Spatial Fixed Effects & State & State & State & State \\
\hline Observations & 1,387 & 1,387 & 1,387 & 1,387 \\
\hline R-squared & 0.115 & 0.115 & 0.115 & 0.116 \\
\hline Adjusted R-squared & 0.0885 & 0.0889 & 0.0893 & 0.0879 \\
\hline
\end{tabular}


Table 1-6: Percent change in Population from 2006 to 2016

\begin{tabular}{|c|c|c|c|c|}
\hline VARIABLES & (1) & (2) & (3) & (4) \\
\hline Percent change in total population from 1969 to 1979 & $\begin{array}{c}0.081 * * * \\
(0.017)\end{array}$ & $\begin{array}{c}0.082 * * * \\
(0.017)\end{array}$ & $\begin{array}{c}0.082 * * * \\
(0.016)\end{array}$ & $\begin{array}{c}0.081 * * * \\
(0.017)\end{array}$ \\
\hline Historical industrial diversification measure (coefficient of specialization), 1969 & $\begin{array}{l}-0.041 * \\
(0.022)\end{array}$ & $\begin{array}{l}-0.041 * \\
(0.022)\end{array}$ & $\begin{array}{c}-0.044 * * \\
(0.022)\end{array}$ & $\begin{array}{l}-0.041 * \\
(0.022)\end{array}$ \\
\hline Population density, 2000 & $\begin{array}{c}0.222 * \\
(0.122)\end{array}$ & $\begin{array}{c}0.223 * \\
(0.121)\end{array}$ & $\begin{array}{c}0.250 * * \\
(0.127)\end{array}$ & $\begin{array}{l}0.218^{*} \\
(0.121)\end{array}$ \\
\hline Unemployment rate, 2005 & $\begin{array}{c}-1.197 * * * \\
(0.150)\end{array}$ & $\begin{array}{c}-1.200 * * * \\
(0.150)\end{array}$ & $\begin{array}{c}-1.209 * * * \\
(0.150)\end{array}$ & $\begin{array}{c}-1.203 * * * \\
(0.150)\end{array}$ \\
\hline Median age, 2005 & $\begin{array}{c}-0.714 \text { *** } \\
(0.086)\end{array}$ & $\begin{array}{c}-0.714 * * * \\
(0.086)\end{array}$ & $\begin{array}{c}-0.706^{* * * *} \\
(0.086)\end{array}$ & $\begin{array}{c}-0.714 * * * \\
(0.086)\end{array}$ \\
\hline Percent of population 25 years and older with a high school degree, 2000 & $\begin{array}{c}0.058 \\
(0.048)\end{array}$ & $\begin{array}{c}0.056 \\
(0.048)\end{array}$ & $\begin{array}{c}0.049 \\
(0.048)\end{array}$ & $\begin{array}{c}0.058 \\
(0.048)\end{array}$ \\
\hline Percent of population 25 years and older with a bachelor's degree or higher, 2000 & $\begin{array}{c}0.317 * * * \\
(0.043)\end{array}$ & $\begin{array}{c}0.317 * * * \\
(0.043)\end{array}$ & $\begin{array}{c}0.322 * * * \\
(0.043)\end{array}$ & $\begin{array}{c}0.316 * * * \\
(0.043)\end{array}$ \\
\hline Percent of white, non-Hispanic population, 2000 & $\begin{array}{c}0.056^{* * *} \\
(0.019)\end{array}$ & $\begin{array}{c}0.055^{* * *} \\
(0.019)\end{array}$ & $\begin{array}{c}0.054 * * * \\
(0.019)\end{array}$ & $\begin{array}{c}0.056 * * * \\
(0.019)\end{array}$ \\
\hline Natural amenity score, 1999 & $\begin{array}{c}-0.179 \\
(0.135)\end{array}$ & $\begin{array}{c}-0.177 \\
(0.134)\end{array}$ & $\begin{array}{c}-0.183 \\
(0.135)\end{array}$ & $\begin{array}{l}-0.175 \\
(0.135)\end{array}$ \\
\hline Mean temperature in July, 1941-1970 & $\begin{array}{c}0.095 \\
(0.076)\end{array}$ & $\begin{array}{c}0.096 \\
(0.076)\end{array}$ & $\begin{array}{c}0.091 \\
(0.076)\end{array}$ & $\begin{array}{c}0.096 \\
(0.076)\end{array}$ \\
\hline Average annual capacity in megawatts for existing generating units, 2003 & $\begin{array}{c}0.000 \\
(0.000)\end{array}$ & $\begin{array}{c}0.000 \\
(0.000)\end{array}$ & $\begin{array}{c}0.000 * \\
(0.000)\end{array}$ & $\begin{array}{c}0.000 \\
(0.000)\end{array}$ \\
\hline Distance to nearest metro $(\mathrm{km})$ & $\begin{array}{c}-0.013 * * \\
(0.006)\end{array}$ & $\begin{array}{c}-0.013 * * \\
(0.006)\end{array}$ & $\begin{array}{l}-0.012 * \\
(0.006)\end{array}$ & $\begin{array}{c}-0.014 * * \\
(0.006)\end{array}$ \\
\hline Incremental distance to a metro $>250,000$ population & $\begin{array}{c}-0.005 \\
(0.004)\end{array}$ & $\begin{array}{l}-0.005 \\
(0.004)\end{array}$ & $\begin{array}{c}-0.006 \\
(0.004)\end{array}$ & $\begin{array}{l}-0.005 \\
(0.004)\end{array}$ \\
\hline Incremental distance to a metro $>500,000$ population & $\begin{array}{c}-0.009 * * \\
(0.004)\end{array}$ & $\begin{array}{c}-0.009 * * \\
(0.004)\end{array}$ & $\begin{array}{c}-0.010^{* *} \\
(0.004)\end{array}$ & $\begin{array}{c}-0.009 * * \\
(0.004)\end{array}$ \\
\hline Incremental distance to a metro $>1,500,000$ population & $\begin{array}{c}0.006^{* *} \\
(0.003)\end{array}$ & $\begin{array}{c}0.006^{* *} \\
(0.003)\end{array}$ & $\begin{array}{c}0.006^{* *} \\
(0.003)\end{array}$ & $\begin{array}{c}0.007 * * \\
(0.003)\end{array}$ \\
\hline Share of non-farm proprietors employment, 2005 & $\begin{array}{c}0.224 * * * \\
(0.041)\end{array}$ & $\begin{array}{c}0.224 * * * \\
(0.041)\end{array}$ & $\begin{array}{c}0.223 * * * \\
(0.041)\end{array}$ & $\begin{array}{c}0.225^{* * * *} \\
(0.041)\end{array}$ \\
\hline Share of manufacturing employment, 2005 & $\begin{array}{c}0.024 \\
(0.023)\end{array}$ & $\begin{array}{c}0.024 \\
(0.023)\end{array}$ & $\begin{array}{c}0.023 \\
(0.023)\end{array}$ & $\begin{array}{c}0.024 \\
(0.023)\end{array}$ \\
\hline County is in nonattainment for 1-hour ozone (1979) standard, 2004 & $\begin{array}{c}0.136 \\
(0.662)\end{array}$ & & & \\
\hline County is in nonattainment for 8-hour ozone (1997) standard, 2004 & $\begin{array}{c}0.881 * \\
(0.470)\end{array}$ & & & \\
\hline County is in nonattainment for PM-2.5 (1997) standard, 2005 & $\begin{array}{l}1.444 * * \\
(0.598)\end{array}$ & $\begin{array}{l}1.511 * * \\
(0.614)\end{array}$ & & $\begin{array}{l}1.413 * * \\
(0.597)\end{array}$ \\
\hline County is in nonattainment for 8-hour ozone (1997) standard, 2005 & & $\begin{array}{c}0.784 * \\
(0.465)\end{array}$ & & \\
\hline County is in nonattainment for either PM-2.5 or 8-hour ozone standard, 2005 & & & $\begin{array}{c}1.371 * * * \\
(0.432)\end{array}$ & \\
\hline County remains in nonattainment through ozone standard change, 2004 & & & & $\begin{array}{c}1.176 \\
(0.798)\end{array}$ \\
\hline County changes from attainment to nonattainment through ozone standard change, 2004 & & & & $\begin{array}{c}0.769 \\
(0.491)\end{array}$ \\
\hline County changes from nonattainment to attainment through ozone standard change, 2004 & & & & $\begin{array}{l}-0.917 \\
(0.834)\end{array}$ \\
\hline Constant & $\begin{array}{c}10.718 \\
(7.948)\end{array}$ & $\begin{array}{c}10.753 \\
(7.944)\end{array}$ & $\begin{array}{l}11.406 \\
(7.978)\end{array}$ & $\begin{array}{l}10.709 \\
(7.949)\end{array}$ \\
\hline Spatial Fixed Effects & State & State & State & State \\
\hline Observations & 1,386 & 1,386 & 1,386 & 1,386 \\
\hline R-squared & 0.598 & 0.598 & 0.596 & 0.598 \\
\hline Adjusted R-squared & 0.586 & 0.586 & 0.584 & 0.585 \\
\hline
\end{tabular}


Table 1-7: Percent change in Industrial Diversification from 2006 to 2016

\begin{tabular}{|c|c|c|c|c|}
\hline VARIABLES & (1) & $(2)$ & (3) & (4) \\
\hline Percent change in total population from 1969 to 1979 & $\begin{array}{c}-0.021 \\
(0.072)\end{array}$ & $\begin{array}{l}-0.085 \\
(0.082)\end{array}$ & $\begin{array}{c}-0.086 \\
(0.083)\end{array}$ & $\begin{array}{c}-0.029 \\
(0.073)\end{array}$ \\
\hline Historical industrial diversification measure (coefficient of specialization), 1969 & $\begin{array}{c}0.394 \\
(0.518)\end{array}$ & $\begin{array}{c}0.385 \\
(0.515)\end{array}$ & $\begin{array}{c}0.374 \\
(0.507)\end{array}$ & $\begin{array}{c}0.388 \\
(0.515)\end{array}$ \\
\hline Population density, 2000 & $\begin{array}{c}-0.047 \\
(0.272)\end{array}$ & $\begin{array}{c}-0.344 \\
(0.284)\end{array}$ & $\begin{array}{c}-0.334 \\
(0.275)\end{array}$ & $\begin{array}{c}-0.099 \\
(0.268)\end{array}$ \\
\hline Unemployment rate, 2005 & $\begin{array}{c}2.471 \\
(2.277)\end{array}$ & $\begin{array}{c}2.495 \\
(2.280)\end{array}$ & $\begin{array}{c}2.487 \\
(2.270)\end{array}$ & $\begin{array}{c}2.384 \\
(2.245)\end{array}$ \\
\hline Median age, 2005 & $\begin{array}{l}-1.637 * \\
(0.920)\end{array}$ & $\begin{array}{c}-1.656^{*} \\
(0.919)\end{array}$ & $\begin{array}{l}-1.652 * \\
(0.920)\end{array}$ & $\begin{array}{c}-1.638 * \\
(0.920)\end{array}$ \\
\hline Percent of population 25 years and older with a high school degree, 2000 & $\begin{array}{c}-0.009 \\
(0.358)\end{array}$ & $\begin{array}{c}0.037 \\
(0.365)\end{array}$ & $\begin{array}{c}0.012 \\
(0.356)\end{array}$ & $\begin{array}{c}-0.003 \\
(0.360)\end{array}$ \\
\hline Percent of population 25 years and older with a bachelor's degree or higher, 2000 & $\begin{array}{c}0.771 \\
(0.731)\end{array}$ & $\begin{array}{c}0.730 \\
(0.719)\end{array}$ & $\begin{array}{c}0.728 \\
(0.723)\end{array}$ & $\begin{array}{c}0.758 \\
(0.724)\end{array}$ \\
\hline Percent of white, non-Hispanic population, 2000 & $\begin{array}{c}0.091 \\
(0.196)\end{array}$ & $\begin{array}{c}0.144 \\
(0.185)\end{array}$ & $\begin{array}{c}0.154 \\
(0.185)\end{array}$ & $\begin{array}{c}0.094 \\
(0.195)\end{array}$ \\
\hline Natural amenity score, 1999 & $\begin{array}{c}2.454 \\
(2.385)\end{array}$ & $\begin{array}{c}2.595 \\
(2.442)\end{array}$ & $\begin{array}{c}2.615 \\
(2.437)\end{array}$ & $\begin{array}{c}2.509 \\
(2.407)\end{array}$ \\
\hline Mean temperature in July, 1941-1970 & $\begin{array}{c}-1.442 \\
(1.402)\end{array}$ & $\begin{array}{l}-1.402 \\
(1.385)\end{array}$ & $\begin{array}{c}-1.345 \\
(1.385)\end{array}$ & $\begin{array}{c}-1.427 \\
(1.398)\end{array}$ \\
\hline Average annual capacity in megawatts for existing generating units, 2003 & $\begin{array}{c}0.000 \\
(0.001)\end{array}$ & $\begin{array}{c}0.000 \\
(0.002)\end{array}$ & $\begin{array}{c}0.000 \\
(0.001)\end{array}$ & $\begin{array}{c}0.000 \\
(0.002)\end{array}$ \\
\hline Distance to nearest metro $(\mathrm{km})$ & $\begin{array}{l}0.155 * * \\
(0.071)\end{array}$ & $\begin{array}{c}0.158 * * \\
(0.071)\end{array}$ & $\begin{array}{l}0.155^{* *} \\
(0.072)\end{array}$ & $\begin{array}{c}0.146^{* *} \\
(0.069)\end{array}$ \\
\hline Incremental distance to a metro $>250,000$ population & $\begin{array}{c}0.061 \\
(0.083)\end{array}$ & $\begin{array}{c}0.085 \\
(0.092)\end{array}$ & $\begin{array}{c}0.085 \\
(0.091)\end{array}$ & $\begin{array}{c}0.054 \\
(0.080)\end{array}$ \\
\hline Incremental distance to a metro $>500,000$ population & $\begin{array}{c}0.012 \\
(0.036)\end{array}$ & $\begin{array}{c}0.024 \\
(0.038)\end{array}$ & $\begin{array}{c}0.025 \\
(0.037)\end{array}$ & $\begin{array}{c}0.010 \\
(0.036)\end{array}$ \\
\hline Incremental distance to a metro $>1,500,000$ population & $\begin{array}{c}-0.036 * \\
(0.021)\end{array}$ & $\begin{array}{c}-0.031 \\
(0.020)\end{array}$ & $\begin{array}{c}-0.031 \\
(0.020)\end{array}$ & $\begin{array}{l}-0.035 * \\
(0.021)\end{array}$ \\
\hline Share of non-farm proprietors employment, 2005 & $\begin{array}{c}-0.177 \\
(0.384)\end{array}$ & $\begin{array}{c}-0.174 \\
(0.387)\end{array}$ & $\begin{array}{c}-0.178 \\
(0.385)\end{array}$ & $\begin{array}{c}-0.168 \\
(0.385)\end{array}$ \\
\hline Share of manufacturing employment, 2005 & $\begin{array}{c}0.688 \\
(0.950)\end{array}$ & $\begin{array}{c}0.689 \\
(0.954)\end{array}$ & $\begin{array}{c}0.693 \\
(0.951)\end{array}$ & $\begin{array}{c}0.680 \\
(0.946)\end{array}$ \\
\hline County is in nonattainment for 1-hour ozone (1979) standard, 2004 & $\begin{array}{c}-23.125^{*} \\
(12.098)\end{array}$ & & & \\
\hline County is in nonattainment for 8-hour ozone (1997) standard, 2004 & $\begin{array}{c}-11.572 * * * \\
(3.817)\end{array}$ & & & \\
\hline County is in nonattainment for PM-2.5 (1997) standard, 2005 & $\begin{array}{c}3.003 \\
(5.511)\end{array}$ & $\begin{array}{l}-0.160 \\
(4.997)\end{array}$ & & $\begin{array}{c}2.559 \\
(5.383)\end{array}$ \\
\hline County is in nonattainment for 8-hour ozone (1997) standard, 2005 & & $\begin{array}{c}-13.330 * * \\
(5.205)\end{array}$ & & \\
\hline County is in nonattainment for either PM-2.5 or 8-hour ozone standard, 2005 & & & $\begin{array}{c}-14.247 \text { *** } \\
(4.268)\end{array}$ & \\
\hline County remains in nonattainment through ozone standard change, 2004 & & & & $\begin{array}{c}-32.383^{* *} \\
(12.599)\end{array}$ \\
\hline County changes from attainment to nonattainment through ozone standard change, 2004 & & & & $\begin{array}{c}-13.196 \text { **** } \\
(4.238)\end{array}$ \\
\hline County changes from nonattainment to attainment through ozone standard change, 2004 & & & & $\begin{array}{c}-38.479 * \\
(21.568)\end{array}$ \\
\hline Constant & $\begin{array}{l}129.194 \\
(92.719)\end{array}$ & $\begin{array}{l}120.877 \\
(91.628)\end{array}$ & $\begin{array}{l}116.638 \\
(91.842)\end{array}$ & $\begin{array}{l}129.056 \\
(92.803)\end{array}$ \\
\hline Spatial Fixed Effects & State & State & State & State \\
\hline Observations & 1,385 & 1,385 & 1,385 & 1,385 \\
\hline R-squared & 0.052 & 0.046 & 0.047 & 0.053 \\
\hline Adjusted R-squared & 0.0232 & 0.0179 & 0.0193 & 0.0233 \\
\hline
\end{tabular}




\section{References}

Bartik, T. J. 2015. "The Social Value of Job Loss and Its Effect on the Costs of U.S. Environmental Regulations." Review of Environmental Economics and Policy 9 (2): 179-197.

Bayer, P., N. Keohane, and C. Timmins. 2009. "Migration and hedonic valuation: The case of air quality." Journal of Environmental Economics and Management 58(1): 1-14.

Becker, R., and V. Henderson. 1997. Effects of air quality regulation on decisions of firms in polluting industries. Cambridge, MA: National Bureau of Economic Research.

Berman, E., and L. T. Bui. 2001. "Environmental regulation and labor demand: Evidence from the south coast air basin." Journal of Public Economics 79 (2): 265-295.

Bernard, S. M., J. M. Samet, A. Grambsch, K. L. Ebi, and I. Romieu. 2001. "The potential impacts of climate variability and change on air pollution-related health effects in the United States." Environmental Health Perspectives 109 (2): 199-209.

Brown, R. S., and L. R. Christensen. 1980. "Estimating elasticities of substitution in a model of partial static equilibrium: an application to US agriculture, 1947-1979." Workshop Series, Social Systems Research Institute, University of Wisconsin 1980 (8007).

Brunekreef, B., and S. T. Holgate. 2002. "Air pollution and health." The Lancet 360 (9341): 12331242.

Carr, D., and W. Yan. 2012. "Federal Environmental Policy and Local Industrial Diversification: The Case of the Clean Air Act." Regional Studies 46 (5): 639-649.

Carroll, M. C., N. Reid, and B. W. Smith. 2008. "Location quotients versus spatial autocorrelation in identifying potential cluster regions." The Annals of Regional Science 42 (2): 449-463.

Davenport, C. "Obama Builds Environmental Legacy with 1970 Law." The New York Times, November 26, 2014. Accessed April 7, 2015. http://www.nytimes.com/2014/11/27/us/withoutpassing-a-single-law-obama-crafts-bold-enviornmental-policy.html?ref=topics.

Davis, S. J., and T. M. von Wachter. 2011. Recessions and the Cost of Job Loss. National Bureau of Economic Research (w17638).

Deller, S.C., T.H. Tsai, D.W. Marcouiller, and D.B.K. English. 2001. "The role of amenities and quality of life in rural economic growth." American Journal of Agricultural Economics 83: $352-365$. 
Deschenes, O. 2014. "Environmental regulations and labor markets." IZA World of Labor.

Faggian, A., M. R. Olfert, and M.D. Partridge. 2012. "Inferring Regional Well-being from Individual Reveal Preferences: The "Voting with your Feet" Approach." Cambridge Journal of Regions, Economy and society 5:163-180.

Fotheringham, A. S., and D. W. S. Wong. 1991. "The Modifiable Areal Unit Problem in Multivariate Statistical Analysis." Environment and Planning A: Economy and Space 23 (7): 1025-1044.

Fraas, A. G., J. D. Graham, and J. Holmstead. 2017. "EPA's New Source Review Program: Time for Reform?" Environmental Law Reporter 47 (1): 10026-10040.

Glaeser, E. L., J. A. Scheinkman, and A. Schleifer. 1995. "Economic Growth in a Crosssection of Cities." Journal of Monetary Economics 36:117-43.

Gray, W. B., R. J. Shadbegian, C. Wang, and M. Meral. 2014. "Do EPA regulations affect labor demand? Evidence from the pulp and paper industry." Journal of Environmental Economics and Management 68 (1): 188-202.

Greenstone, Michael. 2002. "The Impacts of Environmental Regulations on Industrial Activity: Evidence from the 1970 and 1977 Clean Air Act Amendments and the Census of Manufactures". Journal of Political Economy 110 (6): 1175-1219.

Guttmann, J. S., A. W. Sierck, and D.M. Friedland. 1992. "The new clean air act's big squeeze on America's manufacturing base" Business Horizons 35 (2): 37-40.

Harvey, C. E. 1986. Coal in Appalachia: An Economic Analysis. Lexington, Kentucky: University Press of Kentucky.

Holmes, J. (2017, December 05) The Best Places to Live: The Rust Belt Revival - Pittsburgh and Cleveland. Retrieved March 20, 2018, from https:/www.mensjournal.com/travel/the-rust-beltrevival-pittsburgh-and-cleveland-make-a-comeback-20150406/

Jorgenson, D. W, and P. J Wilcoxen. 1990. "Environmental Regulation and U.S. Economic Growth." The Rand Journal of Economics 21 (2): 314-340.

Jung, C., K. Krutilla, and R. Boyd, 1996. Incentives for advanced pollution abatement technology at the industry level: An evaluation of policy alternatives. Journal of Environmental Economics and Management 30 (1): 95-111. 
Louis, L.V.S. 1980. "A measure of regional diversification and efficiency." The Annals of Regional Science 14:21-30.

Kampa, M., and E. Castanas. 2008. "Human health effects of air pollution." Environmental Pollution 151 (2): 362-367.

Kodrzycki, Y. K. 2007. "Using unexpected recalls to examine the long-term earnings effects of job displacement". FRB of Boston Working Paper No. 07-2. Available at SSRN: https://ssrn.com/abstract=982388 or http://dx.doi.org/10.2139/ssrn.982388.

Kotkin, J. (2014, October 14). The Cities That Are Benefiting the Most from The Economic Recovery. $\quad$ Retrieved March 20, 2018, from https://www.forbes.com/sites/joelkotkin/2014/10/06/the-u-s-cities-that-are-benefiting-themost-from-the-economic-recovery/\#16b6d17b3780

Porter, M. E. 2000. "Location, Competition, and Economic Development: Local Clusters in a Global Economy." Economic Development Quarterly 14(1): 15-34.

Rappaport, J. 2007. "Moving to Nice Weather.” Regional Science and Urban Economics 37: 375398.

Roback, J. 1982. Wages, rents and the quality of life. The Journal of Political Economy 90 (6): $1257-1278$.

Sanchez, C. M, and W. McKinley. 1998. "Environmental regulatory influence and product innovation: The contingency effects of organizational characteristics." Journal of Engineering and Technology Management 15 (4): 257-278.

Sayago-Gomez, J.T. and C. Stair. 2015. Location Quotient, Coefficient of Specialization and ShiftShare Technical Document (2015-01). Regional Research Institute, West Virginia University.

Schoeni, R., and M. Dardia. 2003. Estimates of earnings losses of displaced workers using California administrative data. PSC Research Report (03-543).

Stephens, H. M., and M. D. Partridge. 2011. "Do entrepreneurs enhance economic growth in lagging regions?" Growth and Change 42 (4): 431-465.

Stephens, H. M., and M. D. Partridge. 2015. "Lake Amenities, Environmental Degradation, and Great Lakes Regional Growth." International Regional Science Review 38 (1): 61-91.

Stiglitz, J.E., 1996. The role of government in economic development. In Annual World Bank Conference on Development Economics: 11-23. 
Walker, W.R., 2011. Environmental regulation and labor reallocation: Evidence from the Clean Air Act. The American Economic Review, 101(3): 442-447.

Wong, David. 2009. "The modifiable areal unit problem (MAUP)." The SAGE handbook of spatial analysis: $105-123$.

Yan, W., and D. A. Carr. 2013. "Federal Environmental Regulation Impacts on Local Economic Growth and Stability." Economic Development Quarterly 27 (3): 179-192.

Yang, T.C. 2005. “Modifiable Areal Unit Problem”. GIS Resource Document 5 (65): 135. 


\title{
CHAPTER 3: ESSAY 2 - ASSESSMENT OF THE SPATIAL DISTRIBUTION OF NRCS ASSISTANCE PROGRAMS IN WEST VIRGINIA
}

\author{
With Alan Collins and Donald Lacombe
}

\begin{abstract}
The purpose of this essay is to assess the spatial distribution of Natural Resource Conservation Service (NRCS) assistance programs throughout the state of West Virginia. Previous literature on government program participation has focused on factors explaining individual or farm level decisions. However, this essay is the first to assess factors impacting federal program participation at a regional (census tract) extent or scale. We hypothesize that social networking influences individuals in their conservation practice decisions, thus individual participation decisions can be reflective of groups. In addition, if conservation practices are spatially autocorrelated, we assume social networking is influencing individual decision making between areas. With data available at both the census tract and county levels, we utilize a spatial hierarchical model to predict the number of applied practices at the census tract level. The quantity of agricultural land, stream miles, and distance to NRCS local field offices have statistically significant effects on the number of applied practices within a census tract. Spillover effects across census tracts exist with variables that assess public land ownership, developed land, and surface mined lands. All county level (level 2) variables in the spatial hierarchical model (number of farms, average farm size, cattle sales, poultry sales, and percent of farms with internet connection) have statistically significant total spillover effects on the number of applied practices. These results provide evidence of factors influencing social networks among farmers leading to increased conservation practice adoption at a regional scale. Finally, based on our empirical analysis, census tracts are then classified as underserved or overserved by their designated local NRCS field office. By targeting outreach efforts to underserved regions along with exposing regional factors impacting the distributional aspects of the assistance programs, the results of this study assist in illustrating the new priority areas in West Virginia for NRCS.
\end{abstract}

Keywords: Resource and Environmental Policy Analysis, Rural/Community Development, Natural Resource Economics, Spatial Econometrics, Spatial Analysis

\section{Acknowledgements:}

This research was funded by a cooperative agreement between the USDA Natural Resource Conservation Service (NRCS) and West Virginia University. Special thanks to Jacquelyn Strager of West Virginia University Natural Resource Analysis Center (NRAC) for assistance with data collection and GIS analysis. 


\section{Introduction}

Historically, West Virginia has seen a tremendous amount of resource extraction of its timber, coal, oil, and natural gas resources. This resource extraction has been the largest contributor to the state's economic development. In 1980, West Virginia and Kentucky counties had the highest share of earnings in resource-extraction industries in the U.S., making these states historically resource dependent (James and Aadland, 2011). High levels of non-regulated extraction have led to the rapid degradation of the state's remaining resources. Bernhardt et al. (2012) find surface coal mining has a significant impact on the biodiversity found within streams. They also found that surface mining significantly decreased the amount of water availability. In southern WV, regional streams were buried in valley fills and larger watershed areas were drained so the land could be converted into surface mines. Palmer et al. (2010) also find that mountaintop mining with valley fills (MTM/VF), widely implemented in WV and KY, led to the clearing of upper elevation forests and the removal of topsoil to access buried coal. Previously, these forests provided habitats to diverse species, even some endangered species. It is important to address resource concerns related to extraction and other activities in order to preserve the remaining environmental quality of the land. Conservation programs developed by federal agencies, such as Natural Resource Conservation Service (NRCS), address resource concerns such as water quality, soil quality, water conservation, air quality, as well as wildlife habitats. NRCS has developed Resource Conservation and Development Areas that are locally sponsored through technical and financial assistance programs to address conservation and land management related issues. Given its history, the entire state of West Virginia is designated as a focus area for resource conservation. A goal of conservation programs is to improve economic activity and enhance utilization of resources in a region.

These programs are most effective if conducted with cooperation from landowners or farmers. NRCS aspires to build new and existing relationships to increase program participation and expand their local audience. The mission of NRCS is 'Help People, Help the Land' (USDA NRCS 2014 Farm Bill Program Outreach Strategy). The goal of the agency is to "ensure that all programs and services are made equally accessible to all customers, with emphasis to the underserved." Key issues for NRCS related to conservation program participation include understanding why individuals participate in these programs and what barriers inhibit participation. Thus, the objective of this study is to identify factors that influence program participation and to identify areas that are underserved by their local NRCS field office.

For program participants, there are several potential social and economic benefits associated with the adoption of conservation practices. These programs provide financial incentives with shortterm input costs and long-term profits, risk aversion to crop or establishment failure, and an increase in technology or productivity (Pannell et al., 2006).

Using NRCS technical and financial assistance practices from 2004 to 2015 aggregated at the census tract level, we identify factors that influence the spatial distribution of NRCS assistance programs throughout West Virginia. This study expands from the previous literature by examining the factors that influence the regional distribution of NRCS conservation programs. Our method allows us to control for socioeconomic characteristics and land cover attributes. We are especially 
interested in measuring social factors, such as community collaboration or social networking, that may influence program adoption. We utilize spatial econometric techniques to control for the spatial dependence of the factors affecting adoption. We also test farm-based explanatory variables at a regional level that could proxy for social networking levels within a community. These variables include number of farms, average farm size, percent of farms with internet access, and the magnitude of farming operations for cattle and poultry. Regions with a larger share of farming operations could have a stronger social network; this could have a positive influence on conservation practice adoption throughout the state.

In addition, a spatial hierarchical model is utilized in this research for two purposes. First, we examine the direct and indirect spillover effects of factors that influence practice adoption. We allow spillovers to affect both neighboring census tracts along with the entire region. Direct effects at the census tract level are statistically significant for agricultural land, stream mileage, and distance to an NRCS field office. Indirect spillover effects exist for agricultural land, distance to an NRCS field office, share of public land, percentage developed land, and surface mining. Secondly, we include factors that are only observed at the county level, such as information collected through the US Census of Agriculture on the number of farms, average farm size, and number of cattle. We find these variables have limited statistical significance for both direct and indirect effects, but each measure has a statistically significant total effect on the number of applied practices in a county. This identifies that factors that influence a social network of farmers could influence conservation practice adoption throughout the state.

In this study, we evaluate whether federal assistance is distributed efficiently to meet local needs and concerns. If support is provided to the appropriate regions, this will lead to greater benefits as assistance programs are implemented throughout the state. Based on the results of the spatial econometric analyses, we identify census tracts that are underserved or overserved by their local NRCS field office. To do this, we utilize the spatial model results to classify census tracts based on residuals (actual minus predicted number of applied practices). It is important to address the spatial inequality of program participation at the state level as areas that are underserved (a negative residual) have both landowner and environmental conservation needs that are not being satisfied by NRCS assistance programs. The results of this study will illustrate new priority areas for outreach efforts conducted by NRCS.

The development of this project was based upon an interest of the WV NRCS state office in evaluating program participation and promoting outreach efforts throughout West Virginia. The overarching research question is: What regional factors influence the spatial distribution of NRCS assistance programs in WV? There are three main objectives in answering this question: to observe the spatial distribution of the applied practices, identify significance variables that explain practice adoption, and to identify underserved/overserved census tracts. This essay is organized as follows: we first provide a background on NRCS conservation programs and agricultural production in West Virginia. Next, we discuss previous research related to our research question. We then provide an overview of the theoretical framework, methodology and data utilized within our analysis. We conclude by discussing the results, the areas identified as priority areas for future outreach efforts by WV NRCS, and policy implications. 


\subsection{West Virginia Natural Resource Conservation Service Assistance Programs}

The Natural Resource Conservation Service (NRCS) is a federal agency operating under the United States Department of Agriculture (USDA). This agency provides financial and technical assistance to farmers and landowners for aid in the management and sustainability of natural resources. The agency also provides incentives to farmers and landowners for putting land under long-term easements. This agency is federally regulated but provides assistance at the state and local levels. This analysis focuses on the financial and technical assistance programs offered by NRCS. This section discusses the type of programs offered, as well as participation levels in WV.

Through financial assistance programs, the agency provides cost-share support to projects with landowners such as planning and implementing conservation practices to address resource concerns or to promote ecological preservation on agricultural land and non-industrial, private forest land. NRCS financial assistance programs currently include: Agricultural Management Assistance (AMA), Conservation Stewardship Program (CSP), and Environmental Quality Incentives Program (EQIP). AMA helps producers use conservation techniques to manage risk and solve natural resource issues. CSP assists agricultural producers in maintaining and improving their conservation systems. The program also promotes conservation activities to address priority resource concerns. This program incentivizes conservation performance quality: the higher the conservation performance, the higher the payment. EQIP provides both financial and technical assistance to producers to address natural resource concerns and to deliver improved environmental benefits. EQIP has the highest enrollment levels for financial assistance programs. ${ }^{17}$

Conservation Technical Assistance Programs (CTA) do not provide cost-share assistance; however, they can provide other resources such as: resource assessment, practice design, resource monitoring, and follow-up consultations of installed practices. Technical assistance is available to a larger audience than financial assistance. Only programs that the NRCS state office identified as having potential outreach abilities to increase program adoption throughout the state were included in this study. CTA-General and EQIP are the most applied conservation practices in WV.

Figure 2-1 displays the annual number of implemented practices throughout the state of West Virginia from 1995 to 2015. In 2004, there was a sharp increase in the annual number of applied conservation practices in West Virginia. NRCS assistance programs were on a steady increase from 2004 to 2013; however, in 2014 program participation began to decrease.

\footnotetext{
${ }^{17}$ USDA NRCS. "NRCS Conservation Programs” Accessed on April 12, 2017
}

https://www.nrcs.usda.gov/wps/portal/nres/main/national/programs/ 


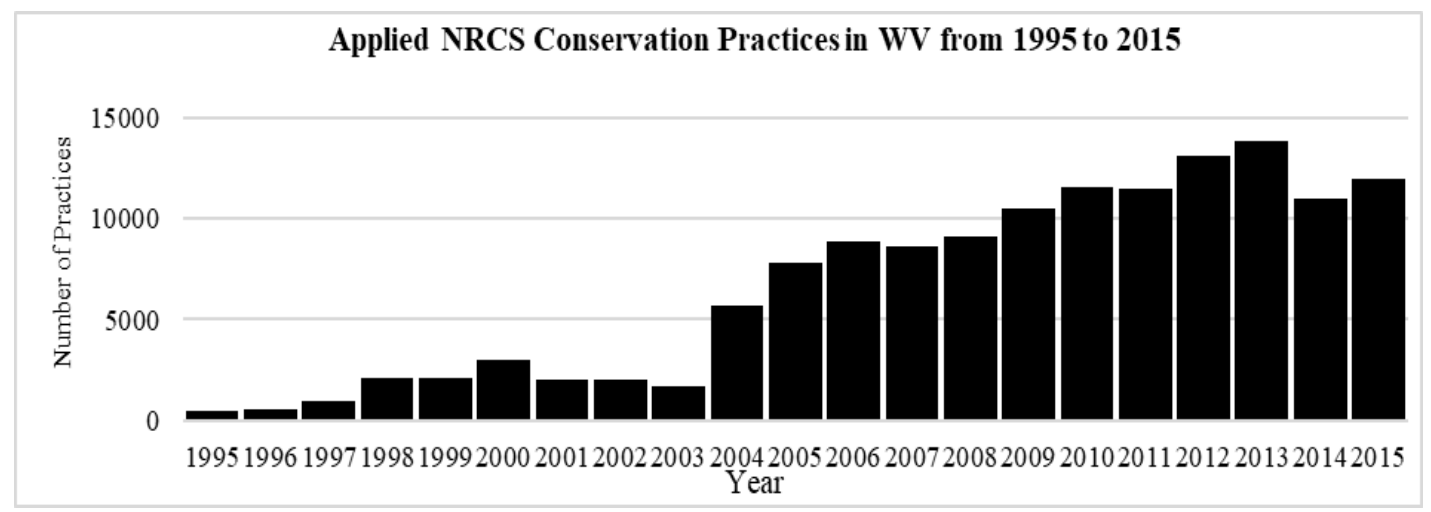

Figure 2-1: WV NRCS Applied Conservation Practices

The noticeable increases in the annual number of applied practices are correlated with the amendments to the US Farm Bills. From 1995 to 2015, four amendments were made to the US Farm Bill. These amendments include the Federal Agriculture Improvement and Reform Act of 1996, the Farm Security and Rural Investment Act of 2002, the Food, Conservation, and Energy Act of 2008, and the Agricultural Act of 2014. If we assume at least a two-year delay between the introduction of the amendment and its application, we can identify a direct positive effect on the number of conservation practices applied in West Virginia. ${ }^{18}$ To increase program participation, it is important to identify underserved regions as future target areas for NRCS so that participation levels may once again be on the rise. Our study focuses on financial and technical assistance practices applied from 2004 to 2015.

Table 2-1 below displays the number of applied assistance programs throughout West Virginia. From 2004 to 2015, there were a total number of 123,659 applied conservation practices throughout the state. Of this total, 57,833 practices were financial assistance programs while 65, 826 practices were technical assistance programs. The CTA-General program has the highest count of technical assistance practices, while the EQIP program has the highest count of financial assistance practices. Prescribed grazing is the most implemented conservation practice in WV.

Programs that will not be included in this study are Agricultural Conservation Easement Program (ACEP), Conservation Technical Assistance- Natural Resource Inventory (CTA-NRI), Emergency Conservation Program (ECP), Emergency Watershed Protection (EWP), and Farm and Ranchland Protection Program (FRPP) ${ }^{19}$. These programs are related to emergency assistance after natural disasters and other rare circumstances. By the removal of these programs, only a total of 13 practices were removed from the dataset. Currently the major financial assistance programs offered by the WV NRCS include AMA, CSP, and EQIP. Former financial assistance programs include AWEP, CCPI, and WHIP, which has been folded into EQIP.

\footnotetext{
${ }^{18} \mathrm{We}$ assume a two-year lag between the Farm Bill amendments and its applications to account for the time need to process approved funding, and to implement approved programs and practices.

19 During our meeting in December 2016 with the NRCS administrative team, the advisors from NRCS decided these programs should not be included within the study as they do not have outreach potential.
} 
Table 2-1: WV NRCS Assistance Programs Applied from 2004-2015

\begin{tabular}{|l|l|l|l|}
\hline Program & Full Name & Count & Program Type \\
\hline AMA & Agricultural Management Assistance Program & 807 & Financial \\
\hline CBWI & Chesapeake Bay Watershed Initiative & 3869 & Financial \\
\hline CRP & Conservation Reserve Program & 972 & Financial \\
\hline CSP & Conservation Security Program & 2937 & Financial \\
\hline CStwP & Conservation Stewardship Program & 9399 & Financial \\
\hline CTA-GENRL & Conservation Technical Assistance - General & 62330 & Technical \\
\hline CTA-GLC & $\begin{array}{l}\text { Conservation Technical Assistance - Grazing Land } \\
\text { Conservation }\end{array}$ & 3496 & Technical \\
\hline EQIP & Environmental Quality Incentives Program & 34090 & Financial \\
\hline GRP & Grasslands Reserve Program & 834 & Financial \\
\hline WF-03 & Flood Prevention Operations & 318 & Financial \\
\hline WHIP & Wildlife Habitat Incentives Program & 4573 & Financial \\
\hline WRP & Wetlands Reserve Program & 34 & Financial \\
\hline
\end{tabular}

\subsection{Agriculture in West Virginia}

According to the WV Annual Bulletin No. 47, there were 20,900 farms, the majority of these farms being family-owned and operated ${ }^{20}$ in 2015. Although the number of farms has decreased over the last five years, the average size of the farm has increased from 169 to 172 acres per farm. There is a total of 3.6 million acres of farmland throughout the state of West Virginia.

For an entity to be considered a farm, it only needs to produce $\$ 1,000$ worth of goods. In 2012, most farms within the state had sales less than $\$ 10,000$ for the year. The distribution of the percentage of farms with sales less than $\$ 10,000$ is displayed in Figure 2-2 below. Since farming operates on a low-income scale throughout the state, many operators treat farming as a secondary or alternative occupation. Figure 2-3 displays the distribution of the percentage of farm operators in each county that listed farming as their primary occupation in 2012. In most of the counties, only 35-44 percent of the operators recorded farming as their primary occupation in WV. Boone County is the only county where the majority of operators identified farming as their primary occupation.

Nationwide, West Virginia is not a dominant agricultural production state. However, WV's production of crops, livestock, and poultry rank nationally. In 2015, the state's apple production ranked $9^{\text {th }}$, trout production ranked $10^{\text {th }}$, peach production ranked $11^{\text {th }}$, turkey production ranked $14^{\text {th }}$, and broiler chicken production ranked $18^{\text {th }}$. Table $2-2$ is reproduced from the WV Annual Bulletin No. 47 and displays the ranking and magnitude of production for agricultural products produced in West Virginia in 2015.

\footnotetext{
${ }^{20}$ Farms can also be operated by partnerships or corporations.
} 




Figure 2-2: Percent of Farms in WV with Sales Less than $\$ 10,000$

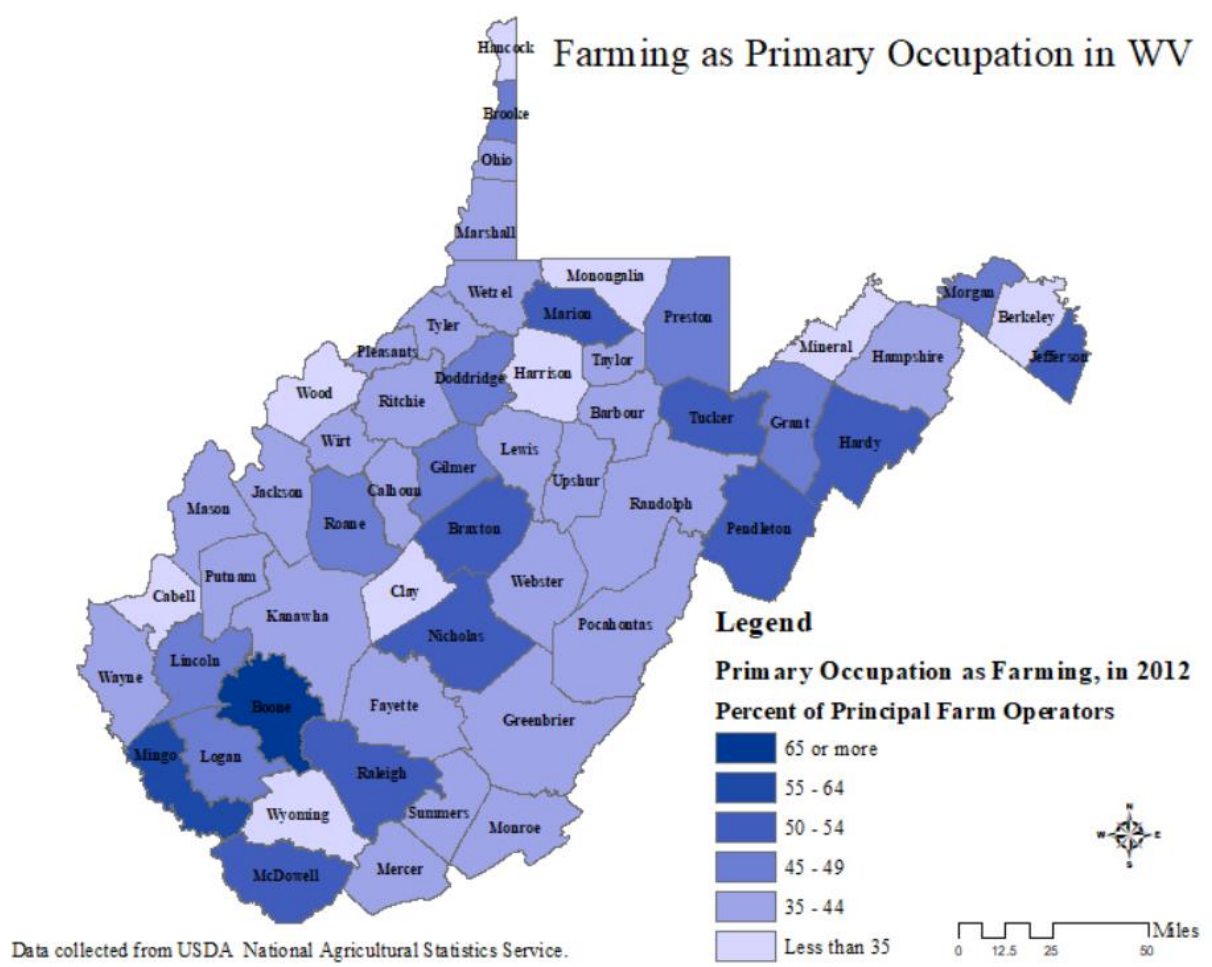

Figure 2-3: Percent of Farm Operators Listing Farming as their Primary Occupation 
Table 2-2: West Virginia's Farm Production Data

GENERAL

West Virginia's Rank in the Nation's Agriculture - 2015

\begin{tabular}{|c|c|c|c|c|c|}
\hline \multirow{2}{*}{$\begin{array}{l}\text { Crops, Livestock } \\
\text { and Poultry }\end{array}$} & \multicolumn{4}{|c|}{ West Virginia } & \multirow{2}{*}{$\begin{array}{l}\text { United States } \\
\text { Leading State }\end{array}$} \\
\hline & $\begin{array}{l}\text { Rank Among } \\
\text { States }{ }^{1 /}\end{array}$ & Production & Unit & $\begin{array}{l}\text { Value of Production } \\
\text { (Dollars) }\end{array}$ & \\
\hline Apples 2 ' & 9 & $90,000,000$ & Lbs. & $13,532,000$ & Washington \\
\hline Broilers & 18 & $356,100,000$ & Lbs. & $191,582,000$ & Georgia \\
\hline Cattle \& Calves & 39 & $136,673,000$ & Lbs. & $220,334,000$ & Texas \\
\hline Chickens, All ${ }^{3 /}$ & 31 & $2,112,000$ & Birds & $16,474,000$ & lowa \\
\hline Corn for Grain & 40 & $5,180,000$ & $\mathrm{Bu}$. & $20,461,000$ & lowa \\
\hline Corn for Silage & 38 & 252,000 & Tons & $4 /$ & Wisconsin \\
\hline Eggs & 32 & $274,000,000$ & Eggs & $53,872,000$ & lowa \\
\hline Hay Alfalfa & 32 & 66.000 & Tons & $13,530,000$ & California \\
\hline Hay, All & 37 & $1,035,000$ & Tons & $134,655,000$ & Texas \\
\hline Hay, Other & 26 & 969,000 & Tons & $121,125,000$ & Texas \\
\hline Hogs \& Pigs & 41 & $1,420,000$ & Lbs. & 787,000 & lowa \\
\hline Honey & 40 & 175,000 & Lbs. & 777,000 & North Dakota \\
\hline Milk & 42 & $141,000,000$ & Lbs. & $24,675,000$ & California \\
\hline Peaches ${ }^{2 /}$ & 11 & 5,700 & Tons & $6,056,000$ & California \\
\hline Soybeans & 30 & $1,248,000$ & Bu. & $11,232,000$ & lowa \\
\hline Trout ${ }^{5 /}$ & 10 & 4 & & $1,052,000$ & Idaho \\
\hline Turkeys & 14 & $90,600,000$ & Lbs. & $73,477,000$ & North Carolina \\
\hline Wheat, Winter & 41 & 240,000 & $\mathrm{Bu}$. & $1,296,000$ & Kansas \\
\hline Wool & 28 & 120,000 & Lbs. & 120,000 & California \\
\hline
\end{tabular}

Source: West Virginia Annual Bulletin No. 47 in 2016

As shown in Table 2-2, the commercial broiler chicken, and cattle and calf industries are the leading agriculture production sectors in the state in terms of monetary value. The total value of agricultural production in 2015 was roughly $\$ 905$ million, in which broilers account for 21 percent and cattle and calves account for 24 percent of the value in production. Combined, broiler chickens and cattle and calf production account for 45 percent of the dollar value of production in 2015 .

The type of agricultural production varies across different regions within West Virginia. Based on the West Virginia Agriculture State Profile 2014, Greenbrier County is the leading county in the state for agriculture. Greenbrier leads the state in the most farm land, number of cattle, and hay production. Hardy County is the leading county for broiler chicken inventory and agricultural sales. Jefferson County leads the state in corn for grain, and soybean and wheat production. Leading counties in the state for all cattle include Greenbrier, Monroe, Hardy, Preston, and Pendleton. Leading counties in the state for chickens include Hardy, Grant, Pendleton, Hampshire, and Mineral. These leading counties have higher levels conservation practice adoption when compared to the rest of the state. County level data on fruit production were not provided within the Bulletin. However, based on the US Census of Agriculture, McDowell County and the counties in the eastern panhandle have the most acres of land in orchards. These variations in production influence the spatial distribution of agriculture and conservation programs throughout the state.

\section{Literature Review}

Previous literature has studied the influential factors explaining individual or farm level participation in government programs. For example, Lambert et al. (2006) examine the farmer demographics and farm characteristics of participants and non-participants. Farm size, commodity 
mix, and operator motivation influence the decision to use different types of conservation practices. Ma et al. (2010) incorporate a constrained utility maximization framework to examine farmer responses to enrollment choices for proposed payment for environmental services programs. Reimer and Prokopy (2014) utilized a mixed-method approach including surveys and interviews to identify motivations and social barriers to individual participation in U.S. Farm Bill programs. Heckman and Smith (2004) also consider the impact of demographics in participation of social programs. While the authors identify ethnicity and education level as playing significant parts in participation, they believe that awareness of the social program and program eligibility play a major role in participation throughout various demographic groups.

Other recent literature has identified that peer beliefs and concern for neighbors can influence participation. Ryan et al. (2003) identify that farmers are more intrinsically motivated by the appearance and management of the land than by economic compensation. They also find farmers are concerned about the effects of their farming practices on downstream neighbors. They make two statements related to the importance of our study: "Farmers' sense of obligation to their community may be a new strategy for convincing farmers to engage in conservation" and "[ $t]$ he social dimension of farmers' conservation behavior is a variable worth further exploration in environmental planning and policy research." Their article hints at the importance of social networking on the adoption of conservation programs in a community.

Several articles have examined how knowledge sharing within a community influences an individual's decision to participate. Phillips (1985), more recently discussed in Pannell et al. (2006), observes the social spread of knowledge through dairy farmers. If a farmer lacked knowledge on a certain project, he or she would seek advice from a nearby entity that he or she perceived as an expert of the project. With the National Woodland Owner Survey, Butler et al. (2005), and Schubert and Mayer (2012) have found that non-industrial, private forest owners get as much information and advice on management and voluntary program enrollment from neighbors and peers as they receive from professional foresters at public agencies. Roughly half of the owners were influenced to some level by other members within the non-industrial private forest community. Both farm and private forest land owners are eligible to participate in NRCS conservation assistance programs. Kaetzel, Hodges, Houston, and Fly (2009) find information from government agencies and from peers, such as foresters, have a positive and significant effect on the probability of participation in conservation assistance programs.

Social networking can explain why some individuals participate in these programs, and it can also explain what barriers may inhibit participation. Breetz et al. (2005) identify that mistrust of government agencies or other regulators will hinder effective communication, and will contribute to farmers' initial unwillingness to participate in conservation programs. They also find that community or social connections such as educational and outreach approaches, third party affiliations, and awareness of existing relationships may relieve these barriers of participation.

Another strain of the previous literature, including Morton (2008), investigates how social networking promotes conservation program adoption within a community. He evaluates the roles of social pressure, internal beliefs, and knowledge play in achieving sustainable practices. Within 
this study, farmers were collectively joined at watershed level to address watershed impairment issues and the role of social networking in tackling water problems and land practices. With the creation of personal networks through community meetings, Morton (2008) identifies a connection between 'the farmers' quest for knowledge and information to make good on-farm decisions to knowledge, beliefs, and conservation ethics of others in their watershed in ways that reaffirm local practices and/or open them to new ways of doing things because of what they've learned." Knoot and Rickenbach (2011) conducted a social network analysis on landowner decisions for program enrollment in Best Management Practices. They found that program enrollees had a larger social network than non-enrollees. Pannell et al. (2006) summarize key social factors that may influence the adoption decision. These factors include the strength of landowners' networks and local organizations, physical proximity to other adopters, and physical distance to the source of information about these programs. Nearby social factors influence adoption of practices within a community framework. Cawley et al. (2018) also investigate how distance to information and additional resources influence program participation among farmers. They find distance to a local office is negatively associated with program participation.

\section{Theoretical Framework}

Social networking theory examines how individuals, organizations, or social groups interact or change their behaviors based on the actions of others within the network. This theory discusses individual interaction and the spread of information which involves channeling personal or media influence, and enabling a change in attitude or behavior (Liu et al., 2003). There has been an abundance of literature on this theory. Early work identifying the importance of social reinforcement includes the work of Leibenstein (1950). He identifies the social reinforcement effect, known as the "bandwagon effect" that recognizes how other people's actions can reinforce or influence one's choices. Social networks are motivated and driven through the maximization of one's utility based on the feeling of belonging, contributing to one's community, or dependence on the choice of others (Granovetter, 1978).

Heal and Kunreuther (2010) and Gladwell (2000) identify other social networking behaviors, such as cascading, entrapment, and tipping, that influence decision making as a community. Cascading behavior is the movement of one behavior in a group to another by a series of individual changes. As individual farmers within a community group start to implement practices on their own farms, members of that same community group could lean towards also adopting practices on their farms. Entrapment represents participation in a group or activity, even though it makes one worse off. This behavior may produce the equilibrium for the group, but not the individual. However, this environment could also make one participant better off while making everyone else worse off (Dixit, 2003). In this situation, a policy intended on helping a community could also be presenting a negative externality on the residents. Tipping is when a small group in the community moves or changes their behavior, and therefore, "tips" the equilibrium of the entire community. As community leaders start promoting and adopting conservation strategies, it becomes more attractive for other members to participate. Banerjee (1992) characterizes "herd" behavior. With this behavior, individuals will follow the actions of others in a community, instead of using their information. In a social network, individuals will make decisions as a community. 
Based on the literature, social networking influences conservation practice adoption at the individual and community level. If there is a strong social connection within a community, the decision to adopt conservation practices may be addressed by the community. We want to identify the significance of a social group, like NRCS conservation program participants, on the spatial distribution of practice application throughout the state. We hypothesize: Conservation practice adoption is a community-wide decision due to the peer influence in a community. We use spatial econometrics to control for the spatial relationships between the applied practices data, and the spatial dependence in the regional data utilized to explain the spatial distribution of these practices. Since these assistance programs are aimed to benefit farmers, we evaluate farm characteristic data to proxy for social networking characteristics. The total number of farms within a region could influence the size of the social network within a community. Social networking connections could depend on the average farm size. A community with smaller farms, closer neighbors, could have stronger social networking ties than a community of farmers with large amounts of land separating each farmer. We also test the percent of farms with internet access as a social networking explanatory variable. Farmers with internet access could have a wide-spread, virtual social network connecting them to many additional online resources provided by West Virginia NRCS assistance programs.

This study expands from this previous literature by explaining government program participation at an aggregate level (census tract) in order to assess the spatial distribution of applied conservation assistance practices while controlling for socioeconomic characteristics and land cover attributes. We assume regions with similar geographical features and socioeconomic traits will also have similar practice adoption behaviors. It is important to observe program participation at a regional level to observe the influence of social objectives, peer influence, and community collaboration. We are particularly interested in the social effects and we hypothesize social effects will influence the spatial dependence of conservation programs.

\section{Spatial Distribution of NRCS Conservation Practices}

To determine whether there is a need for controlling for social networking within our analysis, we will first identify if spatial autocorrelation exists within these data through spatial analysis techniques. Spatial autocorrelation determines whether observations in nearby regions exhibit similar attributes or characteristics to the other observations that are close by. If this correlation exists within these data, it will create a spatial bias in the analysis. Spatial econometric techniques can be implemented to control for the spatial dependence within these data. We assume social interactions and other regional factors influence spatial dependence of applied programs within a census tract.

Through spatial analysis techniques in ArcGIS, patterns of spatial clustering or dispersion within the data can be identified. In this analysis, we test global measures, such as the Average Nearest Neighbor (ANN) analysis, and local measures, such as the Getis-Ord Gi* Hot Spot analysis, to identify spatial autocorrelation in the data. If the data are spatially autocorrelated, we can control for the spatial dependency in the econometric analysis. The spatial distribution of farms within each census tract varies throughout the state; the effects of social influence also vary within a 
community. Areas with a high concentration of applied practices may have community support. Areas of isolated farmers or individuals without attachment to the land may not understand the importance of community involvement; this may lead to areas with a lower number of practices.

Figure 2-4 presents a map of the existing conservation practices throughout the state of West Virginia. From 2004 to 2015, a total of 123,659 NRCS assistance practices were implemented throughout the state. Figure 2-5 displays the regional distribution of applied practices at the census tract level ${ }^{21}$. There are 484 census tracts in the state of West Virginia. The census tract hosting the Buckeye Service Center within Pocahontas County has the highest distribution of practices.

Spatial statistics tools identifying spatial autocorrelation are utilized on the point-level data of applied practices throughout WV from 2004 to 2015. The ANN analysis is a global measure of spatial autocorrelation. This measure observes the spatial relationship as clustering, dispersed, or randomly distributed throughout the study region. This test identified a spatial clustering patterns within these data that are statistically significant at the 99 percent level. The results of this analysis are provided within the bell curve chart on the map in Figure 2-6.

The local hot spot analysis of Getis-Ord $\mathrm{G}_{\mathrm{i}}^{*}$ assesses spatial patterns at a local scale (Getis and Ord 1996; Longley and Batty 1996). Through this analysis we can identify statistically significant local "hot spots" and "cold spots" clusters throughout the state ${ }^{22}$. Hot spots are areas where there is a high density of practices clustered in a region. In these areas, we hypothesize there is more social networking activity than in the areas designated as cold spots. Cold spots are areas where there is a low density of practices clustered in a region. These results are also shown in Figure 2-6. Based on the results of the spatial autocorrelation analyses, we can reject the null hypothesis of randomly distributed patterns within these data. Spatial econometric methods will be used to account for this.

${ }^{21}$ The spatial distribution of practices could be biased as census tracts vary in shape, size, and area. For more information refer to literature discussing the modifiable areal unit problem (Wong (2009); Fotheringham and Wong (1991); and Yang (2005)).

22 The results of the hot spot analysis could be skewed due to the shape of the state. For example, the cold-spot cluster in the eastern panhandle of the state could be over-inflated due to its limitations in neighbors. For the analysis to be performed accurately, the study region would need to be a perfect square. For more information refer to previous literature discussing the modifiable areal unit problem (Wong (2009); Fotheringham and Wong (1991); and Yang (2005)). 


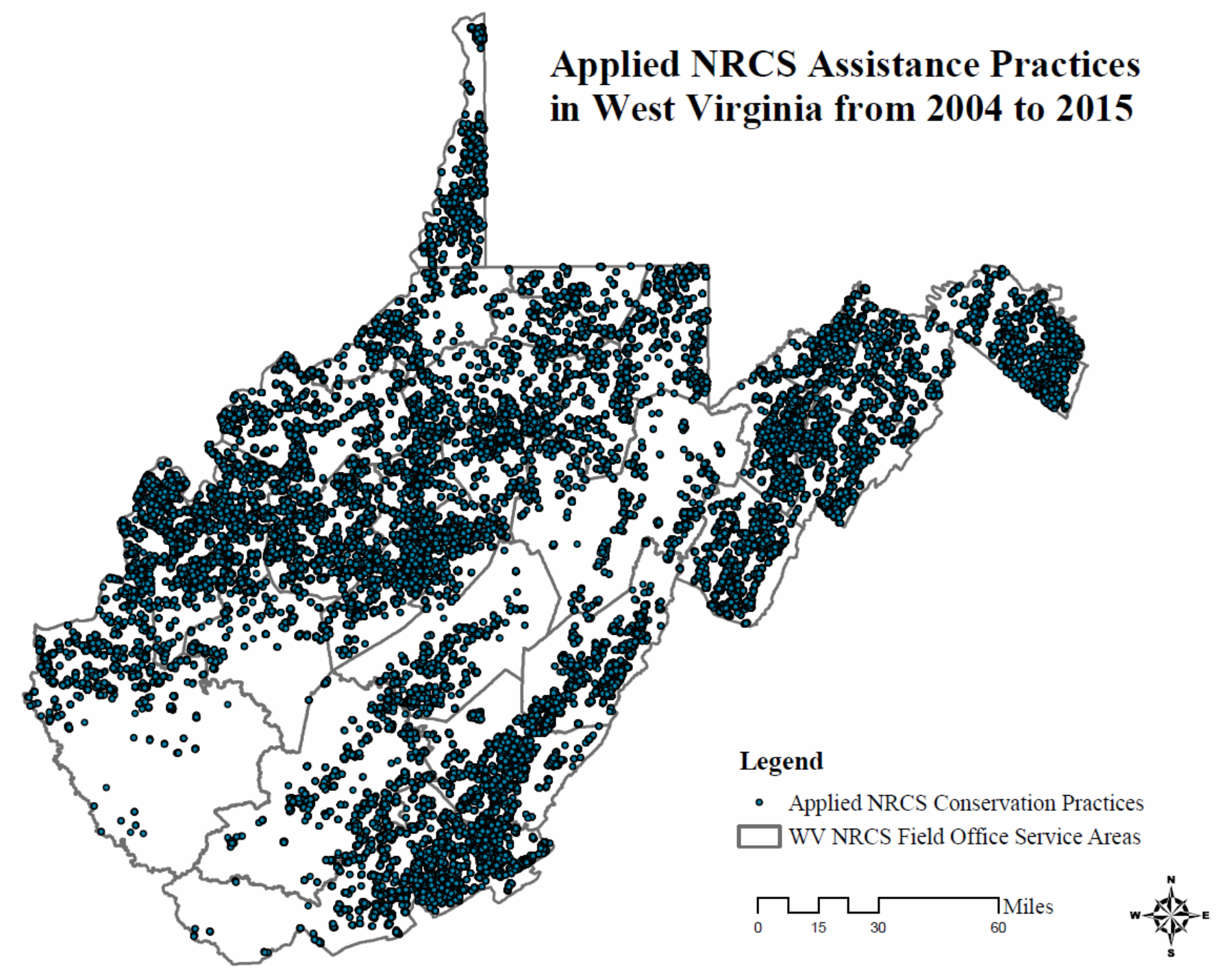

Figure 2-4: Applied NRCS Conservation Practices in WV 


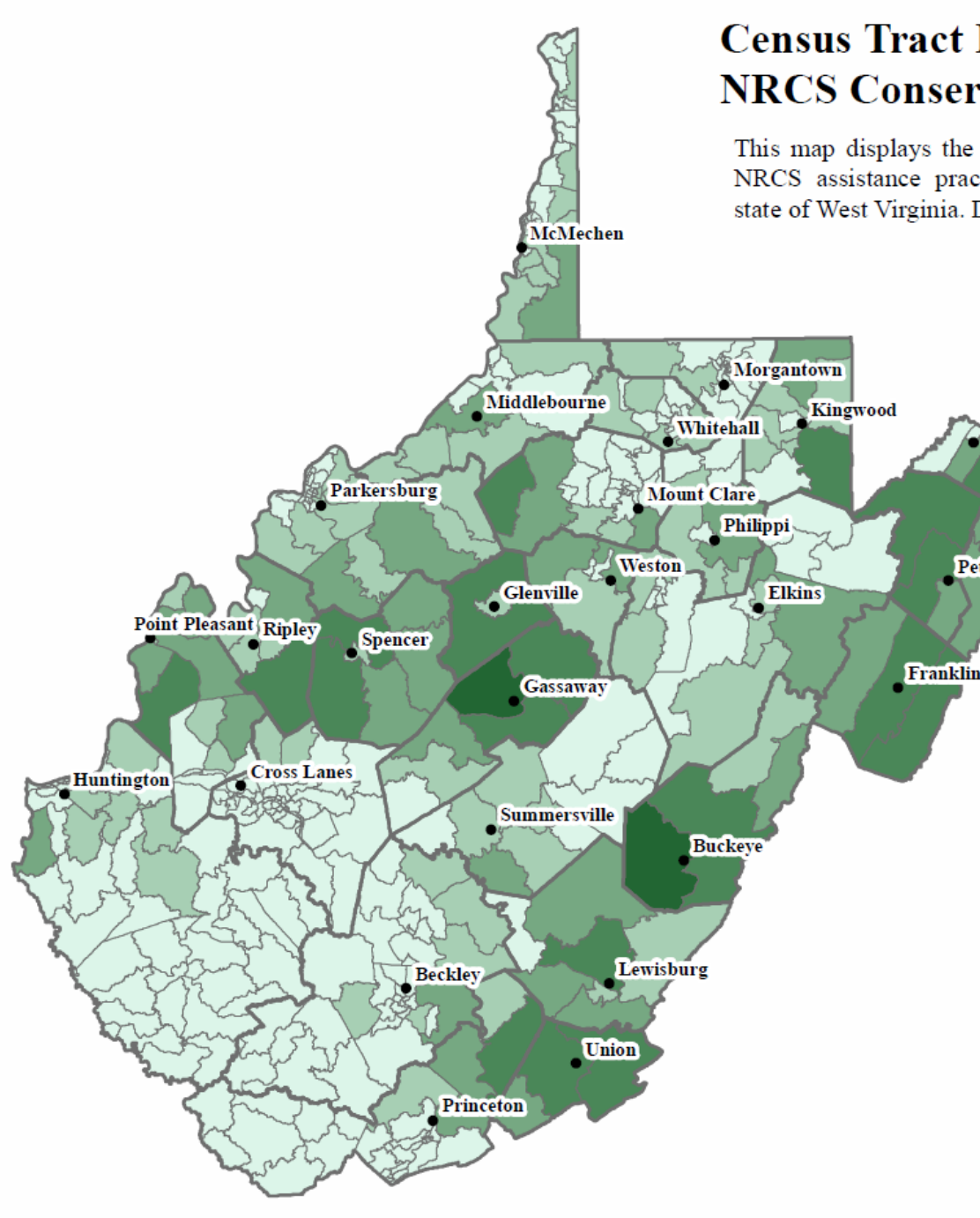

\section{Census Tract Level Distribution of RCS Conservation Practices in WV}

pisplays the census tract leveldistribution of applied RCS assistance practices from 2004-2015 throughout the .

Figure 2-5: Census Tract Level Distribution of Applied Practices

- WV NRCS Field Offices

$\square$ WV NRCS Field Office Service Areas Census Tract Distribution PRACTICES




For the Hot Spot analysis, the practices were integrated to the half mile radius. Areas with a z-score greater than 2.58 (denoted in dark red) are identified as hot spots that are statistically significant at the 99 percent level. Hot spots are clusters of high density NRCS conservation practices. Area with a $\mathrm{z}$-score lower than $\mathbf{- 2 . 5 8}$ (denoted in dark blue) are identified as statistically significant cold spots at the 99 percent level. Cold spots represent clusters of low density NRCS conservation practices.

\section{Applied NRCS Assistance Practices in West Virginia from 2004 to 2015}

The Getis-Ord Gi* Local Hot Spot Analysis was conducted on the WV

NRCS financial and technical assistance practices applied between 2004 to 2015 There were a total of 123,659 conservation practices implemented in WV.

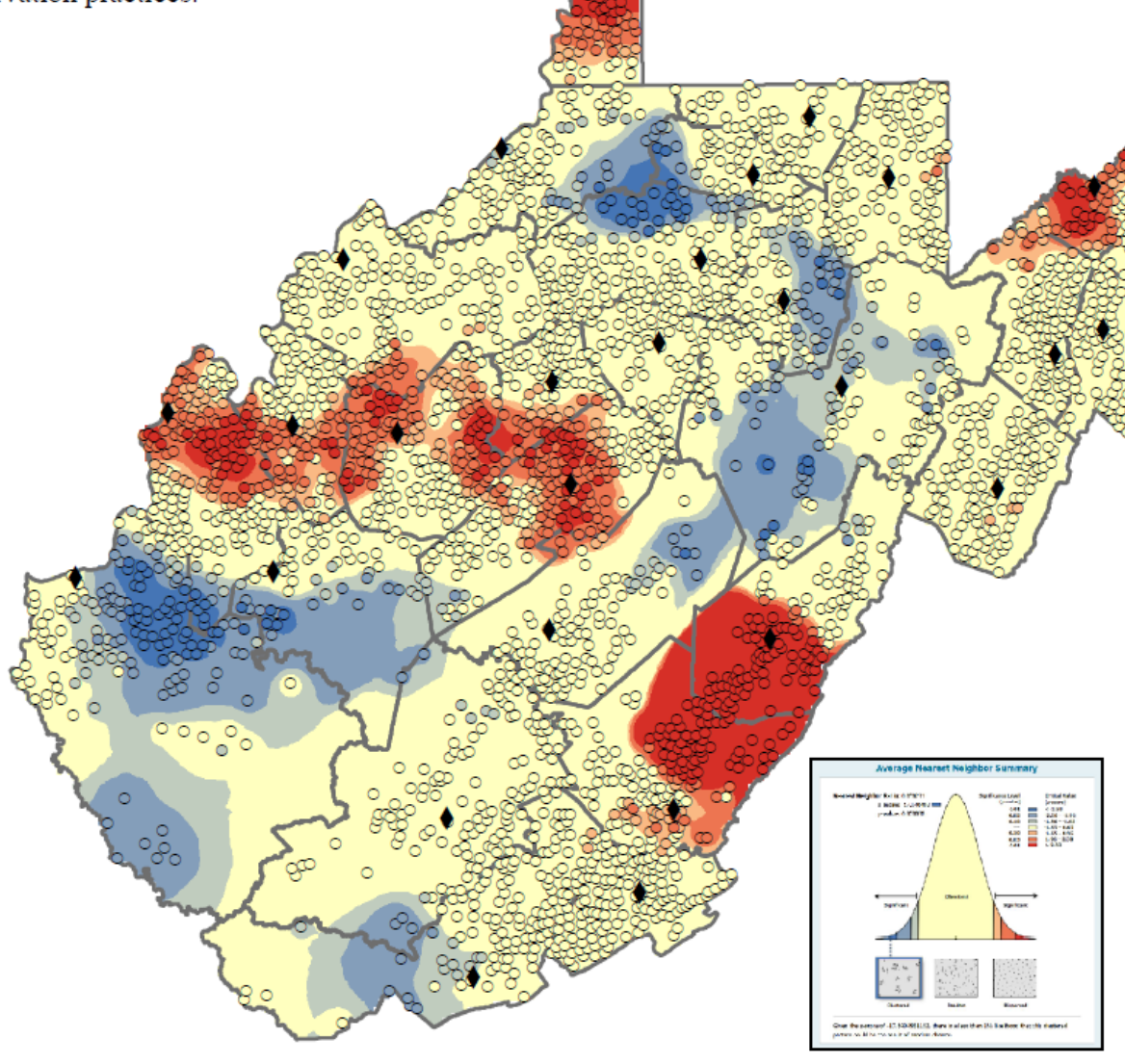

Legend

- WV NRCS Field Offices $\square$ WV NRCS Field Office Service Areas Hot Spot Analysis IDW Gi* Statisical Significance

Cold Spot - 99\% Confidence

Cold Spot - 95\% Confidence Cold Spot - $90 \%$ Confidence $\square$ Not Significant

$\square$ Hot Spot - 90\% Confidence $\square$ Hot Spot - 95\% Confidence Hot Spot - 99\% Confidence
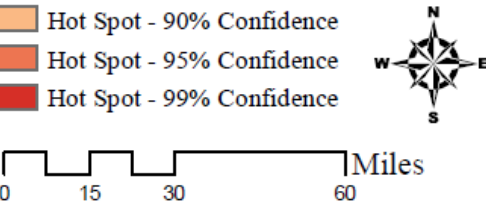


\section{Empirical Methodology and Data}

The purpose of this analysis is to explain the spatial distribution of NRCS assistance programs throughout the state of WV by identifying significant factors that influence NRCS conservation practice adoption at a regional level. Based on the spatial distribution analysis, we know the data display statistically significant clustering patterns. We believe social networking within the local communities strongly influences these clustering patterns. However, other regional attributes influence the placement of conservation practices as well. Various socioeconomic characteristics and land cover attributes are evaluated within this analysis. First, spatial econometric analyses will be conducted to identify significant variables that influence conservation practice adoption at the regional level. The spatial econometric analyses will also estimate the effects of these regional characteristics on neighboring areas. Then, based on the results of our empirical analysis, we will identify if census tracts that are overserved or underserved by their local NRCS service area field office. The model estimated for empirical analysis is below:

$$
\text { PRACTICES }=\alpha+\beta_{i} X_{i}+\varepsilon
$$

A vector of explanatory variables $(X)$ is used to predict total number of conservation practices implemented within a region. These explanatory variables include various land cover attributes and socio-economic characteristics. Data were collected from USDA, WV NRCS, US Census Bureau, National Land Cover Dataset (NLCD 2011), WV Department of Environmental Protection (DEP), WVU Natural Resource Analysis Center (NRAC), and other WV state and federal datasets. Table 2-3 provides a list of the variables used within this analysis. Summary statistics and data sources are also provided in Table 2-3.

With the NLCD 2011 data and ArcGIS we were able to determine where (land cover types) the conservation practices were most frequently implemented. Table 2-4 illustrates the share of practices implemented on each land cover type. ${ }^{23}$ Over half of the practices from 2004 to 2015 were applied on agricultural land. Therefore, we include the amount of agricultural land in each census tract as an explanatory variable. Our agricultural land observations at the census tract level are a proxy measure of pasture/hay areas and cultivated crop areas. Areas with more agricultural lands should be associated with higher levels of conservation practices.

Pannell et al. (2006) use factors including the strength of landowners' networks and local organizations, physical proximity to other adopters, and physical distance to the source of information about these programs as measures of social networking. They find the physical distance to an information source, like a local field office, is important, as more distant landholders are less likely to adopt. Information appears less relevant and less feasible due to limited exposure. There are 30 local NRCS field offices and designated service areas throughout West Virginia. Following the methods of Cawley et al. (2018) we use distance to a field office as an explanatory variable. Each NRCS field office is responsible for the census tracts within its service area. We measure the distance from the centroid of each census tract to its designated field office. We also measure the distance to the nearest farmers market, as these markets could be viewed as common

\footnotetext{
${ }^{23}$ Land cover classifications were derived from the Multi-Resolution Land Characteristics Consortium (MRLC).
} 
social networks for farmers. Distance to local field offices and farmers markets should be negatively associated with practice application within a census tract.

We include population density and the amount of developed land as measures of urbanization; more population and urban development leads to less land for rural or agricultural applications. However, higher populations could also represent more customers/participants in a region. We include other individual or household characteristics to control for regional heterogeneity. Pannell at el. (2006) have also identified a conflicting relationship between education and practice adoption. On one hand, the higher-educated individuals are more likely to adopt innovative ideas. On the other hand, limitations brought on by practice adoption may go unrecognized by less educated individuals. We include the amount of state and public land in the analysis as outreach should occur on mostly private lands. However, state-owned land does include wildlife management areas and federal land includes national forests which could lead to positive correlation with practice application. As mentioned in the introduction, surface mining has degrading effects on land and diminishes natural resources within its proximity. The amount of land impacted by surface mining within a census tract is expected to decrease the expected number of practices. Amount of agricultural land and stream miles in a census tract are attractive features for conservation practices. These features also help control for the variation in the size of the census tracts throughout WV. ${ }^{24}$ Distributing aid to areas in need while preserving land and water quality is the focus of NRCS conservation programs. This analysis evaluates whether federal assistance is indeed distributed to areas that effectively promote conservation.

Table 2-3: Summary Statistics of Census Tract Level Variables

\begin{tabular}{|c|c|c|c|c|c|c|}
\hline VARIABLES & SOURCE & COUNT & MEAN & SD & MIN & MAX \\
\hline Number of applied practices from 2004 to 2015 & WV NRCS & 484 & 255.49 & 485.82 & 0 & 4334 \\
\hline Amount of pasture land (NLCD81) and cropland (NLCD82) in square miles & NLCD 2011 & 484 & 4.42 & 7.12 & 0 & 47.28 \\
\hline Distance (in miles) to designated local NRCS field office & WV NRCS & 484 & 12.56 & 11.70 & 0.32 & 61.49 \\
\hline Distance (in miles) to nearest farmers market & USDA & 484 & 6.90 & 4.71 & 0.16 & 23.71 \\
\hline Population per square mile & US Census 2010 & 484 & 977.74 & 2016.72 & 6.10 & 29181.36 \\
\hline Percent of population with bachelors degree or more & US Census 2010 & 484 & 18.68 & 11.95 & 1.10 & 71.40 \\
\hline Percent of households below poverty level & US Census 2010 & 484 & 18.95 & 10.04 & 1.50 & 75.10 \\
\hline Percent of state-owned land & $\begin{array}{c}\text { WV State and } \\
\text { Federal Datasets }\end{array}$ & 484 & 1.28 & 3.95 & 0.00 & 45.33 \\
\hline Percent of federally-owned land & $\begin{array}{c}\text { WV State and } \\
\text { Federal Datasets }\end{array}$ & 484 & 2.93 & 10.72 & 0.00 & 80.31 \\
\hline Percent of developed land (low, medium, and high intensity) & NLCD 2011 & 484 & 19.29 & 26.50 & 0.05 & 100.00 \\
\hline Percent of total land area permitted for surface mining & WV DEP & 484 & 2.02 & 5.14 & 0.00 & 39.82 \\
\hline Total miles of $24 \mathrm{~K}$ stream length & WVU NRAC & 484 & 113.61 & 148.20 & 0.00 & 794.72 \\
\hline
\end{tabular}

${ }^{24}$ Census tracts vary is shape, size, and area. If these factors are not accounted for the results of our analysis could be biased. We attempted to include total census tract land area as a variable in the model, but major correlation issues were encountered with agricultural land and stream miles. Therefore, we include these variables to reflect the size of a census tract as well as the variable that they measure. 
Table 2-4: Distribution of Applied Practices by Land Cover Type

\begin{tabular}{|c|c|}
\hline Land Cover Class & Percent of Practices \\
\hline Agricultural (Planted/Cultivated) & 54.83 \\
\hline Forest & 34.88 \\
\hline Developed & 6.98 \\
\hline Herbaceous & 2 \\
\hline Barren & 0.69 \\
\hline Wetlands & 0.28 \\
\hline Shrubland & 0.21 \\
\hline Water & 0.14 \\
\hline
\end{tabular}

\subsection{Spatial Hierarchical Econometric Model}

To address the spatial autocorrelation identified earlier within the essay, spatial econometric models were estimated in this analysis. Five spatial econometric models were estimated to identify the direct and indirect spillover effects of factors that influence program participation. By implementing spatial econometrics, we can account for the influence of nearby regions on program participation in a census tract located within the same NRCS designated service area. A census tract level spatial weight matrix (W) is estimated as a block diagonal for each of the service areas. For example, if a census tract is located within the same service area district then it receives a value of one inside the weight matrix, zero if otherwise. Through this classification, we are able to designate census tracts can only be "neighbors" with other census tracts inside of the same service area district (not itself). This is because local field offices can only control practice adoption within census tracts in their designated service area.

We evaluate the effects of farm characteristics on conservation program participation in a region. Unfortunately, the data are only available at the county level. Due to this complication, spatial hierarchical models are implemented. A spatial hierarchical model allows us to use this countylevel data to estimate its impact on program participation at the census tract level. Raudenbush and Bryk (2002) provide the theoretical framework for hierarchical linear models. The county-level data included in this analysis were collected from the US Census of Agriculture of 2007 including: number of farms, average farm size, percent of farms with internet access, cattle sales, and poultry sales. There are 484 census tracts within the 55 counties of West Virginia.

We replicate the modeling approach of Lacombe and Flores (2017) for the Bayesian Hierarchical SLX model: ${ }^{25}$

$$
\begin{gathered}
y=X \beta+W_{1} X \theta+\Delta a+\varepsilon \\
a=Z \gamma+W_{2} Z \delta+u \\
\varepsilon \sim N\left(0, \sigma^{2} I_{n}\right) \\
u \sim N\left(0, \tau^{2} j\right)
\end{gathered}
$$

\footnotetext{
25 This type of model was first implemented in Lacombe and Flores (2017) to measure crime levels in Mexico. For further discussion of the development of the hierarchical spatial econometric models see Lacombe and McIntyre (2017).
} 
The dependent variable in our case, total number of applied practices from 2004 to 2015, is represented by $y$ which is an $N \mathrm{x} 1$ vector, and the explanatory variables, $\mathrm{X}$, are represented as an $(N \times K)$ matrix. $\mathrm{W}_{1}(\mathrm{~N} \times \mathrm{N})$ is the census tract level weight matrix, and both $\beta$ and $\theta$ are parameter vectors $(K \times 1)$ at the census tract level. $\mathrm{W}_{1} X$ is the spatially weighted exogenous explanatory variables. $\varepsilon$ is an $N \times 1$ vector of disturbances with mean 0 and variance $\sigma^{2} I n$. The symbol $\Delta$ represents an $N \times J$ (where $N$ represents the total number of observations and $J$ represents the number of groups) matrix that assigns each level 1 observation to a level 2 group. This matrix matches the census tracts with its designated county. The symbol $\alpha$ represents the $J \times 1$ vector of terms which are predicted in the level 2 model.

The dependent variable in the level 2 model, $a(Z \times 1)$ is a vector of intercepts, which is predicted by Z, a $(J \times m)$ vector of explanatory variables (including a constant) with $\gamma$ as the $(J \times m)$ vector of coefficients, $\mathrm{W}_{2}$ as the $(J \times J)$ county-level nearest-neighbor spatial weight matrix, and $\delta$ as the $(\mathrm{m}$ $\mathrm{x} 1)$ vector of spatially weighted coefficients of the explanatory variables. The vector of error ( $\mathrm{J} X$ 1 ), $u$, has a variance of $\tau^{2} j$ for the county level. We assume that $\varepsilon$ and $u$ are uncorrelated, $u$ and $X$ are uncorrelated, and $u$ and $Z$ are uncorrelated. These are the standard assumptions of the hierarchical models (Raudenbush and Bryk, 2002). Further discussion of the posterior mean estimation for the spatial hierarchical model is included within the Appendix section.

Our model is estimated through Bayesian econometric techniques, in which estimates of the parameters take place on the posterior distribution. The posterior distribution of this model is represented by the equation below. The posterior distribution is proportional to the likelihood times the hierarchical prior, times the priors for all parameters. All the priors utilized in the model are proper leading to a "fully Bayesian" analysis. ${ }^{26} \mathrm{We}$ utilize the posterior mean to interpret the level 1 effects and the level 2 effects estimated by the Bayesian econometric techniques (Lacombe and Flores (2017); and Lacombe and McIntyre (2017)).

$$
\pi(\theta, \alpha \mid y) \propto f(y \mid \theta, \alpha) f(\alpha \mid \theta) \pi(\theta)
$$

The marginal likelihood for model $\alpha$ takes the equation above where $\pi(y \mid \theta, \alpha)$ denotes the likelihood for model $\alpha$ and $f(\alpha \mid \theta)$ denotes the prior distribution for the parameters in model $\alpha$.

We estimate separate spatial hierarchical SLX models for five county-level variables: number of farms, average farm size, percent of farms with internet access, cattle sales and poultry sales. The first three variables are intended to reflect social networking effects. Total number of farms measures the size of a farmer's social network within a county. A larger social network could lead to more community engagement, and potentially more involvement in conservation programs. Average farm size represents the distance between the farmers, as larger farms would have more distant neighbors. Larger, more distant farms could lead to a weaker social connection between farmers in a county, and therefore less community involvement. However, farm size could also represent the size of farming operations within a county. Larger farms may require more assistance to maintain operations leading to higher levels of program participation. Farms with larger operations are more likely to accept federal assistance (Lambert et al., 2006). Farms with internet availability have access to more information and are more likely to adopt conservation practices.

${ }^{26}$ Full discussion of the posterior distribution for the hierarchical model is provided by Lacombe and Flores (2016). 
The final two county-level variables reflect the impact on conservation practices based on differing farming operations throughout the state. Since West Virginia agriculture is primarily based on animal agriculture, we include two measures of farm animal sales: cattle sales and poultry sales. Descriptive statistics for all five county-level variables are provided in Table 2-5.

Table 2-5: Descriptive Statistics of County Level Variables

\begin{tabular}{|c|c|c|c|c|c|}
\hline VARIABLE & COUNT & MEAN & SD & MIN & MAX \\
\hline Total number of farms & 55 & 429.42 & 261.31 & 15 & 1048 \\
\hline Average farm size in acres & 55 & 150.05 & 52.60 & 41 & 313 \\
\hline $\begin{array}{c}\text { Percent of farms with } \\
\text { internet access }\end{array}$ & 55 & 60.91 & 1.16 & 44.44 & 100 \\
\hline $\begin{array}{c}\text { Cattle including calf sales, } \\
\text { measured in million \$USD }\end{array}$ & 55 & 2.93 & 3.70 & 0 & 19.84 \\
\hline $\begin{array}{c}\text { Poultry including eggs sales, } \\
\text { measured in million \$USD }\end{array}$ & 55 & 5.48 & 21.62 & 0 & 137.34 \\
\hline
\end{tabular}

Data were collected from the US Census of Agriculture of 2007.

We believe local spillover effects are more appropriate for our research question as practice adoption in the southern part of the state will be heterogenous to that in the northern panhandle. Since there are only 55 counties in the state of West Virginia, we estimated the effects of each level 2 variable in separate regressions. We employ the Deviance Information Criterion (DIC), developed by Spiegelhalter et al. (2002), to identify the appropriate spatial weight matrix for each of the county level variables. The DIC value also identifies the superior model of the five estimated hierarchical SLX models. The model with the lowest DIC value identifies the model of best fit, which is the model estimated with cattle sales as the level 2 variable.

\section{Spatial Hierarchical Model Results}

We implement the service area spatial weight matrix as discussed previously for the level 1 (census tract) estimates. For the level 2 (county) estimates we used the nearest-neighbor spatial weight matrix. The appropriate number of "neighbors" for each level 2 variable was identified through the calculation of the DIC value. The results of the spatial hierarchical models remain relatively consistent. The model estimating cattle sales was identified as the superior model as it has the lowest DIC value estimate of the five spatial hierarchical models. ${ }^{27}$

For the Bayesian analysis, the $95 \%$ credible intervals for all the parameters estimated in this model were identified. If the interval does not contain zero, then the parameter is statistically significant and helps to explain the variation in the dependent variable.

\subsection{Spatial Hierarchical Econometric Model Level 1 Effects}

Level 1 results are displayed in Table 2-6. As mentioned above, the results of level 1 effects for the five models are consistent. Given that the cattle sales model was identified as the superior model, the following focuses on the level 1 effect estimates for that model.

\footnotetext{
${ }^{27}$ We utilize the Gibbs sampling algorithm to cycle through each conditional distribution for each of the parameters. We run 100,000 iterations with the first 50,000 as the 'burn-in' process, leaving the remaining 50,000 iterations.
} 
For the level 1 estimates, agricultural land, distance to field office, and stream mileage had statistically significant direct effect estimates. As the amount of agricultural land within a census tract increases by one square mile, the number of applied practices within the census tract should increase by about 37 practices. The more agricultural land within a census tract, the more land opportunities for practice adoption. ${ }^{28}$ For every additional mile away from the designated field office, the number of applied practices within the census tract decreases by four practices. This makes sense as farmers are more likely to adopt practices if access to assistance through the local office is nearby and/or easily accessible. As the total number of stream miles in a census tract increases by 10 miles, the expect number of practices with the census tract will increase by about 8 practices. Based on this estimate, we can say NRCS is motivated to implement conservation practices at sites to protect water quality. Prescribed grazing and nutrient management are the most adopted practices in the state of West Virginia. Both practices try to protect/improve stream water quality. Prescribed grazing can improve water infiltration, protect stream banks from erosion, and manage animal waste material away from water bodies. Nutrient management optimizes the placement of fertilizers to maximize the protection of local air quality, soil quality, and water quality.

With the indirect effects, we can identify which attributes affect not only practice application within the same census tract, but also how those attributes effect practice application in nearby tracts. The explanatory variables agricultural land, distance to field office, state-owned land, federally-owned land, developed land, and permitted surface mining have statistically significant indirect (spillover) effects. The amount of agricultural land and distance to the designated field office within a census tract creates a competitive effect on practice adoption in surrounding census tracts. If the amount of agricultural land in a census tract increases by 1 sq. mi., the number of practices in neighboring census tracts will decrease by 20 practices. As the distance to the designated field office increases by one mile within a census tract, the number of applied practices in surrounding census tracts increases by about 14 practices. These neighboring census tracts could be closer to the field office, and therefore may receive more attention by NRCS.

Since practices are mostly adopted on private land, the percent of federally-owned land within a census tract increases the number of practices within surrounding census tracts. If the amount of federally-owned land were to increase by one percent in a census tract, the number of practices applied in nearby census tracts appears to increase by 11 practices. Even though the direct effect is not statistically significant, state-owned land has negative direct and indirect effects on practice adoption. The percent of developed land within a census tract decreases the amount of conservation practices applied in the nearby census tracts. A one percent increase in developed land indicates a decrease of about 19 practices in surrounding census tracts. This may be an indication that NRCS conservation practices are less likely to be applied around urban census tracts. Urbanized census tracts have smaller amount of land area, since the area of a census tract is designated by population size. There is a limit on the amount of land within a census tract. As the share of public, developed land increases within a census tract, it restricts the amount of land that could be used to implement conservation practices. The percent of surface mined area within a

\footnotetext{
${ }^{28}$ This effect may be considered smaller than expected but this could be because practices are installed in other land cover types such as forest areas. Other land cover types would be highly correlated with agricultural land and therefore are not included within this analysis.
} 
census tract also has a negative indirect effect. As the amount of surface mining area increases by one percent in a census tract, the expected number of practices within nearby census tracts will decrease by 56 practices. Our interpretation of this impact is based on the very small distribution of practices in the areas where surface mining has occurred. Land impacted by surface mining does not provide opportunities for conservation practice adoption as the resources of the land have already been degraded.

The total effect can have varying interpretations. In this analysis, we will identify how attributes within a census tract influence the number of applied practices within the total region. Total effects are estimated as the sum of the direct and indirect effects. The explanatory variables-- agricultural land, state-owned land, federally-owned land, developed land, surface mining, and stream mileage --have statistically significant total effects on the region. The amount of agricultural land, share of federally-owned land and stream mileage have positive total effects. Share of state-owned land, developed land and surface mining have negative total effects. As the amount of agricultural land increases by 1 sq. mile in a census tract, practice adoption will increase by 16 practices in the total region. As stream mileage in a census tract increases by one mile, the total number of conservation practices in the total region will increase by one practice as well. Agricultural land and stream mileage are statistically significant, contributing to conservation practice adoption in West Virginia. As the amount of developed land increases within a census tract by one percent, practice adoption for the entire region will decrease by 19 practices. As the percent of land degraded by surface mining in a census tract increases by one percent, the expected number of practices in the total region will decrease by 60 practices. Surface mining is also a statistically significant, constricting component for conservation practice adoption. The share of public land throughout the state restricts the land available for conservation practice adoption. Land cover attributes with a negative relationship have a larger impact on practice adoption, than the effect of the attributes with a positive relationship.

\subsection{Spatial Hierarchical Econometric Model Level 2 Effects}

Lacombe and Flores (2017) state the benefit of a hierarchical model is the estimation of level 2 covariates which provides more interpretation than standard models with fixed-effects. With this model, we can also identify the significant direct, indirect, and total effects of these variables. In this analysis, we evaluate the influence of farm characteristic data on program participation. Knowler and Bradshaw (2007) create a synthesis of recent research on farmers' adoption of conservation agriculture. They identify farm size and dairy farms were significant attributes of conservation practice adoption. They also indicate farm tenure influences conservation practice adoption. We also utilize farm characteristics as a proxy for social influence on program participation. The number of farms, average farm size, percent of farms with internet access, and size of farming operations (cattle sales and poultry sales) within a county were estimated as the level 2 variables. Results of the coefficient estimates for the level 2 effects of each model are displayed in Table 2-7.

The number of farms within a county has positive direct, indirect, and total effects on conservation program participation. With an increase in the number of farms within a county, there exists a larger social network of farmers and a larger social network could lead to more community engagement, and more involvement in conservation programs. The indirect effects and total effects are statistically significant at the 95 percent confidence interval. A growth in the number of farms 
within a county creates a stronger social networking connection across county borders. This will increase the level of conservation practices implemented in surrounding counties. As the total number of farms increases by ten farms within a county, it is associated with an increase of three practices in surrounding counties or four additional practices for the total region.

Average farm size has positive direct, indirect, and total effects on the number of conservation practices at the county level. Larger farms may require more federal assistance to maintain operations leading to higher levels of program participation. Farms with larger operations may also rely on the advice of peers for successful operations. Average farm size has a statistically significant total effect on conservation practice adoption. On average, every square mile increase in farm size is associated with one additional practice in the total region.

Farms with internet access have access to more information and are more likely to adopt conservation practices. Internet access extends information availability and social connections beyond the face-to-face social networking aspect. Internet access has positive direct, indirect, and total effects on conservation practice adoption at the county level. Internet access has a statistically significant total effect. Every one percent increase in farms with internet access is associated with an increase of four conservation practices in the total region.

Farms with larger operations are more likely to accept federal assistance (Lambert et al. (2006). Since farming operations vary throughout the state we include two types of farm sales. We measure cattle sales and poultry sales at the county level. Based on the DIC values estimated within the spatial hierarchical SLX models, the model with the cattle sales as the level 2 variable was the superior model. Cattles sales, measured in millions of dollars, have positive direct, indirect, and total effects on the number of practices applied in a county. The total effect is statistically significant at the 95 percent level. The magnitude of farm operations influences conservation practice adoption in West Virginia. As cattle sales within county increases by one million dollars, it is associated with an increase of 31 additional conservation practices within the total region. Even though poultry sales are significantly larger than cattle sales in WV, cattle sales have a larger influence on conservation practice adoption as it requires more resources such as more land. Poultry sales, measured in millions of dollars, has positive direct, indirect, and total effects on the number of practices applied in a county. The total effect is statistically significant at the 95 percent confidence interval. As poultry sales within county increases by one million dollars, it's associated with an increase of 5 conservation practices within the region.

Based upon these level 2 results, we find some evidence from the farm count, farm size, and internet models that as social networks for farmers within a community grow, the community is more likely to work together to achieve conservation goals. A stronger, more supported social network will have positive total effects on conservation program participation at the county level.

\section{Evaluation of Underserved and Overserved Census Tracts}

By normalizing the residuals of the spatial models, census tracts were identified as overserved or underserved in terms of applied conservation practices. A consolidated residual value estimate was used to categorize census tracts as overserved or underserved by their designated NRCS field office, results are displayed in the map in Figure 2-7. Classification process of each census tract in West Virginia is based on an aggregated residual value and is described below: 
If the residual value was positive (greater than zero), then the actual number of practices was greater than the predicted number of practices, then the census tract was designated as an overserved area for conservation practices. Areas that are designated as overserved might be more sensitive to social objectives. These areas may focus their collaboration efforts towards achieving environmental and community needs. In Figure 2-7, overserved areas are designated in red. If the residual value was negative (less than zero), then the actual number of practices was less than the predicted number or practices, then the census tract was designated as an underserved area. These underserved areas are not meeting the needs of the community and therefore, may have a weak social networking foundation. On the other hand, regions that have more applied practices than the predicted number of practices for their region are categorized as overserved by their local service area field office. In Figure 2-7, underserved areas are designated in blue. Understanding which areas are underserved will provide NRCS with target outreach areas for the future.

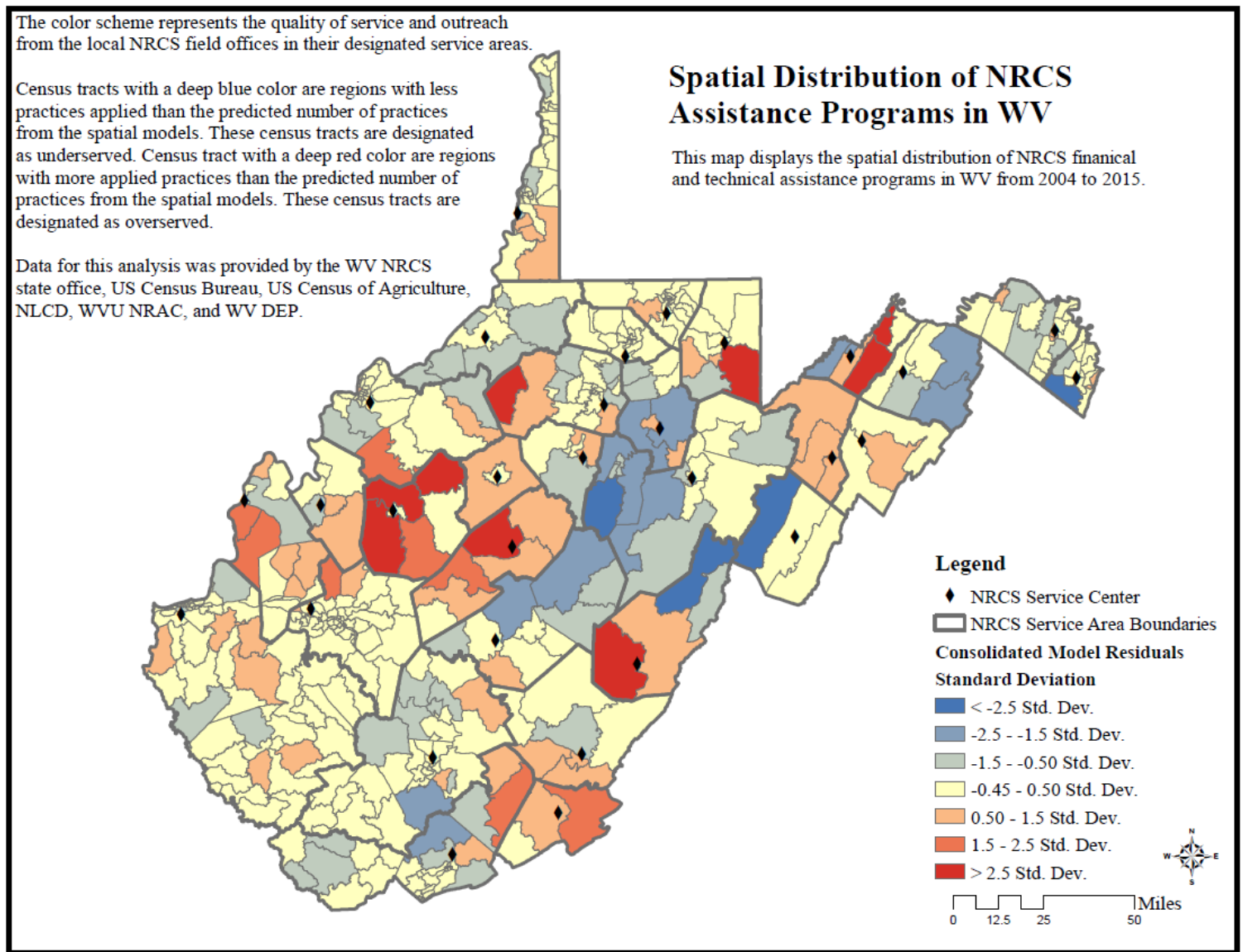

Figure 2-7: Spatial Distribution of WV NRCS Financial and Technical Assistance Practices 
Table 2-6: Level 1 Coefficient Estimates for Spatial Hierarchical Models

\begin{tabular}{|lcrr|}
\hline NUMBER OF FARMS MODEL & $\begin{array}{c}\text { DIRECT EFFECTS } \\
\text { Posterior Mean }\end{array}$ & $\begin{array}{c}\text { INDIRECT EFFECTS } \\
\text { Posterior Mean }\end{array}$ & $\begin{array}{c}\text { TOTAL EFFECTS } \\
\text { Posterior Mean }\end{array}$ \\
\hline Amount of agricultural land & $37.0189 * *$ & $-20.2214 * *$ & $16.7976 * *$ \\
Distance to designated NRCS field office & $-4.5765 * *$ & $15.6796 * *$ & 11.1031 \\
Distance to nearest farmers market & 0.5786 & -13.6382 & -13.0595 \\
Population density & -0.0002 & 0.2082 & 0.208 \\
Percent of population with bachelors degree & 0.059 & -6.6174 & -6.5584 \\
Percent of households below poverty level & -0.5447 & -1.0034 & -1.548 \\
Percent of state-owned land & -1.6093 & $-32.758 * *$ & $-34.3673 * *$ \\
Percent of federally-owned land & -1.2527 & $10.5379 * *$ & $9.2852 * *$ \\
Percent of developed land & -0.3315 & $-18.6705 * *$ & $-19.002 * *$ \\
Percent of land permitted for surface mining & -4.3987 & $-54.1457 * *$ & $-58.5444 * *$ \\
Total stream length & $0.8144 * *$ & 0.2771 & $1.0915 * *$ \\
\hline
\end{tabular}

\begin{tabular}{|lccc|}
\hline AVERAGE FARM SIZE MODEL & DIRECT EFFECTS & INDIRECT EFFECTS & TOTAL EFFECTS \\
Level 1 Variable Estimates & Posterior Mean & $\begin{array}{c}\text { Posterior Mean } \\
\text { Posterior Mean }\end{array}$ \\
\hline Amount of agricultural land & $36.9682 * *$ & $-20.0233 * *$ & $16.9449 * *$ \\
Distance to designated NRCS field office & $-4.4782 * *$ & 12.7002 & 8.222 \\
Distance to nearest farmers market & -0.0396 & -14.0927 & -14.1323 \\
Population density & 0.0005 & 0.1717 & 0.1722 \\
Percent of population with bachelors degree & -0.0878 & -8.3146 & -8.4023 \\
Percent of households below poverty level & -0.6291 & -1.7728 & -2.4019 \\
Percent of state-owned land & -1.3471 & -30.5591 & -31.9063 \\
Percent of federally-owned land & -1.0768 & $11.3449 * *$ & $10.2681 * *$ \\
Percent of developed land & -0.3509 & $-16.0926 * *$ & $-16.4435 * *$ \\
Percent of land permitted for surface mining & -4.4463 & $-56.9974 * *$ & $-61.4437 * *$ \\
Total stream length & $0.8082 * *$ & 0.2025 & $1.0107 * *$ \\
\hline
\end{tabular}

\begin{tabular}{|lccc|}
\hline FARMS WITH INTERNET ACCESS MODEL & $\begin{array}{c}\text { DIRECT EFFECTS } \\
\text { Posterior Mean }\end{array}$ & $\begin{array}{c}\text { INDIRECT EFFECTS } \\
\text { Posterior Mean }\end{array}$ & $\begin{array}{c}\text { TOTAL EFFECTS } \\
\text { Posterior Mean }\end{array}$ \\
\hline Amount of agricultural land & $37.0987 * *$ & $-20.045 * *$ & $17.0537 * *$ \\
Distance to designated NRCS field office & $-4.5435 * *$ & $14.3521 * *$ & 9.8087 \\
Distance to nearest farmers market & 0.123 & -12.3347 & -12.2117 \\
Population density & 0 & 0.1833 & 0.1833 \\
Percent of population with bachelors degree & -0.0499 & -6.9308 & -6.9807 \\
Percent of households below poverty level & -0.5719 & -0.869 & -1.4409 \\
Percent of state-owned land & -1.0966 & -28.7108 & -29.8074 \\
Percent of federally-owned land & -1.2744 & $10.6484 * *$ & $9.374 * *$ \\
Percent of developed land & -0.3393 & $-17.0138 * *$ & $-17.3531 * *$ \\
Percent of land permitted for surface mining & -4.2837 & $-52.1801 * *$ & $-56.4638 * *$ \\
Total stream length & $0.8148 * *$ & 0.259 & $1.0738 * *$ \\
\hline
\end{tabular}

\begin{tabular}{|c|c|c|c|}
\hline TOTAL CATTLES SALES MODEL & DIRECT EFFECTS & INDIRECT EFFECTS & TOTAL EFFECTS \\
\hline Level 1 Variable Estimates & Posterior Mean & Posterior Mean & Posterior Mean \\
\hline Amount of agricultural land & $36.9238 * *$ & $-20.4954 * *$ & $16.4283 * *$ \\
\hline Distance to designated NRCS field office & $-4.6276 * *$ & $14.0533 * *$ & 9.4256 \\
\hline Distance to nearest farmers market & 0.2 & -16.0305 & -15.8305 \\
\hline Population density & 0.0014 & 0.2023 & 0.2037 \\
\hline Percent of population with bachelors degree & -0.0554 & -8.8645 & -8.9199 \\
\hline Percent of households below poverty level & -0.5966 & -2.4175 & -3.014 \\
\hline Percent of state-owned land & -1.7403 & $-34.1614 * *$ & $-35.9017 * *$ \\
\hline Percent of federally-owned land & -1.1411 & $11.7098 * *$ & $10.5687 * *$ \\
\hline Percent of developed land & -0.4806 & $-18.5343 * *$ & $-19.0149 * *$ \\
\hline Percent of land permitted for surface mining & -4.4749 & $-56.0609 * *$ & $-60.5358 * *$ \\
\hline Total stream length & $0.8186 * *$ & 0.2137 & $1.0323 * *$ \\
\hline TOTAL POULTRY SALES MODEL & DIRECT EFFECTS & INDIRECT EFFECTS & TOTAL EFFECTS \\
\hline Level 1 Variable Estimates & Posterior Mean & Posterior Mean & Posterior Mean \\
\hline Amount of agricultural land & $36.6437 * *$ & $-20.5703 * *$ & $16.0734 * *$ \\
\hline Distance to designated NRCS field office & $-4.6982 * *$ & 13.4614 & 8.7631 \\
\hline Distance to nearest farmers market & 0.5144 & -14.915 & -14.4006 \\
\hline Population density & 0.0024 & 0.2158 & 0.2181 \\
\hline Percent of population with bachelors degree & -0.126 & -10.3449 & -10.4709 \\
\hline Percent of households below poverty level & -0.717 & -0.9266 & -1.6436 \\
\hline Percent of state-owned land & -1.9196 & $-35.8438 * *$ & $-37.7634 * *$ \\
\hline Percent of federally-owned land & -1.0942 & $12.5352 * *$ & $11.4409 * *$ \\
\hline Percent of developed land & -0.507 & $-19.4508 * *$ & $-19.9578 * *$ \\
\hline Percent of land permitted for surface mining & -4.637 & $-54.8886 * *$ & $-59.5256 * *$ \\
\hline Total stream length & $0.8199 * *$ & 0.1648 & $0.9847 * *$ \\
\hline
\end{tabular}


Table 2-7: Level 2 Estimates for Spatial Hierarchical Models

\begin{tabular}{|lc|}
\hline NUMBER OF FARMS MODEL & LEVEL 2 EFFECTS \\
Variable Estimates & Posterior Mean \\
\hline Constant & 18.6212 \\
Direct Effect & 0.1753 \\
Indirect Effect & 0.3184 ** \\
Total Effect & $0.4937 * *$ \\
\hline
\end{tabular}

2-nearest neighbors spatial weight matrix was implemented.

DIC value: 340801.1608

\begin{tabular}{|lc|}
\hline AVERAGE FARM SIZE MODEL & LEVEL 2 EFFECTS \\
Variable Estimates & Posterior Mean \\
\hline Constant & 7.7566 \\
Direct Effect & 0.6352 \\
Indirect Effect & 0.9824 \\
Total Effect & $1.6176 * *$ \\
\hline
\end{tabular}

2-nearest neighbors spatial weight matrix was implemented.

DIC value: 340723.499

\begin{tabular}{|lr|}
\hline FARMS WITH INTERNET ACCESS MODEL & $\begin{array}{r}\text { LEVEL 2 EFFECT } \\
\text { Variable Estimates }\end{array}$ \\
\hline Constant & 1.0873 \\
Direct Effect & 0.5623 \\
Indirect Effect & 3.5303 \\
Total Effect & $4.0926 * *$ \\
\hline
\end{tabular}

5-nearest neighbors spatial weight matrix was implemented.

DIC value: 340939.5694

\begin{tabular}{|lc|}
\hline TOTAL CATTLE SALES MODEL & LEVEL 2 EFFECTS \\
Variable Estimates & Posterior Mean \\
\hline Constant & 60.9054 ** \\
Direct Effect & 14.7148 \\
Indirect Effect & 16.7432 \\
Total Effect & $31.4579 * *$ \\
\hline
\end{tabular}

2-nearest neighbors spatial weight matrix was implemented.

DIC value: 340597.9546

\begin{tabular}{|lc|}
\hline TOTAL POULTRY SALES MODEL & LEVEL 2 EFFECTS \\
Variable Estimates & Posterior Mean \\
\hline Constant & 77.1697 \\
Direct Effect & 0.9635 \\
Indirect Effect & 4.5445 \\
Total Effect & $5.508 * *$ \\
\hline
\end{tabular}

4-nearest neighbors spatial weight matrix was implemented.

DIC value: 340615.8522 


\section{Conclusions}

This essay highlights the spatial dependence of participation in NRCS assistance programs. This is important because spatial dependence within these data may be related to the quality of social networking within agricultural communities. The results of our spatial analysis indicate statistically-significant spatial dependence within the applied assistance programs from 2004 to 2015. The results suggest it is important to observe program participation at a regional level to account for social networking and community collaboration. Spillover effects of various land attributes cover attributes play significant roles in the application of conservation programs. We incorporate spatial econometrics models to control for the spatial dependence within the applied practices data and the explanatory variables.

We include factors that evaluate peer influence and other social networking factors on conservation practice adoption. We use farm characteristics as proxies for social networking at the regional level. The total number of farms within a county represents a potential size of the social network within the region. It is associated with a positive effect on conservation practices in neighboring counties and a positive total effect within a region. Average size of a farm within a county represents the size of farming operations. It is associated with a positive total effect on conservation practice adoption. Larger farming operations increase the need of federal assistance. It could also require farmers to depend on the resources and knowledge of others. We also measure the percent of farms with internet access within a county. This variable represents the information availability beyond the face-to-face social networking aspect. Internet access has a positive total influence on the number of applied practices over an entire region. In summary, we find that factors representing stronger social networks of farmers have positive total effects on conservation practice adoption for the state.

Lastly, we include cattle sales and poultry sales as measures of farming operations to reflect different farm production types which require different resources and have different conservation practice needs. Cattle sales and poultry sales within a county are associated with increased conservation practices in the total region. Cattle sales has a larger impact on practice adoption as cattle operations requires more conservation resources than poultry (which tend to be confined production operations).

From the spatial econometric census tract level (level 1) analysis, the amount of agricultural land, federally-owned land, and stream mileage have positive total effects. The number of practices applied in a census tract are constrained by the amount and quality of the land available within the same census tract as well as the amount of land available for conservation practice application within the surrounding census tracts of the same service area.

Variables for the distance to the designated local NRCS field office, percentage of state-owned land, percentage of developed land and percentage of surface mined land have negative total effects. These results indicate NRCS is strategically targeting areas to promote efficient farm management techniques and to protect stream water quality. The negative spillover effect of surface mining discourages practice implementation within surface-mined affect areas in the census tract and the neighboring areas. Distance to an NRCS field office influences practice adoption within a census tract. Access to information and nearby resources has a significant effect on conservation practice adoption. 
This research was the first phase of a two-phase project. The results from the spatial econometric analysis we used to evaluate the quality of service received in each census tract. By identifying census tracts that are underserved and overserved by the local NRCS service area field offices, we can identify regions throughout the state for future outreach target areas.



Figure 2-8: Selected Areas for Future Outreach Efforts

One of the end results of phase one was a December 2016 meeting between WV NRCS State Administrators, and WVU researchers. In this meeting, the assessment of the spatial distribution of NRCS conservation assistance practices was reviewed. Based on identification of underserved regions, five areas have been selected as focus for the second phase of the study (Figure 2-8).

Figure 2-8 illustrates the areas for future outreach, and further examination in phase two of the cooperative agreement between WV NRCS and West Virginia University. Focus areas selected include the Southern Conservation District, the West Fork Conservation District, the Buckeye Service Area, the Keyser Service Area, and the Romney Service Area. The West Fork Conservation District and the Hampshire Service Area were selected due to their high magnitude of underserved areas. The Southern Conservation District, Pocahontas Service Area, and the Mineral Service Area were selected due to the variation in the quality of service throughout their region by the local field offices. The second phase will involve working with farming and landowner communities to implement outreach plans or marketing strategies to increase involvement and awareness of conservation services provided by NRCS.

These results are useful in understanding how federal assistance is distributed within a region. Additionally, we evaluate whether the assistance is meeting the needs and addressing the concerns of a region at the local level. Local communities that are considered underserved by these federal programs are potential target areas for future outreach. 


\section{References}

Banerjee, A. V. 1992. “A Simple Model of Herd Behavior”. The Quarterly Journal of Economics 107(3): 797-817.

Bernhardt, E. S., B. D. Lutz, R.S. King, J. P. Fay, C. E. Carter, A. M. Helton, D. Campagna, and J. Amos. 2012. "How many mountains can we mine? Assessing the regional degradation of central Appalachian rivers by surface coal mining." Environmental Science \& Technology 46(15): 8115-8122.

Breetz, H. L., K. Fisher-Vanden, H. Jacobs, and C. Schary. 2005. "Trust and communication: mechanisms for increasing farmers' participation in water quality trading." Land Economics 81(2): 170-190.

Butler, B. J., E. C. Leatherberry, and M. S. Williams. 2005. "Design, implementation, and analysis methods for the National Woodland Owner Survey."

Cawley, A., C. O'Donoghue, K. Heanue, R. Hilliard, and M. Sheehan. 2018. "The Impact of Extension Services on Farm-Level Income: An Instrumental Variable Approach to Combat Endogeneity Concerns." Applied Economic Perspectives and Policy.

Dixit, A.K. 2003. "Clubs with entrapment.” American Economic Review 93(5): 1824-1829.

Elhorst, J. P. 2010. "Applied Spatial Econometrics: Raising the Bar." Spatial Economic Analysis 5(1): 9-28.

Fotheringham, A. S., and D. W. S. Wong. 1991. "The Modifiable Areal Unit Problem in Multivariate Statistical Analysis". Environment and Planning A: Economy and Space 23 (7): 1025-1044.

Getis, A., and J. K. Ord. 1996. "Local Spatial Statistics: An Overview." Spatial analysis: modelling in a GIS environment 374.

Gladwell, M. 2000. The Tipping Point: How Little Things Can Make a Big Difference. New York, NY: Little, Brown and Company.

Granovetter, M. 1978. "Threshold models of collective behavior." American Journal of Sociology 83(6): 1420-1443.

Heal, G., and H. Kunreuther. 2010. "Social reinforcement: Cascades, entrapment, and tipping." American Economic Journal: Microeconomics 2(1): 86-99.

Heckman, J. J., and J. A. Smith. 2003. "The determinants of participation in a social program: evidence from a prototypical job training program." Cambridge, Mass: National Bureau of Economic Research.

James, A., and D. Aadland. 2011. The curse of natural resources: An empirical investigation of US counties. Resource and Energy Economics 33(2): 440-453. 
Kaetzel, B. R., D. G. Hodges, D. Houston, and J. M. Fly. 2009. "Predicting the Probability of Landowner Participation in Conservation Assistance Programs: A Case Study of the Northern Cumberland Plateau of Tennessee". Southern Journal of Applied Forestry 33(1): 5-8.

Knoot, T. G., and M. Rickenbach. 2011. "Best management practices and timber harvesting: the role of social networks in shaping landowner decisions." Scandinavian Journal of Forest Research 26(2): 171-182.

Knowler, D., and B. Bradshaw. 2007. "Farmers' adoption of conservation agriculture: A review and synthesis of recent research." Food policy 32(1): 25-48.

Lacombe, D. J., and M. Flores. 2017. "A hierarchical SLX model application to violent crime in Mexico." The Annals of Regional Science 58(1): 119-134.

Lacombe, D. J., and S. G. McIntyre. 2017. "Hierarchical Spatial Econometric Models in Regional Science." Regional Research Frontiers 2: 151-167. Springer, Cham.

Lambert, D., P. Sullivan, R. Claassen, and L. Foreman. 2006. "Conservation-compatible practices and programs: who participates?" [Washington, D.C.]: United States Dept. of Agriculture, Economic Research Service.

Leibenstein, H. 1950. "Bandwagon, snob, and Veblen effects in the theory of consumers' demand." The Quarterly Journal of Economics 64(2): 183-207.

LeSage, J. P. 2014."What Regional Scientists Need to Know About Spatial Econometrics." The Review of Regional Studies 44(1): 13-32.

LeSage, J. P., and R. K. Pace. 2009. Introduction to Spatial Econometrics. CRC Press.

Liu, W., A. Sidhu, A. M. Beacom, and T. W. Valente. 2003. "Social network theory." The International Encyclopedia of Media Effects.

Longley, P. A., and M. Batty. ed.1996. Spatial analysis: Modelling in a GIS environment. John Wiley \& Sons, Inc.

Ma, S., S. M. Swinton, F. Lupi, and C. B. Jolejole. "Why Farmers Opt Not to Enroll in Paymentfor-Environmental-Services Programs." In Selected Paper prepared for presentation at the Agricultural \& Applied Economics Association's 2010 AAEA, CAES, \& WAEA Joint Annual Meeting in Denver, July 25-July 27, 2010.

Morton, L. W. 2008. "The role of civic structure in achieving performance-based watershed management." Society and Natural Resources 21(9): 751-766.

Palmer, M. A., E. S. Bernhardt, W. H. Schlesinger, K.N. Eshleman, E. Foufoula-Georgiou, M.S. Hendryx, A.D. Lemly, G.E. Likens, O.L. Loucks, M.E. Power, P.S. White and P.R. Wilcock. 2010. "Mountaintop mining consequences." Science 327(5962): 148-149. 
Pannell, D. J., G. R. Marshall, N. Barr, A. Curtis, F. Vanclay, and R. Wilkinson. 2006. "Understanding and promoting adoption of conservation practices by rural landholders." Animal Production Science 46 (11): 1407-1424.

Phillips, T. Ian. 1985. The Development of Methodologies for the Determination and Facilitation of Learning for Dairy Farmers. University of Melbourne, Melbourne.

Raudenbush, S. W., and Bryk, A. S. 2002. Hierarchical linear models: Applications and Data Analysis Methods (1). Sage.

Reimer, A. P., and L. S. Prokopy. 2014. "Farmer Participation in U.S. Farm Bill Conservation Programs." Environmental Management 53 (2): 318-332.

Ryan, R. L., D. L. Erickson, and R. D. Young. 2003. "Farmers' Motivations for Adopting Conservation Practices Along Riparian Zones in a Mid-Western Agricultural Watershed." Journal of Environmental Planning and Management 46 (1): 19-37.

Schelling, T. 1978. Micromotives and Macrobehavior. New York: Norton.

Schubert, J. R., and A. L. Mayer. 2012. "Peer Influence of Non-Industrial Private Forest Owners in the Western Upper Peninsula of Michigan." Open Journal of Forestry 2 (3): 150-158.

Spiegelhalter, D. J., N. G. Best, B. P. Carlin, and A. Van Der Linde. 2002. "Bayesian measures of model complexity and fit." Journal of the Royal Statistical Society: Series B (Statistical Methodology) 64 (4): 583-639.

U.S. Department of Agriculture, Natural Resource Conservation Service. 2014. 2014 Farm Bill Outreach Strategy. Washington DC.

Wong, David. 2009. "The modifiable areal unit problem (MAUP)." The SAGE handbook of spatial analysis: 105-123.

Yang, T.C. 2005. "Modifiable Areal Unit Problem.” GIS Resource Document 5 (65): 135. 


\title{
CHAPTER 4: ESSAY 3 - THE INFLUENCE OF ARC FUNDING ON REGIONAL ECONOMIC RESILIENCE IN APPALACHIA
}

With Alan Collins and Stephan Goetz

\begin{abstract}
Han and Goetz (2015) state "[r]egional economic resilience is defined as a region's capacity to absorb and resist shocks as well as recover from them". The purpose of this essay is to predict regional economic resilience in the greater Appalachian region. It expands upon the previous literature such as Boettner et al. (Forthcoming) by investigating the influence of Appalachian Regional Commission (ARC) project funding on county-level resilience. We hypothesize locationbased funding will produce a significant impact on regional economic resilience as it provides additional support to the local economies. We utilize spatial econometric techniques to identify socioeconomic characteristics that influence resilience. In 1983, the ARC changed its funding strategy to target economically distressed regions. In this analysis, we investigate the change in project investment from 1986 to 2006. Our analysis does not find any statistically significant evidence that support our hypothesis. We do determine that project investments generally have a positive influence on resilience. We further expand upon this analysis by discussing local and regional policy approaches to strengthen resilience throughout the greater ARC region. Regional policy approaches are identified as multi-county cooperative strategies or competitive strategies. ARC investments are most beneficial as a cooperative regional approach.
\end{abstract}

Keywords: Regional economic resilience, Appalachian Regional Commission, location-based funding, rural development 


\section{Introduction}

In 1965, Congress created the Appalachian Regional Commission (ARC) to address the persistent poverty within the Appalachian region. ARC provides support to communities through public works projects and economic development programs in order to improve the economic livelihood of the Appalachian region. This agency funds various grant projects including: education and job training, community development, housing, highways, and infrastructure support. From 1966 to 2006 , over $\$ 30$ billion dollars were invested into such projects. ${ }^{29}$ Since the establishment of the ARC, the region has grown rapidly in population, per capita income, earnings, and employment in various industry sectors (Isserman and Rephann, 1995). Poverty within this region has fallen, however it remains high when compared nationally.

After the recent economic shock of the Great Recession in 2007-2008 government agencies began exploring different resources to rebuild and strengthen local economies. The ARC and the US Economic Development Administration are currently collaborating to identify new methods in which the coal-impacted regions in Appalachia can transform their local economies to build resilience against future economic shocks, through the Partnerships for Opportunity and Workforce and Economic Revitalization (POWER) Initiative. Economic resilience identifies how a region recovers from economic shocks and their related post-impacts. Negative economic shocks result in significant impacts on a region's economy. Firms could face bankruptcies along with potential impacts to workers such as salary reductions and/or increased in unemployment (Han and Goetz, 2015). Reductions in the labor market will lead to decreases in per capita income and increases in poverty rates. There may also be a decrease in the amount of human capital within the region. Terrorist attacks, natural disasters, and stock market crashes are a few examples of negative economic demand shocks. Examples that have occurred recently within the US include Hurricane Sandy in 2012 and the September 11, 2001 terrorist attacks. These events are unpredictable and can result in severe economic changes.

In this essay, we observe the influence of location-based federal funding on local economic resilience within the Appalachian region. Economic resilience as defined by Han and Goetz (2015) is "a region's capacity to absorb and resist shocks as well as recover from them." In this analysis, economic resilience is measured by the changes in local employment levels. We hypothesize that federal support will increase stability, making communities more resilient to economic shocks. Economics shocks will occur again in the future; a region must promote economic resilience to minimize the effects of these future, uncertain shocks.

The objective of this study is to examine the effects of ARC grant project investments from 1966 to 2006 on economic resilience to the 2007-2009 Great Recession. ${ }^{30}$ Our study region consists of the greater Appalachian region which includes all the counties in the states that are at least partially in the federally-designated ARC region. We expand our analysis beyond the counties in the ARC region as we believe the social and economic benefits of federally-funded grant projects could spill

\footnotetext{
${ }^{29}$ Funding includes total support from ARC funding, local, state, and other federal funding, and private investments. Investment dollars are adjusted to 2006 dollars.

${ }^{30}$ According to the National Bureau of Economic Research, the Great Recession started in December 2007 and ended in June 2009.
} 
over county borders into neighboring regions. We utilize economic control variables as measured before the economic shock to predict county-level economic resilience to the Great Recession.

Based on the results of our analysis, we can make three major conclusions from this study. First, we identify socioeconomic characteristics that could promote or restrict local economic resilience. Boettner et al. (Forthcoming) investigated predictors of county-level economic resilience throughout the US. For example, they identified labor market characteristics such as a diversified industry portfolio, innovation potential, and increased labor market participation have a positive effect on county-level economic resilience. Boettner et al. (Forthcoming) do not find a significant relationship between federal funding and economic resilience; however, we hypothesize locationbased funding may have a significant impact. This article contributes to the literature by investigating the effects of ARC grant project investments on local economic resilience in the greater Appalachian region. While our analysis does not find any statistically significant evidence that ARC grant project investments have influenced county level economic resilience, we do determine that project investments generally have a positive influence on resilience.

Furthermore, we can recommend policy strategies to promote and enhance economic resilience throughout the region. Socioeconomic characteristics that influence a region's economic resilience could infer local or regional policy strategies to further promote resilience. When making policy recommendations one must take into consideration the spillover effects beyond the county where the policy may be implemented. The President's Appalachian Regional Commission report from 1964 discusses the importance of interdependence for future growth of the sub regions in Appalachia. The prosperity of the region is based upon the investments in the urban growth centers, as well as the investments in the related rural "hinterlands" (Isserman and Rephann, 1995). Some policies may have different impacts within different regions; regional approaches can improve upon national approaches in promoting development (Pender and Reeder, 2011).

For policy strategies to be the most effective, some policies are best dealt with as a county level (local) issue, while others need to be approached as a conjoint effort with surrounding counties (regional) or even at the state level. Policies introduced within a county may impact economic resilience levels in surrounding counties. Policies with spillover effects could influence cooperative strategies, having the same impact on the focus county and surrounding counties, or they could introduce competitive strategies, creating an inverse effect between the focus county and surrounding counties. Therefore, we use spatial econometric techniques to control for these neighboring (spillover) effects.

Based on the results of our analysis we identify policy strategies, local and regional, to strengthen resilience in the ARC region. We find policies related to educational attainment and employment within the coal industry should be addressed as a local policy strategy. These approaches do not help nor hurt resilience levels of the neighboring counties. Policies that are related to mobility, workforce participation, and entrepreneurship should be addressed as cooperative regional strategies. These policies strengthen resilience throughout the entire region. Policies that influence innovation potential, residence-born population, and employment in the oil and gas industry are competitive regional strategies. These policies benefit the county implementing the policy but hurt the surrounding counties. We find ARC investments are generally most effective as a cooperative regional approach. Project investments provide the greatest benefit on a regional basis. 
Last, we can identify which counties are performing at high levels of economic resilience. Counties that are performing at higher levels of resilience than what our models predict can be identified as highly resilient counties. These counties should be examined as case studies to identified localized strategies for resilience. Based on the results from our analysis we identified over 20 highly resilient counties. Future researchers should be cautious on selecting counties to examine as case studies for resilience as some of the counties that identified as highly resilient experienced employment shocks due to the recent natural gas industry boom. Industry booms do not provide a foundation for long-term economic resilience.

This essay proceeds with a brief review of the ARC and the economic conditions of the Appalachian region followed by the discussion of recent literature related to the ARC investments and economic growth in its region. These sections are then followed by the theoretical framework, empirical methodology and data, results, policy discussion, and conclusion.

\subsection{Appalachian Regional Commission (ARC) and Economic Status in Appalachia} Appalachian Regional Commission (ARC) was established to address the poor economic status of the counties located within the Appalachian region as compared to the rest of the nation. ${ }^{31}$ Based on the region's high unemployment rates and poverty rates, and low-income levels, a large portion of its counties were classified as economically distressed. Historically, this region has been dependent upon sectors that experienced significant industry cycles such as the coal industry. Being industry specialized leaves the region more vulnerable to economic shocks.

Isserman and Rephann (1996) describe the historical economic conditions of the Appalachian region. There are 13 states with counties included in this region: Alabama, Georgia, Kentucky, Maryland, Mississippi, New York, North Carolina, Ohio, Pennsylvania, South Carolina, Tennessee, Virginia, and West Virginia. In 1975, the ARC was divided into three distinct economic regions: the northern Appalachian region, the central Appalachian region, and the southern Appalachian region. Northern Appalachia is composed of counties in states such as New York, Ohio, Pennsylvania, and including most of West Virginia. It was identified as the rustbelt, highly dependent upon the manufacturing industry. Central Appalachia consisted of portions of the states Kentucky, Tennessee, and West Virginia and was identified as a mountainous, isolated coal area. Southern Appalachia extended from Virginia to Mississippi and was known for its exhausted agricultural area. Central Appalachia was identified as the smallest, poorest, and least populated sub-region. ARC supports this region by providing additional stability to its local economies through location-based projects and investments. Since 1965, additional counties have been added to the ARC region. Currently, 420 counties are designated within the ARC region. These counties are indicated in the figure below. West Virginia is the only state in which all its counties are designated within the ARC region.

\footnotetext{
${ }^{31}$ In 1965, Congress passed the Appalachian Regional Development Act which created the Appalachian Regional Commission.
} 


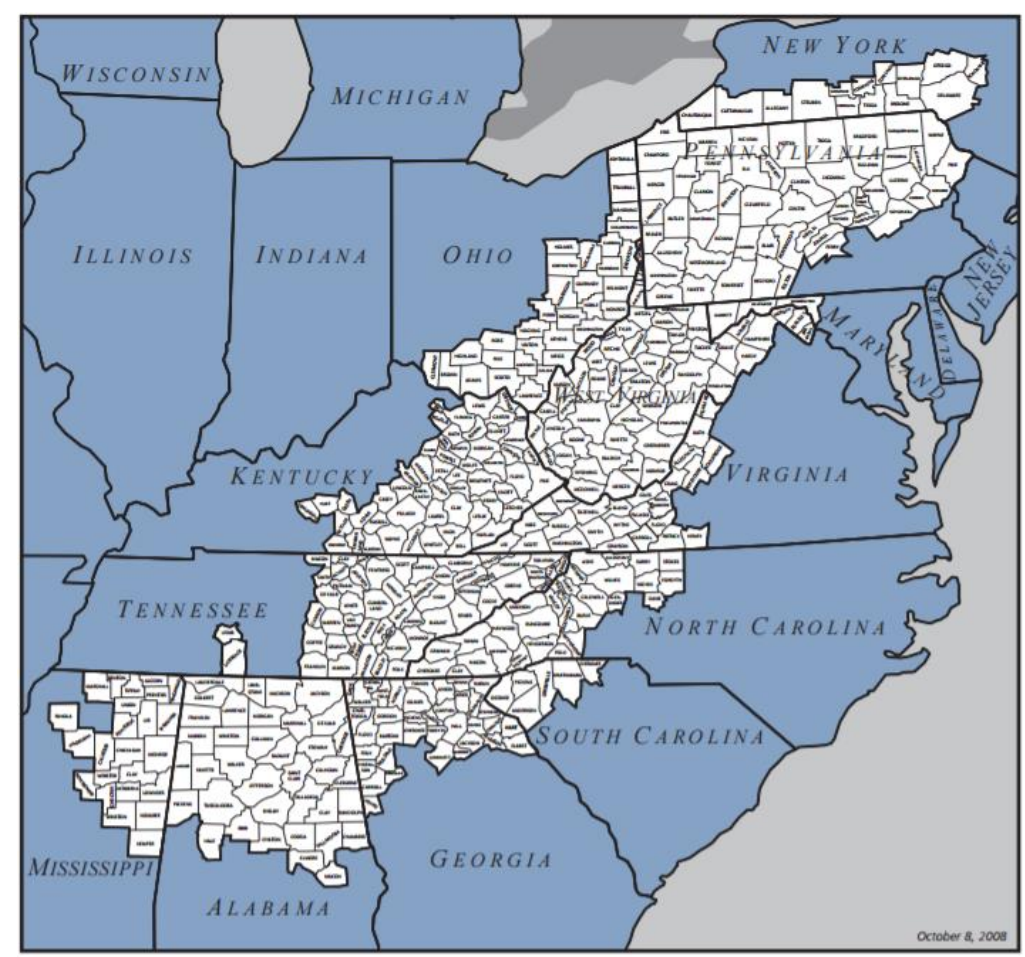

Figure 3-1: Counties within the ARC region

Source: Appalachian Regional Commission

The ARC produces an annual report identifying the economic status of each county within the region, as compared to the rest of the United States. The economic status is based on an index composed of three economic measures: unemployment rate, per capita market income, and the poverty rate. These values for each county are compared to the national average and then categorized based on the definitions provided in the Figure 3-2 below.

ARC County Economic Status Designation by National Index Value Rank

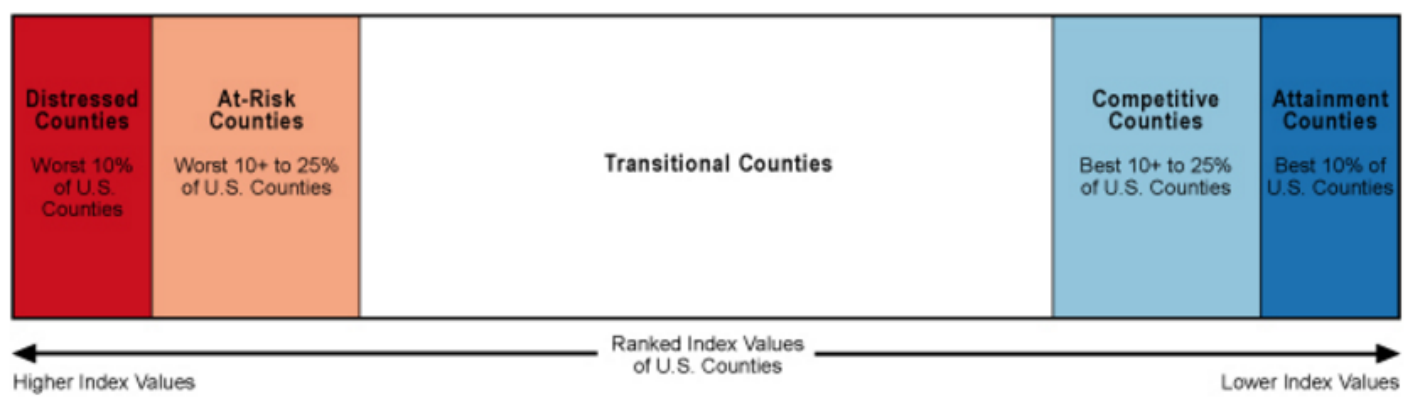

Figure 3-2: ARC County Economic Status Designations

Source: Appalachian Regional Commission 

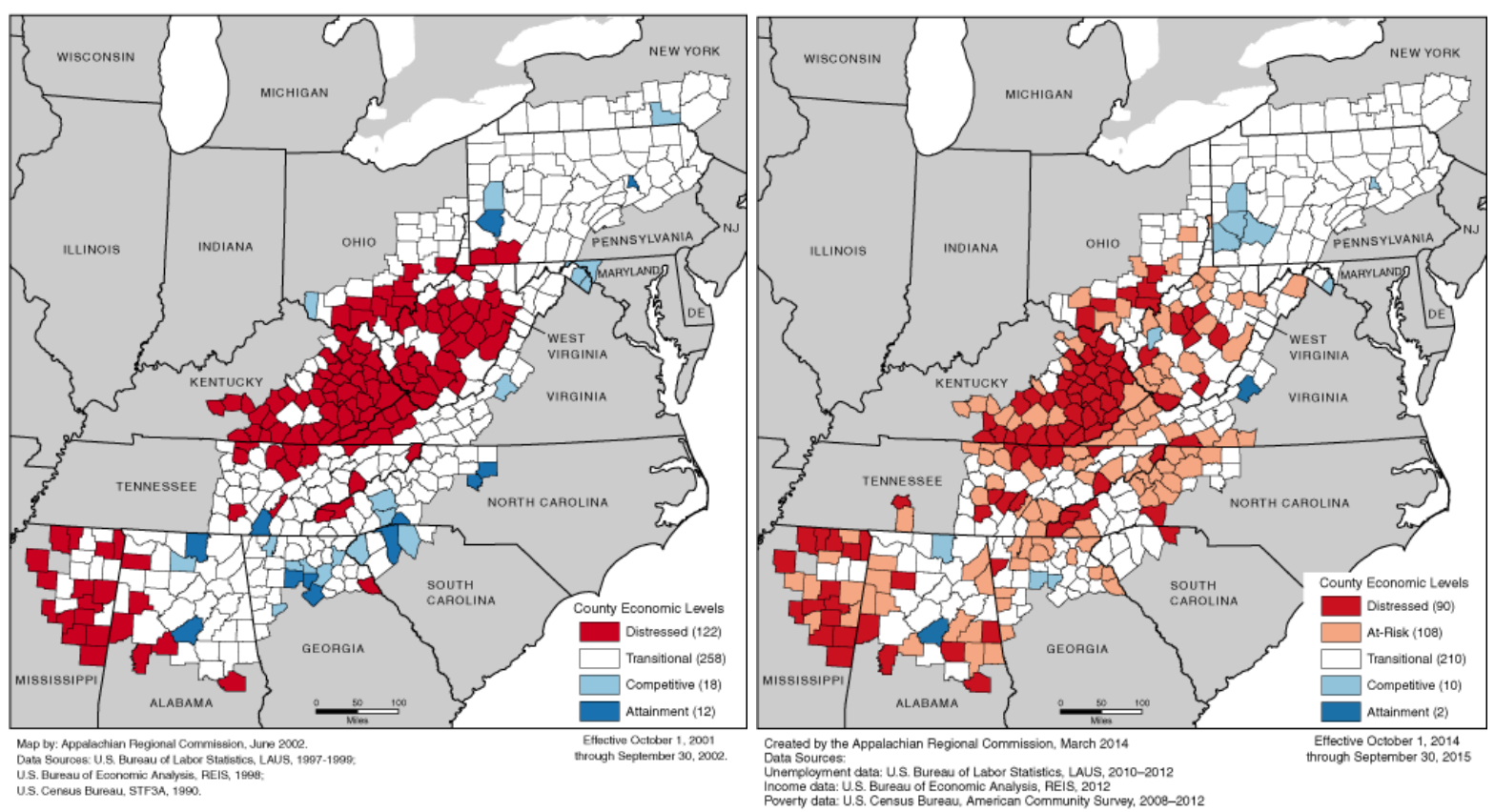

Figure 3-3: County Economic Status Designations in 2002 and 2008

Source: Appalachian Regional Commission

Poverty within the this region has fallen since the installation of the $\mathrm{ARC}$, however it still remains high when compared to the rest of the nation. The Figure 3-3 displays the change in the county designations from FY 2002 and 2008. In 2008 more counties moved from the distressed category to the lesser, at-risk category. By targeting distressed and at-risk counties, project investments may positively affect the resilience levels for the entire region.

\subsection{Overview of ARC Grant Project Investments}

As mentioned previously, ARC grant project investments began in 1966. From 1966 to 2006, ARC-led projects have invested over 30 billion dollars into the region. These projects are not only financially supported by the ARC, but also with matching contributions from other local, state, and federal government agencies. After the drastic decrease in federal support in the 1980s, ARC transitioned its focus towards helping the most-distressed communities. Project match rates were determined by the counties' economic status designations. ${ }^{32}$ For example counties in the distressed or at-risk category would have a 20 percent match rate; however, counties in the transitional or competitive categories would have a higher percantage of a local share between 50-70 percent match rate. Figure 3-4 below displays the total funding invested in ARC-led projects from 1966 to 2006 per year.

\footnotetext{
32 During the Reagan administration support for federal programs significantly decreased, thus the significant decrease in project investments during that time (Wood and Bischak, 2000). This decrease in federal support lead to the initiation of the Distressed Counties Program introduced by the ARC which based project cost-share on a county's economic designation.
} 


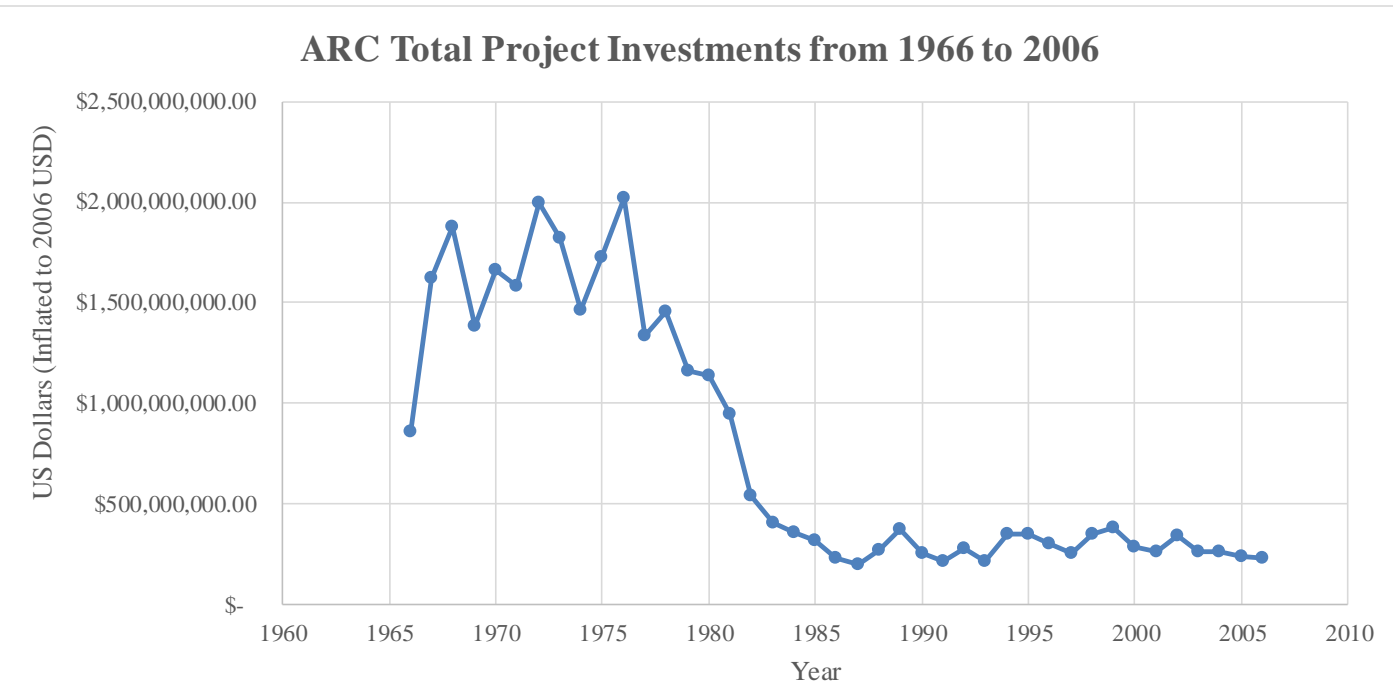

Figure 3-4: ARC Total Project Investments from 1966 to 2006

Based on the ARC projects included in this analysis, on average, ARC has accounted for approximately 32 percent of the total cost of these projects. Communities involved in these projects are also contributing their own resources to improve their local conditions. Through the project-match requirement, ARC projects lead to relationships with other public and private organizations. On average local and state government along with other federal agencies have contributed 31, 12, and 25 percent of the total cost share, respectively. Due to these joint-efforts, Hall (2008) finds counties with an ARC designation were able to access more federal grants than non-ARC counties. Since the late 1980's, federal support to the ARC region has grown. Additional support to the region could lead to more economic stability and higher resilience levels in the long run.

The ARC supports a diverse range of grant projects including: business development, child development, community development, education and workforce development, education and job training, environment and natural resources, health, highways and access roads, housing, leadership and civic capacity, local development district planning and administration, research and technical assistance. Each of these project types provides numerous benefits to the region. ${ }^{33}$ The paragraphs below discuss the different project categories supported by the ARC and the benefits each of these projects provide to the local communities within the Appalachian region.

Business development projects enhance the local community by attracting more businesses to the region. This category includes projects that construct or improve access roads to expand access to local capital. Other types of projects in this category include grants that support business growth in the region such as: creating business incubators, developing business sites, providing technical assistance, and supporting entrepreneurship. This category also includes projects that enhance local sanitation by improving water systems and sewage systems for local businesses. A community that supports local businesses is more attractive to other business owners and entrepreneurs.

\footnotetext{
${ }^{33}$ Information regarding project categories were collected through the project investment data provided by the ARC.
} 
Child development projects improve school-readiness levels and provide additional parenting resources. ARC supports parenting workshops for topics such as homeschooling, nutrition, and other parenting matters such as health issues. The agency also supports local education development programs such as day care and summer library programs. These projects create local support groups for the family lifestyle and build stronger social networks within the community.

Community development projects create a better foundation for growth and social networking within a community. Projects in this category focus on community infrastructures and community revitalization. For example, previous projects include building community facilities and public housing. Community facilities increase engagement within the community. This category also includes projects that improve water and sewer lines and repair flood damage within a community. Communities with improved local resources are more attractive to individuals and firms.

Education and Workforce Development projects and Education and Job Training projects aim to provide better resources to the workforce and the education system within a community. ARC supports local schools and colleges by providing teacher training and by funding local educational programs. ARC projects improve telecommunications within a community; these projects increase accessibility to new training and educational opportunities (Appalachian Regional Commission, 2015). The ARC also hosts workshops for technical training and professional development. Through these workshops, the community can receive career counseling and earn credentials. These ARC projects help the community become more competitive in the workforce.

ARC projects in the Environment and Natural Resources category promote recreational tourism, cultural tourism, and heritage tourism. Natural amenities are positively related to economic growth (Stephens and Partridge, 2011; Deller et al., 2001). Endorsing tourism will attract more people into the region, increasing local spending, and attract new firms into the region, creating new jobs.

Health projects fund health seminars and informational workshops for communities. A healthy community leads to a healthier workforce, which in turn, increases productivity by reducing illness and sick days. These projects also fund the purchase of healthcare equipment. Improved healthcare equipment creates many benefits in a community such as more patients can be treated within the community instead of being transported elsewhere for care.

Isolation was a significant weakness to the Appalachian region due to its limited transportation network. ARC has made a significant impact on the region's economy by building and improving highways and access roads throughout the region. Through the Appalachian Development Highway System program, ARC has improved the region's accessibility by increasing traffic flows through Appalachia, and in turn increases regional competitiveness throughout Appalachia. Other direct benefits include improved road safety, reduced travel time, and reduced travel costs (Appalachian Regional Commission, 2015). Previous literature has identified the various benefits of ARC highway investments (Rephann, 1993; Brown, 1999). Highway development influences business location decisions, improved access for rural residents and businesses, reduced travel costs, and reduced travel time. However, highway maintenance costs may burden local communities. 
Housing projects through the ARC provide homes to families within the Appalachian region. These projects fund the construction of low-income housing units and provide additional support to existing public housing programs. This project category also includes the collection of housing research. This research could lead to the allocation of more federal support, development of community policy strategies, and increased awareness of the current housing market.

The last three project categories aid local policymakers and leaders within the community. Leadership and Civic Capacity (LCC) projects assist with strategic planning for community development and provides technical assistance to community leadership programs. These projects improve economically distressed regions by promoting leadership and community development. Strategic planning, entrepreneurship programs, and tourism infrastructure lead to new startup activity within a community and encourages existing businesses to adapt to new business methods. Promoting tourism within a community promotes local business and increases labor demand (Appalachian Regional Commission, 2015). LCC projects also provide resources for the youth, the future leaders of the community. For example, projects can cover academic conference costs and provide additional resources for youth programs promoting education and skills training. Local Development District Planning and Administration (LDD) projects fund grants to support local planning councils and development commissions. These projects directly benefit the community by providing more resources to the local policymakers. Research and Technical Assistance projects support research within Appalachia through funding and technical assistance. With these projects, the ARC can remain aware of local issues throughout the region. ARC projects provide numerous benefits to the communities within the Appalachian region.

\section{Federal Funding and Regional Strategies to Address Rural Development}

In this section, we will focus on previous literature related to federal programs and rural development in the US. Literature related to measures of economic resilience, and factors that predict economic resilience will be discussed later within this essay.

Federal agencies are focusing their attention on regional strategies for rural economic development. Pender and Reeder (2011) identify discuss federal agencies that were developed to improve rural development. In 1998, the Denali Commission was created to promote regional development throughout Alaska. In 2000, the Delta Regional Authority was authorized to enhance development in the Mississippi Delta region. In the 2014 Farm Bill, the US Department of Agriculture began to favor programs that support community and economic development strategies operating at a multi-community approach.

Pender and Reeder (2011) also identify numerous benefits to the regional approaches to rural development which includes: allowing for large scale operations, optimizing the location of facilities and services, reducing competition among neighboring communities, and formulating regional development strategies.

\subsection{ARC Project Investments and Rural Development}

Many of the ARC projects have a multi-county or even multi-state collaborations to enhance the well-being of the citizens in the Appalachian region. An abundance of articles has identified the impact of ARC investments on economic activity within its region. Pender and Reeder (2011) provided a synthesis report of the literature discussing economic impacts of the ARC. In this 
section, we will review studies that evaluate the influence of ARC projects on the economic condition of the region.

Some studies compared economic growth rates between ARC region and non-ARC region. Isserman and Rephann (1995) utilize quasi-experimental techniques to observe the difference in growth rates between counties in the ARC region as well as "matched" non-ARC counties identified as the control group. They use characteristics such as spatial structure, income, economic structure, and previous growth patterns to identify counties for the control group. In their comparison study, they find the ARC counties grew faster in population, per capita income, earnings, and employment in various industry sectors from 1969 to 1991. They estimated roughly $\$ 8.4$ billion more income for the ARC region when compared to the matched non-ARC counties. Sayago-Gomez et al. (2018) also use the propensity score matching technique to evaluate ARC project investments. They find the counties in the ARC region had higher per-capita income growth and employment growth than the matched counties. From 1965 - 2012, ARC counties grew (on average) 5.5 percent more than their matched counterparts in per-capita income growth. During this time frame, ARC counties had higher employment growth by 4.2 percent than their matched counties.

Some studies focused on evaluating the impacts of ARC project investments on the ARC region. Brandow Co. Inc and EDR Group (2000) evaluated ARC projects based on the number of jobs created, private and public funding generated, and other indirect or induced economic impacts. They observed 99 closed projects for the period of 1990 to 1997. They found for each $\$ 1$ provided by ARC, there was related growth with another $\$ 2.61$ in public funding and almost $\$ 100$ in private investment. They also found growth in the number of jobs created, wage income, and total public funds. In 2007, BizMiner/Brandow Co. Inc and EDR Group evaluated ARC projects based on the number of jobs created, private and public funding generated, and other indirect or induced economic impacts through the same methodology as the previous study. They observed 78 closed projects between of 1999 to 2005 . They found for each $\$ 1$ provided by ARC, it was related to another $\$ 4.87$ in public funding and $\$ 75$ in private investment. They also found growth in the number of jobs created, wage income, and total public funds. As compared to the previous study, the more recent investments (closed projects) create a larger investment in the region.

Glaesar and Gottlieb (2008) apply regression analysis techniques to explain growth in population and per capita income in the ARC counties from 1970 to 1980 and from 1970 to 2000. In the shortterm study (1970-1980), population was growing faster in the ARC counties. However, income per capita growth was found to be slower in the ARC counties in the long-term study (1970 to 2000). However, this study does not include regional economic control variables within its models.

Wood (2000) examined the influence of ARC projects on the number of economically distressed counties within the Appalachian region, overtime. Since 1960, there has been a general decline in the number of economically distressed counties in the ARC region. He also identified policy strategies to promote economic development in the region. He finds policies that reduce the share of resource extraction employment improves the region's economic conditions. Counties should diversify their economic base for improved economic stability. He also finds policies that promote educational attainment create a competitive workforce and therefore, increase the economic conditions within the ARC region. 


\section{Theoretical Framework}

Norris et al. (2008) identified four different adaptive capacities influencing community resilience to various disasters ranging from natural, technical, or human causes. The four capacities include: economic development, social capital, information and communication, and community competence. Sherrieb et al. (2010) identify variables from secondary data sources to measure the first two capacities identified in the previous study. In our model, we attempt to categorize variables from secondary data sources into similar categories as these four key categories.

The economic development capacity relates to a community's assets such as natural resources, human capital, physical capital, and access to employment opportunities. The capacity is related to the abundance of these assets, the dependency upon these resources, as well as the diversity of the economic resources within the community (Norris et al., 2008). Communities with limited access to resources or which have a high dependency upon a specialized set of resources are at higher risk. Sherrieb et al. (2010) identify variables that indicate a community's resource level, resource equity, and resource diversity. Variables in the resource level category include: the ratio of employment levels to population levels, median household income, number of medical doctors, corporate tax revenues, and the percent of people in creative class occupations. Variables within the resource equity category are: income equity and racial density of the under-educated. Variables in the resource diversity category include: birth/death ratio of industries, occupational diversity, and urban influence. Many of these variables are included within the economic and industry (EI) category of the explanatory variables included within the analysis of this study. Industry diversity will provide more stability to economic shocks, therefor making a community more resilient.

The social capital capacity identifies the individuals of the community as resources who invest, access, and consume within social networks and gain returns from these social networks (Lin, 2001). Social capital extends to the discussion of network structures and linkages, social support, and community bonds, roots, and commitments (Norris et al., 2008). The "sense of belonging" developed through the trust and support within social networks provides a strong foundation for resilience within a community. Sheerieb et al. (2010) develops three categories for measuring social capital: social support, social participation, and community bonds. The social support category includes a variable measuring the proportion of two-parent households with children within the community. The social participation category includes variables measuring the availability of arts/sports and civic related organizations, voter participation, and religious adherents. Community bonds are evaluated by net migration rates, and property crime rates. Migration into the region, as well as community awareness and support, will improve the resilience of the community.

In this study, we explore the significance of ARC as a social capital stock within a community. The agency was created to address various needs specific to the Appalachian region. As a resource, ARC provides additional support to improve the economic foundation of the region. This federal agency is effective as they are aware of local needs and concerns. ARC projects cover many categories and address a wide range of local issues within the region. ARC projects also promote regional collaboration which creates a larger social network and stronger community bonds. 
The information and communication capacity is composed of a community's communication systems and its significance in addressing infrastructure or community-based needs. This capacity is composed of systems and infrastructure for informing the public, and communication and narrative (Norris et al., 2008). For this capacity, we include variables such as distance to city, knowledge diversity ${ }^{34}$, and a measure for broadband services areas. Larger cities have larger populations and more resources which can help with economic resilience.

The community competence capacity is based upon the awareness of the strengths and the weaknesses in the economic foundation of and the planning for the local community. A community that is aware of the risks and available options when adopting policies is more willing to participate collectively to solve problems or brainstorm. The components of this capacity include collective action and decision-making, and collective efficacy and empowerment (Norris et al., 2008). A community that is aware of potential risks and is willing to communicate will develop a stronger foundation for long-term economic resilience. ${ }^{35}$

\section{Empirical Methodology and Data}

In this study, we replicate the methodology utilized within Boettner et al. (Forthcoming) to predict economic resilience in the greater Appalachian region. Their study was the first to model and predict regional economic resilience for all counties throughout the US, based on attributable regional capacities that underlie resilience (Pfefferbaum et al., 2008; Sheerieb, 2010). Boettner et al. (Forthcoming) included an aggregated measure of federal funding as a measure of the impact of federal funding, however they were unable to identify a significant impact on resilience at the county level. Our study expands from this analysis by identifying the influence of location-based federal funding within the Appalachia region on economic resilience. In the sections below, we discuss how previous studies have measured economic resilience, and how we observe economic resilience at the county-level. We utilize the Han and Goetz (2015) measure of regional economic resilience as our dependent variable, which measures employment change. We also discuss the explanatory variables utilized in our study and the spatial econometric models implemented within our analysis. We observe the influence of ARC projects on economic resilience to the Great Recession in the greater Appalachian region. ${ }^{36}$

\subsection{Measuring Regional Economic Resilience}

Han and Goetz (2015) state resilience can be observed through changes in a region's "representative measure" as a response to a shock. The previous literature measures resilience through correlated changes in unemployment, GDP, population and industry-level employment (Davies, 2011). Fingleton et al. (2012) measure resilience through changes in employment during two periods: recessionary and recovery. Brown and Greenbaum (2017) explore unemployment stability as a measure of economic resilience. Preceding studies have only observed resilience at a country or large regions level (Brigugilo et al., 2006; Davies, 2011; Fingleton et al., 2012; Martin, 2012), or large cities or metropolitan areas (Augustine et al., 2013; Clark, 2009; Simmie and Martin, 2010).

\footnotetext{
${ }^{34}$ Variable defined and developed by the ARC, Feser et al. (2014).

${ }^{35} \mathrm{We}$ currently do not include any predictor variables in our analysis that would measure the influence of community competence.

${ }^{36}$ The greater Appalachian region includes all the counties in the states that are at least partially in the Appalachian region.
} 
Han and Goetz (2015) is the only study to estimate resilience at the county level by observing a drop and recovery period after a shock. They isolate the employment change due to the Great Recession of 2007-2009 in each county. Measuring employment is a more appropriate measure of resilience than the unemployment rate, as it is sensitive to workers entering and exiting the labor market. Employment levels are an aggregate measure of the movement of households and firms in a region (e.g. Stephens and Partridge 2011; Roback 1982). As Stephens and Partridge (2015) state "[h]ousehold movements affect labor supply and firm movements affect labor demand; and they jointly determine a region's employment level." By observing employment as the resilience measure, we are capturing the effects of changes in household and firm levels. Changes in population are a good proxy for household migrations and reveal households' assessment of a county's well-being when compared to surrounding areas (Rappaport 2007; Faggian, Olfert, and Partridge 2012).

Martin and Sunley (2015) identify economic resilience occurs over several elements: vulnerability (sensitivity of the region), the shock or disturbance, the resistance (the initial impact), robustness (how the region adapts), and recoverability (the recovery process). Our study examines the local economic characteristics for the counties' vulnerability, and uses the change in employment to identify the other elements of resilience. They also identify five determinants of resilience: industrial and business structure, financial arrangements, governance arrangements, labor market conditions, and agency and decision-making. These determinants focus mostly on a region's labor market portfolio and the support from public institutions. Our study expands upon these determinants to include more community traits in the definition of local resilience.

Han and Goetz (2015) find that counties experience different magnitudes of effects during the recession; some counties may even experience employment growth. They also state, "regional economic resilience need not imply a return to a previous path or equilibrium state after a shock; instead, the system may evolve in an entirely new direction." We utilize their measure for observing economic resilience at the county level in Appalachia which implements a systematic approach to measuring resilience. In this section of the essay, we will provide a brief overview of how county-level resilience is measured in this study. Figure 3-5 below displays the movement of the recessionary shock on employment within its various phases.

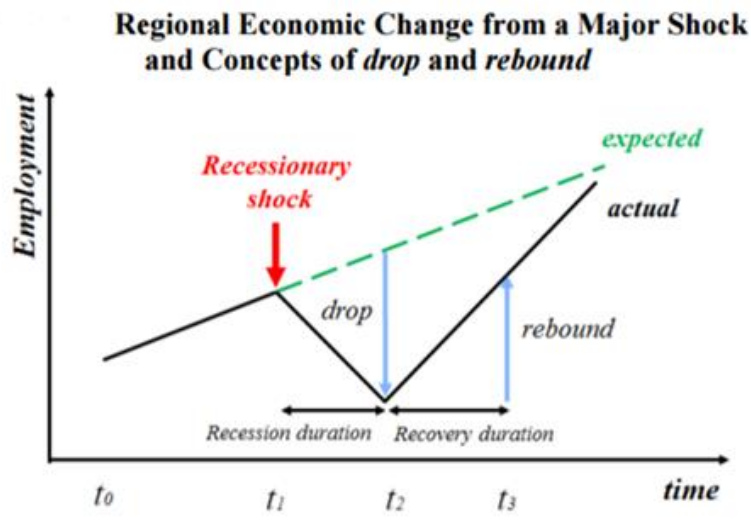

Figure 3-5: Employment Changes in Response to Economic Shock Source: Han and Goetz (2015) 
Han and Goetz (2015) identify two stages of response to a recessionary shock: drop and rebound. Monthly employment data collected from the Bureau of Labor Statistics were utilized to estimate these responses. They used a compound growth rate of employment change (for a period before the recession) to predict how employment growth would occur in each county, if the recession had not occurred. Based on this predicted employment growth rate, they identified a "drop" period and "rebound" period for each county. These time periods may vary for each county. Han and Goetz (2015) identify four different time periods for measuring resilience: before recessionary shock $\left(t_{0}-\right.$ $\left.t_{l}\right)$, recessionary shock $\left(t_{l}\right)$, recessionary shock to lowest post-shock employment level (drop) $\left(t_{t^{-}}\right.$ $t_{2}$ ), and lowest post-shock employment level to most current time-period or recovered employment (rebound) $\left(t_{2}-t_{3}\right)$.

The "drop" in employment is measured in the third time-period as the difference in the expected employment level and the lowest post-shock employment level occurring before recover. The value of the drop ranges between 0 and 1 , with 1 indicating the largest negative impact. The equation they used to measure employment $(y)$ drop is:

$$
\text { Drop }=\frac{\hat{y}_{t_{2}}-y_{t_{2}}}{\hat{y}_{t_{2}}}
$$

The "rebound" in employment is measured in the fourth time-period as the difference in the lowest post-shock employment level to the recovered employment measure. The value of the calculated rebound ranges between 0 and 1 , with 1 indicating the largest rebound. The equation they used to measure employment $(y)$ rebound is:

$$
\text { Rebound }=\frac{y_{t_{3}}-y_{t_{2}}}{y_{t_{2}}} * \frac{1}{t_{3}-t_{2}}
$$

Both these drop and rebound measures are then included within the measure of resilience:

$$
\begin{gathered}
\text { Resilience }=\frac{\text { ratio }- \text { average }(\text { ratio })}{\text { standard deviation }(\text { ratio })} \\
\text { where ratio }=\ln \left(\frac{\text { Rebound }-\operatorname{minimum}(\text { Rebound })+s}{\text { Drop }-\operatorname{minimum}(\text { Drop })+s}\right)
\end{gathered}
$$

To ensure ratio is a positive number, the $s$ is added as a small, insignificant positive number so the natural logarithmic form can be calculated. Counties that have smaller values of drop and larger values of rebound are attributed with higher levels of resilience to the recessionary shock. The resilience measure is based on the peak and trough of counties in the economic cycle. However, some counties do not replicate this cycle as their employment levels continuously rose (no drop), continuously decreased (no rebound), or did not show a peak around the time frame of the national peak. Counties displaying these characteristics are removed from the analysis. 
The dependent variable is calculated by monthly employment data from the Bureau of Labor Statistics and is provided by Han and Goetz (2015). Slight modifications to the dependent variable measure include considerations for the growth rate in the period leading up to the peak and subsequent decline, as well as extending the measure for long-term recovery through March 2016. A seasonal adjustment filter was applied to the monthly data to smoothen the series.

\subsection{Regional Factors Underlying Economic Resilience}

In this essay, we utilize explanatory variables with data collected prior to 2008 as predictors of county level economic resilience occurring after the housing market crash. This analysis can be used to identify variables that could promote or restrict future resilience levels. We can also infer local or regional policy recommendations to further influence economic resilience throughout the region. The explanatory variables used within this analysis are derived from the three distinct categories: Demographics and Mobility (DM). Economic and Industry (EI), and Community and Health $(\mathrm{CH})$. These categories are based upon the adaptive capacities discussed previously. County-level variable definitions, data sources, and descriptive statistics are provided in Table 3-1.

The first category is defined as Demographics and Mobility (DM). This category represents the traits of the county's population as well as its migration patterns. It provides an aggregated measure for community involvement and social networking within these communities. For a county to be resilient it should experience high in-migration rates and low out-migration rates. It should also have a higher share of population that is educated and eligible for the workforce. The migration and residence-born were derived from Sherrieb et al. (2010)'s social capital, community bonds capacity discussed previously. The other variables included within DM category could be considered as part of the social capital (social participation) capacity.

The second category is Economic and Industry (EI). This category identifies the economic resources and industrial composition of the county. For a county to be resilient it should be able to meet the needs of the community with its local resources. Residents should be willing to invest within the community. Investment in the community is measured by home ownership, low poverty rates, high labor market participation rates, as well as a diverse industry mix. A diverse industry mix provides economic stability to future economic shocks. The variables selected for this category were derived from economic development capacity as well as some components of the information and communication capacity (diverse knowledge and distance to city) from Sherrieb et al. (2010), discussed previously in the theoretical framework of the essay. We expect the distance to city to have an inverse relationship with resilience as closer proximity to urban areas provides rural areas access to diverse markets and additional resources.

The last category of predictor variables is Community and Health $(\mathrm{CH})$. This category identifies the community's opportunities and traits, in addition to the health and wellbeing of the community. This category is also built upon the social capital capacity as well as the information and communication capacity as discussed in Sherrieb et al. (2010). The social capital capacity is incorporated into the predictive variables including employment in education, child/elder care, recreational opportunity, natural amenities, social capital index, and voting competitiveness. Communities with a high level of social capital will be more resilient. Natural amenities are positively related to economic growth in rural communities (Stephens and Partridge, 2011; Deller et al., 2001) as they provide opportunities for recreational tourism. Broadband access is a measure 
within the information and communication capacity; access to information and social networks should also lead to high levels of resilience. Stenberg et al. (2009) find broadband connectivity increases employment rates and earnings when compared to regions without connectivity.

With these three categories, we can identify traits that promote or restrict economic resilience at the county level. Another trait that we investigate is the influence of location-based federal funding. Boettner et al. (Forthcoming) include an aggregated measure of federal funding in their study; however, they do not find significance on predicting resilience at the county level. Our study expands from this analysis by assessing the influence of ARC project investments on economic resilience within the greater Appalachian region (displayed in Figure 3-6).

In 1965 , only 360 counties were originally included in the ARC region. In 2006, the number increased to 410 counties designated in the ARC region. ${ }^{37}$ In 2008, the number increased to 420 counties in 13 different states: Alabama, Georgia, Kentucky, Maryland, Mississippi, New York, North Carolina, Ohio, Pennsylvania, South Carolina, Tennessee, Virginia and West Virginia. The ARC region has not grown since 2008. Figure 3-1 indicates the 420 counties in the ARC region. Since the project investments directly benefit only the counties located within the Appalachian region, we separated each state into two regions: an ARC region and a non-ARC region. ${ }^{38}$

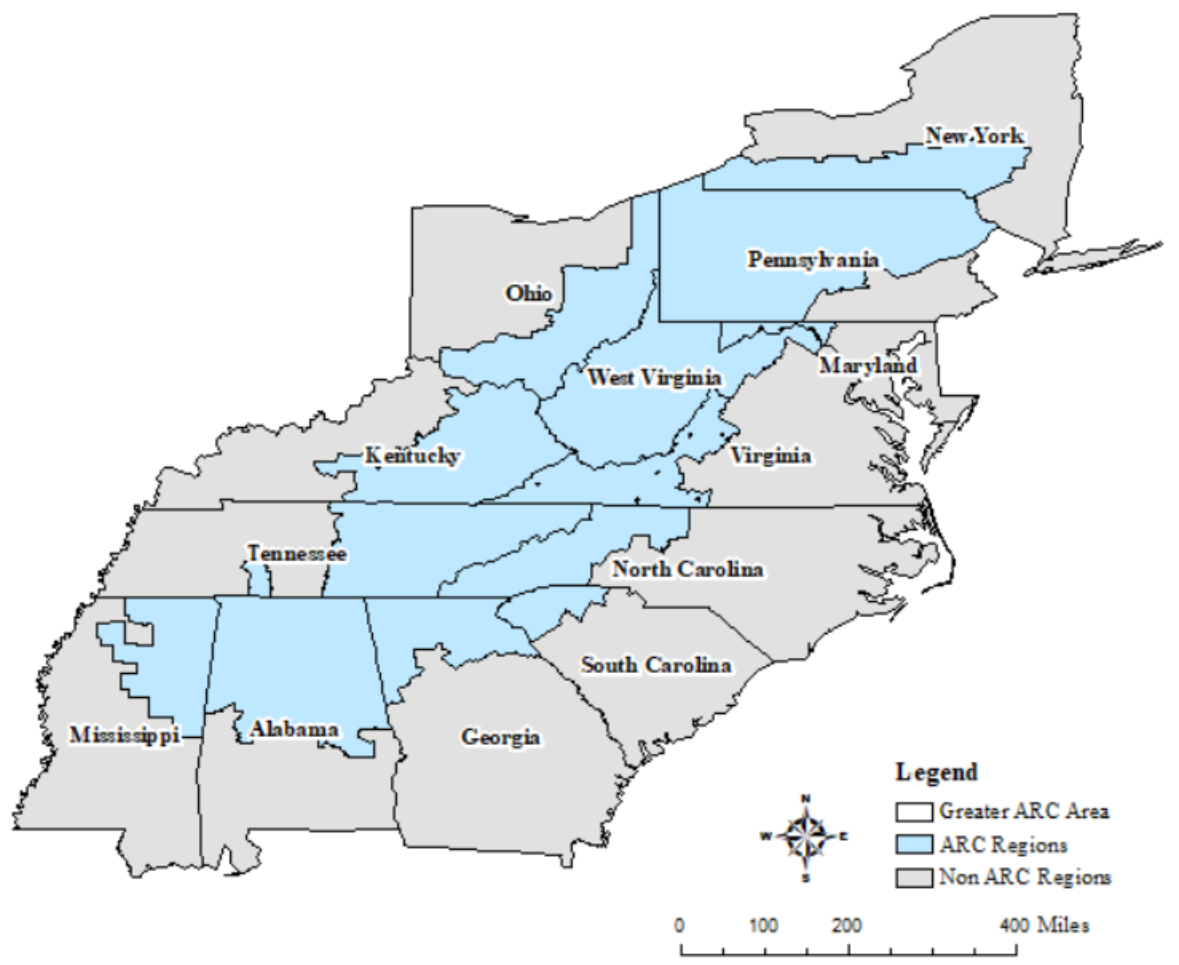

Figure 3-6: ARC and Non-ARC Regions in Each State

\footnotetext{
${ }^{37}$ We use this designation in our analysis as our investment data only includes projects conducted from 1966 - 2006.

${ }^{38}$ There are 13 states in the greater Appalachian region, and in each state there is an ARC region and a non-ARC region. There are 25 regions in our study since all of West Virginia is designated within the ARC region.
} 
Table 3-1. Explanatory Variable Definitions and Data Sources

\begin{tabular}{|c|c|c|c|c|c|c|c|}
\hline \multicolumn{8}{|c|}{ Demographics/Mobility (DM) Explanatory Variables } \\
\hline Variable & Definition & Source & Count & Mean & SD & Minimum & Maximum \\
\hline Age 25 to 44 & Percent of population 25-44 years in age, 2005 & Census Bureau & 1073 & 36.05 & 4.12 & 17.60 & 54.50 \\
\hline Age 65 and Up & Percent of population 65 years or more in age, 2005 & Census Bureau & 1073 & 18.95 & 3.62 & 3.90 & 36.20 \\
\hline Ethnic Diversity & Ethnic diversity of minorities (except white), 2000 & Census Bureau & 1073 & 0.06 & 0.11 & 0.00 & 0.75 \\
\hline Mobility In-Migration & Share of in-migration (in-migrants/population), 2000 & Census Bureau & 1073 & 17.14 & 7.30 & 0.00 & 65.12 \\
\hline Mobility Out-Migration & Share of out-migration (out-migrants/population), 2000 & Census Bureau & 1073 & 15.18 & 6.21 & 0.00 & 100.00 \\
\hline Mobility In-Commuting & Share of in-communting (in-commuters/employment), 2000 & Census Bureau & 1073 & 35.96 & 16.30 & 6.97 & 100.00 \\
\hline Mobility Out-Commuting & Share of out-communting (out-commuters/employment), 2000 & Census Bureau & 1073 & 57.32 & 31.80 & 2.11 & 100.00 \\
\hline Residence-Born & Percent of population born in state of residence, 2000 & Census Bureau & 1073 & 73.22 & 12.89 & 16.07 & 93.44 \\
\hline Population & Total population, $\log$ form, 2005 & Census Bureau & 1073 & 4.58 & 0.50 & 3.24 & 6.20 \\
\hline Land Area & Land area in square miles, 2000 & ESRI & 1073 & 477.95 & 257.26 & 1.99 & 2685.60 \\
\hline College & Percent of population age 25 or more with bachelor's degree or higher, 2000 & Census Bureau & 1073 & 15.31 & 8.21 & 4.90 & 63.70 \\
\hline
\end{tabular}

\begin{tabular}{|c|c|c|c|c|c|c|c|}
\hline \multicolumn{8}{|c|}{ Economic/Industry (EI) Explanatory Variables } \\
\hline Variable & Definition & Source & Count & Mean & SD & Minimum & Maximum \\
\hline Distance to City & Distance (miles) to county with 250,000 population or more, 2005 & Author & 1073 & 57.06 & 34.60 & 0.00 & 163.51 \\
\hline Business Density & Number of establishments per 1,000 population age 20-64, 2005 & Census Bureau & 1073 & 35.28 & 13.59 & 6.29 & 181.05 \\
\hline Self Employment & Percent of nonfarm proprietors employment, 2005 & BEA & 1073 & 20.49 & 8.03 & 3.00 & 61.80 \\
\hline Owner-Occupied Housing & Sercent of owner-occupied housing, 2000 & Census Bureau & 1073 & 74.56 & 7.81 & 20.14 & 88.84 \\
\hline Poverty & Percent of poverty (all ages), 2005 & Census Bureau & 1073 & 16.88 & 7.03 & 2.70 & 46.40 \\
\hline Participation & Percent of participation, 2000 & Census Bureau & 1073 & 59.12 & 6.92 & 22.60 & 77.10 \\
\hline Innovation Potential & Potential for economic innovation, 2005 & Goetz and Han (2017) & 1073 & 0.33 & 0.09 & 0.01 & 0.70 \\
\hline Industry Diversity & Industry-based economic diversity & Feser et al. (2014) & 1073 & 4.61 & 0.46 & 0.91 & 5.54 \\
\hline Knowledge Diversity & Knowledge-based economic diversity & Feser et al. (2014) & 1073 & 2.44 & 0.06 & 2.01 & 2.66 \\
\hline Farming & Percent of farming employment, 2005 & BEA & 1073 & 5.07 & 4.95 & 0.00 & 34.08 \\
\hline Oil and Gas Industry & Percent of oil and gas industry employment, 2005 & Census Bureau & 1073 & 0.06 & 0.42 & 0.00 & 9.46 \\
\hline Coal & Percent of coal employment, 2005 & Census Bureau & 1073 & 0.59 & 3.30 & 0.00 & 49.65 \\
\hline Manufacturing & Percent of manufacturing employment, 2005 & Census Bureau & 1073 & 20.74 & 13.37 & 0.00 & 69.33 \\
\hline
\end{tabular}

\begin{tabular}{|c|c|c|c|c|c|c|c|}
\hline \multicolumn{8}{|c|}{ Community/Health (CH) Explanatory Variables } \\
\hline Variable & Definition & Source & Count & Mean & SD & Minimum & Maximum \\
\hline Primary and Secondary & $\begin{array}{l}\text { Employment in elementary and secondary schools (NAICS 6111) per 1,000 } \\
\text { population age 5-19, log form, } 2005\end{array}$ & Census Bureau & 1073 & 0.70 & 0.54 & 0.00 & 2.20 \\
\hline Community Colleges & $\begin{array}{l}\text { Employment in community college (NAICS } 611210 \text { ) per 1,000 population age } \\
\text { 20-64. } \log \text { form, } 2005\end{array}$ & Census Bureau & 1073 & 0.15 & 0.45 & 0.00 & 3.02 \\
\hline Broadband & $\begin{array}{l}\text { Percent of population who live within one or more broadband service areas, } \\
2010\end{array}$ & USDC & 1073 & 76.33 & 20.54 & 0.00 & 100.00 \\
\hline Child/Elder Care & $\begin{array}{l}\text { Employment in child day care services (NAICS 62441) per 1,000 population } \\
\text { age } 5 \text { or under, and the elderly and persons with disabilites (NAICS 61412) } \\
\text { per 1,000 population age } 65 \text { and up, log form, } 2005\end{array}$ & Census Bureau & 1073 & 1.70 & 0.43 & 0.00 & 2.83 \\
\hline Healthcare Practitioners & $\begin{array}{l}\text { Employment in offices of physicians, dentists, and other health practitioners } \\
\text { (NAICS } 6211-3 \text { ) per 1,000 population, } 2005\end{array}$ & Census Bureau & 1073 & 8.86 & 7.97 & 0.00 & 99.02 \\
\hline Recreational Opportunity & $\begin{array}{l}\text { Employment in arts, entertainment, and recreation (NAICS 71) per 100k } \\
\text { population, log form, } 2005\end{array}$ & Census Bureau & 1073 & 0.55 & 0.35 & 0.00 & 2.44 \\
\hline Natural Amenity & Natural amenity score & USDA ERS & 1073 & -0.20 & 1.18 & -3.98 & 3.55 \\
\hline Social Capital & Social capital index, 2005 & NERCRD & 1073 & -0.62 & 0.97 & -3.78 & 14.38 \\
\hline Federal Funding & Total amount of federal funds per capita, $\log$ form 2005 & USDA ERS & 1073 & 3.25 & 0.34 & 2.56 & 5.21 \\
\hline Voting Competitiveness & Percent of margin in voting for US Presidental elections & Leip (2008) & 1073 & 24.12 & 16.50 & 0.03 & 78.49 \\
\hline Agritourism & Agritourism receipts (\$) per operation, 2007 & USDA & 1073 & 5372.91 & 17686.29 & 0.00 & 336882.40 \\
\hline Direct Farm Sales & Direct farm sales (\$) per farm with direct sales, 2007 & USDA & 1073 & 5691.96 & 7920.81 & 0.00 & 99100.00 \\
\hline
\end{tabular}


Unfortunately, ARC project investments are only recorded at the state level. Due to this limitation, a hierarchical model will be estimated. ${ }^{39}$ Through this method of analysis, data collected from a smaller region, such as a county, and a larger region, such as a state, can be combined into one regression model for estimation capturing the influence of state-level ARC project investments on county-level economic resilience. We evaluate the impact of ARC project investments from 1966 to 2006 for the project types listed in Table 3-2. We hypothesize project investments will improve the region, making the communities more attractive, and in turn, become more resilient.

\subsection{Spatial Hierarchical Econometric Model}

Economic resilience is not just a county-level phenomenon. A change in one county's ability to generate economic resilience may have a multi-county response. Spatial econometric models account for the spatial dependence within county-level data. Spatial econometric techniques are applied to identify the spillover effects, effects on the surrounding areas, of the economic control variables to address policy issues that are better handled as a regional or conjoint effort by multiple nearby counties or at the state level. Spillover effects exist when economic activities pursued in one county influence the resilience in surrounding counties. Previous literature has examined changes in local infrastructure and facilities like roads (Pfaff et al. 2007) or universities (Anselin, Varga, and Acs 2000) and their spillover effects. It has also examined the spillovers initiated with changes in development; i.e., the rural impacts of urban sprawl (Thomas and Howell 2003; Heimlich and Anderson 2001; Carruthers and Vias 2005; and Byun, Waldorf, and Esparza 2005). Spillovers can have either positive or negative impacts on surrounding communities. Taking regional approaches is suggested to address development strategies, as policies can minimize the effects of the negative spillovers, or it can maximize the benefits of positive spillover effects (Pender and Reeder 2011).

By conducting a spatial hierarchical econometric model, we can observe the influence of the ARC project investments on economic resilience in the counties within the ARC region as well as the surrounding counties in the greater Appalachian region. We investigate the significance of the change in project investment per capita over time. ${ }^{40}$ Due to the drastic decrease in federal funding in the early 1980's (illustrated in Figure 3-1), we observe the change in investments over a twentyyear period, 1987-2006. We investigate the change in investment per capita between two ten-year periods, from 1987-1996 and 1997-2006. ${ }^{41}$ Total project investments and investments per capita from 1987-1996 are displayed in Tables 3-3 and 3-5. Total project investments and investments per capita from 1997-2006 are displayed in Tables 3-4 and 3-6. The descriptive statistics for the region-level project investment explanatory variables are displayed in Table 3-7.

\footnotetext{
${ }^{39}$ Raudenbush and Bryk (2002) provide the theoretical framework for hierarchical linear models.

${ }^{40}$ We investigated the influence of total investment per capita from 1966 to 2006 and found similar results to change in investments per capita model. The change in investments models had lower DIC scores, therefore, making them the superior models.

${ }^{41}$ Projects implemented as multi-state collaboration projects are not included within this analysis.
} 
Table 3-2: Total Funding by Project Type for Each State for Projects from 1966-2006

\begin{tabular}{|l|r|r|r|r|r|r|r|r|}
\hline \multicolumn{7}{|c|}{ Total ARC Project Investments from 1966 to 2006 by Project Category in Each State, Inflated to 2006 USD } \\
\hline Project Categories & \multicolumn{1}{|c|}{ AL } & \multicolumn{1}{c|}{ GA } & \multicolumn{1}{c|}{ KY } & \multicolumn{1}{|c|}{ MD } & \multicolumn{1}{c|}{ MS } & NY & NC \\
\hline Business Development & 83577419.86 & 72214122.03 & 110363320.78 & 60647013.13 & 88389811.23 & 93070274.87 & 84234236.65 \\
\hline Child Development & 121800561.53 & 159713169.35 & 106756841.67 & 39038597.60 & 76035309.09 & 104700787.23 & 214468514.36 \\
\hline Community Development & 823964672.75 & 748167600.84 & 1203596194.53 & 424782977.76 & 464102536.94 & 706970779.37 & 586677556.56 \\
\hline Education and Job Training & 680909965.87 & 288453880.63 & 379385087.44 & 170316241.39 & 271686259.91 & 446158649.25 & 331700066.69 \\
\hline Environment and Natural Resources & 12177425.49 & 1879855.78 & 11490184.73 & 21521483.58 & 6981046.01 & 9997984.22 & 5771490.15 \\
\hline Health & 458292737.95 & 340575788.26 & 629491045.81 & 153215214.25 & 138329797.86 & 313553490.31 & 420137178.02 \\
\hline Highways and Access Roads & 237706498.77 & 82300484.62 & 42576639.90 & 56259397.45 & 229479639.66 & 51466228.95 & 63500721.85 \\
\hline Housing & 5486656.74 & 94086170.82 & 423874230.14 & 99601288.33 & 28827552.24 & 15294483.49 & 135724264.52 \\
\hline Leadership and Civic Capacity & 4986462.24 & 2202787.36 & 7988113.13 & 588347.88 & 5808770.41 & 3668878.61 & 6974684.29 \\
\hline Local Development District Planning \& Administration & 62045611.40 & 54062841.97 & 81126838.78 & 15893395.76 & 35992949.76 & 37833353.09 & 64752451.21 \\
\hline Research and Technical Assistance & 22570881.52 & 15972571.41 & 19564533.03 & 10920720.49 & 16120972.85 & 17850165.02 & 34122634.64 \\
\hline Total Investment & 2513518894.10 & 1859812919.01 & 3016213029.95 & 1052784677.63 & 1361754645.96 & 1800565074.41 & 1948063798.94 \\
\hline
\end{tabular}

\begin{tabular}{|l|r|r|r|r|r|r|}
\hline \multicolumn{7}{|c|}{ Total ARC Project Investments from 1966 to 2006 by Project Category in Each State, Inflated to 2006 USD } \\
\hline Project Categories & \multicolumn{1}{|c|}{ OH } & \multicolumn{1}{c|}{ PA } & \multicolumn{1}{c|}{ SC } & \multicolumn{1}{c|}{ TN } & \multicolumn{1}{c|}{ VA } & WV \\
\hline Business Development & 79380945.42 & 403242579.75 & 70615686.77 & 111346261.23 & 63223688.14 & 70143656.66 \\
\hline Child Development & 134505967.20 & 108327513.30 & 134186794.64 & 170171580.45 & 28864676.98 & 118414905.39 \\
\hline Community Development & 550274160.52 & 2341818656.27 & 404378042.45 & 1132383838.73 & 599662226.65 & 1535042714.24 \\
\hline Education and Job Training & 512261543.24 & 1606699174.03 & 392185833.82 & 534274481.13 & 327458777.58 & 736645421.89 \\
\hline Environment and Natural Resources & 21239240.32 & 406523342.71 & 1284105.87 & 9411594.79 & 13692177.85 & 29846794.65 \\
\hline Health & 426195420.62 & 1491030761.67 & 433994819.10 & 453576494.17 & 197972164.39 & 636552106.87 \\
\hline Highways and Access Roads & 112480887.01 & 267155446.87 & 138621737.25 & 155625070.76 & 65177909.58 & 103626313.26 \\
\hline Housing & 58654992.71 & 144873823.19 & 1246989.79 & 9545954.62 & 99143834.66 & 74758338.37 \\
\hline Leadership and Civic Capacity & 5872446.91 & 8145022.99 & 3437735.98 & 2571124.17 & 2304034.90 & 6905701.52 \\
\hline Local Development District Planning \& Administration & 46725313.82 & 80534806.13 & 21683920.47 & 50255783.56 & 58447572.22 & 115666664.18 \\
\hline Research and Technical Assistance & 15252321.03 & 36592239.27 & 6418963.50 & 17354522.96 & 6065905.40 & 18381941.07 \\
\hline Total Investment & 1962843238.81 & 6894943366.17 & 1608054629.62 & 2646516706.57 & 1462012968.36 & 3445984558.09 \\
\hline
\end{tabular}


Table 3-3: Total Funding by Project Type for Projects from 1987-1996

\begin{tabular}{|l|r|r|r|r|r|r|r|}
\hline \multicolumn{9}{|c|}{ Total ARC Project Investments from 1987 to 1996 by Project Category in Each State, Inflated to 2006 USD } \\
\hline Project Categories & \multicolumn{1}{|c|}{ AL } & \multicolumn{1}{|c|}{ GA } & \multicolumn{1}{|c|}{ KY } & MD & MS & NY & NC \\
\hline Business Development & 10334915.84 & 7806009.25 & 18378553.41 & 8151893.27 & 16569041.78 & 12693609.09 & 5906180.34 \\
\hline Child Development & 511937.01 & 344224.68 & 1062160.57 & 0.00 & 0.00 & 5904510.31 & 0.00 \\
\hline Community Development & 206613484.05 & 132876685.48 & 287291811.31 & 72695841.35 & 74517096.75 & 69623241.71 & 125826565.00 \\
\hline Education and Job Training & 8946114.74 & 6404834.69 & 19779117.64 & 5476427.22 & 7800227.59 & 31590746.58 & 9548270.69 \\
\hline Environment and Natural Resources & 242045.81 & 0.00 & 1476784.68 & 0.00 & 0.00 & 0.00 & 520239.28 \\
\hline Health & 2188856.50 & 55832.80 & 0.00 & 7858865.75 & 35926477.86 & 0.00 & 0.00 \\
\hline Highways and Access Roads & 3920745.43 & 0.00 & 14226927.64 & 0.00 & 1352663.17 & 2551817.16 & 2448572.98 \\
\hline Housing & 377191.73 & 59458457.38 & 87275996.57 & 29519600.43 & 0.00 & 1158718.80 & 2145957.69 \\
\hline Leadership and Civic Capacity & 539075.08 & 0.00 & 1173854.38 & 73966.26 & 407444.87 & 1555404.70 & 830296.83 \\
\hline Local Development District Planning \& Administration & 11995491.79 & 15155807.52 & 12348150.69 & 5299946.58 & 6998403.65 & 8052578.60 & 16298626.30 \\
\hline Research and Technical Assistance & 3616997.07 & 6117797.21 & 6021466.30 & 3942983.48 & 4851616.12 & 6980067.90 & 12639514.83 \\
\hline Total Investment & 249286855.06 & 228219649.01 & 449034823.19 & 133019524.35 & 148422971.78 & 140110694.84 & 176164223.94 \\
\hline
\end{tabular}

\begin{tabular}{|l|r|r|r|r|r|r|}
\hline \multicolumn{7}{|c|}{ Total ARC Project Investments from 1987 to 1996 by Project Category in Each State, Inflated to 2006 USD } \\
\hline Project Categories & \multicolumn{1}{|c|}{ OH } & \multicolumn{1}{c|}{ PA } & \multicolumn{1}{c|}{ SC } & \multicolumn{1}{c|}{ TN } & VA & WV \\
\hline Business Development & 79380945.42 & 403242579.75 & 70615686.77 & 111346261.23 & 63223688.14 & 70143656.66 \\
\hline Child Development & 134505967.20 & 108327513.30 & 134186794.64 & 170171580.45 & 28864676.98 & 118414905.39 \\
\hline Community Development & 550274160.52 & 2341818656.27 & 404378042.45 & 1132383838.73 & 599662226.65 & 1535042714.24 \\
\hline Education and Job Training & 512261543.24 & 1606699174.03 & 392185833.82 & 534274481.13 & 327458777.58 & 736645421.89 \\
\hline Environment and Natural Resources & 21239240.32 & 406523342.71 & 1284105.87 & 9411594.79 & 13692177.85 & 29846794.65 \\
\hline Health & 426195420.62 & 1491030761.67 & 433994819.10 & 453576494.17 & 197972164.39 & 636552106.87 \\
\hline Highways and Access Roads & 112480887.01 & 267155446.87 & 138621737.25 & 155625070.76 & 65177909.58 & 103626313.26 \\
\hline Housing & 58654992.71 & 144873823.19 & 1246989.79 & 9545954.62 & 99143834.66 & 74758338.37 \\
\hline Leadership and Civic Capacity & 5872446.91 & 8145022.99 & 3437735.98 & 2571124.17 & 2304034.90 & 6905701.52 \\
\hline Local Development District Planning \& Administration & 46725313.82 & 80534806.13 & 21683920.47 & 50255783.56 & 58447572.22 & 115666664.18 \\
\hline Research and Technical Assistance & 15252321.03 & 36592239.27 & 6418963.50 & 17354522.96 & 6065905.40 & 18381941.07 \\
\hline Total Investment & 1962843238.81 & 6894943366.17 & 1608054629.62 & 2646516706.57 & 1462012968.36 & 3445984558.09 \\
\hline
\end{tabular}


Table 3-4: Total Funding by Project Type for Projects from 1997-2006

\begin{tabular}{|l|r|r|r|r|r|r|r|}
\hline \multicolumn{7}{|c|}{ Total ARC Project Investments from 1997 to 2006 by Project Category in Each State, Inflated to 2006 USD } \\
\hline Project Categories & \multicolumn{1}{|c|}{ AL } & \multicolumn{1}{|c|}{ GA } & \multicolumn{1}{|c|}{ KY } & \multicolumn{1}{c|}{ MD } & \multicolumn{1}{c|}{ MS } & NY & NC \\
\hline Business Development & 63281374.70 & 51101452.14 & 57837770.51 & 48090808.27 & 66288549.63 & 24357832.67 & 40616400.62 \\
\hline Child Development & 8474769.35 & 7515281.41 & 202290.54 & 0.00 & 1205193.26 & 2294666.46 & 3944012.78 \\
\hline Community Development & 69241578.76 & 28108382.37 & 341596945.10 & 27472494.74 & 106912547.54 & 59720066.20 & 56568327.13 \\
\hline Education and Job Training & 31139160.93 & 12943755.20 & 30462337.42 & 4912115.08 & 7695187.67 & 12452633.18 & 7060046.00 \\
\hline Environment and Natural Resources & 106723.13 & 154838.71 & 77000.00 & 4443799.74 & 30967.74 & 0.00 & 0.00 \\
\hline Health & 421225.27 & 5172554.56 & 0.00 & 15494857.40 & 16899093.44 & 0.00 & 113833.99 \\
\hline Highways and Access Roads & 6101433.64 & 745889.08 & 15071881.24 & 196328.87 & 2794209.80 & 2585825.04 & 3683133.71 \\
\hline Housing & 0.00 & 0.00 & 134113047.50 & 17980494.98 & 0.00 & 0.00 & 0.00 \\
\hline Leadership and Civic Capacity & 2828948.28 & 502483.78 & 5435257.41 & 10672.31 & 4711916.22 & 1936048.17 & 1921317.47 \\
\hline Local Development District Planning \& Administration & 11433741.31 & 10259194.36 & 13455753.64 & 2811638.86 & 8012099.62 & 15447306.65 & 10669264.36 \\
\hline Research and Technical Assistance & 3953517.78 & 3724704.88 & 4685908.99 & 4530658.34 & 5460290.04 & 4407059.48 & 11204690.18 \\
\hline Total Investment & 196982473.15 & 120412182.43 & 602938192.35 & 125943868.59 & 220010054.95 & 123201437.83 & 135781026.24 \\
\hline
\end{tabular}

\begin{tabular}{|l|r|r|r|r|r|r|}
\hline \multicolumn{7}{|c|}{ Total ARC Project Investments from 1997 to 2006 by Project Category in Each State, Inflated to 2006 USD } \\
\hline Project Categories & \multicolumn{1}{|c|}{ OH } & \multicolumn{1}{c|}{ PA } & SC & TN & VA & WV \\
\hline Business Development & 59804936.25 & 213024887.77 & 43201440.73 & 47508624.47 & 53161065.78 & 54200887.34 \\
\hline Child Development & 5770628.80 & 0.00 & 0.00 & 800423.50 & 0.00 & 6967224.48 \\
\hline Community Development & 109497147.53 & 24185409.14 & 46005632.11 & 86199465.05 & 108858159.13 & 152105902.22 \\
\hline Education and Job Training & 16144953.90 & 19168453.12 & 28043481.04 & 11047516.02 & 6120715.73 & 23803329.04 \\
\hline Environment and Natural Resources & 137075.63 & 77419.35 & 0.00 & 0.00 & 0.00 & 0.00 \\
\hline Health & 30143947.19 & 30507048.35 & 0.00 & 308152.17 & 10142430.66 & 0.00 \\
\hline Highways and Access Roads & 11688917.99 & 316809.53 & 3785999.29 & 8689992.35 & 7272604.84 & 2684346.93 \\
\hline Housing & 0.00 & 123260.87 & 0.00 & 0.00 & 9208783.56 & 0.00 \\
\hline Leadership and Civic Capacity & 4010976.10 & 4576334.55 & 551270.43 & 2066243.26 & 976768.04 & 4733093.75 \\
\hline Local Development District Planning \& Administration & 12324783.40 & 13945796.58 & 3755826.50 & 9597392.61 & 10507860.61 & 25973234.47 \\
\hline Research and Technical Assistance & 3721480.65 & 6767762.12 & 798485.98 & 5001513.56 & 2614133.22 & 7976018.22 \\
\hline Total Investment & 253244847.46 & 312693181.38 & 126142136.08 & 171219322.99 & 208862521.57 & 278444036.45 \\
\hline
\end{tabular}


Table 3-5: Funding Per Capita by Project Type for Projects from 1987-1996

\begin{tabular}{|l|r|r|r|r|r|r|r|r|r|r|r|r|r|}
\hline \multicolumn{7}{|c|}{ Total ARC Project Investments from 1987 to 1996 by Project Category in Each State, Inflated to 2006 USD } \\
\hline Project Categories & AL & GA & KY & \multicolumn{1}{|c|}{ MD } & MS & NY & NC & OH & PA & SC & TN & VA & WV \\
\hline Business Development & 4.02 & 5.05 & 17.17 & 36.32 & 29.33 & 11.66 & 4.52 & 6.87 & 18.17 & 21.53 & 3.56 & 12.62 & 3.76 \\
\hline Child Development & 0.20 & 0.22 & 0.99 & 0.00 & 0.00 & 5.42 & 0.00 & 0.85 & 0.05 & 0.00 & 0.00 & 3.96 & 0.85 \\
\hline Community Development & 80.39 & 85.91 & 268.35 & 323.85 & 131.89 & 63.96 & 96.29 & 113.23 & 13.79 & 68.50 & 68.08 & 233.07 & 107.06 \\
\hline Education and Job Training & 3.48 & 4.14 & 18.47 & 24.40 & 13.81 & 29.02 & 7.31 & 13.41 & 3.61 & 27.23 & 6.92 & 11.19 & 6.10 \\
\hline Environment and Natural Resources & 0.09 & 0.00 & 1.38 & 0.00 & 0.00 & 0.00 & 0.40 & 0.13 & 0.57 & 0.00 & 0.00 & 0.14 & 0.07 \\
\hline Health & 1.53 & 0.00 & 13.29 & 0.00 & 2.39 & 2.34 & 1.87 & 0.54 & 0.55 & 4.16 & 0.16 & 2.05 & 0.51 \\
\hline Highways and Access Roads & 0.85 & 0.04 & 0.00 & 35.01 & 63.59 & 0.00 & 0.00 & 4.69 & 4.35 & 3.92 & 0.00 & 15.45 & 9.96 \\
\hline Housing & 0.15 & 38.44 & 81.52 & 131.50 & 0.00 & 1.06 & 1.64 & 6.93 & 0.14 & 0.00 & 0.19 & 19.25 & 8.16 \\
\hline Leadership and Civic Capacity & 0.21 & 0.00 & 1.10 & 0.33 & 0.72 & 1.43 & 0.64 & 0.74 & 0.30 & 0.31 & 0.00 & 0.69 & 0.36 \\
\hline Local Development District Planning \& Administration & 4.67 & 9.80 & 11.53 & 23.61 & 12.39 & 7.40 & 12.47 & 9.80 & 2.39 & 3.92 & 4.07 & 22.39 & 25.02 \\
\hline Research and Technical Assistance & 1.41 & 3.96 & 5.62 & 17.57 & 8.59 & 6.41 & 9.67 & 3.85 & 2.04 & 1.25 & 3.15 & 2.16 & 3.86 \\
\hline Total Investment & 97.00 & 147.55 & 419.42 & 592.58 & 262.69 & 128.72 & 134.82 & 161.06 & 45.96 & 130.82 & 86.13 & 322.97 & 165.73 \\
\hline
\end{tabular}

Table 3-6: Funding Per Capita by Project Type for Projects from 1997 - 2006

Total ARC Project Investments from 1997 to 2006 by Project Category in Each State, Inflated to 2006 USD

\begin{tabular}{|l|r|r|r|r|r|r|r|r|r|r|r|r|r|}
\hline \multicolumn{7}{|c|}{ Total ARC Project Investments from 1997 to 2006 by Project Category in Each State, Inflated to 2006 USD } \\
\hline Project Categories & \multicolumn{1}{|c|}{ AL } & \multicolumn{1}{|c|}{ GA } & \multicolumn{1}{|c|}{ KY } & \multicolumn{1}{|c|}{ MS } & \multicolumn{1}{|c|}{ NY } & NC & OH & PA & \multicolumn{1}{c|}{ SC } & \multicolumn{1}{c|}{ TN } & \multicolumn{1}{c|}{ VA } & WV \\
\hline Business Development & 22.30 & 23.15 & 50.67 & 203.17 & 107.71 & 22.71 & 26.61 & 41.09 & 36.60 & 42.00 & 19.16 & 88.99 & 29.97 \\
\hline Child Development & 2.99 & 3.40 & 0.18 & 0.00 & 1.96 & 2.14 & 2.58 & 3.97 & 0.00 & 0.00 & 0.32 & 0.00 & 3.85 \\
\hline Community Development & 24.40 & 12.73 & 299.25 & 116.07 & 173.71 & 55.67 & 37.06 & 75.24 & 4.16 & 44.72 & 34.77 & 182.22 & 84.11 \\
\hline Education and Job Training & 10.98 & 5.86 & 26.69 & 20.75 & 12.50 & 11.61 & 4.63 & 11.09 & 3.29 & 27.26 & 4.46 & 10.25 & 13.16 \\
\hline Environment and Natural Resources & 0.04 & 0.07 & 0.07 & 18.77 & 0.05 & 0.00 & 0.00 & 0.09 & 0.01 & 0.00 & 0.00 & 0.00 & 0.00 \\
\hline Health & 2.15 & 0.34 & 13.20 & 0.83 & 4.54 & 2.41 & 2.41 & 8.03 & 0.05 & 3.68 & 3.50 & 12.17 & 1.48 \\
\hline Highways and Access Roads & 0.15 & 2.34 & 0.00 & 65.46 & 27.46 & 0.00 & 0.07 & 20.71 & 5.24 & 0.00 & 0.12 & 16.98 & 0.00 \\
\hline Housing & 0.00 & 0.00 & 117.49 & 75.96 & 0.00 & 0.00 & 0.00 & 0.00 & 0.02 & 0.00 & 0.00 & 15.41 & 0.00 \\
\hline Leadership and Civic Capacity & 1.00 & 0.23 & 4.76 & 0.05 & 7.66 & 1.80 & 1.26 & 2.76 & 0.79 & 0.54 & 0.83 & 1.64 & 2.62 \\
\hline Local Development District Planning \& Administration & 4.03 & 4.65 & 11.79 & 11.88 & 13.02 & 14.40 & 6.99 & 8.47 & 2.40 & 3.65 & 3.87 & 17.59 & 14.36 \\
\hline Research and Technical Assistance & 1.39 & 1.69 & 4.11 & 19.14 & 8.87 & 4.11 & 7.34 & 2.56 & 1.16 & 0.78 & 2.02 & 4.38 & 4.41 \\
\hline Total Investment & 69.43 & 54.55 & 528.19 & 532.08 & 357.48 & 114.84 & 88.97 & 174.01 & 53.73 & 122.63 & 69.06 & 349.62 & 153.98 \\
\hline
\end{tabular}


Table 3-7: Descriptive Statistics of Level 2 Explanatory Variables

\begin{tabular}{|l|l|r|r|r|r|r|}
\hline \multicolumn{2}{|c|}{ Level 2 Explanatory Variables } & Count & \multicolumn{1}{c|}{ Mean } & \multicolumn{2}{c|}{ SD } & \multicolumn{2}{l|}{ Minimum } & Maximum \\
\hline \multicolumn{2}{|c|}{ Change in Project Investments Per Capita Between 1987-1996 Period and 1997-2006 Period } \\
\hline BUDPOPCHG & Change in Business Development per capita & 25 & 21.58 & 37.32 & 0 & 166.86 \\
\hline CHDPOPCHG & Change in Child Development per capita & 25 & 0.35 & 1.72 & -3.96 & 3.18 \\
\hline CODPOPCHG & Change in Community Development per capita & 25 & -20.41 & 47.37 & -207.78 & 41.83 \\
\hline EJTPOPCHG & Change in Education \& Job Training Development per capita & 25 & -0.26 & 4.62 & -17.42 & 8.21 \\
\hline ENRPOPCHG & Change in Environment \& Natural Resources per capita & 25 & 0.65 & 3.79 & -1.31 & 18.77 \\
\hline HEAPOPCHG & Change in Health per capita & 25 & 1.02 & 2.51 & -0.49 & 10.12 \\
\hline HARPOPCHG & Change in Highways \& Access Roads per capita & 25 & 0.03 & 10.43 & -36.13 & 30.45 \\
\hline HOUPOPCHG & Change in Housing per capita & 25 & -3.20 & 15.46 & -55.54 & 35.97 \\
\hline LCCPOPCHG & Change in Leadership \& Civic Capacity per capita & 25 & 0.76 & 1.57 & -0.28 & 6.93 \\
\hline LDDPOPCHG & Change in Local Development District Plan \& Admin per capita & 25 & -1.29 & 3.77 & -11.73 & 7.00 \\
\hline RTAPOPCHG & Change in Research \& Technical Assistance per capita & 25 & -0.30 & 1.07 & -2.33 & 2.21 \\
\hline TOTALPOPCHG & Change in Total Investment per capita & 25 & -1.08 & 39.57 & -93.01 & 108.77 \\
\hline
\end{tabular}

Since there are only 13 states in the greater Appalachian region, we estimated the effects of each level 2 variable in separate regressions. Twelve spatial hierarchical Spatial Lag of X (SLX) models were estimated to identify the direct and indirect spillover effects of factors that influence economic resilience. The SLX model estimates local spillover effects. We believe local spillover effects are more appropriate for our research question as economic resilience will be heterogenous throughout the states. The spatial lag controls for the spatial dependence within these data.

Our models will estimate the direct, indirect and total effects of the change in the project investments per capita on economic resilience. The direct effect will estimate the influence investment per capita growth in one region on economic resilience in the same region. The indirect effect will estimate the influence investment per capita growth in one region on economic resilience in the surrounding regions. The total effect is the sum of the direct effect and indirect effect. The total effect will estimate the influence investment per capita growth in one region on economic resilience for the entire region.

We employ the Deviance Information Criterion (DIC), developed by Spiegelhalter et al. (2002), to identify the appropriate spatial weight matrix for each of the county level variables. The DIC value also identifies the superior model of the twelve estimated hierarchical SLX models. The model with the lowest DIC value identifies the model of best fit, which is the model estimated.

Both county and state level data have been standardized within our model estimation. With data standardization, the coefficient estimates are imputed as z-score values such that econometric estimation provides standardized coefficients. Standardization allows for direct comparisons of the magnitude of coefficients. The interpretation of the beta coefficients is measured by changes in the standard deviation. ${ }^{42}$

\footnotetext{
42 The interpretation of the beta coefficients is explained with the following example: $\beta_{\text {Farm }}=0.50$ : A 1 standard deviation increase in the percent of employment in the farming industry is predicted to result in $1 / 2$ standard deviation increase in economic resilience. http://www.bwgriffin.com/gsu/courses/edur8132/notes/Notes8h_RegressionStandardizedCoefficients.pdf
} 
The Bayesian Hierarchical SLX model implemented in this analysis is provided below:

$$
\begin{gathered}
y=X \beta+W_{1} X \theta+\Delta a+\varepsilon \\
a=Z \gamma+W_{2} Z \delta+u \\
\varepsilon \sim N\left(0, \sigma^{2} I_{n}\right) \\
u \sim N\left(0, \tau^{2} j\right)
\end{gathered}
$$

The dependent variable in our case, county-level economic resilience, is represented by $y$ which is an $N \mathrm{x} 1$ vector, and the explanatory variables, $\mathrm{X}$, are represented as an $(N \times K)$ matrix. $\mathrm{X}$ is composed of three categories of variables: Demographics and Mobility (DM), Economic and Industry $(\mathrm{EI})$, and Community and Health $(\mathrm{CH})$. We observe the joint efforts of these variables on predicting resilience, while controlling for the spatial dependence in the explanatory variables.

$$
\mathrm{X}=[\mathrm{DM}, \mathrm{EI}, \mathrm{CH}]
$$

$W_{1}(\mathrm{~N} \times \mathrm{N})$ is the county-level nearest-neighbors spatial weight matrix, and both $\beta$ and $\theta$ are parameter vectors $(K \times 1)$ at the county level. $W_{1} X$ represents the spatially-weighted exogenous explanatory variables. $\varepsilon$ is an $N \times 1$ vector of disturbances with mean 0 and variance $\sigma^{2} I n$. The symbol $\Delta$ represents an $N \times J$ (where $N$ represents the total number of observations and $J$ represents the number of groups) matrix that assigns each level 1 observation to a level 2 group. This matrix matches the county with its designated state. The symbol $\alpha$ represents the $J \times 1$ vector of terms which are predicted in the level 2 model.

The dependent variable in the level 2 model, $a(Z \times 1)$ is a vector of intercepts, which is predicted by Z, a $(J \times m)$ vector of explanatory variables, ARC project investments (including a constant), with $\gamma$ as the $(J \times m)$ vector of coefficients, $\mathrm{W}_{2}$ as the $(J \times J)$ region-level nearest-neighbor spatial weight matrix, and $\delta$ as the ( $\mathrm{mx} 1$ ) vector of spatially weighted coefficients of the explanatory variables. The vector of error $(\mathrm{J} \times 1), u$, has a variance of $\tau^{2} j$ for the county level. We assume that $\varepsilon$ and $u$ are uncorrelated, $u$ and $X$ are uncorrelated, and $u$ and $Z$ are uncorrelated. These are the standard assumptions of the hierarchical models (Raudenbush and Bryk, 2002).

Our model is estimated through Bayesian econometric techniques, in which estimates of the parameters take place on the posterior distribution. The posterior distribution is proportional to the likelihood multiplied by the hierarchical prior and the priors for all parameters. All the priors utilized in the model are proper leading to a "fully Bayesian" analysis. ${ }^{43} \mathrm{We}$ utilize the posterior mean to interpret the level 1 effects and the level 2 effects estimated by the Bayesian econometric techniques (Lacombe and Flores, 2017; Lacombe and McIntyre, 2017).

$$
\pi(\theta, \alpha \mid y) \propto f(y \mid \theta, \alpha) f(\alpha \mid \theta) \pi(\theta)
$$

\footnotetext{
${ }^{43}$ Full discussion of the posterior distribution for the hierarchical model is provided by Lacombe and Flores (2016).
} 


\section{Spatial Hierarchical Econometric Model Results}

Twelve spatial hierarchical Spatial Lag of X (SLX) models were estimated to identify the direct and indirect spillover effects of factors that influence economic resilience within the greater Appalachian region. Tables 8-19 display the results from the estimated spatial hierarchical SLX models. A 3-nearest neighbor spatial weight matrix was implemented for both levels. ${ }^{44}$ For the level 1 effects, the results of the spatial hierarchical models remain relatively consistent. The model estimating the change in the total investment per capita was identified as the superior model as it has the lowest DIC value estimate of the twelve spatial hierarchical models. For the Bayesian analysis, the $95 \%$ credible intervals for all the parameters estimated in this model were identified. If the interval does not contain zero, then the parameter is statistically significant, and it explains the variation in the dependent variable. In the following sections, we interpret the level 1 (county level) effects and the level 2 (region level) effects.

\subsection{Spatial Hierarchical Model Level 1 Results}

Throughout the twelve estimated models, the beta coefficients for the level 1 effects remain relatively consistent. In this section, we interpret the statistically significant level 1 control variable effects. None of the explanatory variables within the Community and Health $(\mathrm{CH})$ category were identified as statistically significant at the $95 \%$ confidence interval and will not be discussed.

The Demographics and Mobility (DM) category represents the traits of the county's population as well as its migration patterns. The characteristics of a county's population influence its resilience level as well as the resilience levels of the surrounding counties. The share of population with a bachelor's degree or higher has a positive direct effect. As the percent of the population with a bachelor's degree or higher increases within a county, the resilience of that county also increases. The percent of population age 25 to 44 has a positive indirect effect. Attracting workers into a county will increase resilience within surrounding counties. Four variables measuring mobility were included within this analysis: in-migration, out-migration, in-commuting, and outcommuting. Mobility, in relation to in-migration, has positive direct and indirect effects. As more people migrate to a county, the resilience of the county and the surrounding counties increase. As communities create places where people want to live, the populations of these communities will increase as well as resilience of these communities. The share of population that remained residents of their birth-state has a negative total effect. As the share of residence-born population increases within a county, the economic resilience of the total region will decrease. This may signal the competitiveness of the county. Residence-born has the largest negative effect on economic resilience within the region. If the county is not attracting new individuals or firms to the region it is at an economic disadvantage, which in turn, weakens the resilience of the region.

The Economic and Industry (EI) category identifies the economic status and industrial composition of the county. The industry composition of a county is also reflective of resilience. Employment in the coal industry has a negative direct effect. As employment in the coal industry increases in a county, resilience of the same county will decrease. Employment in the oil and gas industry has a

\footnotetext{
${ }^{44}$ We tested the number of nearest neighbors from 2-10 for each spatial weight matrix for each of the estimated models. Through the DIC value, we determined the 3-nearest neighbor spatial weight matrix for level 1 and level 2 produces the superior model for each estimation.
} 
negative indirect effect. As employment in the oil and gas industry increases in a county, resilience of the surround counties will decrease. Employment in resource extraction industries does not provide a foundation for economic resilience. However, the share of self-employment (entrepreneurs) has a positive total effect. As the share of self-employed workers increase within a county, the economic resilience increases for the entire region. Labor force participation has a positive total effect. It has the largest positive effect on economic resilience. As labor force participation increases in a county, the economic resilience of the entire region will also increase. Innovation potential has a positive direct effect but a negative total effect. The innovation potential measures opportunities both supplier-based and buyer-based product innovation. A county that adapts for efficiency between a supplier and buyer is more flexible and adaptive, and therefore more attractive to other firms. As the innovation potential increases within a county, the economic resilience within the same county will increase; however, it will decrease throughout the entire region. Innovation potential creates a competitive effect on resilience throughout the region.

\subsection{Spatial Hierarchical Model Level 2 Results}

This paper expands from previous literature by examining the influence of ARC project investments on economic resilience. We evaluate the change in project investments per capita over a 20-year period. Unfortunately, we do not find any statistically significant effects from any of these region-level variables at any level - direct indirect, or total. Therefore, we will not interpret the effects of the level 2 investment variables as they are not statistically different from zero. 
Table 3-8: Change in Business Development Per Capita Model

\begin{tabular}{|c|c|c|c|}
\hline Business Development & Direct Effects & Indirect Effects & Total Effects \\
\hline Level 1 Variables & Posterior Mean & Posterior Mean & Posterior Mean \\
\hline \multicolumn{4}{|c|}{ Demographic and Mobility } \\
\hline Age 25 to 44 & 0.050 & $0.194 * *$ & -0.132 \\
\hline Age 65 and Up & -0.076 & 0.155 & 0.151 \\
\hline Ethnic Diversity & 0.017 & -0.019 & 0.255 \\
\hline Mobility In-Migration & $0.182 * *$ & $0.195 * *$ & 0.294 \\
\hline Mobility Out-Migration & -0.076 & -0.076 & 0.238 \\
\hline Mobility In-Commuting & 0.065 & -0.112 & 0.341 \\
\hline Mobility Out-Commuting & 0.018 & -0.042 & 0.048 \\
\hline Residence-Born & 0.066 & 0.066 & $-0.515 * *$ \\
\hline Population & 0.138 & 0.016 & -0.143 \\
\hline Land Area & 0.051 & -0.001 & -0.655 \\
\hline College & $0.212 * *$ & -0.075 & -0.044 \\
\hline \multicolumn{4}{|c|}{ Economic and Industry } \\
\hline Distance to City & -0.010 & 0.035 & 0.155 \\
\hline Business Density & -0.035 & -0.087 & -0.251 \\
\hline Self-Employment & 0.017 & 0.048 & $0.244 * *$ \\
\hline Owner-Occupied Housing & 0.096 & -0.110 & 0.080 \\
\hline Poverty & -0.024 & -0.050 & -0.002 \\
\hline Participation & 0.100 & 0.113 & $0.377 * *$ \\
\hline Innovation Potential & $0.087 * *$ & -0.058 & -0.152 \\
\hline Industry Diversity & 0.052 & -0.087 & -0.046 \\
\hline Knowledge Diversity & -0.052 & 0.090 & -0.024 \\
\hline Farming & -0.040 & 0.055 & 0.132 \\
\hline Oil and Gas & 0.005 & $-0.096 * *$ & 0.153 \\
\hline Coal & $-0.075 * *$ & -0.031 & 0.050 \\
\hline Manufacturing & -0.037 & 0.044 & 0.137 \\
\hline \multicolumn{4}{|c|}{ Community and Health } \\
\hline Primary and Secondary & 0.033 & -0.006 & 0.025 \\
\hline Community College & -0.004 & -0.035 & -0.122 \\
\hline Broadband & -0.063 & -0.027 & 0.065 \\
\hline Child/Elder Care & -0.012 & -0.049 & -0.014 \\
\hline Healthcare Practitioner & -0.059 & 0.102 & -0.074 \\
\hline Recreational Opportunity & 0.078 & -0.012 & 0.213 \\
\hline Natural Amenity & 0.017 & 0.082 & 0.029 \\
\hline Social Capital & -0.034 & 0.085 & -0.035 \\
\hline Voting Competitiveness & -0.014 & -0.036 & 0.038 \\
\hline Agritourism & 0.013 & 0.051 & 0.016 \\
\hline Direct Farm Sales & 0.013 & -0.065 & -0.091 \\
\hline
\end{tabular}

Statistical significance indicated by $* * \mathrm{p}<0.05$. ARC and state fixed effects are utilized.

\begin{tabular}{|l|c|}
\hline \multicolumn{2}{|l|}{ Business Development } \\
\hline Level 2 Variable & Posterior Mean \\
\hline Constant & 0.004 \\
\hline Direct Effects & 0.003 \\
\hline Indirect Effects & 0.160 \\
\hline Total Effects & 0.163 \\
\hline
\end{tabular}

\begin{tabular}{|l|r|}
\hline Variance & Posterior Mean \\
\hline sigma $^{\wedge} 2$ & 0.836 \\
\hline tau^$^{\wedge}$ & 0.018 \\
\hline
\end{tabular}

DIC value 40790.652 
Table 3-9: Change in Child Development Per Capita Model

\begin{tabular}{|c|c|c|c|}
\hline Child Development & Direct Effects & Indirect Effects & Total Effects \\
\hline Level 1 Variables & Posterior Mean & Posterior Mean & Posterior Mean \\
\hline \multicolumn{4}{|c|}{ Demographic and Mobility } \\
\hline Age 25 to 44 & 0.051 & $0.196 * *$ & -0.133 \\
\hline Age 65 and Up & -0.077 & 0.159 & 0.174 \\
\hline Ethnic Diversity & 0.018 & -0.021 & 0.385 \\
\hline Mobility In-Migration & $\mathbf{0 . 1 8 3} * *$ & $0.194 * *$ & 0.309 \\
\hline Mobility Out-Migration & -0.079 & -0.077 & 0.288 \\
\hline Mobility In-Commuting & 0.064 & -0.111 & 0.371 \\
\hline Mobility Out-Commuting & 0.020 & -0.043 & -0.122 \\
\hline Residence-Born & 0.068 & 0.062 & -0.638 \\
\hline Population & 0.140 & 0.008 & -0.137 \\
\hline Land Area & 0.049 & -0.001 & -0.642 \\
\hline College & $\mathbf{0 . 2 1 3} * *$ & -0.075 & -0.031 \\
\hline \multicolumn{4}{|c|}{ Economic and Industry } \\
\hline Distance to City & -0.008 & 0.032 & 0.035 \\
\hline Business Density & -0.033 & -0.087 & -0.455 \\
\hline Self-Employment & 0.015 & 0.049 & $0.247 * *$ \\
\hline Owner-Occupied Housing & 0.095 & -0.108 & 0.081 \\
\hline Poverty & -0.024 & -0.047 & -0.003 \\
\hline Participation & 0.101 & 0.113 & $0.378 * *$ \\
\hline Innovation Potential & $\mathbf{0 . 0 8 7} * *$ & -0.058 & -0.156 \\
\hline Industry Diversity & 0.050 & -0.088 & -0.047 \\
\hline Knowledge Diversity & -0.053 & 0.088 & -0.023 \\
\hline Farming & -0.041 & 0.055 & 0.130 \\
\hline Oil and Gas & 0.006 & $-0.097 * *$ & 0.148 \\
\hline Coal & $\mathbf{- 0 . 0 7 5} * *$ & -0.030 & 0.047 \\
\hline Manufacturing & -0.037 & 0.045 & 0.138 \\
\hline \multicolumn{4}{|c|}{ Community and Health } \\
\hline Primary and Secondary & 0.034 & -0.004 & 0.024 \\
\hline Community College & -0.003 & -0.035 & -0.120 \\
\hline Broadband & -0.064 & -0.027 & 0.064 \\
\hline Child/Elder Care & -0.012 & -0.048 & -0.013 \\
\hline Healthcare Practitioner & -0.060 & 0.102 & -0.071 \\
\hline Recreational Opportunity & 0.077 & -0.012 & 0.213 \\
\hline Natural Amenity & 0.017 & 0.082 & 0.030 \\
\hline Social Capital & -0.034 & 0.084 & -0.037 \\
\hline Voting Competitiveness & -0.015 & -0.037 & 0.035 \\
\hline Agritourism & 0.013 & 0.050 & 0.014 \\
\hline Direct Farm Sales & 0.013 & -0.063 & -0.091 \\
\hline
\end{tabular}

Statistical significance indicated by $* * \mathrm{p}<0.05$. ARC and state fixed effects are utilized.

\begin{tabular}{|l|c|}
\hline \multicolumn{2}{|l|}{ Child Development } \\
\hline Level 2 Variable & Posterior Mean \\
\hline Constant & 0.011 \\
\hline Direct Effects & -0.054 \\
\hline Indirect Effects & -0.131 \\
\hline Total Effects & -0.185 \\
\hline
\end{tabular}

\begin{tabular}{|l|r|}
\hline Variance & Posterior Mean \\
\hline sigma $^{\wedge} 2$ & 0.836 \\
\hline tau^2 $^{\wedge}$ & 0.019 \\
\hline
\end{tabular}

DIC value 40799.113 
Table 3-10: Change in Community Development Per Capita Model

\begin{tabular}{|c|c|c|c|}
\hline Community Development & Direct Effects & Indirect Effects & Total Effects \\
\hline Level 1 Variables & Posterior Mean & Posterior Mean & Posterior Mean \\
\hline \multicolumn{4}{|c|}{ Demographic and Mobility } \\
\hline Age 25 to 44 & 0.051 & $0.199 * *$ & -0.132 \\
\hline Age 65 and Up & -0.076 & 0.160 & 0.023 \\
\hline Ethnic Diversity & 0.018 & -0.021 & 0.192 \\
\hline Mobility In-Migration & $\mathbf{0 . 1 8 5} * *$ & $0.195 * *$ & 0.163 \\
\hline Mobility Out-Migration & -0.081 & -0.076 & 0.490 \\
\hline Mobility In-Commuting & 0.063 & -0.112 & 0.054 \\
\hline Mobility Out-Commuting & 0.020 & -0.043 & -0.221 \\
\hline Residence-Born & 0.070 & 0.061 & -0.439 \\
\hline Population & 0.142 & -0.005 & -0.135 \\
\hline Land Area & 0.048 & -0.001 & -0.146 \\
\hline College & $0.213 * *$ & -0.074 & -0.007 \\
\hline \multicolumn{4}{|c|}{ Economic and Industry } \\
\hline Distance to City & -0.008 & 0.032 & 0.071 \\
\hline Business Density & -0.033 & -0.085 & -0.253 \\
\hline Self-Employment & 0.015 & 0.048 & $0.250 * *$ \\
\hline Owner-Occupied Housing & 0.095 & -0.107 & 0.083 \\
\hline Poverty & -0.022 & -0.047 & -0.002 \\
\hline Participation & 0.102 & 0.112 & $0.380 * *$ \\
\hline Innovation Potential & $\mathbf{0 . 0 8 7} * *$ & -0.056 & $\mathbf{- 0 . 1 5 7} * *$ \\
\hline Industry Diversity & 0.050 & -0.087 & -0.049 \\
\hline Knowledge Diversity & -0.052 & 0.088 & -0.022 \\
\hline Farming & -0.041 & 0.054 & 0.130 \\
\hline Oil and Gas & 0.006 & $\mathbf{- 0 . 0 9 7} * *$ & 0.138 \\
\hline Coal & $\mathbf{- 0 . 0 7 5} * *$ & -0.029 & 0.047 \\
\hline Manufacturing & -0.038 & 0.045 & 0.138 \\
\hline \multicolumn{4}{|c|}{ Community and Health } \\
\hline Primary and Secondary & 0.034 & -0.002 & 0.025 \\
\hline Community College & -0.003 & -0.035 & -0.118 \\
\hline Broadband & -0.064 & -0.026 & 0.063 \\
\hline Child/Elder Care & -0.013 & -0.048 & -0.012 \\
\hline Healthcare Practitioner & -0.061 & 0.100 & -0.068 \\
\hline Recreational Opportunity & 0.076 & -0.011 & 0.214 \\
\hline Natural Amenity & 0.017 & 0.081 & 0.031 \\
\hline Social Capital & -0.033 & 0.084 & -0.036 \\
\hline Voting Competitiveness & -0.015 & -0.038 & 0.036 \\
\hline Agritourism & 0.012 & 0.049 & 0.013 \\
\hline Direct Farm Sales & 0.013 & -0.062 & -0.092 \\
\hline
\end{tabular}

Statistical significance indicated by $* * \mathrm{p}<0.05$. ARC and state fixed effects are utilized.

\begin{tabular}{|l|c|}
\hline \multicolumn{2}{|l|}{ Community Development } \\
\hline Level 2 Variable & Posterior Mean \\
\hline Constant & 0.016 \\
\hline Direct Effects & 0.066 \\
\hline Indirect Effects & 0.222 \\
\hline Total Effects & 0.288 \\
\hline
\end{tabular}

\begin{tabular}{|l|r|}
\hline Variance & Posterior Mean \\
\hline sigma $^{\wedge} 2$ & 0.836 \\
\hline tau$^{\wedge} 2$ & 0.018 \\
\hline
\end{tabular}

DIC value 40811.087 
Table 3-11: Change in Education and Job Training Per Capita Model

\begin{tabular}{|c|c|c|c|}
\hline Education and Job Training & Direct Effects & Indirect Effects & Total Effects \\
\hline Level 1 Variables & Posterior Mean & Posterior Mean & Posterior Mean \\
\hline \multicolumn{4}{|c|}{ Demographic and Mobility } \\
\hline Age 25 to 44 & 0.050 & $0.196 * *$ & -0.133 \\
\hline Age 65 and Up & -0.078 & 0.158 & 0.033 \\
\hline Ethnic Diversity & 0.019 & -0.021 & 0.180 \\
\hline Mobility In-Migration & $\mathbf{0 . 1 8 3} * *$ & $0.194 * *$ & 0.172 \\
\hline Mobility Out-Migration & -0.080 & -0.076 & 0.387 \\
\hline Mobility In-Commuting & 0.063 & -0.110 & 0.281 \\
\hline Mobility Out-Commuting & 0.021 & -0.043 & -0.016 \\
\hline Residence-Born & 0.068 & 0.062 & -0.432 \\
\hline Population & 0.134 & 0.001 & -0.139 \\
\hline Land Area & 0.049 & -0.002 & -0.346 \\
\hline College & $0.212 * *$ & -0.074 & -0.028 \\
\hline \multicolumn{4}{|c|}{ Economic and Industry } \\
\hline Distance to City & -0.008 & 0.030 & 0.096 \\
\hline Business Density & -0.033 & -0.085 & -0.196 \\
\hline Self-Employment & 0.014 & 0.049 & $0.246 * *$ \\
\hline Owner-Occupied Housing & 0.095 & -0.109 & 0.080 \\
\hline Poverty & -0.025 & -0.045 & -0.003 \\
\hline Participation & 0.100 & 0.113 & $0.377 * *$ \\
\hline Innovation Potential & $0.087 * *$ & -0.057 & -0.156 \\
\hline Industry Diversity & 0.051 & -0.087 & -0.047 \\
\hline Knowledge Diversity & -0.054 & 0.087 & -0.022 \\
\hline Farming & -0.040 & 0.054 & 0.129 \\
\hline Oil and Gas & 0.006 & $\mathbf{- 0 . 0 9 7 * *}$ & 0.135 \\
\hline Coal & $-0.075 * *$ & -0.030 & 0.047 \\
\hline Manufacturing & -0.038 & 0.045 & 0.138 \\
\hline \multicolumn{4}{|c|}{ Community and Health } \\
\hline Primary and Secondary & 0.034 & -0.004 & 0.023 \\
\hline Community College & -0.003 & -0.036 & -0.118 \\
\hline Broadband & -0.063 & -0.027 & 0.062 \\
\hline Child/Elder Care & -0.012 & -0.047 & -0.014 \\
\hline Healthcare Practitioner & -0.059 & 0.101 & -0.070 \\
\hline Recreational Opportunity & 0.077 & -0.012 & 0.213 \\
\hline Natural Amenity & 0.016 & 0.083 & 0.030 \\
\hline Social Capital & -0.034 & 0.083 & -0.035 \\
\hline Voting Competitiveness & -0.015 & -0.037 & 0.033 \\
\hline Agritourism & 0.012 & 0.051 & 0.014 \\
\hline Direct Farm Sales & 0.013 & -0.063 & -0.091 \\
\hline
\end{tabular}

Statistical significance indicated by $* * \mathrm{p}<0.05$. ARC and state fixed effects are utilized.

\begin{tabular}{|l|c|}
\hline \multicolumn{2}{|l|}{ Education and Job Training } \\
\hline Level 2 Variable & Posterior Mean \\
\hline Constant & -0.001 \\
\hline Direct Effects & 0.009 \\
\hline Indirect Effects & 0.053 \\
\hline Total Effects & 0.061 \\
\hline
\end{tabular}

\begin{tabular}{|l|r|}
\hline Variance & Posterior Mean \\
\hline sigma $^{\wedge} 2$ & 0.836 \\
\hline tau$^{\wedge} 2$ & 0.019 \\
\hline
\end{tabular}

DIC value

40809.081


Table 3-12: Change in Environment and Natural Resources Per Capita Model

\begin{tabular}{|c|c|c|c|}
\hline Environment \& Natural Resources & Direct Effects & Indirect Effects & Total Effects \\
\hline Level 1 Variables & Posterior Mean & Posterior Mean & Posterior Mean \\
\hline \multicolumn{4}{|c|}{ Demographic and Mobility } \\
\hline Age 25 to 44 & 0.050 & $0.197 * *$ & -0.133 \\
\hline Age 65 and Up & -0.077 & 0.159 & 0.051 \\
\hline Ethnic Diversity & 0.018 & -0.020 & 0.185 \\
\hline Mobility In-Migration & $0.184 * *$ & $0.193 * *$ & 0.213 \\
\hline Mobility Out-Migration & -0.081 & -0.076 & 0.103 \\
\hline Mobility In-Commuting & 0.064 & -0.110 & 0.282 \\
\hline Mobility Out-Commuting & 0.020 & -0.044 & -0.064 \\
\hline Residence-Born & 0.068 & 0.060 & $-0.448 * *$ \\
\hline Population & 0.140 & 0.001 & -0.150 \\
\hline Land Area & 0.048 & -0.002 & -0.607 \\
\hline College & $0.212 * *$ & -0.075 & -0.016 \\
\hline \multicolumn{4}{|c|}{ Economic and Industry } \\
\hline Distance to City & -0.008 & 0.031 & 0.113 \\
\hline Business Density & -0.034 & -0.087 & -0.203 \\
\hline Self-Employment & 0.015 & 0.049 & $0.247 * *$ \\
\hline Owner-Occupied Housing & 0.094 & -0.107 & 0.082 \\
\hline Poverty & -0.025 & -0.046 & -0.002 \\
\hline Participation & 0.100 & 0.112 & $0.376 * *$ \\
\hline Innovation Potential & $\mathbf{0 . 0 8 7} * *$ & -0.056 & -0.157 \\
\hline Industry Diversity & 0.050 & -0.086 & -0.046 \\
\hline Knowledge Diversity & -0.054 & 0.087 & -0.024 \\
\hline Farming & -0.040 & 0.054 & 0.128 \\
\hline Oil and Gas & 0.006 & $-0.096 * *$ & 0.141 \\
\hline Coal & $\mathbf{- 0 . 0 7 6} * *$ & -0.031 & 0.046 \\
\hline Manufacturing & -0.037 & 0.046 & 0.137 \\
\hline \multicolumn{4}{|c|}{ Community and Health } \\
\hline Primary and Secondary & 0.035 & -0.003 & 0.023 \\
\hline Community College & -0.003 & -0.035 & -0.121 \\
\hline Broadband & -0.063 & -0.027 & 0.063 \\
\hline Child/Elder Care & -0.011 & -0.047 & -0.013 \\
\hline Healthcare Practitioner & -0.059 & 0.103 & -0.072 \\
\hline Recreational Opportunity & 0.077 & -0.012 & 0.212 \\
\hline Natural Amenity & 0.016 & 0.083 & 0.031 \\
\hline Social Capital & -0.034 & 0.083 & -0.036 \\
\hline Voting Competitiveness & -0.015 & -0.037 & 0.033 \\
\hline Agritourism & 0.012 & 0.050 & 0.014 \\
\hline Direct Farm Sales & 0.013 & -0.064 & -0.090 \\
\hline
\end{tabular}

Statistical significance indicated by $* * \mathrm{p}<0.05$. ARC and state fixed effects are utilized.

\begin{tabular}{|l|c|}
\hline \multicolumn{2}{|l|}{ Environment \& Natural Resources } \\
\hline Level 2 Variable & Posterior Mean \\
\hline Constant & 0.014 \\
\hline Direct Effects & 0.040 \\
\hline Indirect Effects & 0.136 \\
\hline Total Effects & 0.175 \\
\hline
\end{tabular}

\begin{tabular}{|l|r|}
\hline Variance & Posterior Mean \\
\hline sigma $^{\wedge} 2$ & 0.836 \\
\hline tau$^{\wedge}$ & 0.017 \\
\hline
\end{tabular}

DIC value

40794.128 
Table 3-13: Change in Highways and Access Roads Per Capita Model

\begin{tabular}{|c|c|c|c|}
\hline Highways and Access Roads & Direct Effects & Indirect Effects & Total Effects \\
\hline Level 1 Variables & Posterior Mean & Posterior Mean & Posterior Mean \\
\hline \multicolumn{4}{|c|}{ Demographic and Mobility } \\
\hline Age 25 to 44 & 0.049 & $0.194 * *$ & -0.129 \\
\hline Age 65 and Up & -0.079 & 0.155 & 0.226 \\
\hline Ethnic Diversity & 0.020 & -0.022 & -1.130 \\
\hline Mobility In-Migration & $\mathbf{0 . 1 8 2} * *$ & $0.194 * *$ & $\mathbf{0 . 3 8 3} * *$ \\
\hline Mobility Out-Migration & -0.076 & -0.076 & -1.961 \\
\hline Mobility In-Commuting & 0.064 & -0.110 & $3.280 * *$ \\
\hline Mobility Out-Commuting & 0.020 & -0.041 & 0.057 \\
\hline Residence-Born & 0.065 & 0.065 & $-1.672 * *$ \\
\hline Population & 0.124 & 0.006 & $-2.701 * *$ \\
\hline Land Area & 0.051 & -0.002 & $-4.035 * *$ \\
\hline College & $0.210 * *$ & -0.073 & -0.026 \\
\hline \multicolumn{4}{|c|}{ Economic and Industry } \\
\hline Distance to City & -0.009 & 0.033 & -0.931 \\
\hline Business Density & -0.033 & -0.082 & $-1.483 * *$ \\
\hline Self-Employment & 0.013 & 0.048 & $0.243 * *$ \\
\hline Owner-Occupied Housing & 0.097 & -0.111 & 0.076 \\
\hline Poverty & -0.027 & -0.045 & -0.002 \\
\hline Participation & 0.100 & 0.113 & $0.376 * *$ \\
\hline Innovation Potential & $\mathbf{0 . 0 8 8} * *$ & -0.057 & -0.152 \\
\hline Industry Diversity & 0.054 & -0.084 & -0.046 \\
\hline Knowledge Diversity & -0.053 & 0.089 & -0.022 \\
\hline Farming & -0.039 & 0.054 & 0.131 \\
\hline Oil and Gas & 0.006 & $\mathbf{- 0 . 0 9 7 * *}$ & 0.131 \\
\hline Coal & $-\mathbf{0 . 0 7 4} * *$ & -0.030 & 0.049 \\
\hline Manufacturing & -0.038 & 0.046 & 0.138 \\
\hline \multicolumn{4}{|c|}{ Community and Health } \\
\hline Primary and Secondary & 0.034 & -0.006 & 0.023 \\
\hline Community College & -0.003 & -0.038 & -0.115 \\
\hline Broadband & -0.061 & -0.029 & 0.061 \\
\hline Child/Elder Care & -0.011 & -0.047 & -0.014 \\
\hline Healthcare Practitioner & -0.060 & 0.099 & -0.072 \\
\hline Recreational Opportunity & 0.078 & -0.013 & 0.212 \\
\hline Natural Amenity & 0.016 & 0.084 & 0.031 \\
\hline Social Capital & -0.034 & 0.083 & -0.031 \\
\hline Voting Competitiveness & -0.015 & -0.038 & 0.036 \\
\hline Agritourism & 0.011 & 0.051 & 0.015 \\
\hline Direct Farm Sales & 0.013 & -0.063 & -0.091 \\
\hline
\end{tabular}

Statistical significance indicated by $* * \mathrm{p}<0.05$. ARC and state fixed effects are utilized.

\begin{tabular}{|l|c|}
\hline \multicolumn{2}{|l|}{ Highways and Access Roads } \\
\hline Level 2 Variable & Posterior Mean \\
\hline Constant & -0.236 \\
\hline Direct Effects & 0.840 \\
\hline Indirect Effects & 2.466 \\
\hline Total Effects & 3.306 \\
\hline
\end{tabular}

\begin{tabular}{|l|r|}
\hline Variance & Posterior Mean \\
\hline sigma $^{\wedge} 2$ & 0.836 \\
\hline tau$^{\wedge} 2$ & 0.018 \\
\hline
\end{tabular}

\section{DIC value} 40791.622 
Table 3-14: Change in Health Per Capita Model

\begin{tabular}{|c|c|c|c|}
\hline Health & Direct Effects & Indirect Effects & Total Effects \\
\hline Level 1 Variables & Posterior Mean & Posterior Mean & Posterior Mean \\
\hline \multicolumn{4}{|c|}{ Demographic and Mobility } \\
\hline Age 25 to 44 & 0.051 & $0.195 * *$ & -0.131 \\
\hline Age 65 and Up & -0.075 & 0.158 & 0.097 \\
\hline Ethnic Diversity & 0.018 & -0.022 & 0.206 \\
\hline Mobility In-Migration & $\mathbf{0 . 1 8 3} * *$ & $\mathbf{0 . 1 9 7} * *$ & 0.247 \\
\hline Mobility Out-Migration & -0.075 & -0.077 & 0.384 \\
\hline Mobility In-Commuting & 0.064 & -0.110 & 0.342 \\
\hline Mobility Out-Commuting & 0.019 & -0.040 & -0.017 \\
\hline Residence-Born & 0.068 & 0.066 & -0.513 \\
\hline Population & 0.140 & 0.014 & -0.160 \\
\hline Land Area & 0.051 & 0.000 & -0.450 \\
\hline College & $0.212 * *$ & -0.074 & -0.023 \\
\hline \multicolumn{4}{|c|}{ Economic and Industry } \\
\hline Distance to City & -0.007 & 0.034 & 0.124 \\
\hline Business Density & -0.033 & -0.084 & -0.233 \\
\hline Self-Employment & 0.018 & 0.045 & $0.247 * *$ \\
\hline Owner-Occupied Housing & 0.096 & -0.109 & 0.083 \\
\hline Poverty & -0.021 & -0.046 & -0.004 \\
\hline Participation & 0.104 & 0.115 & $0.380 * *$ \\
\hline Innovation Potential & $0.087 * *$ & -0.058 & -0.152 \\
\hline Industry Diversity & 0.051 & -0.089 & -0.046 \\
\hline Knowledge Diversity & -0.051 & 0.091 & -0.021 \\
\hline Farming & -0.040 & 0.056 & 0.133 \\
\hline Oil and Gas & 0.005 & $-0.096 * *$ & 0.154 \\
\hline Coal & $-0.075 * *$ & -0.030 & 0.050 \\
\hline Manufacturing & -0.038 & 0.044 & 0.138 \\
\hline \multicolumn{4}{|c|}{ Community and Health } \\
\hline Primary and Secondary & 0.033 & -0.005 & 0.027 \\
\hline Community College & -0.004 & -0.035 & -0.116 \\
\hline Broadband & -0.064 & -0.027 & 0.063 \\
\hline Child/Elder Care & -0.012 & -0.049 & -0.012 \\
\hline Healthcare Practitioner & -0.061 & 0.099 & -0.068 \\
\hline Recreational Opportunity & 0.077 & -0.011 & 0.219 \\
\hline Natural Amenity & 0.017 & 0.081 & 0.029 \\
\hline Social Capital & -0.034 & 0.084 & -0.038 \\
\hline Voting Competitiveness & -0.014 & -0.038 & 0.040 \\
\hline Agritourism & 0.012 & 0.050 & 0.016 \\
\hline Direct Farm Sales & 0.013 & -0.062 & -0.092 \\
\hline
\end{tabular}

Statistical significance indicated by $* * \mathrm{p}<0.05$. ARC and state fixed effects are utilized.

\begin{tabular}{|l|c|}
\hline Health \\
\hline Level 2 Variable & Posterior Mean \\
\hline Constant & -0.012 \\
\hline Direct Effects & -0.022 \\
\hline Indirect Effects & 0.043 \\
\hline Total Effects & 0.022 \\
\hline
\end{tabular}

\begin{tabular}{|l|r|}
\hline Variance & Posterior Mean \\
\hline sigma $^{\wedge} 2$ & 0.836 \\
\hline tau$^{\wedge} 2$ & 0.018 \\
\hline
\end{tabular}

DIC value 40797.824 
Table 3-15: Change in Housing Per Capita Model

\begin{tabular}{|c|c|c|c|}
\hline Housing & Direct Effects & Indirect Effects & Total Effects \\
\hline Level 1 Variables & Posterior Mean & Posterior Mean & Posterior Mean \\
\hline \multicolumn{4}{|c|}{ Demographic and Mobility } \\
\hline Age 25 to 44 & 0.049 & $0.198 * *$ & -0.131 \\
\hline Age 65 and Up & -0.078 & 0.159 & 0.046 \\
\hline Ethnic Diversity & 0.019 & -0.020 & 0.279 \\
\hline Mobility In-Migration & $0.185 * *$ & $0.192 * *$ & 0.183 \\
\hline Mobility Out-Migration & -0.083 & -0.075 & 0.446 \\
\hline Mobility In-Commuting & 0.063 & -0.112 & 0.275 \\
\hline Mobility Out-Commuting & 0.020 & -0.043 & -0.070 \\
\hline Residence-Born & 0.068 & 0.061 & -0.447 \\
\hline Population & 0.137 & -0.007 & -0.046 \\
\hline Land Area & 0.048 & -0.003 & -0.246 \\
\hline College & $0.212 * *$ & -0.072 & -0.004 \\
\hline \multicolumn{4}{|c|}{ Economic and Industry } \\
\hline Distance to City & -0.007 & 0.029 & 0.108 \\
\hline Business Density & -0.033 & -0.086 & -0.208 \\
\hline Self-Employment & 0.013 & 0.049 & $0.247 * *$ \\
\hline Owner-Occupied Housing & 0.095 & -0.107 & 0.081 \\
\hline Poverty & -0.024 & -0.047 & -0.001 \\
\hline Participation & 0.101 & 0.113 & $0.377 * *$ \\
\hline Innovation Potential & $\mathbf{0 . 0 8 7} * *$ & -0.057 & $-0.157 * *$ \\
\hline Industry Diversity & 0.051 & -0.087 & -0.049 \\
\hline Knowledge Diversity & -0.053 & 0.087 & -0.023 \\
\hline Farming & -0.041 & 0.053 & 0.129 \\
\hline Oil and Gas & 0.006 & $-0.097 * *$ & 0.130 \\
\hline Coal & $-0.075 * *$ & -0.029 & 0.045 \\
\hline Manufacturing & -0.038 & 0.045 & 0.140 \\
\hline \multicolumn{4}{|c|}{ Community and Health } \\
\hline Primary and Secondary & 0.035 & -0.003 & 0.022 \\
\hline Community College & -0.002 & -0.036 & -0.120 \\
\hline Broadband & -0.063 & -0.027 & 0.063 \\
\hline Child/Elder Care & -0.012 & -0.047 & -0.012 \\
\hline Healthcare Practitioner & -0.060 & 0.102 & -0.071 \\
\hline Recreational Opportunity & 0.077 & -0.013 & 0.214 \\
\hline Natural Amenity & 0.016 & 0.083 & 0.030 \\
\hline Social Capital & -0.033 & 0.082 & -0.036 \\
\hline Voting Competitiveness & -0.015 & -0.038 & 0.033 \\
\hline Agritourism & 0.012 & 0.050 & 0.012 \\
\hline Direct Farm Sales & 0.013 & -0.063 & -0.090 \\
\hline
\end{tabular}

Statistical significance indicated by $* * \mathrm{p}<0.05$. ARC and state fixed effects are utilized.

\begin{tabular}{|l|c|}
\hline \multicolumn{2}{|l|}{ Housing } \\
\hline Level 2 Variable & Posterior Mean \\
\hline Constant & 0.010 \\
\hline Direct Effects & 0.017 \\
\hline Indirect Effects & 0.117 \\
\hline Total Effects & 0.134 \\
\hline
\end{tabular}

\begin{tabular}{|l|r|}
\hline Variance & Posterior Mean \\
\hline sigma^2 & 0.836 \\
\hline tau^2 $^{\wedge}$ & 0.019 \\
\hline
\end{tabular}

DIC value

40810.259


Table 3-16: Change in Leadership and Civic Capacity Per Capita Model

\begin{tabular}{|c|c|c|c|}
\hline Leadership and Civic Capacity & Direct Effects & Indirect Effects & Total Effects \\
\hline Level 1 Variables & Posterior Mean & Posterior Mean & Posterior Mean \\
\hline \multicolumn{4}{|c|}{ Demographic and Mobility } \\
\hline Age 25 to 44 & 0.050 & $0.195 * *$ & -0.136 \\
\hline Age 65 and Up & -0.077 & 0.157 & 0.065 \\
\hline Ethnic Diversity & 0.017 & -0.019 & 0.163 \\
\hline Mobility In-Migration & $0.182 * *$ & $0.194 * *$ & 0.187 \\
\hline Mobility Out-Migration & -0.078 & -0.076 & 0.379 \\
\hline Mobility In-Commuting & 0.064 & -0.114 & 0.145 \\
\hline Mobility Out-Commuting & 0.018 & -0.044 & -0.023 \\
\hline Residence-Born & 0.067 & 0.062 & -0.445 \\
\hline Population & 0.131 & -0.014 & -0.155 \\
\hline Land Area & 0.049 & 0.000 & -0.354 \\
\hline College & $0.212 * *$ & -0.072 & -0.073 \\
\hline \multicolumn{4}{|c|}{ Economic and Industry } \\
\hline Distance to City & -0.012 & 0.031 & 0.138 \\
\hline Business Density & -0.036 & -0.090 & -0.193 \\
\hline Self-Employment & 0.017 & 0.049 & $0.245 * *$ \\
\hline Owner-Occupied Housing & 0.096 & -0.110 & 0.080 \\
\hline Poverty & -0.023 & -0.047 & -0.003 \\
\hline Participation & 0.099 & 0.115 & $0.376 * *$ \\
\hline Innovation Potential & $\mathbf{0 . 0 8 7} * *$ & -0.057 & -0.154 \\
\hline Industry Diversity & 0.053 & -0.085 & -0.050 \\
\hline Knowledge Diversity & -0.052 & 0.090 & -0.026 \\
\hline Farming & -0.040 & 0.051 & 0.129 \\
\hline Oil and Gas & 0.006 & $\mathbf{- 0 . 0 9 6} * *$ & 0.118 \\
\hline Coal & $-\mathbf{0 . 0 7 3} * *$ & -0.029 & 0.049 \\
\hline Manufacturing & -0.037 & 0.044 & 0.141 \\
\hline \multicolumn{4}{|c|}{ Community and Health } \\
\hline Primary and Secondary & 0.033 & -0.007 & 0.019 \\
\hline Community College & -0.003 & -0.035 & -0.126 \\
\hline Broadband & -0.063 & -0.026 & 0.066 \\
\hline Child/Elder Care & -0.012 & -0.049 & -0.014 \\
\hline Healthcare Practitioner & -0.058 & 0.103 & -0.071 \\
\hline Recreational Opportunity & 0.079 & -0.011 & 0.214 \\
\hline Natural Amenity & 0.017 & 0.082 & 0.029 \\
\hline Social Capital & -0.034 & 0.085 & -0.032 \\
\hline Voting Competitiveness & -0.015 & -0.036 & 0.038 \\
\hline Agritourism & 0.012 & 0.049 & 0.011 \\
\hline Direct Farm Sales & 0.015 & -0.064 & -0.091 \\
\hline
\end{tabular}

Statistical significance indicated by $* * \mathrm{p}<0.05$. ARC and state fixed effects are utilized.

\begin{tabular}{|l|c|}
\hline \multicolumn{2}{|l|}{ Leadership and Civic Capacity } \\
\hline Level 2 Variable & Posterior Mean \\
\hline Constant & 0.026 \\
\hline Direct Effects & 0.018 \\
\hline Indirect Effects & 0.178 \\
\hline Total Effects & 0.197 \\
\hline
\end{tabular}

\begin{tabular}{|l|r|}
\hline Variance & Posterior Mean \\
\hline sigma $^{\wedge} 2$ & 0.836 \\
\hline tau$^{\wedge} 2$ & 0.019 \\
\hline
\end{tabular}

DIC value 40795.569 
Table 3-17: Change in Local Development District Planning \& Administration Per Capita Model

\begin{tabular}{|c|c|c|c|}
\hline $\begin{array}{l}\text { Local Development District } \\
\text { Planning \& Administration }\end{array}$ & Direct Effects & Indirect Effects & Total Effects \\
\hline Level 1 Variables & Posterior Mean & Posterior Mean & Posterior Mean \\
\hline \multicolumn{4}{|c|}{ Demographic and Mobility } \\
\hline Age 25 to 44 & 0.051 & $\mathbf{0 . 1 9 7} * *$ & -0.137 \\
\hline Age 65 and Up & -0.077 & 0.160 & 0.024 \\
\hline Ethnic Diversity & 0.018 & -0.022 & 0.179 \\
\hline Mobility In-Migration & $0.182 * *$ & $0.195 * *$ & 0.173 \\
\hline Mobility Out-Migration & -0.078 & -0.078 & 0.321 \\
\hline Mobility In-Commuting & 0.064 & -0.110 & 0.247 \\
\hline Mobility Out-Commuting & 0.021 & -0.042 & -0.133 \\
\hline Residence-Born & 0.068 & 0.063 & $-0.572 * *$ \\
\hline Population & 0.149 & 0.014 & -0.286 \\
\hline Land Area & 0.048 & 0.000 & -0.522 \\
\hline College & $0.212 * *$ & -0.077 & -0.147 \\
\hline \multicolumn{4}{|c|}{ Economic and Industry } \\
\hline Distance to City & -0.007 & 0.033 & -0.039 \\
\hline Business Density & -0.032 & -0.087 & -0.341 \\
\hline Self-Employment & 0.017 & 0.048 & $0.248 * *$ \\
\hline Owner-Occupied Housing & 0.095 & -0.108 & 0.082 \\
\hline Poverty & -0.024 & -0.047 & -0.004 \\
\hline Participation & 0.100 & 0.112 & $0.378 * *$ \\
\hline Innovation Potential & $0.087 * *$ & -0.057 & -0.156 \\
\hline Industry Diversity & 0.049 & -0.089 & -0.046 \\
\hline Knowledge Diversity & -0.053 & 0.087 & -0.022 \\
\hline Farming & -0.041 & 0.055 & 0.131 \\
\hline Oil and Gas & 0.005 & $\mathbf{- 0 . 0 9 8 * *}$ & 0.163 \\
\hline Coal & $-0.076 * *$ & -0.031 & 0.048 \\
\hline Manufacturing & -0.036 & 0.045 & 0.135 \\
\hline \multicolumn{4}{|c|}{ Community and Health } \\
\hline Primary and Secondary & 0.034 & -0.004 & 0.026 \\
\hline Community College & -0.004 & -0.033 & -0.118 \\
\hline Broadband & -0.065 & -0.028 & 0.065 \\
\hline Child/Elder Care & -0.012 & -0.047 & -0.013 \\
\hline Healthcare Practitioner & -0.060 & 0.102 & -0.071 \\
\hline Recreational Opportunity & 0.076 & -0.011 & 0.212 \\
\hline Natural Amenity & 0.018 & 0.081 & 0.030 \\
\hline Social Capital & -0.034 & 0.085 & -0.040 \\
\hline Voting Competitiveness & -0.015 & -0.035 & 0.034 \\
\hline Agritourism & 0.013 & 0.051 & 0.015 \\
\hline Direct Farm Sales & 0.012 & -0.063 & -0.092 \\
\hline
\end{tabular}

Statistical significance indicated by $* * \mathrm{p}<0.05$. ARC and state fixed effects are utilized.

\begin{tabular}{|l|c|}
\hline \multicolumn{2}{|l|}{ Local Development District } \\
\hline Level 2 Variable & Posterior Mean \\
\hline Constant & -0.0043 \\
\hline Direct Effects & 0.0528 \\
\hline Indirect Effects & 0.017 \\
\hline Total Effects & 0.0698 \\
\hline
\end{tabular}

\begin{tabular}{|l|r|}
\hline Variance & Posterior Mean \\
\hline sigma $^{\wedge} 2$ & 0.836 \\
\hline tau$^{\wedge} 2$ & 0.018 \\
\hline
\end{tabular}

DIC value 40792.923 
Table 3-18: Change in Research and Technical Assistance Per Capita Model

\begin{tabular}{|c|c|c|c|}
\hline Research and Techincal Assistance & Direct Effects & Indirect Effects & Total Effects \\
\hline Level 1 Variables & Posterior Mean & Posterior Mean & Posterior Mean \\
\hline \multicolumn{4}{|c|}{ Demographic and Mobility } \\
\hline Age 25 to 44 & 0.050 & $0.196 * *$ & -0.130 \\
\hline Age 65 and Up & -0.077 & 0.158 & 0.083 \\
\hline Ethnic Diversity & 0.019 & -0.021 & 0.251 \\
\hline Mobility In-Migration & $\mathbf{0 . 1 8 4} * *$ & $0.194 * *$ & 0.240 \\
\hline Mobility Out-Migration & -0.080 & -0.075 & 0.351 \\
\hline Mobility In-Commuting & 0.064 & -0.110 & 0.295 \\
\hline Mobility Out-Commuting & 0.022 & -0.041 & -0.033 \\
\hline Residence-Born & 0.069 & 0.065 & $-0.504 * *$ \\
\hline Population & 0.135 & 0.012 & -0.144 \\
\hline Land Area & 0.050 & -0.002 & -0.481 \\
\hline College & $0.212 * *$ & -0.074 & -0.026 \\
\hline \multicolumn{4}{|c|}{ Economic and Industry } \\
\hline Distance to City & -0.008 & 0.032 & 0.076 \\
\hline Business Density & -0.033 & -0.083 & -0.258 \\
\hline Self-Employment & 0.012 & 0.049 & $0.245 * *$ \\
\hline Owner-Occupied Housing & 0.096 & -0.109 & 0.081 \\
\hline Poverty & -0.026 & -0.047 & -0.002 \\
\hline Participation & 0.101 & 0.110 & $0.378 * *$ \\
\hline Innovation Potential & $0.087 * *$ & -0.057 & -0.155 \\
\hline Industry Diversity & 0.051 & -0.087 & -0.046 \\
\hline Knowledge Diversity & -0.053 & 0.089 & -0.019 \\
\hline Farming & -0.040 & 0.055 & 0.133 \\
\hline Oil and Gas & 0.006 & $\mathbf{- 0 . 0 9 7} * *$ & 0.147 \\
\hline Coal & $-0.075 * *$ & -0.030 & 0.048 \\
\hline Manufacturing & -0.039 & 0.047 & 0.138 \\
\hline \multicolumn{4}{|c|}{ Community and Health } \\
\hline Primary and Secondary & 0.035 & -0.003 & 0.02 \\
\hline Community College & -0.004 & -0.037 & -0.12 \\
\hline Broadband & -0.062 & -0.028 & 0.06 \\
\hline Child/Elder Care & -0.012 & -0.047 & -0.01 \\
\hline Healthcare Practitioner & -0.060 & 0.101 & -0.07 \\
\hline Recreational Opportunity & 0.077 & -0.012 & 0.21 \\
\hline Natural Amenity & 0.016 & 0.083 & 0.03 \\
\hline Social Capital & -0.034 & 0.082 & -0.04 \\
\hline Voting Competitiveness & -0.015 & -0.037 & 0.04 \\
\hline Agritourism & 0.013 & 0.052 & 0.01 \\
\hline Direct Farm Sales & 0.013 & -0.063 & -0.09 \\
\hline
\end{tabular}

Statistical significance indicated by $* * \mathrm{p}<0.05$. ARC and state fixed effects are utilized.

\begin{tabular}{|l|c|}
\hline \multicolumn{2}{|l|}{ Research and Techincal Assistance } \\
\hline Level 2 Variable & Posterior Mean \\
\hline Constant & 0.000 \\
\hline Direct Effects & -0.003 \\
\hline Indirect Effects & 0.052 \\
\hline Total Effects & 0.049 \\
\hline
\end{tabular}

\begin{tabular}{|l|r|}
\hline Variance & Posterior Mean \\
\hline sigma $^{\wedge} 2$ & 0.836 \\
\hline tau^$^{\wedge}$ & 0.019 \\
\hline
\end{tabular}

\begin{tabular}{|c|}
\hline DIC value \\
\hline 40804.101 \\
\hline
\end{tabular}


Table 3-19: Change in Total Project Investments Per Capita Model

\begin{tabular}{|c|c|c|c|}
\hline Total Project Investments & Direct Effects & Indirect Effects & Total Effects \\
\hline Level 1 Variables & Posterior Mean & Posterior Mean & Posterior Mean \\
\hline \multicolumn{4}{|c|}{ Demographic and Mobility } \\
\hline Age 25 to 44 & 0.049 & $0.196 * *$ & -0.129 \\
\hline Age 65 and $\mathrm{Up}$ & -0.076 & 0.157 & 0.091 \\
\hline Ethnic Diversity & 0.020 & -0.020 & 0.271 \\
\hline Mobility In-Migration & $0.185 * *$ & $0.194 * *$ & 0.248 \\
\hline Mobility Out-Migration & -0.080 & -0.073 & 0.406 \\
\hline Mobility In-Commuting & 0.064 & -0.114 & 0.172 \\
\hline Mobility Out-Commuting & 0.020 & -0.040 & -0.074 \\
\hline Residence-Born & 0.068 & 0.066 & $-0.513 * *$ \\
\hline Population & 0.131 & 0.000 & -0.110 \\
\hline Land Area & 0.050 & -0.001 & -0.413 \\
\hline College & $0.212 * *$ & -0.070 & -0.001 \\
\hline \multicolumn{4}{|c|}{ Economic and Industry } \\
\hline Distance to City & -0.009 & 0.031 & 0.086 \\
\hline Business Density & -0.034 & -0.082 & -0.309 \\
\hline Self-Employment & 0.013 & 0.048 & $0.245 * *$ \\
\hline Owner-Occupied Housing & 0.097 & -0.110 & 0.081 \\
\hline Poverty & -0.024 & -0.048 & -0.001 \\
\hline Participation & 0.103 & 0.112 & $0.379 * *$ \\
\hline Innovation Potential & $0.087 * *$ & -0.057 & -0.153 \\
\hline Industry Diversity & 0.053 & -0.087 & -0.049 \\
\hline Knowledge Diversity & -0.051 & 0.092 & -0.020 \\
\hline Farming & -0.041 & 0.054 & 0.135 \\
\hline Oil and Gas & 0.006 & $-0.097 * *$ & 0.132 \\
\hline Coal & $-0.074 * *$ & -0.029 & 0.049 \\
\hline Manufacturing & -0.039 & 0.046 & 0.142 \\
\hline \multicolumn{4}{|c|}{ Community and Health } \\
\hline Primary and Secondary & 0.034 & -0.005 & 0.022 \\
\hline Community College & -0.003 & -0.038 & -0.116 \\
\hline Broadband & -0.062 & -0.026 & 0.062 \\
\hline Child/Elder Care & -0.012 & -0.048 & -0.013 \\
\hline Healthcare Practitioner & -0.060 & 0.100 & -0.072 \\
\hline Recreational Opportunity & 0.077 & -0.012 & 0.215 \\
\hline Natural Amenity & 0.016 & 0.083 & 0.030 \\
\hline Social Capital & -0.033 & 0.082 & -0.034 \\
\hline Voting Competitiveness & -0.015 & -0.038 & 0.041 \\
\hline Agritourism & 0.012 & 0.051 & 0.013 \\
\hline Direct Farm Sales & 0.014 & -0.063 & -0.091 \\
\hline
\end{tabular}

Statistical significance indicated by $* * \mathrm{p}<0.05$. ARC and state fixed effects are utilized.

\begin{tabular}{|l|c|}
\hline Total Project Investments \\
\hline Level 2 Variable & Posterior Mean \\
\hline Constant & 0.033 \\
\hline Direct Effects & 0.015 \\
\hline Indirect Effects & 0.170 \\
\hline Total Effects & 0.184 \\
\hline
\end{tabular}

\begin{tabular}{|l|r|}
\hline Variance & Posterior Mean \\
\hline sigma^2 & 0.835 \\
\hline tau$^{\wedge} 2$ & 0.018 \\
\hline
\end{tabular}

\section{DIC value}

40788.998 


\section{Local and Regional Policy Strategies for Economic Resilience}

When making policy recommendations one must take into consideration the spillover effects beyond the county or state where the policy may be implemented. Some policies are best dealt with as a county level (local) issue, while others need a conjoint effort with surrounding counties (regional) or even at the state level. Regional policies may be most effective as cooperative strategies or as competitive strategies. Cooperative strategies strengthen the resilience of surrounding counties, while competitive strategies weaken their resilience. In this section, we will discuss the most-effective policy strategies for the level 1 (county level) variables. Again, we are unable to interpret any of the level 2 effects as they were all statistically insignificant. ARC project investments cannot be implemented as policy strategies to promote resilience. Table 3-20 summarizes the level 1 policy strategies discussed within this section. ${ }^{45}$

We follow the policy strategy identification approach of Boettner et al. (Forthcoming) to identify effective strategies to promote resilience in the greater Appalachian region. Based on the direct, indirect, and total effect estimates, we identify policy issues for economic resilience that are most appropriately addressed as local issues versus regional or statewide issues for variables where important spillover effects occur. Based on the direct and indirect coefficient signs, we can also identify variables that provide either competitive or cooperative strategies. Competitive strategies are defined as policies impacting independent variables which have the opposite signs for direct and indirect coefficient estimates, such that variables in county $i$ that promote resilience in county $i$ while detracting from resilience in county $j$. Alternatively, cooperative strategies are those policies which impact independent variables that have the same coefficient signs for direct and indirect coefficients, resulting in the same influence on resilience both within and outside a county.

County characteristics such as educational attainment and share of employment in the coal industry only have statistical significant direct effects. These factors are best suited as local or strictly county level policy strategies as these approaches do not help nor hurt resilience levels of the neighboring counties. Policy strategies that retain individuals with a college degree as well as policy strategies that reduce the share of employment within the coal industry will increase resilience at the county level. With local policy strategies, policymakers can take county level approaches without the concern of spillover effects into the surrounding regions.

Based on our results, we can identify two levels of multi-county cooperative policy strategy approaches. We separate these policies into cooperative strategies and altruistic-cooperative strategies. Cooperative policy strategies include variables with statistically significant coefficients for direct and indirect effects that have the same signs. Policies in this classification include policies that increase in-migration. Altruistic-Cooperative policies include variables with statistically insignificant direct effects but statistically significant positive coefficients for the indirect and/or total effects. Policies in this classification include policies increase workforce participation and policies that promote self-employment. Policies that promote workforce participation, cultivate entrepreneurs, and support business start-ups are beneficial for economic resilience of the greater Appalachian region. If county-level policy makers take an isolated

\footnotetext{
${ }^{45} \mathrm{We}$ focus on the level 1 policy strategies as none of the level 2 project investment beta estimates were statistically significant.
} 
approach to these altruistic-cooperative policy issues, the $\mathrm{ARC}$ region will not receive measurable benefits from these policies. Thus, regional or statewide approaches are most appropriate when focusing on these policies strategies to improve resilience.

Based on our model results, we can identify two levels of competitive policy strategy approaches: competitive and ultra-competitive. Competitive policy strategies include variables with statistically significant coefficients for direct and indirect effects with opposite signs. Policies strategies within this classification include policies that promote innovation potential. Counties that have higher innovation potential are more adaptive and flexible to industry changes; making these counties competitive with surrounding counties. Ultra-Competitive policies strategies include variables with statistically insignificant coefficients for direct effects but statistically significant negative coefficients of indirect or total effects. These strategies include policies that increase residenceborn population and policies that increase the share of employment in the oil and gas industry. Ultra-competitive policy strategies provide no benefits to the county and they hurt the resilience levels for the surrounding counties and the entire region.

Table 3-20: Policy Strategies to Influence Economic Resilience

\begin{tabular}{|c|c|c|c|c|}
\hline \multirow{2}{*}{$\begin{array}{l}\text { Strictly County } \\
\text { Level Impacts }^{\mathrm{a}}\end{array}$} & \multicolumn{4}{|c|}{ Regional Level Impacts } \\
\hline & Cooperative $^{\mathrm{b}}$ & $\begin{array}{c}\text { Altruistic- } \\
\text { Cooperative }^{\mathrm{c}}\end{array}$ & Competitive $^{\mathrm{d}}$ & Ultra-Competitive $^{\mathrm{e}}$ \\
\hline $\begin{array}{l}\text { Policies that retain } \\
\text { individuals with a } \\
\text { college degree } \\
\text { Policies that } \\
\text { decrease the share } \\
\text { of employment in } \\
\text { the coal industry }\end{array}$ & $\begin{array}{l}\text { Policies that } \\
\text { increase the in- } \\
\text { migration of county } \\
\text { level population }\end{array}$ & $\begin{array}{l}\text { Policies that } \\
\text { increase workforce } \\
\text { participation } \\
\text { Policies that } \\
\text { promote self- } \\
\text { employment or } \\
\text { entrepreneurship }\end{array}$ & $\begin{array}{l}\text { Policies that } \\
\text { increase innovation } \\
\text { potential }\end{array}$ & $\begin{array}{l}\text { Policies that increase } \\
\text { the portion of the } \\
\text { population that stay } \\
\text { within their birth } \\
\text { state } \\
\text { Policies that increase } \\
\text { the share of oil and } \\
\text { gas employment }\end{array}$ \\
\hline
\end{tabular}

${ }^{a}$ Variables with statistically significant coefficients for direct effects but no indirect or total effects.

${ }^{\mathrm{b}}$ Variables with statistically significant coefficients for direct and indirect effects with the same signs.

${ }^{c}$ Variables with statistically insignificant coefficients for direct effects but statistically significant positive coefficients for indirect or total effects.

${ }^{\mathrm{d}}$ Variables with statistically significant coefficients for direct and indirect effects with opposite signs.

e Variables with statistically insignificant coefficients for direct effects but statistically significant negative coefficients for indirect or total effects.

\section{Highly Resilient Counties in Appalachia}

Based on the results of our analysis we can identify counties that are highly resilient as well as counties that currently have low resilience levels. These counties should be examined as case studies to identified localized strategies to promote long-term resilience. The resilience performance levels are based upon the residual values estimated for each county from the total investment spatial hierarchical SLX model. Residual values are calculated as the difference between the observed resilience value minus the predicted resilience value from the spatial model. Counties that have a positive residual that is greater than 2.5 standard deviations from the mean are 
identified as highly resilient. The spatial hierarchical SLX model identified 25 counties within the greater Appalachian region that over-performed with high levels of resilience. ${ }^{46}$ Table 3-21 ranks the top twenty counties. Four of these highly resilient counties are within the Appalachian region.

Kemper County, Mississippi experienced rapid industry growth in the construction industry due to the construction of a power plant. Doddridge County, WV experienced employment growth in the natural resources and mining industry due to the recent expansion of shale gas production. These counties cannot be used as future case studies as resource extraction and short-term construction projects cannot be implemented as a long-term policy strategy to promote resilience.

Table 3-21: Top 20 Most Resilient Counties in the Greater ARC Region

\begin{tabular}{|c|l|l|l|c|c|r|}
\hline Rank & County & State & FIPS & ARC County? & Resilience & Residual \\
\hline 1 & Twiggs & Georgia & 13289 & No & 1.252405 & 6.748163 \\
\hline 2 & Fairfield & South Carolina & 45039 & No & 1.275179 & 6.522157 \\
\hline $\mathbf{3}$ & Kemper & Mississippi & $\mathbf{2 8 0 6 9}$ & Yes & $\mathbf{1 . 0 8 0 9 7 1}$ & $\mathbf{5 . 5 6 0 2 0 1}$ \\
\hline $\mathbf{4}$ & Doddridge & West Virginia & $\mathbf{5 4 0 1 7}$ & Yes & $\mathbf{0 . 9 0 0 8 0 4}$ & $\mathbf{3 . 4 1 8 3 7 2}$ \\
\hline 5 & Lancaster & South Carolina & 45057 & No & 0.958154 & 3.336527 \\
\hline 6 & Goochland & Virginia & 51075 & No & 1.03071 & 3.18511 \\
\hline 7 & Troup & Georgia & 13285 & No & 0.939617 & 3.097208 \\
\hline 8 & St. Mary's & Maryland & 24037 & No & 0.964262 & 3.083387 \\
\hline 9 & Coffee & Georgia & 13069 & No & 0.900566 & 3.015171 \\
\hline 10 & Montgomery & Ohio & 39113 & No & 0.959011 & 2.942791 \\
\hline $\mathbf{1 1}$ & Swain & North Carolina & $\mathbf{3 7 1 7 3}$ & Yes & $\mathbf{0 . 9 0 8 4 8 6}$ & $\mathbf{2 . 8 8 9 3 9 2}$ \\
\hline 12 & Stafford & Virginia & 51179 & No & 0.971736 & 2.81753 \\
\hline 13 & Bedford & Virginia & 51019 & No & 0.937101 & 2.814659 \\
\hline $\mathbf{1 4}$ & Jackson & Georgia & $\mathbf{1 3 1 5 7}$ & Yes & $\mathbf{0 . 8 9 5 0 5}$ & $\mathbf{2 . 7 2 5 1 2 2}$ \\
\hline 15 & Bullitt & Kentucky & 21029 & No & 0.92511 & 2.704705 \\
\hline 16 & Lake & Tennessee & 47095 & No & 0.872116 & 2.689667 \\
\hline 17 & Burke & Georgia & 13033 & No & 0.865048 & 2.580131 \\
\hline 18 & Prince William & Virginia & 51153 & No & 0.980587 & 2.431251 \\
\hline 19 & Montgomery & Tennessee & 47125 & No & 0.901595 & 2.339392 \\
\hline 20 & Lafayette & Mississippi & 28071 & No & 0.845018 & 2.316475 \\
\hline
\end{tabular}

${ }^{46}$ Only one county was identified with a poor resilience level as it had a negative residual greater than -2.5 standard deviations from the mean. Harland County, Kentucky was identified as the county with poor resilience. This county was a coal mining town that never recovered from the diminishing demand for the industry. This county suffers from extremely high unemployment rates when compared to the national unemployment rate. 




Figure 3-7: Counties with the Highest and Lowest Resilience Levels

\section{Conclusion}

This study evaluates county-level socio-economic characteristics on their ability to predict local economic resilience. This essay expands upon the research of Boettner et al. (Forthcoming) by investigating the influence of location-based federal funding on local economic resilience. We explore the effects of ARC project investments on predicting economic resilience of the greater Appalachian region. ARC projects provide numerous economic and social benefits that could improve the resilience levels within a community and the surrounding region.

Since investment data provided by the Appalachian Regional Commission are only available at the state level, the spatial hierarchical SLX model was estimated. Our results indicate ARC project investments do not have statistically significant impacts on economic resilience; however, estimated effects for ARC project investments generally were positive. ARC project investments are most beneficial as a regional cooperative strategy approach as they provide a greater benefit to the entire region than the benefit received by the county in which the project was implemented.

We also investigated county-level policy strategies to promote and enhance economic resilience throughout the greater ARC region. For policy strategies to be the most effective some policies are best dealt with as a county level (local) issue, while others need to be approached as a conjoint effort with surrounding counties (regional) or even at the state level. Policies with spillover effects 
could influence cooperative or competitive strategies. Based on the results of our analysis we identify policy strategies, local and regional, to strengthen resilience in the ARC region. We find educational attainment and share of coal employment are policy strategies that are most effective as local policy strategies. These policies do not help nor hurt resilience levels in surrounding counties. In-migration, workforce participation, and self-employment policies are most effective as cooperative policy strategies. These policies strategies increase economic resilience in the ARC region as well as the greater ARC region. Innovation potential, residence-born population, and share of oil and gas employment strategies are most effective as competitive policy strategies. These policy strategies increase resilience in the ARC region but are harmful to the resilience levels of the greater ARC region. Policymakers should pay attention to the regional impacts of policies that are implemented as they may be beneficial or harmful to surrounding regions.

The last part of our analysis identifies the most resilient counties in the greater ARC region. Counties that are performing at higher levels of resilience than what our models predict are identified as highly resilient counties. Based on the results from our analysis we identified over 20 highly resilient counties. These counties should be examined as future case studies to identify local or regional strategies to enhance resilience throughout the greater Appalachian region. However, future researchers should be cautious on selecting counties to examine as case studies as some of these highly resilient counties experienced employment shocks due to the recent natural gas industry boom. Industry booms do not provide a foundation for long-term economic resilience.

Previous literature measures resilience through correlated changes in unemployment, GDP, population and industry-level employment (Davies 2011). Future research should explore these different resilience measures and their efficiencies at the county-level. While employment is a more appropriate measure of resilience than unemployment, as it is sensitive to workers entering and exiting the labor market, it may not capture the whole dynamic system of economic resilience. Future studies should also consider addressing endogeneity issues related to ARC project investments. For example, communities that are already better off may receive more funding opportunities; however, this would contradict ARC's "worst-first" project funding strategy. 


\section{References}

Anselin, L., A. Varga, and Z. Acs. 2000. "Geographical spillovers and university research: A spatial econometric perspective." Growth and Change 31 (4): 501-515.

Appalachian Regional Commission. 1969. 1969 Annual Report. Washington, DC: ARC.

Appalachian Regional Commission. 1975. 1975 Annual Report. Washington, DC: ARC.

Appalachian Regional Commission. 2015. Appalachia Then and Now: Examining Changes to the Appalachian Region Since 1965. Center for Regional Economic Competitiveness.

Augustine, N., H. Wolman, H. Wial, and M. McMillen. 2013. "Regional Economic Capacity, Economic Shocks and Economic Resilience." Washington, DC: MacArthur Foundation Research Network.

Berkman, M. B., and E. Plutzer. 2004. "Gray peril or loyal support? The effects of the elderly on educational expenditures." Social Science Quarterly 85 (5): 1178-1192.

BizMiner/Brandow Company Inc., and Economic Development Research (EDR) Group. 2007. Program Evaluation of the Appalachian Regional Commission's Infrastructure and Public Works Projects. Developed for the Appalachian Regional Commission.

Boettner, F., C. Gyovai, S. J. Goetz, Y. Han, A. Collins, and B. R. Zimmerman. Forthcoming. Strengthening Economic Resilience in Appalachian Communities. Final report prepared for the Appalachian Regional Commission.

Bradshaw, Michael. 2015. The Appalachian Regional Commission: Twenty-Five Years of Government Policy. University Press of Kentucky.

Brandow Company Inc., and Economic Development Research (EDR) Group. 2000. Evaluation of the Appalachian Regional Commission's Infrastructure and Public Works Projects. Developed for the Appalachian Regional Commission.

Briguglio, L., G. Cordina, N. Farrugia, and S. Vella. 2006. "Conceptualizing and measuring economic resilience." Building the Economic Resilience of Small States, Malta: Islands and Small States Institute of the University of Malta and London: Commonwealth Secretariat: 265-288.

Brown, D.M., 1999. Highway Investment and Rural Economic Development. U.S. Department of Agriculture, Economic Research Service.

Button, J., and W. Rosenbaum. 1990. "Gray Power, Gray Peril, or Gray Myth? The Political Impact of the Aging in Local Sun Belt Politics." Social Science Quarterly 71 (1): 25. 
Byun, P., B. S. Waldorf, and A. X. Esparza. 2005. "Spillovers and local growth controls: An alternative perspective on suburbanization." Growth and Change 36 (2): 196-219.

Carruthers, J. I., and A. C. Vias. 2005. "Urban, suburban, and exurban sprawl in the Rocky Mountain West: evidence from regional adjustment models." Journal of Regional Science 45 (1): 21-48.

Clark, G. 2009. Recession, Recovery and Reinvestment: The Role of Local Economic Leadership in a Global Crisis. OECD Publishing: Paris.

Davies, S. 2011."Regional resilience in the 2008-2010 downturn: comparative evidence from European countries." Cambridge Journal of Regions, Economy and Society 4 (3): 369-382.

Deller, S.C., T.H. Tsai, D.W. Marcouiller, and D.B.K. English. 2001. "The role of amenities and quality of life in rural economic growth". American Journal of Agricultural Economics 83: $352-365$.

Faggian, A., M. R. Olfert, and M.D. Partridge. 2012. "Inferring Regional Well-being from Individual Reveal Preferences: The 'Voting with your Feet' Approach. Cambridge Journal of Regions, Economy and Society 5:163-180.

Feser, E., T. Mix, M. White, K. Pole, D. Markley, and E. Pages. 2014. Economic Diversity in Appalachia: Statistics, Strategies, and Guides for Action. Prepared for the Appalachian Regional Commission.

Fingleton, Bernard, Harry Garretsen, and Ron Martin. 2012. "Recessionary shocks and regional employment: evidence on the resilience of UK regions." Journal of Regional Science 52 (1): 109-133.

Glaeser, E. L., and J. D. Gottlieb. 2008. The Economics of Place-Making Policies. No. w14373. National Bureau of Economic Research.

Han, Y., and S. J. Goetz. 2015. "The economic resilience of US counties during the Great Recession." The Review of Regional Studies 45 (2): 131-149.

Heimlich, R. and W. Anderson. 2001. Development at the urban fringe and beyond: impacts on agriculture and rural. United States Department of Agriculture, Economic Research Service.

Isserman, A., and T. Rephann. 1995. "The economic effects of the Appalachian Regional Commission: An empirical assessment of 26 years of regional development planning." Journal of the American Planning Association 61 (3): 345-364. 
Lacombe, D. J., and M. Flores. 2017. "A hierarchical SLX model application to violent crime in Mexico." The Annals of Regional Science 58 (1): 119-134.

Lacombe, D. J., and S. G. McIntyre. 2017. "Hierarchical Spatial Econometric Models in Regional Science.” Regional Research Frontiers 2: 151-167. Springer, Cham.

LeSage, J. P. 2014. "What regional scientists need to know about spatial econometrics." The Review of Regional Studies 44 (1): 13-32.

LeSage, J. P., and R. K. Pace. 2009. Introduction to Spatial Econometrics. CRC Press.

Lin, N. 2002. Social capital: A Theory of Social Structure and Action. Vol. 19. Cambridge University Press.

Martin, R. 2012. "Regional economic resilience, hysteresis and recessionary shocks." Journal of Economic Geography 12 (1): 1-32.

Martin, R. and P. Sunley. 2015. "On the notion of regional economic resilience: conceptualization and explanation.” Journal of Economic Geography 15(1): 1-42/

Norris, F. H., S. P. Stevens, B. Pfefferbaum, K. F. Wyche, and R. L. Pfefferbaum. 2008. "Community resilience as a metaphor, theory, set of capacities, and strategy for disaster readiness." American Journal of Community Psychology 41 (1-2): 127-150.

Pender, J., and R. J. Reeder. 2011. Impacts of Regional Approaches to Rural Development: Initial Evidence on the Delta Regional Authority. US Department of Agriculture, Economic Research Service.

Pfaff, A., J. Robalino, R. Walker, S. Aldrich, M. Caldas, E. Reis, S. Perz et al. 2007. "Road investments, spatial spillovers, and deforestation in the Brazilian Amazon." Journal of Regional Science 47 (1): 109-123.

President's Appalachian Regional Commission. 1964. Appalachia. Washington, DC: U.S. Government Printing Office.

Rappaport, J. 2007. "Moving to Nice Weather.” Regional Science and Urban Economics 37: 375398.

Raudenbush, S. W., and Bryk, A. S. 2002. Hierarchical linear models: Applications and Data Analysis Methods (1). Sage.

Rephann, T.J. 1993. Highway investment and regional economic development: decision methods and empirical foundations. Urban Studies 30(2): 437-450. 
Roback, J. 1982. "Wages, rents and the quality of life." The Journal of Political Economy 90 (6): $1257-1278$.

Sayago-Gomez, J.T., G. Piras, R. Jackson, and D. Lacombe. 2018. "Impact Evaluation of Investments in the Appalachian Region: A Reappraisal.” International Regional Science Review 41(6): 601-629.

Shaffer, R., Deller, S. and D. Marcouiller. 2006. "Rethinking community economic development." Economic Development Quarterly 20 (1): 59-74.

Sherrieb, K., F. H. Norris, and S. Galea. 2010. "Measuring capacities for community resilience." Social Indicators Research 99 (2): 227-247.

Simmie, J., and R. Martin. 2010. "The economic resilience of regions: towards an evolutionary approach." Cambridge Journal of Regions, Economy and Society 3 (1): 27-43.

Spiegelhalter, D. J., N. G. Best, B. P. Carlin, and A. Van Der Linde. 2002. "Bayesian measures of model complexity and fit." Journal of the Royal Statistical Society: Series B (Statistical Methodology) 64 (4): 583-639.

Stephens, H. M., and M. D. Partridge. 2011. "Do entrepreneurs enhance economic growth in lagging regions?" Growth and Change 42 (4): 431-465.

Stenberg, P., Morehart, M., Vogel, S., Cromartie, J., Breneman, V. and D. Brown. 2009. Broadband Internet's Value for Rural America. US Department of Agriculture, Economic Research Service.

Stephens, H. M., and M. D. Partridge. 2011. "Do entrepreneurs enhance economic growth in lagging regions?" Growth and Change 42 (4): 431-465.

Stephens, H. M., and M. D. Partridge. 2015. "Lake Amenities, Environmental Degradation, and Great Lakes Regional Growth." International Regional Science Review 38 (1): 61-91.

Thomas, J. K., and F. M. Howell. 2003. "Metropolitan proximity and US agricultural productivity, 1978-1997." Rural Sociology 68 (3): 366-386.

Wood, L.E. and G. A. Bischak. 2000. "Progress and Challenges in Reducing Economic Distress in Appalachia: An Analysis of National and Regional Trends since 1960.” Appalachian Regional Commission. Washington, DC. 


\section{CHAPTER 5: CONCLUSION}

The purpose of this dissertation was to identify the effects of federal involvement on local economies, and whether these federal activities provide a net gain to the local market. This research is beneficial to anyone who is interested in the fields of environmental economics, regional economics, or public policy. In this dissertation, regional economic analysis methods, spatial econometrics techniques, and other spatial analysis tools are used.

Since the passage of the Clean Air Act of 1990, the air pollution standards have become more stringent as new information has become available about the health impacts of these pollutants. The first essay investigates the effects of these changes in the pollution standards on local economic growth in the eastern United States. Increasing air pollution standards can increase the operating costs of manufacturing firms and other polluting industries. This may lead to the shutdown of firms, decrease the demand for labor in the manufacturing sector and potentially reduce total employment for the region. However, the loss of dependency on the manufacturing sector could also be a driving force behind industrial diversification in a region, which is beneficial for economic sustainability.

This essay investigates the changes in the air pollution standards on employment and population levels, and on industrial composition at the county level. Our data indicates nonattainment regions, in the long run, are diversifying their industry portfolios. Based on the results of our analysis, it appears that nonattainment regions are adapting to the stricter pollution standards to gain attainment status. Possibly due to change in the region's industry diversity, the region is still seeing small, but positive employment growth and population growth. By having a more diverse industry portfolio, counties are in a better, more stable position to weather future economic shocks. The effects of nonattainment on manufacturing employment were negative, but not significant. We believe this is due to the overall national trend downward in manufacturing employment, regardless of attainment status.

Resource extraction has been a large contributor to West Virginia's economic development. High levels of non-regulated extraction have led to the rapid degradation of the state's ecosystem services throughout the state. West Virginia's Natural Resource Conservation Service (NRCS) offers assistance programs to address concerns related to conservation and preservation of local resources. The second essay examines the determinants of participation in NRCS assistance programs in West Virginia. This essay expands from the previous literature by measuring program participation at a regional level, instead of using an individual measure. It is important to observe program participation at a regional level to account for social networking and community collaboration. We incorporate spatial econometrics models to control for the spatial dependence of applied assistance programs. In this essay, we also observe factors that could influence a social network for program participants, such as the number of farms, average farm size, farm operation size, and internet accessibility.

Overall, the amount of agricultural land, hosting a field office, and the amount of stream miles within a census tract have positive influences on practice application, while the amount of permitted surface mining land has a negative effect. We also evaluate whether federal assistance distributed efficiently to meet the local needs and concerns throughout the state. These results 
indicate NRCS is strategically targeting areas to promote efficient farm management techniques and to protect stream water quality. We also find strengthening the social network of farmers has a positive effect on conservation practice adoption. In collaboration with NRCS, we identify future target areas to promote future conservation efforts throughout the state.

The Appalachian Regional Commission (ARC) was established to address the persistent poverty issues throughout the Appalachian region. This agency supports projects to improve the economic conditions of the region including: education and job training, community development, network improvement and infrastructure support. The benefits from these projects help build a foundation for industrial growth and employment opportunities. Since the establishment of the ARC, the region has grown rapidly in population, per capita income, earnings, and employment.

The third essay evaluates the influence of federal funding on regional economic resilience. This essay contributes to the literature by observing the influence of location-based ARC project investments on regional economic resilience in the greater Appalachian region. Our analysis does not find any statistically significant evidence that ARC grant project investments influence economic resilience in the greater Appalachian region. However, we do determine that project investments generally have a positive estimated impact on resilience. We also find ARC investments are most advantageous as a cooperative regional approach as they provide the greatest benefit to the greater Appalachian region.

We also identify county-level policy strategies to promote and enhance economic resilience throughout the region. We investigate characteristics such as employment, industry composition, demographics, mobility, and community assets and health. Based on our analysis, we identify policy strategies that are most effective as local (county-level) policy strategies or regional (multi-county) policy strategies. Policymakers should attention to the regional impacts of policies that are implemented as they may be beneficial or harmful to surrounding regions. Regional policy approaches are identified as multi-county cooperative strategies or competitive strategies. The last part of our analysis identifies the most resilient counties in the greater Appalachian region. Highly resilient counties should be investigated further to identify strategies to enhance resilience throughout the region. 